\title{
Reentrant ventricular tachycardia after myocardial infarction in the rabbit heart
}

Citation for published version (APA):

Danse, P. W. (2002). Reentrant ventricular tachycardia after myocardial infarction in the rabbit heart.

[Doctoral Thesis, Maastricht University]. Universiteit Maastricht. https://doi.org/10.26481/dis.20021212pd

Document status and date:

Published: 01/01/2002

DOI:

10.26481/dis.20021212pd

Document Version:

Publisher's PDF, also known as Version of record

\section{Please check the document version of this publication:}

- A submitted manuscript is the version of the article upon submission and before peer-review. There can be important differences between the submitted version and the official published version of record.

People interested in the research are advised to contact the author for the final version of the publication, or visit the DOI to the publisher's website.

- The final author version and the galley proof are versions of the publication after peer review.

- The final published version features the final layout of the paper including the volume, issue and page numbers.

Link to publication

\footnotetext{
General rights rights.

- You may freely distribute the URL identifying the publication in the public portal. please follow below link for the End User Agreement:

www.umlib.nl/taverne-license

Take down policy

If you believe that this document breaches copyright please contact us at:

repository@maastrichtuniversity.nl

providing details and we will investigate your claim.
}

Copyright and moral rights for the publications made accessible in the public portal are retained by the authors and/or other copyright owners and it is a condition of accessing publications that users recognise and abide by the legal requirements associated with these

- Users may download and print one copy of any publication from the public portal for the purpose of private study or research.

- You may not further distribute the material or use it for any profit-making activity or commercial gain

If the publication is distributed under the terms of Article $25 \mathrm{fa}$ of the Dutch Copyright Act, indicated by the "Taverne" license above, 
REENTRANT VENTRICULAR TACHYCARDIA

AFTER MYOCARDIAL INFARCTION

IN THE RABBIT HEART

Voor Laura 


\section{Danse, Peter Willem}

Thesis Maastricht-With Ref

Drukker: Rooduijn Vorm \& Druk, Den Haag

ISBN: 90-9016456-1

O 2002 P.W. Danse, Maastricht

Lay-out: Aan Zet Grafische Vormgevers Sassenheim

Omslag: Bert Vredegoor. - Krachtcentrale 5 - 100x80 gebleekt fluweel, 1999 


\section{REENTRANT VENTRICULAR TACHYCARDIA \\ AFTER MYOCARDIAL INFARCTION \\ IN THE RABBIT HEART}

\section{PROEFSCHRIFT}

ter verkrijging van de graad van doctor aan

de Universiteit Maastricht,

op gezag van de Rector Magnificus, Prof.dr. A.C. Nieuwenhuijzen Kruseman

volgens het besluit van het College van Decanen,

in het openbaar te verdedigen

op donderdag 12 december 2002 om 16.00 uur

door

Peter Willem Danse 
Promotor: Prof.dr. M.A. Allessie

Beoordelingscommissie:

Prof.dr. H.J.G.M. Crijns (voorzitter)

Prof.dr. M.J. Schalij, (Universiteit Leiden)

Prof.dr. J.F.M. Smits

Prof.dr. H.J.J. Wellens

Prof.dr. A.L. Wit, (Colombia University, New York)

The study described in this thesis was supported by a grant of the Netherlands Heart Foundation (NHF-grant 94056). Financial support by the Netherlands Heart Foundation for the publication of this thesis is gratefully acknowledged.

Additional financial support for the publication of this thesis was kindly provided by Medtronic B.V., Vitatron B.V. and 3M Pharma B.V.. 


\section{CONTENTS}

Chapter 1. Ventricular tachycardia after myocardial infarction. Review of the literature and introduction to the thesis.

Chapter 2. Preferential depression of conduction around a pivot point in rabbit ventricular myocardium by potassium and flecainide.

Chapter 3. Flecainide widens the excitable gap at pivot points of premature turning wavefronts in rabbit ventricular myocardium.

Chapter 4. Reentrant ventricular tachycardia in isolated rabbit hearts with a healed myocardial infarction.

Chapter 5. Differentiation of the substrate of VT by resetting.

Chapter 6. Differential effects of overdrive pacing on reentrant VT with or without a segment of slow conduction through healed myocardial infarction.

Chapter 7. Differential effects of antiarrhythmic drugs on various types of reentrant VT in rabbit hearts with a healed myocardial infarction.

Chapter 8. Synthesis.

Chapter 9. Summary and conclusions.

Samenvatting

Nawoord

Publicaties

Curriculum vitae 

Chapter 1

\section{Reentrant Ventricular Tachycardia After Myocardial Infarction}

Review of the Literature and Introduction to the Thesis 


\section{Chapter 1}

\section{Contents:}

- Clinical background

- Reentry as a mechanism for cardiac arrhythmias

- Mechanisms of slow conduction and conduction block

- Ventricular arrhythmias after myocardial infarction

- Objectives of the thesis 


\section{Clinical Background}

Ischemic heart disease is one of the most common fatal diseases in the industrialized countries. ${ }^{1}$ In the Netherlands in 1999, 18304 people died of ischemic heart disease accounting for $13 \%$ of total mortality in that year. ${ }^{2}$ Most of the deaths from ischemic heart disease (13457) resulted from acute myocardial infarction. In the setting of an acute myocardial infarction cardiac death is mostly due to a ventricular arrhythmia, in particular ventricular fibrillation. ${ }^{3.5}$ During the last two decades, improvements in the acute treatment of myocardial infarction by thrombolysis and coronary angioplasty have significantly reduced the mortality associated with acute myocardial infarction. ${ }^{6.7}$ Consequently, the prevalence of patients with chronic ischemic heart disease has increased. ${ }^{8.9}$ In the chronic phase of myocardial infarction the major causes of morbidity and mortality are residual coronary ischemia, pump failure and ventricular arrhythmias. ${ }^{10}$

Approximately $60 \%$ of patients with a previous myocardial infarction have some kind of ventricular arrhythmia. About $20 \%$ of patients have frequent ventricular premature depolarizations (VPD) and about $40 \%$ have multiform VPDs. ${ }^{11-13}$ Nonsustained ventricular tachycardia (VT) occurs in $10-20 \%$ of patients, ${ }^{11,14,15}$ and sustained VT is present in 1$3 \%{ }^{16-18}$ The occurrence and severity of these arrhythmias relate to the occurrence of sudden cardiac death. The 2-year mortality in patients with more than $10 \mathrm{VPBs}$ per hour is 410 percent, increasing to $10-20 \%$ in patients with non sustained VT and to as high as $50 \%$ in patients with sustained VT. ${ }^{16,19,20}$ In comparison, patients without such arrhythmias have a two-year mortality of less than 4 percent.

Sudden death after myocardial infarction usually results from VF that is often preceded by monomorphic or polymorphic VT. ${ }^{4,21,22}$ Numerous studies have been undertaken to identify patients with a particular high risk for those ventricular tachyarrhythmias and many different clinical features have been evaluated as possible risk factors. Patients with large myocardial scars, left ventricular aneurysms or residual coronary ischemia have an increased risk for sustained VT and sudden death. ${ }^{23-25}$ Left ventricular dysfunction, as measured by the left ventricular ejection fraction, is one of the most powerful predictors of both arrhythmogenic and non-arrhythmogenic cardiac death. ${ }^{10.23 .26 .27}$ An association has been noted between an increased risk of death and the occurrence of frequent VPDs or non sustained VT on 24 hour ambulatory monitoring. ${ }^{12,13,19.28}$ Exercise stress testing has been used to identify patients without spontaneous ventricular arrhythmias. ${ }^{29}$ Late potentials on the signal averaged ECG are indicative of late and slow impulse conduction through the scarred myocardium. ${ }^{30}$ They indicate the potential for reentry, and their presence may identify patients with a high risk for sustained VT and sudden death. ${ }^{31.32}$ Clinical electrophysiological studies have shown that patients with a previous myocardial infarction and inducible VT had a higher incidence of an arrhythmic event and sudden cardiac death when compared to those in whom VT was not induced. ${ }^{23.33-36}$ Approximately 35 percent of patients with a previous myocardial infarction will have an arrhythmia induced with an electrophysiological study. About $20 \%$ of these patients (range 6 to 41 percent in the various studies) will have an arrhythmic event during a one year follow-up period. In con- 
trast, the incidence of an arrhythmic event is only 7 percent (range $0-14$ percent) in noninducible patients. ${ }^{23,33-36}$ Heterogeneity in repolarization, as measured from the QT-interval on the surface ECG, may indicate the presence of a substrate for malignant ventricular tachyarrhythmias. ${ }^{37,38}$ Finally, reduced heart rate variability after myocardial infarction is associated with an increased mortality. ${ }^{39,40}$

Despite the present tools to identify high-risk patients after myocardial infarction, prevention of ventricular tachyarrhythmias and sudden death in patients with a previous myocardial infarction has been disappointing. In the CAST trial, a study aimed at reducing mortality by suppressing the number of premature beats that induce lethal arrhythmias, treatment of the study population with the Class IC antiarrhythmic drugs flecainide or encainide resulted in increased mortality in the treated groups (7.7 versus 3.0 percent in placebogroup). ${ }^{41}$ The increased mortality was primarily due to an excess in arrhythmic deaths (4.5 versus 1.2 percent). d-Sotalol, a Class III anti-arrhythmic drug, was evaluated in a postinfarction study known as SWORD. ${ }^{42}$ Also in this study, an increased incidence of deaths was found in patients treated with d-sotalol ( 5.0 versus 3.1 percent in placebo-group), primarily due to arrhythmic deaths (3.6 versus 2.0 percent). ${ }^{42,43}$ Treatment with the new class III anti-arrhythmic agent dofetilide does not affect total cardiac mortality or arrhythmic deaths. ${ }^{44}$ Amiodarone, an antiarrhythmic drug with multiple actions including beta blockade, does reduce the number of arrhythmic deaths (relative risk about 0.7 ), but not total mortality as was shown both in a large European (EMIAT) ${ }^{45}$ and Canadian trial (CAMIAT). ${ }^{46}$ The antiarrhythmic effect was greatest in patients with a low left ventricular ejection fraction and congestive heart failure. However, a large number of patients $(12 \%$ in the EMIAT-trial) discontinue amiodarone therapy because of side effects. The only pharmacological intervention after myocardial infarction that provides a desirable clinical outcome is beta blockade, ${ }^{47}$ although the mechanism is probably related to mechanical and metabolic unloading of the heart and reduction in heart rate, rather than to a direct antiarrhythmic effect. ${ }^{48}$

Because of the high failure rate and proarrhythmic actions of the antiarrhythmic drugs, alternative nonpharmacologic therapy has received increasing attention. Catheter ablation of the arrhythmogenic focus has been modestly successful in patients with chronic ischemic heart disease. In many patients, catheter ablation of the arrhythmogenic site(s) cannot be performed because the VT cannot be induced, the arrhythmia is hemodynamically unstable or multiple morphologies of VT are present. ${ }^{49}$ In case the presumed arrhythmogenic site(s) can be identified and ablated, 20 to $50 \%$ of the patients still have recurrences of ventricular tachyarrhythmias. ${ }^{49-52}$ Because of the high recurrence rate of potentially fatal VT, up to now catheter ablation should be considered adjunctive and palliative to other forms of treatment. Cardiac surgery has also been used as a method to remove the arrhythmogenic focus. The surgical techniques most commonly used are endocardial resection," cryoablation, ${ }^{54}$ and myocardial excision. ${ }^{55}$ An important drawback of surgery is the high peri-operative mortality rate, exceeding $8 \%$ at most centers. ${ }^{56-58}$ As with catheter ablation, the success of cardiac surgery largely depends on the possibility to accurately localize the 
arrhythmogenic site(s) by mapping. ${ }^{59}$ After the operation, 10 to $30 \%$ of the patients still have recurrences of ventricular tachyarrhythmias ${ }^{58}$ In selected individuals, cardiac transplantation can be an ultimate option.

As pointed out above, prevention of ventricular arrhythmias and cardiac death by pharmacological agents and ablative or surgical techniques has failed in many high-risk patients with chronic ischemic heart disease. Therefore, rather than prevention, reversal of tachyarrhythmias by an implantable cardioverter defibrillator (ICD) is becoming more and more the cornerstone of therapy in high-risk patients. ${ }^{60,61}$ The ICD is highly effective in terminating VT/VF and in aborting sudden cardiac death. ${ }^{62,63}$ There are many reports showing an impressive improvement in expected arrhythmia mortality in patients with an ICD implanted. ${ }^{60,64,65,66,67}$ A meta-analysis of three large trials (CASH, ${ }^{65} \mathrm{CIDS}^{66}$ and $\mathrm{AVID}^{67}$ ), including patients with VT, VF or syncope, found a significant 28 percent reduction in mortality with an ICD compared to amiodarone. ${ }^{68}$ The reduction in mortality was entirely due to a $50 \%$ reduction in sudden death and was only seen in patients with a left ventricular ejection fraction of less than 35 percent. The ICD may also have a role in primary prevention of sudden death in high risk asymptomatic patients with a previous myocardial infarction, left ventricular dysfunction, non sustained VT, a positive signal averaged ECG and inducible VT, as was demonstrated by the MADIT and MUSST trials. ${ }^{69,70}$ However, the ICD is expensive and its cost-effectiveness is a major concern. ${ }^{71-73}$ Therefore, in many countries, ICD therapy is limited to a highly selective subgroup of patients. Local political and budgetary considerations may also determine the amount of ICDs implanted. In the Netherlands, 1:25.000 persons have an ICD implanted, compared to 1:2.000 in the United States. For individual patients, a major drawback of the device is that frequent painful (and sometimes inappropriate) shocks may cause a state of anxiety and may even require psychotherapy.

Although the ICD is highly effective in terminating VT/VF and in aborting sudden cardiac death, its use is still limited and, in fact, is a surrogate treatment for a disease whose mechanisms are inadequately understood. The incidence of ventricular arrhythmias and sudden death in patients with chronic ischemic heart disease stresses the importance of further insights into their mechanisms. It has well been established that reentry within the infarcted area is the underlying mechanism of ventricular tachyarrhythmias after myocardial infarction. ${ }^{74}$ However, it is still difficult, if not impossible, to fully characterize the electrophysiological properties of the arrhythmogenic substrate (like dispersion of refractoriness, cell-cell coupling, excitability, tissue architecture) in a particular patient. If it would be possible to identify the key parameters for arrhythmogenicity in individual patients, antiarrhythmic therapy might be applied with a much higher success rate. For this purpose, both clinical as well as experimental studies are needed to further unravel the mechanisms of this lethal disease. 


\section{Chapter 1}

\section{Reentry as a Mechanism for Cardiac Arrhythmias}

Reentry is defined as a continuous repetitive propagation of an excitation wave traveling in a circular path, returning to its site of origin to reactivate this site. Probably the first demonstration of reentry was in 1906 by Mayer who noted that the application of a stimulus to tissue from a jellyfish initiated a rhythmic contraction. ${ }^{75}$ Reentry was first described as a mechanism for reentrant arrhythmias in 1913 by Mines when he recognized that reentrant tachycardias arose from circular electrical pathways. ${ }^{76} \mathrm{He}$ established that reentry could only be induced and perpetuate if: 1) at least two alternative pathways for impulse conduction were present, 2) unidirectional or transient conduction block occurred in one pathway, and 3) conduction was slow enough so that the conduction time in the reentrant circuit exceeded the refractory period of the conducting tissue. ${ }^{76,77}$ The ultimate proof for the presence of reentry is that cutting the reentrant circuit terminates the arrhythmia.

Reentrant tachycardias have been divided into two different forms based upon the type of substrate: anatomic or functional. During anatomic reentry the impulse circulates around an anatomical inexcitable barrier (for example scar tissue), resulting in a fixed length and localization of the reentrant circuit. The cycle length of the tachycardia is determined by the size of the central anatomical obstacle and the conduction velocity of the impulse. Because the cycle length usually largely exceeds the refractory period of the cardiac cells, in all segments of the circuit an excitable gap is present between the head and the tail of the circulating wave. ${ }^{78}$ Functional reentry occurs without the involvement of an anatomical obstacle and depends upon the intrinsic heterogeneity of the electrophysiologic properties of cardiac muscle. ${ }^{79,80}$ Local differences may exist in tissue excitability, refractoriness and intercellular resistance (for example due to regional ischemia). These differences may cause local functional conduction block, around which a reentrant circuit can be formed. ${ }^{80}$ The location and size of functional reentrant circuits may vary due to the absence of an anatomically fixed circuit. The size of the circuits is usually small and is determined by the wavelength of the circulating impulse, defined as the product of conduction velocity and refractory period. ${ }^{81,82}$ However, the inability of cardiac tissue to propagate waves with a very high curvature requires a liminal area for functional reentry to occur. ${ }^{83,84}$ Therefore, functional reentrant circuits can have a small excitable gap. ${ }^{78,85}$ Various types of functional circuits have been described, including leading circle, ${ }^{86}$ anisotropic reentry, ${ }^{87,88}$ figureof-eight, ${ }^{89}$ and spiral wave. ${ }^{90}$

In clinical practice, many different forms of reentry have been established, such as circus movement tachycardia in the presence of accessory pathways, ${ }^{91,92}$ bundle branch reentry, reentry in the Purkinje fiber network, ${ }^{94}$ reentry in the AV-node, ${ }^{95}$ reentry in chronic myocardial infarction, ${ }^{96,97}$ atrial flutter around functional and / or anatomical barriers, ${ }^{98}$ and multiple wavelet reentry causing atrial, ${ }^{99}$ or ventricular fibrillation. ${ }^{100}$ Both a trigger and an appropriate substrate are needed for the occurrence of reentry. For example, VT after myocardial infarction is often initiated by premature ventricular depolarizations (trigger), which may occur spontaneously or may be elicited by electrical stimuli. These premature beats may cause slowing in conduction and conduction block in the infarcted area (sub- 
strate $)^{101}$ to find the conditions required for reentry.

\section{Mechanisms of Slow Conduction and Conduction Block}

The main factors governing propagation are the excitability of the cardiac cells determined by the properties of the ionic channels, the passive electrical properties of the tissue and the curvature of the excitation wave. ${ }^{102}$ Alterations in these factors may cause slow conduction and conduction block and thus promote the occurrence of reentrant arrhythmias.

\section{Tissue excitability}

In atrial and ventricular myocardium, the inward $\mathrm{Na}^{*}$ - current is mainly responsible for the depolarization of the cardiac cells and for generating the local current for propagation. ${ }^{103}$ The inward $\mathrm{Na}^{*}$ - current is generated by voltage-gated ion channels. ${ }^{104} \mathrm{~A}$ reduction of the inward $\mathrm{Na}^{*}$ - current by pharmacological blockade of the $\mathrm{Na}^{\prime}$-channels results in a decrease of tissue excitability and slowing of conduction. ${ }^{104}$ Experimental studies as well as computer models have shown that blocking the fast inward $\mathrm{Na}^{\prime}$ - current can decrease conduction velocity to about $30-50 \%$ of its initial value before conduction block occurs, i.e. very slow conduction has never been observed as a result of $\mathrm{Na}^{+}$blockade alone. ${ }^{105,106}$ Because the $\mathrm{Na}^{*}$-channels are voltage dependent, one of the major mechanisms of pathological conduction is alteration of the resting membrane potential. At membrane potentials more positive than $-70 \mathrm{mV}$, a large fraction of the $\mathrm{Na}^{+}$-channels is in the inactivated state, so that less sodium current is available and conduction gets disturbed. ${ }^{104,107,108}$ Such changes are observed for instance during myocardial ischemia, when the membrane potential is reduced because of cellular loss of $\mathrm{K}^{+}$and extracellular $\mathrm{K}^{+}$accumulation. ${ }^{108,109}$

In normal myocardium, the recovery of excitability after a previous excitation is mainly voltage-dependent and is directly related to the time course of the action potential repolarization. ${ }^{104}$ In case of an early premature beat, the cardiac cells are not yet fully repolarized and only part of the $\mathrm{Na}^{+}$channels have recovered from inactivation. The reduced amount of inward $\mathrm{Na}^{+}$- current results in slowing of conduction of the premature impulse. Spatial dispersion in refractory periods causes heterogeneity in the recovery of $\mathrm{Na}^{+}$channels from inactivation, which can lead to local functional conduction block of a critically timed premature beat. ${ }^{80}$ In diseased myocardium, recovery from inactivation may no longer follow the time course of repolarization but may also be time-dependent. ${ }^{110}$ The period of inexcitability can outlast the repolarization phase of the action potential. The mechanism of this postrepolarization refractoriness is probably due to altered function of the $\mathrm{Na}^{+}$channels in diseased myocardium. ${ }^{111,112}$

\section{Tissue Anisotropy}

Ventricular myocytes are rod-shaped and form end-to-end connections with adjacent cells. ${ }^{113}$ In a longitudinal direction, the myocardial fibers are well coupled by gap junctions, ${ }^{114}$ whereas between parallel muscle bundles such gap junctions are less abundant. ${ }^{113}$ 
As a consequence, the gap junctional resistance in the longitudinal direction is lower than in the transverse direction. ${ }^{115,116}$ The directional difference in resistance causes the conduction velocity perpendicular to the fibers to be about three times slower than parallel to the fibers. ${ }^{117}$ In ventricular myocardium, the longitudinal conduction velocity is about 60 $\mathrm{cm} / \mathrm{s}$ compared to about $20 \mathrm{~cm} / \mathrm{s}$ transverse to the fibers. ${ }^{108,115-121}$ Despite the higher conduction velocity during longitudinal propagation, the upstroke of the action potential is actually slower. This is due to a higher dissipation of excitatory current along the lower axial resistance parallel to the fibers. ${ }^{118,122}$ The safety factor for conduction, defined as the ratio between the amount of generated current and the current required for impulse propagation, ${ }^{123}$ therefore is lower in longitudinal direction. ${ }^{118,122}$ The fact that reduction of the inward $\mathrm{Na}^{*}$ - current by early premature beats or antiarrhythmic drugs seems to depress longitudinal conduction more than transverse conduction also indicates that the safety factor for propagation parallel to the fiber orientation is lower. ${ }^{87,108,118-120,122,124,125}$ On the other hand, because of poor electrical coupling in transverse direction, blockade of gap junctions by heptanol preferentially depresses transverse conduction. ${ }^{125-127}$ Gap junctional uncoupling can reduce the conduction velocity to values less than $1 \mathrm{~cm} / \mathrm{s}$, before conduction block occurs. ${ }^{106}$ During this apparent ultra-slow conduction, the activation front follows a meandering pathway and, at the cellular level, conduction is sustained by sequentially activated patches of tissue, each of which consists of a few cells being activated simultaneously. ${ }^{106}$ In aged or diseased myocardium, tissue anisotropy is enhanced by the formation of collagenous septa between adjacent muscle bundles. ${ }^{88,128,129}$ Since these anatomical obstacles are typically oriented parallel to the fibers, they become specifically manifest during transverse propagation. Whereas longitudinal conduction velocity may remain normal, the effective transverse conduction velocity may be as slow as $<5 \mathrm{~cm} / \mathrm{s}^{88}$ During such slow transverse propagation the upstroke of the action potential shows discontinuities and extracellular electrograms become fractionated. ${ }^{128}$ Fractionation of extracellular electrograms can be explained by asynchronous firing of neighbouring bundles, which have become separated by fibrotic tissue. Spach et al. used the observation that fractionated electrograms were recorded from some preparations but not from others to classify anisotropic tissue as being uniform or nonuniform. ${ }^{130} \mathrm{He}$ showed that in nonuniform anisotropic tissue premature impulses were preferentially blocked in a longitudinal direction which could induce functional reentry. ${ }^{87}$

The structural discontinuities in non-uniform anisotropic myocardium can influence impulse propagation in various ways. Computer simulations have shown that periodically spaced resistive obstacles decrease the conduction velocity. ${ }^{131}$ When the resistance of these obstacles is relatively low, the conduction velocity is mainly determined by the number and the value of the resistors (total resistance). However, when the resistance of the obstacles is high, the spatial distribution of the resistors becomes an important determinant of conduction. In case of a short distance between the obstacles, the conduction delays are confined to the high resistance region with almost simultaneous excitation of the small seg- 
ment of conducting elements. ${ }^{131}$ For non-uniform myocardium, this type of propagation has been termed 'saltatory conduction'. ${ }^{132}$ With a very long segment between the obstacles however, the amount of current driven through the obstacle may not be sufficient to excite the large number of conducting elements beyond the obstacle. A mismatch between source and sink may decrease the conduction velocity and may cause activation block. ${ }^{131}$ Similarly, fibrosis in cardiac tissue may produce variations in electrical resistance and mismatches between source and sink due to inhomogeneous loss of side-to-side cell connections. These spatial nonuniformities of electrical loading will give rise to slow conduction and conduction block. ${ }^{133}$ Obstacles can also serve as pivot points, or they may form narrow gates or isthmuses through which the excitation waves are transmitted from one excitable region to another. At the exit of an isthmus, large conduction delays and conduction block may occur due to a sudden increase in current load. ${ }^{134-137}$ Recent studies have indicated that at such sites of large conduction delays, the amount of inward $\mathrm{Ca}^{*}$ current may become critical to maintain propagation. ${ }^{138,139}$ Finally, even when the conduction velocity is normal, in nonuniform anisotropic tissue large activation delays can occur over short distances because of long 'zigzag' pathways. ${ }^{128,140}$

\section{Wavefront Curvature}

In addition to the active and passive properties of the myocardium, the curvature of a wavefront influences wave propagation. It has been shown in ventricular myocardium that a high wavefront curvature may cause slowing of propagation and conduction block. ${ }^{137}$ The current generated by the cells at the front of a convexly curved wave distributes over a larger membrane area downstream, ${ }^{141}$ resulting in a lower safety factor for conduction. In cardiac tissue, in several situations excitation wavefronts may get pronounced curvatures, including waves emerging from narrow tissue structures and waves making a sharp U-turn around an anatomical obstacle or a line of functional conduction block.

Transition from a narrow strand to a large volume of myocardium occurs for instance at the Purkinje-muscle junction, ${ }^{142}$ the junction between an accessory pathway and atrial or ventricular myocardium in the WPW-syndrome, ${ }^{143}$ and at the junction between thin surviving cell strands within infarcted myocardium and the surrounding intact tissue. ${ }^{144}$ Conduction slowing and block at such sites of abrupt tissue expansion has been demonstrated both theoretically and experimentally. ${ }^{136,137,145,146}$ In isolated sheets of ventricular epicardium, Cabo et al. ${ }^{137}$ showed that the excitation wave emerging from a narrow isthmus has an elliptical shape with a pronounced curvature and propagates at reduced velocity (Fig. 1). At a critical width of the isthmus (critical curvature), conduction block occurs. ${ }^{137}$ In the aging heart and after myocardial infarction, fibrotic tissue may form longitudinally oriented anatomical obstacles. ${ }^{88,128,129}$ Computer simulations and recent experiments have demonstrated that the increased wavefront curvature at the end of such lines of anatomic block causes slowing of conduction. ${ }^{84,134,147,148}$ In guinea pig ventricle, Girouard et al..$^{134}$ 
A

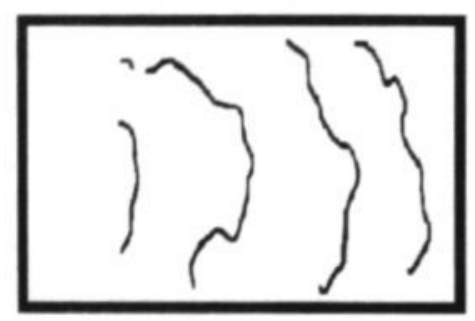

C

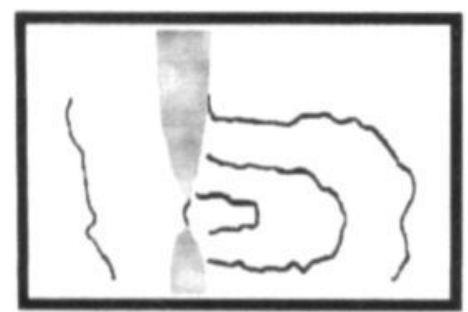

B

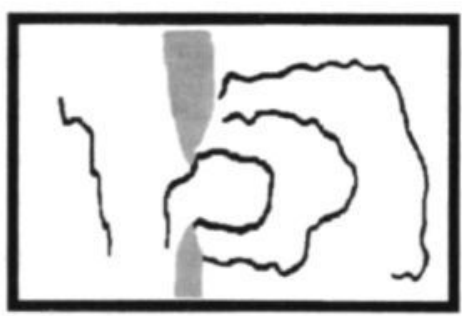

D

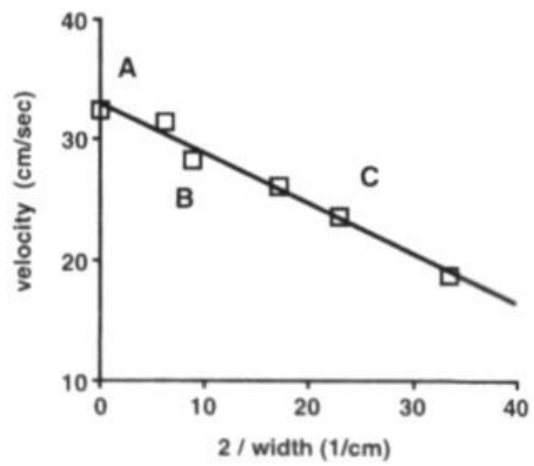

Figure 1. Wave propagation across a narnow isthmus in an isolated preparation of sheep heart. Panel A: Map of activation before the creation of an isthmus. Panel B: Activation spread in the same preparation with an isthmus of $2.26 \mathrm{~mm}$ wide. The isthmus was produced by two cuts (gray zones). Panel C: Activation spread after the isthmus was reduced to $0.88 \mathrm{~mm}$. Panel D: Local conduction velocity measured across the isthmus as a function of isthmus width.

(Cabo et al.; Circ Res. 1994: 75: 1014-1028)

studied propagation of turning wavefronts around a thin linear lesion oriented perpendicular to the epicardial fibers. They found that the turning wavefront slowed down at the pivot point (from 35 to $20 \mathrm{~cm} / \mathrm{s}$ ) despite the fact that the direction of propagation changed from perpendicular to parallel. ${ }^{134}$ In another study, after reduction of tissue excitability by tetrodotoxin, activation block of the pivoting wavefront occurred at the end of the anatomical lesion, causing detachment of the excitation wave from the tip of the lesion. ${ }^{148}$ It is suggessted that conduction slowing at the ends of a line of functional block is also mainly due to increased wavefront curvature. Schalij et al. ${ }^{149}$ recently showed that the line of functional block during anisotropic reentry in fact was Z-shaped (Fig. 2). The short limbs of the Zshaped line of block resulted from delayed activation at the pivot points, which was attributed to pronounced wavefront curvature and an abrupt increase in current load. ${ }^{149}$ 


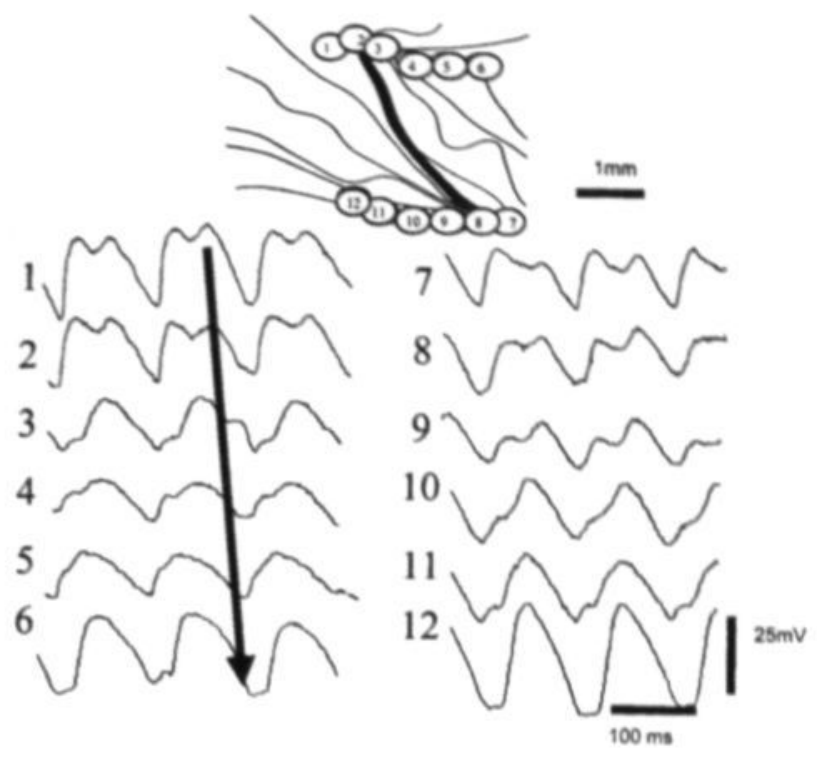

Figure 2. Reentry around a Z-shaped line of functional conduction block. Steps in depolarization occurred at the short limbs of Z (electrodes 3-5 and 9-11). Approximately $2 \mathrm{~mm}$ distal to the pivot points depolarization showed no steps anymore (electrodes 6 and 12). (Schalij et al:; Circulation 2000; 102: 2650-2658)

\section{Ventricular Tachycardia After Myocardial Infaretion}

\section{Clinical Observations}

The results of a large number of clinical electrophysiological studies, beginning with the initial investigation by Wellens et al. in the early seventies, ${ }^{96,150,151}$ have provided convincing evidence that reentry is the underlying mechanism of VT occurring late after myocardial infarction (for review see reference ${ }^{74}$ ). The instruments that have been used to elucidate the mechanism of VT include programmed electrical stimulation and cardiac mapping.

Wellens et al. was one of the first to use programmed electrical stimulation to study the mechanism of VT after myocardial infarction..$^{96,150,151}$ He demonstrated that VT can be reproducibly initiated and terminated by properly timed premature stimuli, a characteristic typical for reentry. After his initial investigations, many others have studied the response of VT to electrical stimulation. Josephson and others demonstrated that premature stimuli can reset VT, indicating that the premature impulses reach the tachycardia site of origin and find it excitable. ${ }^{152-154}$ The fact that, in most cases, premature stimuli can reset VT over a large range of coupling intervals indicates that clinical VTs often have a large excitable gap. ${ }^{152}$ The presence of a large excitable gap suggests that clinical VTs are probably not based on functional reentry but on a circuit around an anatomical obstacle. ${ }^{78}$ However, it 


\section{Chapter 1}

can not be excluded that functional reentry is an important mechanism of fast, hemodynamically unstable VTs, which are difficult to study in the clinical electrophysiology laboratory.

Sustained VT can also be entrained and terminated by overdrive pacing. ${ }^{154-162,163,164}$ Waldo et al. ${ }^{158,165}$ and Henthorn et al. ${ }^{164}$ have developed four criteria for entrainment which demonstrate that VT is due to reentry. The data obtained from electrocardiographic studies and from intracardiac recordings show whether the stimulated impulses enter the circuit during entrainment and activate it in a similar way as the reentrant impulse. At a critical rate of stimulation, the stimulated wavefront blocks in the circuit and causes the tachycardia to terminate. ${ }^{159,163}$ Overdrive pacing has also provided information about the electrophysiological properties of the reentrant circuits causing VT. Failure of entrainment and termination of VT may indicate a small protected circuit into which the stimulated impulses cannot penetrate. ${ }^{166}$ Overdrive stimulation within the reentrant circuit may be followed by a long delay before inscription of the QRS complex on the surface ECG. The long delay has been attributed to the presence of a slowly conducting pathway in the reentrant circuit. $^{162,167-169}$ Termination of VT by overdrive pacing was found to be due to conduction block within this zone of abnormal conduction. ${ }^{162,169}$ At rapid rates of overdrive stimulation, the VT may accelerate rather than terminate or a new tachycardia with a different QRS complex might be initiated. ${ }^{155}$

Mapping of the electrical activation of the left ventricle during VT has shown that the site of earliest activation, which identifies the site of origin of VT, is often located on the endocardial surface of the heart. ${ }^{97,170-175}$ At the site of origin, fractionated electrograms extending throughout the cardiac cycle (continuous electrical activity) can sometimes be recorded from a single electrode, which may imply the presence of a relatively small reentrant circuit on the endocardial surface. ${ }^{176}$ On the other hand, the earliest endocardial activity may only represent the exit site of a large intramural circuit to the rest of the ventricles. ${ }^{97,177}$ De Bakker et al. demonstrated the presence of such macroreentrant circuits in Langendorff perfused human hearts with a chronic myocardial infarction, which were obtained at the time of cardiac transplantation. ${ }^{97,178}$ Figure 3 shows the activation map during one beat of such a VT with a cycle length of $264 \mathrm{msec}$ together with some selected subendocardial electrograms. The site of earliest activation ( site $a, t=0$ ) was located at the septal border of the infarcted region (shaded area). Activation spread from this area to the septum (from a to b) and continued to the anterior wall to arrive at the lateral side of the infarcted area at $\mathrm{t}=192 \mathrm{~ms}$ ( from $\mathrm{b}$ to $\mathrm{c}$ to $\mathrm{d}$ to $\mathrm{e}$ ). Propagation from the lateral side of the infarcted area back to the site of earliest activation seemed to be prevented by the infarct that extended to the endocardial surface, leaving a gap in the activation map of $72 \mathrm{~ms}$ (from $\mathrm{t}=192$ to $264 \mathrm{msec}$ ). The sequence of activation is also illustrated by the electrograms. Starting from the site of earliest activation, all electrograms recorded at the surface of the normal, non-infarcted part of the left ventricle were of high amplitude (site a to e). In the signals recorded from sites $\mathrm{f}, \mathrm{g}$, and $\mathrm{h}$, small deflections were recorded (arrows). The sequence of the small 


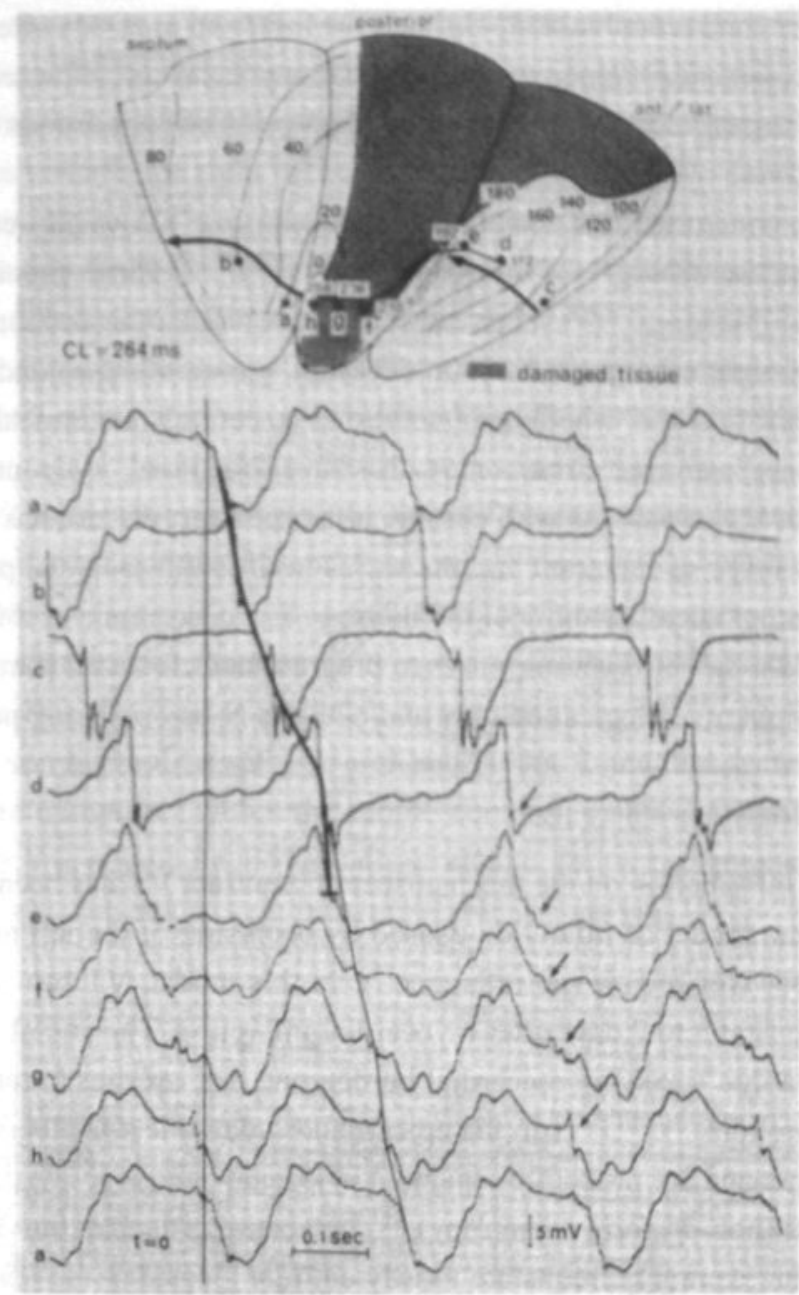

Figure 3. Endocardial activation pattern of one cycle of sustained ventricular tachycardia induced in a Langendorff perfused human heart with extensive infero-posterior infarction. Isochrones, which are constructed from endocardial electrograms with a balloon electrode, are in milliseconds. The site of earliest endocardial activation is taken as $t=0$. Arrows indicate the direction of propagation. At the bottom, endocardial electrograms recorded at sites indicated in the top panel are shown. At sites d$h$, the main deflection is followed by a second small response (arrow). These small potentials bridged the time window between the electrical activation at either side of the infarct (d and a). (de Bakker et al.; Circulation 1988; 77: 589-606)

deflections is such that it suggests the presence of a subendocardial pathway through the infarcted area. The presence of the connecting deep muscle tract in the scar was demonstrated by histological studies of this region. These findings strongly suggested that the VT was based on a large anatomical reentrant circuit around the circumferences of the heart comprising a segment of conduction through the infarcted tissue. De Bakker et al. ${ }^{144}$ fur- 
ther showed that the conduction velocity through the infarcted area was often much slower than the normal conduction velocity in ventricular myocardium. Slow conduction was found to be due to 'zigzag' conduction formed by disruption of connections between bundles by connective tissue of the scar. ${ }^{144}$

Other studies have confirmed that reentrant circuits causing VT usually comprise a segment of slow conduction through the infarcted area. ${ }^{174,175,179-181}$ These circuits may contain a single loop or multiple loops. ${ }^{51,168}$ When two loops have similar conduction times, the circuit has a figure-of-eight configuration. ${ }^{89}$ On occasion, a zone of slow conduction through the infarct is absent and the whole scar serves as a central anatomical obstacle. ${ }^{97,182}$ Anatomically defined reentrant circuits may also have functional components. ${ }^{183}$ In conclusion, mapping of VT in patients with chronic ischemic heart disease has shown that the location, size, and shape of reentrant circuits varies in different patients, probably reflecting the variable pathological anatomy of the infarcts. The occurrence of different kinds of circuits might explain the different responses to programmed electrical stimulation and the varying success of pharmacological therapy and catheter ablation among patients.

\section{Experimental Models}

The most detailed information on the mechanisms of reentrant VT has been obtained from studies in the canine model of infarction caused by occlusion of the left anterior descending coronary artery (for review see reference ${ }^{74}$ ). In this model, VT can reproducibly be initiated during the first 3 to 7 days after myocardial infarction. The site of origin of VT is usually located in a thin surviving epicardial borderzone that overlies a transmural anterior myocardial infarction. ${ }^{101,129,184,185}$ In the epicardial borderzone, the fibers are orientated parallel to each other and are randomly separated by edema or connective tissue formed by the healing process (non-uniform anisotropy) ${ }^{88.129}$ Because of lack of surviving intramural muscle fibers, the reentrant circuits are mostly entirely located in the epicardial borderzone, eliminating the need for three-dimensional mapping.

By using high density mapping arrays, a large number of electrograms have been recorded simultaneously from this epicardial borderzone. Activation maps of the epicardial borderzone have shown how premature stimuli can initiate reentrant VT. ${ }^{101}$ Premature impulses, elicited outside the myocardial scar, propagate into the epicardial borderzone and block. A line of functional conduction block occurs, that may extend for several centimeters. When the conduction time of the premature wave around the ends of the line of functional block is long enough for the myocardium proximal to the line of block to regain excitability, a functional reentrant circuit can be formed. Sustained monomorphic VT is usually based on reentry around one or two lines of functional conduction block, ${ }^{88,101,186}$ but anatomical reentry around areas with no surviving epicardial muscle bundles have also been described. ${ }^{187}$

Figure 4 shows an activation map of a VT in a canine heart with a 4-day-old infarct. The 
site of earliest activation is located between the upper ends of the two lines of functional conduction block (thick black lines), and is indicated by the asterisk. From this site, one wavefront moves to the left of the map, which is the direction of the apex of the ventricle, the other moves towards the right in the direction of the AV-ring. Activation by both wavefronts then moves towards the lateral margin where the two wavefronts coalesce and progress back towards the LAD where activation began. This type of circuit consisting of a clockwise and counterclockwise wavefront around two lines of functional conduction block with a central common pathway has been called figure-of-eight reentry by ElSherif. ${ }^{89}$ The lines of block are usually oriented parallel to the epicardial fiber orientation. The conduction velocity around the circuit varies, due to the anisotropic properties of the myocardium. ${ }^{88}$ Conduction parallel to the lines of functional block (and fiber orientation) is faster than at the ends of the lines of block, where the rotating impulse propagates transverse to the fibers. As a result of tissue anisotropy the circuits usually have an oval shape. ${ }^{88}$ Functional (or anisotropic) reentrant VT in the epicardial borderzone can be reset and entrained, indicating that these circuits have an excitable gap. ${ }^{188-191}$ El-Sherif et al. showed that premature stimuli could reset figure-of-eight reentry, and that decremental conduction of early premature impulses within the central common pathway could terminate VT. ${ }^{188}$ In this study, only a relatively small partially excitable gap was demonstrated. In the same

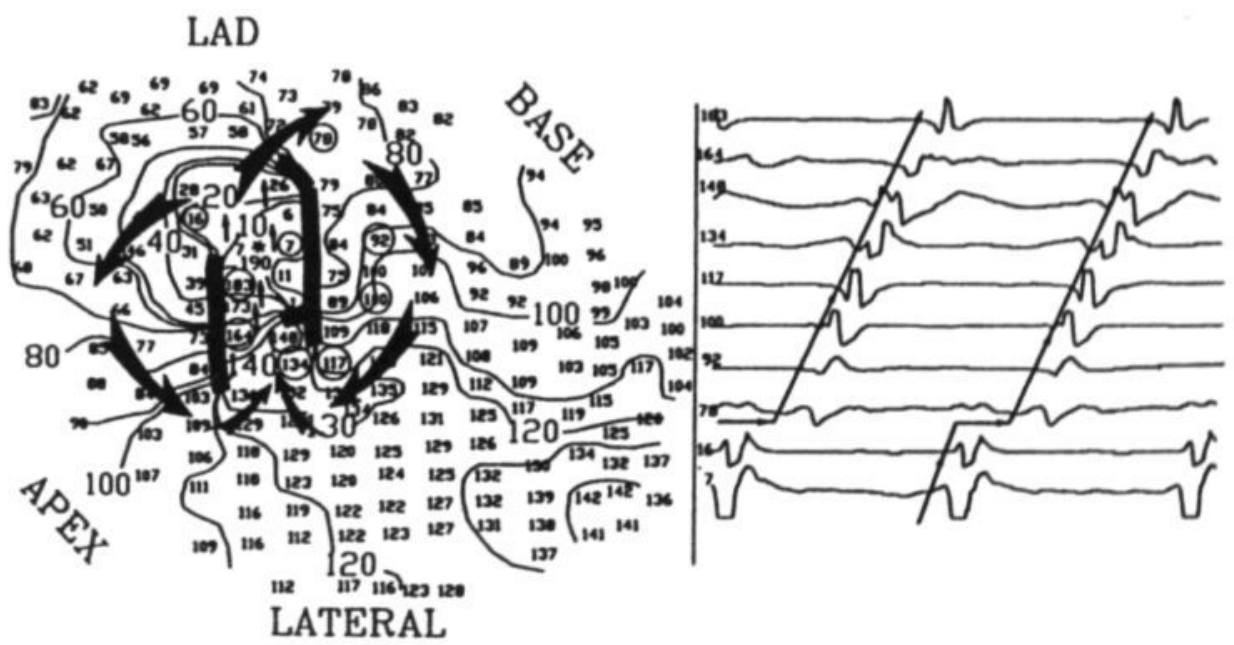

Figure 4. Reentry in the epicardial border zone of a canine heart with a 4-day-old infarct. The activation map shows reentry around two lines of functional conduction block (thick black lines) with a central common pathway (figure-of-eight). Activation times in ms, isochrones at IOms intervals, arrows indicate the direction of propagation. At the right are selected electrograms recorded at sites in the reentrant circuit indicated by the circles in the activation map. (Janse and Wit; Physiol. Rev. 1989: 69: 1049-1169) 


\section{Chapter 1}

experimental model, Peters et al. recently showed that anisotropic reentrant circuits cntain areas which have a fully excitable gap, while others parts only have a partially exctable gap. ${ }^{191}$ It is suggested that the presence of an excitable gap during anisotropic reenty can be explained by a current-to-load mismatch at the ends of the functional lines of blek. ${ }^{149}$ Such a mismatch results in conduction delay at the pivot points, prolongation of thecycle length of the VT and creation of an excitable gap.

Other experimental models using swine, ${ }^{192,193}$ feline, ${ }^{194}$ and rabbit hearts ${ }^{195,196}$ hav also provided valuable contributions to the understanding of the mechanisms of VT. $n$ the Langendorff perfused rabbit heart, an epicardial borderzone can be created artificialy by ablation of the endo- and midmyocardial layers of the left ventricle with a cryoprobeinserted into the left ventricular cavity. ${ }^{195}$ As in the canine model, the myocardial fibersin the epicardial borderzone are oriented parallely. However, because of absence of a myoardial infarction, the fibers are not separated in any way by edema or collagen tissue (uiform anisotropy). Schalij et al. ${ }^{195}$ showed that this anatomy alone is sufficient to cause rentrant VT. Premature impulses can initiate reentrant VT by causing preferential unidiretional block of conduction parallel to the epicardial fiber orientation. ${ }^{195.196}$ Slow conduction perpendicular to the fiber orientation allows time for the recovery of excitability of th cardiac fibers proximal to the line of block. During VT, the line of functional conductiorblock

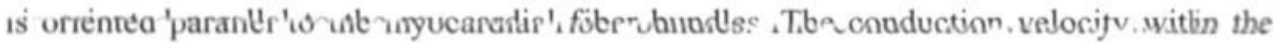
functional circuit varies: conduction is fast parallel to the line of block but slows down sharply at the turning points. ${ }^{195}$ Microelectrode recordings at the turning points showed clear steps in the prolonged depolarization phase and electrotonic prolongation of repolarization. ${ }^{149}$ This local conduction delay at the pivoting points created an excitable gap in all other parts of the reentrant circuit. However, despite the presence of an excitable gap, the majority of these functional VTs could not be reset by premature stimuli. ${ }^{78}$ Failure to reset can be due to slow anisotropic conduction preventing paced impulses to enter the circulating wave, or loss of prematurity of the paced impulse by conduction slowing within the reentrant circuit.

\section{Myocardial Infarction as a Substrate for Reentry}

Ventricular tachyarrhythmias do not occur in all patients with a previous myocardial infarction, even when premature impulses (triggers) are applied by programmed electrical stimulation. An appropriate substrate is needed that enables reentry to occur. Epidemiological studies have shown that ventricular arrhythmias are most likely to occur in patients with a large myocardial infarction, often complicated by formation of a left ventricular aneurysm and associated with left ventricular dysfunction. ${ }^{197-199}$ Histological studies have shown that not only the size of the infarct, but also the survival of cardiac myocytes within the infarcted area is crucial for arrhythmogenesis. ${ }^{184.200-204}$ Areas containing surviving myocardial fibers are potential sites for slow conduction and block. ${ }^{88,101,144,178}$ Surviving fibers may be 
present in subendocardial, subepicardial, and intramural regions. A thin rim of surviving endo- or epicardium has a non-uniform anisotropic structure that influences conduction and may cause reentry. ${ }^{88}$ Surviving bundles in midmyocardial layers of a solid infarct can connect areas of viable myocardium at either side of the infarct zone, forming a return pathway for reentry. ${ }^{97,178}$

During the process of infarct healing, surviving myocardial fibers in the infarcted area become separated by edema and newly formed fibrotic tissue. ${ }^{88.204}$ In the first days to about 2 weeks after infarction, the surviving cells are still arranged parallel to each other, but as the infarets continue to heal the parallel orientation of the fibers is lost. The fibers become oriented in many different directions and side-to-side connections between bundles are not always apparent anymore. ${ }^{204}$ The physical separation of surviving myocytes by fibrous connective tissue results in reduced electrical coupling and an abnormal distribution of gap junctions. ${ }^{205}$ Futhermore, surviving bundles of different size and geometry are randomly connected to each other. ${ }^{178}$ These structural abnormalities of the infarcted area result in slow discontinuous conduction, giving rise to fractionated electrograms with a long duration and prepotentials or notches on the action potential upstrokes. ${ }^{204}$

The arrhythmogeneity of the infarcted area is further enhanced by electrophysiological changes of the cardiac myocytes. In the first week after canine myocardial infarction, the excitability thresholds and refractory periods of the surviving epicardial myocytes are increased. ${ }^{206}$ There is also a marked spatial dispersion of excitability and refractoriness within the epicardial border zone, which may contribute to initiation of reentry. Microelectrode studies have shown that in this same time period the duration of the action potential is shortened. ${ }^{129}$ The prolongation of the refractory periods therefore suggests the development of postrepolarization refractoriness. Next to a shortening of action potential duration, the maximum diastolic potential, action potential amplitude, and upstroke velocity of the action potential are temporarily reduced to return to almost normal values two weeks after infarction. ${ }^{129}$ Action potentials recorded from surviving endocardial muscle overlying healed ( $>2$ months old) myocardial infarction in cats have prolonged durations, with proportional prolongations in local refractoriness. ${ }^{207}$ In patients with a healed myocardial infarction, the refractory periods measured at the endocardial surface of the infarcted area are also prolonged. ${ }^{208}$ The configuration of action potentials recorded from myocardial cells of healed human infarcts was found to be extremely heterogeneous. In some cells, action potentials were recorded with nearly normal resting potentials, while action potentials with slow upstrokes were recorded from other cells with depolarized resting potentials. ${ }^{97.209}$ Heterogeneity of the electrophysiological properties of the myocardial cells after infarction can be enhanced by inhomogeneous distribution of sympathetic fibers. Whereas regions with necrosis and dense scarring show myocardial denervation, ${ }^{210.211}$ other regions of the myocardium may show an increase in sympathetic innervation as a result of injury-related nerve sprouting. ${ }^{210.212}$ Due to the inhomogeneous distribution of sympathetic fibers, sympathetic stimulation increases the dispersion in refractoriness 
between the borderzone and the normal myocardium, promoting the occurrence of reentry. $^{210,212-215}$

Studies on the ionic mechanisms underlying the changes in action potential have shown that isolated cells from the epicardial border zone of 3-7 days old canine infarction have altered functions of the fast $\mathrm{Na}^{+}$-channel, ${ }^{112}$ the slow $\mathrm{Ca}^{+4}$-current, ${ }^{216,217}$ and the transient outward $\mathrm{K}^{*}$ - current. ${ }^{218,219}$ The changes in the fast $\mathrm{Na}^{+}$-channels cause a reduction in $\mathrm{dV} / \mathrm{dt}_{\max }$ and are probably responsible for the development of postrepolarization refractoriness. ${ }^{112} \mathrm{~A}$ reduction in the slow $\mathrm{Ca}^{+4}$-current contributes to the shortening of the duration of the action potential by a loss of the plateau phase. ${ }^{216,217}$ The absence of $\mathrm{i}_{\text {tol }}$ in cells from the infarcted myocardium is related to the loss of the rapid early phase of repolarization and the disappearance of the notch in the action potential in these myocytes. ${ }^{218,219}$

Changes in the anatomical and electrophysiological features of the infarcted area may continue still years after myocardial infarction. The anatomy of the infarcted area continues to change by contraction of the scar, aneurysm formation, and hypertrophy of myocardial cells. ${ }^{220,221}$ Residual coronary ischemia, changes in sympathetic innervation and electrolyte disturbances may also cause alterations in membrane depolarization and repolarization. All of these factors are expected to cause changes in the occurrence and characteristics of ventricular arrhythmias with time.

\section{Objectives of the thesis}

\section{Conduction around a pivot point}

Sharp, longitudinally oriented lines of conduction block, which may be structural or functional in nature, are thought to play an important role in pathological conduction and reentrant arrhythmias. ${ }^{84,88,118}$ In nonuniform anisotropic myocardium, the impulse meanders around the edges of longitudinally oriented anatomical obstacles formed by fibrotic tissue. During functional reentrant VT, the impulse is constantly circulating in a stable circuit around a single or double line of functional conduction block (single loop or figure-ofeight reentry), ${ }^{88,101,186}$ and during ventricular or atrial fibrillation multiple wavelets randomly reenter around arcs of functional conduction block. ${ }^{99,222}$ In recent years it has become evident that the conduction velocity of a sharply turning wavefront slows down because of increased wavefront curvature at the pivot point. ${ }^{84,134,137}$ As a result of the pronounced wavefront curvature, the local excitatory current supplied by the cells at the pivot point (source) is distributed over a larger membrane area (sink). ${ }^{137}$ Therefore, the safety factor for conduction at pivot points is expected to be lower. In chapter 2 we tested the hypothesis that, because of the expected lower safety factor for conduction at pivot points, these sites may be more vulnerable for the action of class I drugs. In an experimental substrate of 'U-turn conduction' around a thin linear lesion in the rabbit ventricle, the effects of lowering of the safety factor for conduction by high extracellular potassium and flecainide were studied by high-density mapping. In Chapter 3 we tested the hypothesis that preferential 
conduction delay at the pivot point by the class IC drug flecainide widens the excitable gap of premature turning wavefronts.

\section{Reentrant VT in rabbit hearts with a healed myocardial infaretion.}

A vast number of clinical and experimental studies have provided a large amount of information on the mechanisms underlying reentrant VT after myocardial infarction. A major limitation of most clinical studies is the lack of high density mapping of the reentrant circuits causing VT and their response to programmed electrical stimulation and administration of antiarrhythmic drugs. For this reason, experimental models of canine myocardial infarction have been developed, which are accessible to mapping. These studies have greatly added to our understanding of the structural and electrophysiological properties of the infarcted area and have provided detailed activation maps of the initiation and termination of VT, resetting and entrainment of VT, and the effects of antiarrhythmic drugs. However, most mapping studies of VT in the canine model have only been performed in the healing phase (3-7 days) after infarction. In this phase, VT is usually based on reentry around one or two lines of functional conduction block. ${ }^{74}$ Mapping data of reentrant VT in the healed phase (weeks to months after infarction) are scarce. Since in the time course between the healing and healed phase of infarction the anatomical and electrophysiological properties of the infarcted area can dramatically change, ${ }^{129}$ it is expected that the mechanisms underlying VT could also change. Indeed, the ability to reset chronic VT over a wide range of coupling intervals in a high percentage of patients, suggests that reentrant circuits in the healed phase are often not functional but anatomical in nature. de Bakker et al. demonstrated the presence of large anatomical reentrant circuits in the hearts of patients suffering from chronic VT. ${ }^{97,177}$ These macroreentrant circuits usually comprise an area of abnormally slow conduction through the healed myocardial infarction. ${ }^{97,144,178}$

Our goal was to develop a rabbit model of healed myocardial infarction in which reentrant VT could be induced with characteristics similar to clinical VT. In Chapter 4 we describe the model that consists of an artificially created two-dimensional layer of left ventricular subepicardium containing an area of healed (approximately 3 months old) myocardial infarction. In this epicardial borderzone different types of reentry could be induced, as demonstrated by high density mapping. In Chapter 5, 6 and 7 we studied the effects of programmed electrical stimulation and antiarrhythmic drugs on these various types of VT. 


\section{References}

1. Lenfant C. Task force on research in epidemiology and prevention of cardiovascular diseases. Circulation. 1994;90:2609-2617.

2. Bron CBS. Doodsoorzaken in Nederland 1999. htttp//www.cbs.nl.

3. Nikolic G, Bishop R, Singh J. Sudden death recorded during holter monitoring. Circulation. 1982:66:218-225.

4. Zipes D, Wellens H. Sudden cardiac death. Circulation. 1998;98:2334-2351.

5. de Vreede-Swagemakers J, Gorgels A, Dubois-Arbouw W, Dalstra J, Daemen M, van Ree J, Stijns R, Wellens H. Circumstances and causes of out-of-hospital cardiac arrest in sudden death survivors. Heart. 1998;79:356-61.

6. Gruppo Italiano per lo Studio della Streptochinasi nell' Infarto Miocardico (GISSI): Long-term effects of intravenous thrombolysis in acute myocardial infarction: Final report of the GISSI study. Lancet. 1987;2:871.

7. Michels KB, Yusuf S. Does PTCA in acute myocardial infarction affect mortality and reinfarc. tion rates? A quantitative overview (meta-analysis) of the randomized clinical trials. Circulation. 1995;91:476.

8. Gheorghiade M, Ruzumna P, Borzak S, Havstad S, Ali A, Goldstein S. Decline in the rate of hospital mortality from acute myocardial infarction: impact of changing management strategies. $\mathrm{Am}$ Heart J. 1996;131:250-256.

9. Reitsma J, Dalstra J, Bonsel G, van der Meulen J, Koster R, Gunning-Schepers L, Tijsen J. Cardiovascular disease in the Netherlands, 1975 to 1999: decline in mortality, but increasing numbers of patients with chronic conditions. Heart. 1999;82:52-56.

10. Multicenter Postinfarction Research Group: Risk stratification and survival after myocardial infarction. N. Engl. J. Med. 1983:309:331.

11. Bigger JJ, Weld FM, Rolnitzky L. Prevalence, characteristics and significance of ventricular tachycardia (three or more complexes) detected with ambulatory electrocardiographic recording in the late hospital phase of acute myocardial infaretion. Am. J. Candiol. 1981;48:815-823.

12. Moss A, Davis H, DeCamilla J, Bayer L. Ventricular ectopic beats and their relation to sudden and nonsudden cardiac death after myocardial infarction. Circulation. 1979;60:998-1003.

13. Maggioni A, Zuanetti G, Franzosi M, Rovelli F, Santoro E, Staszewsky L, Tavazzi L, Tognoni G. Prevalence and prognostic significance of ventricular arrhythmias after acute myocardial infarction in the fibrinolytic era. GISSI-2 results. Circulation. 1993;87:312-22.

14. Moller M, Nielsen B, Fabricius J. Paroxysmal ventricular tachycardia during repeated 24-hour ambulatory electrographic monitoring of postmyocardial infarction patients. $\mathrm{Br}$ Heart J. 1980;43:447-453.

15. Hohnloser S, Klingenheben T, Zabel M, Schopperl M, Mauss O. Prevalence, characteristics and prognostic value during long-term follow-up of nonsustained ventricular tachycardia after myocardial infaretion in the thrombolytic era. JAm Coll Cardiol. 1999:33:1895-902.

16. Wellens H, Brugada P, de Zwaan C, Bendermacher P, Bar F. Clinical characteristics, prognostic significance, and treatment of sustained ventricular tachycardia following acute myocardial infarction. In: Company FP, ed. The First Year After a Myocandial Infarction. New York: Mt. Kisco: 1983:227-237.

17. Mukharji J, Rude R, Pode W, et al. Risk factors for sudden death after acute myocardial infarction. Am J Candiol. 1984;54:31-36.

18. Volpi A, Cavalli A, Turato R, Barlera S, Santoro E, Negri E. Incidence and shortterm prognosis of late sustained ventricular tachycardia after myocardial infarction: results of the Gruppo Italiano per lo Studio della Sopravvivenza nell'Infarto Miocardico (GISSI-3) Data Base. Am Heart J. 2001:142:87-92.

19. Bigger JJ, Fleiss J, Kleiger R, for the The Multicenter Postinfarction Research Group. The relationship between ventricular arrhythmias, left ventricular dysfunction and mortality in the two years after myocardial infarction. Cinculation. 1984:69:250.

20. Marchlinski F, Waxman H, Buxton A, et al. Sustained ventricular tachyarrhythmias during the carly postinfarction period: Electrophysiologic findings and prognosis for survival. $\mathrm{J} \mathrm{Am} \mathrm{Coll}$ Cantiol. 1983:2:240. 
21. Raitt M, Dolack G, Kudenchuk P, et al. Ventricular arrhythmias detected after transvenous defibrillator implantation in patients with a clinical history of only ventricular fibrillation. Implications for use of implantable defibrillator. Circulation. 1995;91:1996.

22. Mont L, Valentino M, Sambola A, Matas M, Aguinaga L, Brugada J. Arrhythmia recurrence in patients with a healed myocardial infarction who received an implantable defibrillator: analysis according to the clinical presentation. JAm Coll Candiol. 1999;34:351-7.

23. Marchlinski FE, Buxton AE, Waxman HL, Josephson ME. Identifying patients at risk of sudden death after myocardial infarction: value of the response to programmed stimulation, degree of ventricular ectopic activity and severity of left ventricular dysfunction. Am $J$ Candiol. 1983:52:1190-6.

24. Meizlish J, Berger H, Plankey M, et al. Functional left ventricular aneurysm formation after acute anterior transmural myocardial infarction. Incidence, natural history, and prognostic implications. N Engl J Med. 1984;3111:1001.

25. Theroux P, Waters D, Halphen C, et al. Prognostic value of exercise testing soon after myocardial infaretion. N Engl J Med. 1979;301:341.

26. Schulze R, Strauss W, Pitt B. Sudden death in the year following myocardial infarction; Relation to ventricular premature contractions in the late hospital phase and left ventricular ejection fraction. Am J Med. 1977;62:192.

27. Nicolisi G, Latini R, Marino P, et al. The prognostic value of predischarge quantitative twodimensional echocardiographic measurements and the effects of early lisinopril treatment on left ventricular structure and function after acute myocardial infarction in the GISSI-3 trial. Eur Heart J. 1996:17:1646.

28. Ruberman W, Weinblatt E, Goldberg J, et al. Ventricular premature beats and mortality after myocardial infarction. N Engl J Med. 1977;297:750.

29. Weld F, Chu K-L, Bigger JJ, Rolnitzky L. Risk stratification with low-level exercise testing 2 weeks after acute myocardial infarction. Circulation. 1981;64:306-314.

30. Josephson ME, Simson MB, Harken AH, Horowitz LN, Falcone RA. The incidence and clinical significance of epicardial late potentials in patients with recurrent sustained ventricular tachycardia and coronary artery disease. Circulation. 1982;66:1199-204.

31. Gomes J, Winters S, Stewart D, et al. A new noninvasive index to predict sustained ventricular tachycardia and sudden death in the first year after myocardial infarction based on signal-averaged electrocardiogram, radionuclide scanning and Holter monitoring. J Am Coll Cardiol. 1987;10:349.

32. Zimmerman M, Sentici A, Adamec R, et al. Long-term prognostic significance of ventricular late potentials after a first acute myocardial infarction. Am Heart J. 1997;1997:1019.

33. Hamer A, Vohra J, Hunt P, et al. Prediction of sudden death by electrophysiologic studies in high risk patients surviving acute myocardial infarction. Am J Cardiol. 1982;50:223.

34. Roy D, Marchand E, Theroux P, et al. Programmed stimulation in survivors of acute myocardial infarction. Circulation. 1985;72:487.

35. Kowey P, Waxman H, Greenspon A, et al. Value of electrophysiologic testing in patients with previous myocardial infarction and nonsustained ventricular tachy cardia. Am $J$ Cardiol. 1990;65:594.

36. Buxton A, Lee K, DiCarlo L, et al. Electrophysiologic testing to identify patients with coronary artery disease who are at risk for sudden death. N Engl J Med. 2000;342:1937.

37. Rosenbaum DS, Jackson LE, Smith JM, Garan H, Ruskin JN, Cohen RJ. Electrical alternans and vulnerability to ventricular arrhythmias. N Engl J Med. 1994;330:235-41.

38. Zabel M, Klingenheben T, Franz M, Hohnloser S. Assessment of QT dispersion for prediction of mortality or arrhythmic events after myocardial infarction: results of a prospective, long-term follow-up study. Circulation. 1998;97:2543-50.

Kleiger R, Miller J, Bigger JJ, et al. Decreases heart rate variability and its association with increased mortality after acute myocardial infarction. Am J Cardiol. 1987;256.

40.

Zuanetti G, Neilson J, Latini R, et al. Prognostic significance of heart rate variability in postmyocardial infarction patients in the fibrinolytic era. The GISSI-2 results. Circulation. 1996;94:432. 


\section{Chapter 1}

41. Echt D, Liebson P, Mitchell L, et al. Mortality and morbidity in patients receiving encainide, flecainide or placebo. The Cardiac Arrhythmia Suppression Trial. N Engl J Med. 1991;327:227.

42. Waldo A, Camm J, de Ruyter H, et al. Effect of d-sotalol on mortality in patients with left ventricular dysfunction after recent and remote myocardial infarction. Lancet. 1996;348:7.

43. Pratt C, Camm A, Cooper W, et al. Mortality in the Survival With ORAL D-sotalol (SWORD) trial: Why did patients die? Am J Cardiol. 1998;81:869.

44. Kober L, Bloch Thomsen P, Moller M, Torp-Pedersen C, Carlsen J, Sandoe E, Egstrup K, Agner E, Videbaek J, Marchant B, Camm A. Effect of dofetilide in patients with recent myocardial farction and left-ventricular dysfunction: a randomised trial. Lancet. 2001;356:2052-8.

45. Julian D, Camm A, Frangin G, et al. Randomised trial of effect of amiodarone on mortality in patients with left-ventricular dysfunction after recent myocardial infarction: EMIAT. Lancet. 1997;349:667.

46. Cairns J, Connolly S, Roberts R, Gent M. Randomised trial of outcome after myocardial infaretion in patients with frequent or repetitive ventricular premature depolarisations: CAMIAT. Canadian Amiodarone Myocardial Infarction Arrhythmia Trial Investigators. Lancet. 1997;349 (9053):675-82.

47. The Norwegian Multicenter Study Group: Timolol-induced reduction in mortality and reinfaretion in patients surviving acute myocardial infarction. New Engl J Med. 1981;304:801-807.

48. Kjekshus J. Importance of heart rate in determining beta-blocker efficacy in acute and long-term acute myocardial infarction intervention trials. Am. J. Cardiol. 1986;57:43F-49F.

49. Stevenson W, Friedman P, Ganz L. Radiofrequency catheter ablation of ventricular tachycardia late after myocardial infarction. J Cardiovasc Electrophysiol. 1997;8:1309-19.

50. Morady F, Harvey M, Kalbfleisch S, el-Atassi R, Calkins H, Langberg J. Radiofrequency catheter ablation of ventricular tachycardia in patients with coronary artery disease. Circulation. 1993;87:363-72.

51. Stevenson W, Khan H, Sager P, Saxon L, Middlekauff H, Natterson P, Wiener I. Identification of reentry circuit sites during catheter mapping and radiofrequency ablation of ventricular tachycardia late after myocardial infarction. Circulation. 1993;88:1647-70.

52. O'Callaghan P, Poloniecki J, Sosa-Suarez G, Ruskin J, McGovern B, Garan H. Long-term clinical outcome of patients with prior myocardial infarction after palliative radiofrequency catheter ablation for frequent ventricular tachycardia. Am J Candiol. 2001;87:975-9.

53. Josephson ME, Harken AH, Horowitz LN. Endocardial excision: a new surgical technique for the treatment of recurrent ventricular tachycardia.Cinculation. 1979;60:1430-9.

54. Caceres J, Akhtar M, Werner P, et al. Cryoablation of refractory sustained ventricular tachycardia due to coronary artery disease. Am J Cardiol. 1989;63:296-300.

55. Boineau J, Cox J. Rationale for a direct surgical approach to control ventricular arrhythmias: Relation of specific intraoperative techniques to mechanism and location of the arrhythmic circuit. Am J Candiol. 1982;49:381-396.

56. Hargrove WCd, Josephson ME, Marchlinski FE, Miller JM. Surgical decisions in the management of sudden cardiac death and malignant ventricular arrhythmias. Subendocardial resection, the automatic internal defibrillator, or both. J Thonac Candiovasc Surg. 1989;97:923-8.

57. Bourke J, Campbell R, McComb J, Furniss S, Doig J, Hilton C. Surgery for postinfarction ventricular tachycardia in the pre-implantable cardioverter defibrillator era: early and long term out comes in 100 consecutive patients. Heart. 1999;82:156-62.

58. Stevenson W. Ventricular tachycardia after myocardial infaretion: from arrhythmia surgery to catheter ablation. J Candiovasc Electrophysiol. 1995;6:942-50.

59. Miller J, Gottlieb C, Marchlinski F, Hargrove WI, Josephson M. Does ventricular tachycardia mapping influence the success rate of antiarrhythmic surgery? $\mathrm{J} \mathrm{Am}$ Coll Cardiol. 1988;11:112A.

60. Wever E, Hauer R, van Capelle F, Tijssen J, Crijns H, Algra A, Wiesfeld A, Bakker P, Robles de Medina E. Randomized study of implantable defibrillator as first choice therapy versus conventional strategy in postinfarct sudden death survivors. Circulation. 1995;91:2195-203.

61. Naccarelli G, Wolbrette D, Dell'Orfano J, Patel H, Luck J. A decade of clinical trial develop- 
ments in postmyocardial infarction, congestive heart failure, and sustained ventricular tachyarrhythmia patients: from CAST to AVID and beyond. Cardiac Arrhythmic Suppression Trial. Antiarrhythmic Versus Implantable Defibrillators. J Candiovase Electrophysiol. 1998;9:864-91.

62. Mirowski M, Reid P, Mower M, Watkins L, Gott V, Schauble J. Termination of malignant ventricular arrhythmias with an implanted automatic defibrillator in human beings. $N$ Engl $J$ Med. 1980;303:322-4.

63. Lehmann M, Steinman R, Schuger C, Jackson K. The automatic implantable cardioverter-defibrillator as antiarrhythmic treatment modality of choice for survivors of cardiac arrest unrelated to acute myocardial infarction. Am J Candiol. 1988;62:803-5.

64. Powell A, Fuchs T, Finkelstein D, Garan H, Cannom D, MeGovern B, Kelly E, Vlahakes G, Torchiana D, Ruskin J. Influence of implantable cardioverter-defibrillators on the long-term prognosis of survivors of out-of-hospital cardiac arrest. Cinculation. 1993;88:1083-92.

65. Siebels J, Kuck K. Implantable cardioverter defibrillator compared with antiar rhythmic drug treatment in cardiac arrest survivors (the Cardiac Arrest Study Hamburg). Am Heart J. 1994;127:1139-44.

66. Connolly S, Gent M, Roberts R, Dorian P, Roy D, Sheldon R. Canadian Implantable Defibrillator Study (CIDS). A randomized trial of the implantable cardioverter defibrillator against amiodarone. Circulation. 2000;101:1297-302.

67. The Antiarrhythmics versus Implantable Defibrillators (AVID) Investigators. A comparison of antiarrhythmic-drug therapy with implantable defibrillators in patients resuscitated from nearfatal ventricular arrhythmias. $N$ Engl J Med. 1997;337:1576-83.

68. Connolly S, Hallstrom A, Cappato R, et al. Meta-analysis of the implantable cardioverter defibrillator secondary prevention trials. AVID, CASH and CIDS studies. Eur Heart $J$. 2000;21:2071.

69. Moss A, Hall W, Cannom D, Daubert J, Higgins S, Klein H, Levine J, Saksena S, Waldo A, Wilber D, Brown M, Heo M. Improved survival with an implanted defibrillator in patients with coronary disease at high risk for ventricular arrhythmia. Multicenter Automatic Defibrillator Implantation Trial Investigators. $N$ Engl J Med. 1996;335:1933-40.

70. Buxton A, Lee K, Fisher J, Josephson M, Prystowsky E. A randomized study of the prevention of sudden death in patients with coronary artery disease. Multicenter Unsustained Tachycardia Trial Investigators. $N$ Engl J Med. 1999;341:1882-90.

71. Wever E, Hauer-RN; Schrijvers-G; van-Capelle-FJ; Tijssen-JG; Crijns-HJ; Algra-A; Ramanna$\mathrm{H}$; Bakker-PF; Robles-de-Medina-EO. Cost-effectiveness of implantable defibrillator as firstchoice therapy versus electrophysiologically guided, tiered strategy in postinfarct sudden death survivors. A randomized study. Circulation. 1996;93:489-96.

72. O'Brien B, Connolly S, Goeree R, Blackhouse G, Willan A, Yee R, Roberts R, Gent M, Investigators ftC. Cost-effectiveness of the implanatable cardioverterdefibrillator. Results from the Canadian Implantable Defibrillator Study (CIDS). Circulation. 2001;103:1416-1421.

73. Zipes D. Implantable cardioverter-defibrillator: A Volkswagen or a Rolls Royce. How much will we pay to save a life? Circulation. 2001;103:1372-1374.

74. Janse M, Wit A. Electrophysiosiological mechanisms of ventricular arrhythmias resulting from myocardial ischemia and infarction. Physiol. Rev. 1989;69:1049-1169.

75. Mayer A. Rhythmical pulsation in scyphomedusae. Carnegie Institution of Washington Publication No.47. 1906.

76. Mines G. On dynamic equilibrium in the heart. J Physiol. 1913;46.

77. Mines GR. On circulating excitations in heart muscles and their possible relation to tachycardia and fibrillation. Trans R S C. 1914;IV:43-53.

78. Boersma L, Brugada J, Kirchhof C, Allessie M. Mapping of reset of anatomic and functional reentry in anisotropic rabbit ventricular myocardium. Circulation. 1994;89:852-62.

79. Allessie MA, Bonke FIM, Schopman FJG. Circus movement in rabbit atrial muscle as a mechanism of tachycardia. Circ Res. 1973;32:54-62.

80. Allessie MA, Bonke FIM, Schopman FJG. Circus movement in rabbit atrial muscle as a mechanism of tachycardia. II. The role of nonuniform recovery of excitability in the occurrence of uni- 
directional block, as studied with multiple microelectrodes. Circ Res. 1976;39:168-177.

81. Han J, Moe G. Nonuniform recovery of excitability in ventricular muscle. Circ Res. 1964;14:44-60.

82. Smeets JLRM. Wave length of the cardiac impulse and reentrant arrhythmias [PhD thesis]. Maastricht, The Netherlands: University of Limburg; 1983.

83. Ramza B, Joyner R, Tan R, Osaka T. Cellular mechanism of the functional refractory period in ventricular muscle. Circ Res. 1990;66:147-162.

84. Fast VG, Kleber AG. Role of wavefront curvature in propagation of cardiac impulse. Candiovase Res. 1997;33:258-71.

85. Ikeda T, Uchida T, Hough D, Lee JJ, Fishbein MC, Mandel WJ, Chen PS, Karagueuzian HS Mechanism of spontaneous termination of functional reentry in isolated canine right atrium. Evidence for the presence of an excitable but nonexcited core. Circulation. 1996;94:1962-73.

86. Allessie MA, Bonke FIM, Schopman FJG. Circus movement in rabbit atrial muscle as a mechanism of tachycardia. III. The "leading circle" concept: A new model of circus movement in cardiac tissue without the involvement of an anatomical obstacle. Circ Res. 1977;41:9-18.

87. Spach MS, Dolber PC, Heidlage JF. Influence of the passive anisotropic properties on directional differences in propagation following modification of the sodium conductance in human atrial muscle. A model of reentry based on anisotropic discontinuous propagation. Circ Res. 1988;62:811-32.

88. Dillon SM, Allessie MA, Ursell PC, Wit AL. Influences of anisotropic tissue structure on reentrant circuits in the epicardial border zone of subacute canine infarcts. Circ Res. 1988;63:182-206.

89. el Sherif N, Gough WB, Zeiler RH, Hariman R. Reentrant ventricular arrhythmias in the late myocardial infarction period. 12. Spontaneous versus induced reentryand intramural versus epicardial circuits. J Am Coll Cardiol. 1985;6:124-32.

90. Pertsov AM, Davidenko JM, Salomonsz R, Baxter WT, Jalife J. Spiral waves of excitation underlie reentrant activity in isolated cardiac muscle. Circ Res. 1993;72:631-50.

91. Durrer D, Schoo L, Schuilenburg RM, Wellens HJ. The role of premature beats in the initiation and the termination of supraventricular tachycardia in the Wolff Parkinson-White syndrome. Circulation. 1967;36:644-62.

92. Gallagher J, Pritchett E, Sealy W, et al. The pre-excitation syndromes. Prog Candiovasc Dis. 1978;20:285-327.

93. Akhtar M, Gilbert C, Wolf F, et al. Reentry within the His-Purkinje system. Eludication of reentrant circuits using right bundle branch and His bundle recor dings. Cinculation. 1978;58:295-304.

94. Wit AL, Cranefield PF, Hoffman BF. Slow conduction and reentry in the ventrcular conducting system. II. Single and sustained circus movement in networks of canine and bovine Purkinje fibers. Cinc Res. 1972;30:11-22.

95. Denes P, Wu D, Amat-Y-Leon F, et al. The determinants of atrioventricular nodal reentrance with premature atrial stimulation in patients with dual AV nodal pathways. Circulation. 1977;56:253.

96. Wellens HJ, Duren DR, Lie KI. Observations on mechanisms of ventricular tachycardia in man. Cinculation. 1976;54:237-44.

97. de Bakker JM, van Capelle FJ, Janse MJ, Wilde AA, Coronel R, Becker AE, Dingemans KP, van Hemel NM, Hauer RN. Reentry as a cause of ventricular tachycardia in patients with chronic ischemic heart disease: electrophysiologic and anatomic correlation. Cinculation. 1988;77:589-606.

98. Waldo A, Maclean W, Karp R, Kouchoukos N, James T. Entrainment and interruption of atrial flutter with atrial pacing. Studies following open heart surgery. Circulation. 1977;56:737-745.

99. Konings KT, Kirchhof CJ, Smeets JR, Wellens HJ, Penn OC, Allessie MA. Highdensity mapping of electrically induced atrial fibrillation in humans. Cinculation. 1994;89:1665-80.

100. Wu TJ, Ong JJ, Hwang C, Lee JJ, Fishbein MC, Czer L, Trento A, Blanche C, Kass RM, Mandel WJ, Karagueuzian HS, Chen PS. Characteristics of wave fronts during ventricular fibrillation in human hearts with dilated cardiomyopathy: role of increased fibrosis in the generation of reentry. J Am Coll Candiol. 1998;32:187-96.

101. Wit AL, Allessie MA, Bonke FI, Lammers W, Smeets J, Fenoglio JJ, Jr. Electrophysiologic mapping to determine the mechanism of experimental ventricular tachycardia initiated by premature impulses. Experimental approach and initial results demonstrating reentrant excitation. $\mathrm{Am}$ J Candiol. 1982;49:166-85. 
102. Kleber A, Janse M, Fast V. Normal and abnormal conduction in the heart. In: The Handbook of Physiology. Volume: The Heart. 1998.

103. Fozzard $\mathrm{H}$. The roles of membrane potential and inward $\mathrm{Na}^{*}$ and $\mathrm{Ca}^{\prime}$ currents in determining conduction. In: Rosen M, Janse M, Wit A, eds. Candiac Electrophysiology: A textbook. New York: Futura Publishing Company; 1990:415-425.

104. Weidmann $\mathrm{S}$. The effect of the cardiac membrane potential on the rapid availability of the sodium-carrying system. I. Physiol. 1955;127:213-224.

105. Shaw RM, Rudy Y. lonic mechanisms of propagation in cardiac tissue. Roles of the sodium and L-type calcium currents during reduced excitability and decreased gap junction coupling. Cinc Res. 1997;81:727-41.

106. Rohr S, Kucera JP, Kleber AG. Slow conduction in cardiac tissue, I: effects of a reduction of excitability versus a reduction of electrical coupling on microconduction. Cire Res. 1998;83:781-94.

107. Grant A, Starmer C. Mechanisms of closure of cardiac sodium channels in rabbit ventricular myocytes: single channel analysis. Cinc Res. 1987;60:897-913.

108. Kleber AG, Janse MJ, Wilms Schopmann FJ, Wilde AA, Coronel R. Changes in conduction velocity during acute ischemia in ventricular myocardium of the isolated porcine heart. Cinculation. 1986;73:189-98.

109. Kleber A. Resting membrane potential, extracellular potassium activity, and intracellular sodium activity during acute global ischemia in isolated perfused guinea pig hearts. Cinc Res. 1983:52:442-450.

110. Lazarra R, Scherlag B. Electrophysiologic basis for arrhythmias in ischemic heart disease. Am J Candiol. 1984;53:1B-7B.

111. Boyden P. Cellular electrophysiologic basis of cardiac arrhythmias. Am J Candiol. 1996:29:4-11.

112. Pu J, Boyden P. Alterations of Nat currents in myocytes from epicardial border zone of infareted heart. A possible mechanism for reduced axcitability and postrepolarization refractoriness. Circ Res. 1997;81:110-119.

113. Sommer J, Johnson E. Ultrastructure of cardiac muscle. In: Berne R, Sperelakis N, Geiger S, eds. Handbook of Physiology sect II, vol.I, The Heart.Bethesda: American Physiological Society; 1980:

114. Sjostrand F, Anderson E. Electron microscopy of the intercalated discs of cardiac muscle tissue. Experientia. 1954;10:369-372.

115. Clerc L. Directional differences of impulse spread in trabecular muscle from mammalian heart. J Physiol. 1976;255:234-245.

116. Roberts D, Hersh L, Scher A. Influence of cardiac fiber orientation on wavefront voltage, conduction velocity, and tissue resistivity. Circ Res. 1979;44:701-12.

117. Sano T, Takayama N, Shimamoto T. Directional difference of conduction velocity in the cardiac ventricular syncytium studied by microelectrodes. Circulation Research. 1959;7:262-268.

118. Spach M, Miller W. The discontinuous nature of propagation in normal canine cardiac muscle. Evidence for recureent discontinuities of intracellular resistance that affect the membrane currents. Circ Res. 1981;48:39-54.

119. Tsuboi N, Kodama I, Toyama J, Yamada K. Anisotropic conduction properties of canine ventricular muscles. Influence of high extracellular $\mathrm{K}^{*}$ concentration and stimulation frequency. Jpn Circ J. 1985;49:487-98.

120. Kadish AH, Spear JF, Levine JH, Moore EN. The effects of procainamide on conduction in anisotropic canine ventricular myocardium. Circulation. 1986;74:616-25.

121. Boersma LVA, Brugada J, Schalij MJ, Kirchhof CJHJ, Allessie MA. The effects of $\mathrm{K}^{*}$ on anisot ropic conduction in sheets of perfused rabbit ventricular epicardium. Journal of Cardiovascular Electrophysiology. 1991;2:492-502.

122. Spach MS, Miller WTd, Dolber PC, Kootsey JM, Sommer JR, Mosher CE, Jr. The functional role of structural complexities in the propagation of depolarization in the atrium of the dog. Cardiac conduction disturbances due to discontinuities of effective axial resistivity. Circ Res. 1982;50:175-91.

123. Schmitt F, Schmitt O. Partial excitation and variable conduction in the squid giant axon. $J$ Physiol. 1940;98:26-46. 
124. Spach MS, Dolber PC, Heidlage JF, Kootsey JM, Johnson EA. Propagating depolarization in anisotropic human and canine cardiac muscle: apparent directional differences in membrane capacitance. A simplified model for selective directional effects of modifying the sodium conductance on Vmax, tau foot, and the propagation safety factor. Circ Res. 1987;60:206-19.

125. Brugada J, Mont L, Boersma L, Kirchhof C, Allessie MA. Differential effects of heptanol, potas. sium, and tetrodotoxin on reentrant ventricular tachycardia around a fixed obstacle in anisotropic myocardium. Circulation. 1991;84:1307-18.

126. Delmar M, Michaels D, Johnson T, et al. Effects of increasing intercellular resistance on transverse and longitudinal propagation in sheep epicardial muscle. Circ Res. 1987;60:780-85.

127. Balke C, Lesh M, Spear J, et al. Effects of cellular uncoupling on conduction in anisotropic canne ventricular myocardium. Circ Res. 1988;63:879-892.

128. Spach MS, Dolber PC. Relating extracellular potentials and their derivatives to anisotropic propagation at a microscopic level in human cardiac muscle. Evidence for electrical uncoupling of side-to-side fiber connections with increasing age. Circ Res. 1986;58:356-71.

129. Ursell PC, Gardner PI, Albala A, Fenoglio JJ, Jr., Wit AL. Structural and electrophysiological changes in the epicardial border zone of canine myocardial infarcts during infarct healing. Cinc Res. 1985;56:436-51.

130. Spach MS, Dolber PC, Heidlage JF. Properties of discontinuous anisotropic propagation at a microscopic level. Ann N Y Acad Sci. 1990;591:62-74.

131. Joyner R. Effects of discrete pattern of electrical coupling on propagation through an electrical syncytium. Circ Res. 1982;50:192-200.

132. Spach MS, Josephson ME. Initiating reentry: the role of nonuniform anisotropy in small circuits. J Candiovasc Electrophysiol. 1994;5:182-209.

133. Spach MS, Boineau JP. Microfibrosis produces electrical load variations due to loss of side-toside cell connections: a major mechanism of structural heart disease arrhythmias. Pacing Clin Electrophysiol. 1997;20:397-413.

134. Girouard SD, Pastore JM, Laurita KR, Gregory KW, Rosenbaum DS. Optical mapping in a new guinea pig model of ventricular tachycardia reveals mechanisms for multiple wavelengths in a single reentrant circuit. Cinculation. 1996;93:603-13.

135. Fast VG, Darrow BJ, Saffitz JE, Kleber AG. Anisotropic activation spread in heart cell monolayers assessed by high-resolution optical mapping. Role of tissue discontinuities. Circ Res. 1996;79:115-27.

136. Fast VG, Kleber AG. Cardiac tissue geometry as a determinant of unidirectional conduction block: assessment of microscopic excitation spread by optical mapping in patterned cell cultures and in a computer model. Candiovasc Res. 1995;29:697-707.

137. Cabo C, Pertsov AM, Baxter WT, Davidenko JM, Gray RA, Jalife J. Wave-front curvature as a cause of slow conduction and block in isolated cardiac muscle. Circ Res. 1994;75:1014-28.

138. Joyner RW, Kumar R, Wilders R, Jongsma HJ, Verheijck EE, Golod DA, Van Ginneken AC, Wagner MB, Goolsby WN. Modulating L-type calcium current affects discontinuous cardiac action potential conduction. Biophys $J$. 1996;71:237-45.

139. Rohr S, Kucera JP. Involvement of the calcium inward current in cardiac impulse propagation: induction of unidirectional conduction block by nifedipine and reversal by Bay K 8644 . Biophys J. 1997;72:754-66.

140. Bakker de JM, van Capelle FJ, Janse MJ, Tasseron S, Vermeulen JT, de Jonge N, Lahpor JR. Slow conduction in the infarcted human heart. 'Zigzag' course of activation. Circulation. 1993;88:915-26

141. Zykov VS. Analytical evaluation of the dependence of the speed of an excitation wave in twodimensional excitable medium of the curvature of its front. Biophysics. 1980;1980:906-911.

142. Mendez C, Mueller WJ, Merideth J, Moe GK. Interaction of transmembrane potentials in canine Purkinje fibers and at Purkinje fiber-muscle junctions. Circ Res. 1969;34:361-372.

143. De la Fuente D, Sasyniuk B, Moe GK. Conduction through a narrow isthmus in isolated canine atrial tissue. A model of the W-P-W syndrome. Circulation. 1971;44:803-9.

144. de Bakker JM, van Capelle FJ, Janse MJ, Tasseron S, Vermeulen JT, de Jonge N, Lahpor JR. 
Slow conduction in the infareted human heart. 'Zigzag' course of activation. Circulation. 1993;88:915-26.

145. Fast VG, Kleber AG. Block of impulse propagation at an abrupt tissue expansion: evaluation of the critical strand diameter in 2- and 3-dimensional computer models. Candiovase Res. 1995;30:449-459.

146. Cabo C, Barr RC. Unidirectional block in a computer model of partially coupled segments of cardiac Purkinje tissue. Ann Biomed Eng. 1993;21:633-44.

147. Pertsov A, Panfilov A, Medvedeva F. Instabilities of autowaves in excitable media associated with critical curvature phenomenon. Biofizika. 1983;28:100-102.

148. Cabo C, Pertsov AM, Davidenko JM, Baxter WT, Gray RA, Jalife J. Vortex shedding as a precursor of turbulent electrical activity in cardiac muscle. Biophys $J$. 1996;70:1105-11.

149. Schalij MJ, Boersma L, Huijberts M, Allessie MA. Anisotropic reentry in a perfused 2-dimensional layer of rabbit ventricular myocardium. Circulation. 2000;102:2650-8.

150. Wellens HJ, Schuilenburg RM, Durrer D. Electrical stimulation of the heart in patients with ventricular tachycardia. Cinculation. 1972;46:216-26.

151. Wellens HJ, Janse MJ, Van Dam RT, Capelle FJv, Meijne NG, Mellink HM, Durrer D. Epicardial mapping and surgical treatment in Wolff-Parkinson-White syndrome Type A. Am Heart $J$ 1974;88:69-78.

152. Almendral JM, Stamato NJ, Rosenthal ME, Marchlinski FE, Miller JM, Josephson ME. Resetting response patterns during sustained ventricular tachycardia: relationship to the excitable gap. Circulation. 1986;74:722-30.

153. Stamato NJ, Rosenthal ME, Almendral JM, Josephson ME. The resetting response of ventricular tachycardia to single and double extrastimuli: implications for an excitable gap. $\mathrm{Am} J$ Candiol. 1987;60:596-601.

154. Josephson M. Response of sustained uniform ventricular tachycardia to stimulation. In: Josephson M, ed. Clinical Cardiac Electrophysiology. Philadelphia/London: Lea and Febiger; 1993:502-543.

155. Fisher J, Mehra R, Furman S. Termination of ventricular tachycardia with bursts of rapid ventricular pacing. Am J Cardiol. 1978;41:94-102.

156. Maclean W, Plumb V, Waldo A. Transient entrainment and interruption of ventricular tachycardia. Pace. 1981;4:358-366.

157. Anderson K, Swerdlow C, Mason J. Entrainment of ventricular tachycardia. Am J Cardiol. 1984;53:335-340.

158. Waldo A, Plumb V, Arciniegas J, Maclean W, Cooper T, Priest M, James T. Transient entrainment and interruption of the atrioventricular bypass pathway type of paroxysmal atrial tachycardia. Circulation. 1983;67:73-83.

159. Waldo A, Henthorn R, Plumb V, MacLean W. Demonstration of the mechanisms of transient entrainment and interruption of ventricular tachycardia by rapid atrial pacing. $\mathrm{J} \mathrm{Am} \mathrm{Coll}$ Cardiol. 1984;3:422.

160. Brugada P, Wellens HJ. Entrainment as an electrophysiologic phenomenon. J Am Coll Cardiol. 1984;3:451-4.

161. Okumura K, Henthorn R, Epstein A, Plumb V, Waldo A. Further observations on transient entrainment: importance of pacing site and properties of the components of the reentrant circuit. Circulation. 1985;6:1293-1307.

162. Okumura K, Olshansky B, Henthorn R, Epstein A, Plumb V, Waldo A. Demonstration of the presence of slow conduction during sustained ventricular tachycardia in man: use of transient entrainment of the tachycardia. Circulation. 1987;75:369-378.

163. Almendral JM, Gottlieb CD, Rosenthal ME, Stamato NJ, Buxton AE, Marchlinski FE, Miller JM, Josephson ME. Entrainment of ventricular tachycardia: explanation for surface electrocardiographic phenomena by analysis of electrograms recorded within the tachycardia circuit. Circulation. 1988;77:569-80.

164. Henthorn R, Okumura K, Olshansky B, Plumb V, Waldo A. A fourth criterion for transient entrainment: the electrogram equivalent of progressive fusion. Circulation. 1988;77:1003-1012. 
165. Waldo A, Henthorn R. Use of transient entrainment during ventricular tachycardia to localize a citical area in the reentry circuit for ablation. Pace. 1989;12:231-244.

166. Josephson ME, Horowitz LN, Farshidi A, Spielman SR, Michelson EL, Greenspan AM. Sustained ventricular tachycardia: evidence for protected localized reentry. Am $\mathrm{J}$ Candiol. 1978;42:416-24.

167. Morady F, Frank R, Kou W, Tonet J, Nelson S, Kounde S, De Buitleir M, Fontaine G. Identification and cathether ablation of a zone of slow conductionin the reentrant circuit of ventricular tachycardia in humans. J Am Coll Cardiol. 1988;11:775-782.

168. Stevenson WG, Nademanee K, Weiss JN, Wiener I, Baron K, Yeatman LA, Sherman CT. Programmed electrical stimulation at potential ventricular reentry circuit sites. Comparison of observations in humans with predictions from computer simulations. Cinculation. 1989;80:793-806.

169. Aizawa Y, Niwano S, Chinushi M, al e. Incidence and mechanism of interruption of reentrant ventricular tachycardia with rapid ventricular pacing. Circulation. 1992;85:589-595.

170. Josephson ME, Horowitz LN, Farshidi A, Spear JF, Kastor JA, Moore EN. Recurrent sustained ventricular tachycardia. 2. Endocardial mapping. Circulation. 1978;57:440-7.

171. Horowitz LN, Josephson ME, Harken AH. Epicardial and endocardial activation during sustained ventricular tachycardia in man. Circulation. 1980;61:1227-38.

172. Miller JM, Marchlinski FE, Buxton AE, Josephson ME. Relationship between the 12-lead electrocardiogram during ventricular tachycardia and endocardial site of origin in patients with coronary artery disease. Circulation. 1988;77:759-66.

173. Harris A, Downar L, Mickleborough N, Shaikh N, Parson I. Activation sequence of ventriculat tachycardia: endocardial and epicardial mapping studies in the human ventricle. $\mathrm{J} \mathrm{Am} \mathrm{Coll}$ Cardiol. 1987;10:1040-1047.

174. Downar E, Harris L, Mickleborough L, Shaikh N, Parson I. Endocardial mappimg of ventricular tachycardia in the intact human ventricle: evidence for reentrant mechanisms. J Am Coll Candiol. 1988;11:783-791.

175. Kaltenbrunner W, Cardinal R, Dubuc M, Shenasa M, Nadeau R, Tremblay G, Vermeulen M, Savard P, Page P. Epicardial and endocardial mapping of ventricular tachycardia in patients with healed myocardial infarction. Is the origin of the tachycardia always subendocardially localized? Circulation. 1991;84:1058-1071.

176. Josephson ME, Horowitz LN, Farshidi A. Continuous local electrical activity. A mechanism of recurrent ventricular tachycardia. Circulation. 1978;57:659-65.

177. de Bakker JM, van Capelle FJ, Janse MJ, van Hemel NM, Hauer RN, Defauw JJ, Vermeulen FE, Bakker de Wekker PF. Macroreentry in the infareted human heart:the mechanism of ventricular tachycardias with a "focal" activation pattern. J Am Coll Candiol. 1991;18:1005-14.

178. de Bakker JM, Coronel R, Tasseron S, Wilde AA, Opthof T, Janse MJ, van Capelle FJ, Becker AE, Jambroes G. Ventricular tachycardia in the infareted, Langendorff- perfused human heart: role of the arrangement of surviving cardiac fibers. J Am Coll Candiol. 1990;15:1594-607.

179. Littman L, Svenson R, Gallagher J, Selle J, Zimmern S, Fedor J, Colavita P. Fuctional role of the epicardium in postinfaretion ventricular tachycardia. Observations derived from computerized epicardial activation mapping, entrainment and epicardial laser photoablation. Circulation. 1991;83:1577-1591.

180. Downar E, Kimber S, Harris L, et al. Endocardial mapping of ventricular tachycardia in the intact human heart. II. Evidence for multiuse reentry in a function sheet of surviviving myocardium. JAm Coll Candiol. 1992;20:869-878.

181. Pogwizd S, Hoyt R, Saffitz J, et al. Reentrant and focal mechanisms underlying ventricular tachycardia in the human heart. Circulation. 1992;86:1872-1887.

182. Miller J, Harken S, Hargrove W, Josephson M. Patterns of endocardial activation during sustained ventricular tachycardia. JAm Coll Candiol. 1985;6:1280-1287.

183. Callans DJ, Zardini M, Gottlieb CD, Josephson ME. The variable contribution of functional and anatomic barriers in human ventricular tachycardia: an analysis with resetting from two sites. $J$ Am Coll Candiol. 1996;27:1106-11.

184. Karagueuzian HS, Fenoglio JJ, Weiss MB, Wit AL. Protracted ventricular tachycardia induced 
by premature stimulation of the canine heart after coronary artery occlusion and reperfusion. Circ.Res. 1979;44:833-846.

185. El Sherif N, Scherlag BJ, Lazzara R, Hope RR. Re-entrant ventricular arrhythmias in the late myocardial infarction period. 1. Conduction characteristics in the infarction zone. Circulation. 1977; 55:686-702.

186. El Sherif N, Smith RA, Evans K. Canine ventricular arrthythmias in the late myocardial infaretion period. 8. Epicardial mapping of reentrant circuits. Cine Res. 1981;49:255-65.

187. Saltman A, Coromilas J, Waldecker B, Dillon S, Wit A. Functional and anatomical reentrant circuits cause ventricular tachycardia in healing canine myocardial infarcts. Circulation. 1993.

188. el Sherif N, Gough WB, Restivo M. Reentrant ventricular arrhythmias in the late myocardial infarction period: 14. Mechanisms of resetting, entrainment, acceleration, or termination of reentrant tachycardia by programmed electrical stimulation. Pacing Clin Electrophysiol. 1987:10:341-71.

189. Waldecker B, Coromilas J, Saltman AE, Dillon SM, Wit AL. Overdrive stimulation of functional reentrant circuits causing ventricular tachycardia in the infarcted canine heart. Resetting and entrainment. Cinculation. 1993;87:1286-305.

190. Dillon SM, Coromilas J, Waldecker B, Wit AL. Effects of overdrive stimulation on functional reentrant circuits causing ventricular tachycardia in the canine heart: mechanisms for resumption or alteration of tachycardia. J Candiovase Electrophysiol. 1993;4:393-411.

191. Peters NS, Coromilas J, Hanna MS, Josephson ME, Costeas C, Wit AL. Characteristies of the temporal and spatial excitable gap in anisotropic reentrant circuits causing sustained ventricular tachycardia. Circ Res. 1998;82:279-93.

192. Eldar M, Ohad D, Bor A, Varda-Bloom N, Swanson D, Battler A. A closed-chest pig model of sustained ventricular tachycardia. Pacing Clin Electrophysiol. 1994;17:1603-9.

193. Greenspon A, Hsu S, Borge R, Smith M, Eldar M. Insights into the mechanism of sustained ventricular tachycardia after myocardial infarction in a closed chest porcine model using a multielectrode "basket" catheter. J Cardiovasc Electrophysiol. 1999;10:1501-16.

194. Myerburg R, Gelband H, Nilsson K, Sung R, Thurer R, Morales A, Bassett A. Long-term electrophysiological abnormalities resulting from experimental myocardial infarction in cats. Circ Res. 1977;41:73-84.

195. Schalij M, Lammers W, Rensma P, Allessie M. Anisotropic conduction and reentry in perfused epicardium of rabbit left ventricle. Am J Physiol. 1992;263:H1466-H1478.

196. Brugada J, Boersma L, Kirchhof C, Heynen V, Allessie M. Reentrant excitation around a fixed anatomical obstacle in uniform anisotropic ventricular myocardium. Circulation. 1991;84:12961306.

197. Stevenson W, Brugada P, Waldecker B, Zehender M, Wellens HJJ. Clinical, angiographic, and electrophysiologic findings in patients with aborted sudden death as compared with patients with sustained ventricular tachycardia after myocardial infarction. Circulation. 1985;71:11461152.

198. Adhar G, Larson L, Brady G, et al. Sustained ventricular arrhythmias: Differences between survivors of cardiac arrest and patients with sustained ventricular tachycardia. J Am Coll Cardiol. 1988; 12:159.

199. Denniss A, Ross D, Richards D, et al. Differences between patients with ventricular tachycardia and ventricular fibrillation is assessed by signal-averaged electrogram, radionuclide ventriculography and cardiac mapping. J Am Coll Cardiol. 1988;11:276.

200. Wit A, Allessie M, Fenoglio JJ, Bonke F, Lammers W, Smeets J. Significance of the endocardial and epicardial borderzones in the genesis of myocardial infarction arrhythmias. In: Harrison D, ed. Cardiac Arrhythmias.Boston: GK Hall medical Publishers; 1981:39-68.

201. Mehra R, Zeiler RH, Gough WB, El Sherif N. Reentrant ventricular arrhythmias in the late myocardial infarction period. 9. Electrophysiologic-anatomic correlation of reentrant circuits. Circulation. 1983;67:11-24.

202. Wetstein L, Mark R, Kaplinsky E, Mitamura H, Kaplan A, Sauermelch C, Michekson E. Histopathologic factors conducive to experimental ventriculartachycardia. Surgery. 
1985;98:532-538.

203. Gardner P, Ursell P, Pham TD, Fenoglio J, Wit A. Experimental chronic ventricular tachycardia: anatomic and electrophysiologic substrates. In: Josephson M, Wellens H, eds. Tachycandias: Mechanisms, Diagnosis, Treatment.Philadelphia: Lea and Febiger, 1983:29-60.

204. Gardner PI, Ursell PC, Fenoglio JJ, Jr., Wit AL. Electrophysiologic and anatomic basis for fractionated electrograms recorded from healed myocardial infarcts. Circulation. 1985;72:596-611.

205. Peters NS, Coromilas J, Severs NJ, Wit AL. Disturbed connexin43 gap junction distribution correlates with the location of reentrant circuits in the epicardial border zone of healing canine infarcts that cause ventricular tachycardia. Circulation. 1997;95:988-96.

206. Michelson EL, Spear JF, Moore EN. Electrophysiologic and anatomic correlates of sustained ventricular tachyarrhythmias in a model of chronic myocardial infarction. Am $J$ Candiol. 1980;45:583-590.

207. Myerburg R, Bassett A, Kimura S, Furukawa T, Kozlovskis P. Electrophysiological properties of the heart with healed myocardial infarction. In:Rosen M, Janse M, Wit A, eds. Candiac Electrophysiology: A textbook. New York: Futura Publishing Company; 1990:773-790.

208. Kienzle MG, Doherty JU, Cassidy D, Buxton AE, Marchlinski FE, Waxman HL, Josephson ME. Electrophysiologic sequelae of chronic myocardial infarction: local refractoriness and electrographic characteristics of the left ventricle. Am J Cardiol. 1986;58:63-9.

209. Spear J, Horowitz L, Hodess A, MacVaugh H, Moore E. Cellular elctrophysiology of human myocardial infarction. 1. Abnormalities of cellular activation. Circulation. 1979;59:247-256.

210. Inoue H, Zipes D. Results of sympathetic denervation in the canine heart: Supersensitivity that may be arrhythmogenic. Circulation. 1987;75:877.

211. Stanton M, Tuli M, Radtke N, et al. Regional sympathetic denervation after myocardial infaretion in humans detected noninvasively using 1-123-meataiodobenzylguanidine. $\mathrm{J} \mathrm{Am} \mathrm{Coll}$ Candiol, 1989;14:1519.

212. Chen P, Chen L, Cao J, Sharifi B, Karagueuzian H, Fishbein M. Sympathetic nerve sprouting, electrical remodeling and the mechanisms of sudden cardiac death. Cardiovasc Res. 2001; 50:409-16.

213. Butrous GS, Gough WB, Restivo M, Yang H, el Sherif N. Adrenergic effects on reentrant ventricular rhythms in subacute myocardial infarction. Circulation. 1992;86:247-54.

214. Opthof T, Coronel R, Vermeulen JT, Verberne HJ, van Capelle FJ, Janse MJ. Dispersion of refractoriness in normal and ischaemic canine ventricle: effects of sympathetic stimulation. Candiovase Res. 1993;27:1954-60.

215. Cao J, Fishbein M, Han J, et al. Relationship between regional cardiac hyperinnervation and ventricular arrhythmia. Circulation. 2000;101:1960.

216. Boyden $\mathrm{P}$, Gardner P, Wit A. Action potentials of cardiac muscle in healing infarcts: Response to norepinephrine and caffeine. J Moll Cell Cardiol. 1988;20:525-537.

217. Aggarwal R, Boyden P. Diminished $\mathrm{Ca} 2+$ and $\mathrm{Ba} 2+$ currents in myocytes surviving in the epicardial border zone of the 5-day infarcted canine heart. Circ Res. 1995;77:1180-91.

218. Lue W, Boyden P. Abnormal electrical properties of myocytes from chronically infarcted canine heart. Alterations in Vmax and the transient outward current. Cinculation. 1992;85:1175-88.

219. Jeck C, Pinto J, Boyden P. Transient outward currents in subendocardial Purkinje myocytes surviving in the infarcted heart. Cinculation. 1995;92:465-73.

220. Hanich R, De Langen C, Kadish A, Michelson E, Levine J, Spear J, Moore E. Induced sustained ventricular tachycardia 4 years after experimental canine myocardial infarction: Electrophysiologic and anatomic comparisons with early healed infarcts. Circulation. 1988;77:445-456.

221. Jugdutt B, Amy R. Healing after myocardial infarction in the dog: Changes in the infarct hydroxyproline and topography. J Am Coll Candiol. 1986;7:91-102.

222. Lee J, Kamjoo K, Hough D, Hwang C, Fan W, Fishbein MC, Bonometti C, Ikeda T, Karagueuzian HS, Chen PS. Reentrant wave fronts in Wiggers' stage II ventricular fibrillation. Characteristics and mechanisms of termination and spontaneous regeneration. Circ Res. 1996;78:660-75. 


\section{Chapter 2}

\section{Preferential Depression of Conduction Around a}

Pivot Point in Rabbit Ventricular Myocardium

\section{by Potassium and Flecainide}

Peter W. Danse, MD; Clifford J. Garratt, MD; Frans Mast, PhD; Maurits A. Allessie, MD, PhD 
Chapter 2

$-40-$ 


\section{Introduction}

Mapping studies have shown that cardiac tachyarrhythmias are often based on circus movement of the impulse around anatomical or functional barriers. During atrial flutter and ventricular tachycardia, the impulse is constantly circulating in a stable circuit around a single or double line of conduction block (single loop or figure of eight reentry). ${ }^{1.3}$ During atrial and ventricular fibrillation multiple wavelets randomly reenter around ares of functional conduction block (random reentry) ${ }^{46}$ Reentrant excitation in atrial and ventricular myocardium may also result from spiral wave activity. ${ }^{7.8} \mathrm{~A}$ common feature of these reentrant arrhythmias is that the wavefronts make a sharp turn around a central core of conduction block. At such a pivot point two abrupt changes occur. 1) In case of tissue anisotropy, the direction of propagation relative to the fiber orientation changes, ${ }^{9,10}$ and 2) The curvature of the wavefront suddenly increases. In recent years it has become evident that the curvature of the wavefront is an important determinant for conduction. ${ }^{11,12}$ Since the current generated by the fibers proximal to the pivot point (source) is distributed over a larger membrane area, the cells distal to the pivot point (sink) will receive less current per $\mathrm{mm}^{2}$ membrane area. Such a mismatch between source and sink will result in a lower safety factor for conduction and may lead to slow conduction and conduction block at pivot points. ${ }^{13,14}$

Class I antiarrhythmic drugs decrease the safety factor for conduction by blockade of the rapid sodium current. However, the exact mechanism of their antiarrhythmic action is still not completely understood. Since the safety factor for conduction at pivot points is already lowered, these sites may be more vulnerable for the action of class I drugs. The aim of the present study was to test the hypothesis that class I drugs preferentially depress conduction of sharply turning wavefronts. In an experimental substrate of U-turn conduction in the rabbit ventricle, the effects of lowering of the safety factor for conduction by high extracellular potassium and flecainide was studied by high-density mapping. Compared to longitudinal and transverse conduction, U-turn conduction at a pivot point was preferentially depressed. At a critical dosage, a line of functional conduction block occurred at the pivot point, which lengthened the effective pathway of the U-turn. The induction of conduction delays at pivot points may explain the effects of class I drugs on reentrant arrhythmias.

\section{Methods}

\section{Preparation}

Sixteen Flemish rabbits of either sex, weighing between 2.7 and $3.6 \mathrm{~kg}$ were used for this study. All experiments were carried out according to the Dutch Law on Animal Experimentation and The European Directive for the Protection of Vertebrate Animals used for Experimental and other Scientific Purposes. The study protocol was approved by the Animal Investigation Committee of Maastricht University. After heparinization (1000 I.U.) 


\section{Chapter 2}

and sedation $\left(\right.$ Hypnorm $\left.^{*}\right)$, the animals were killed by cervical dislocation. The thorax was opened by a midsternal incision, and the heart was rapidly removed and placed in cold per. fusion fluid $\left(10^{\circ} \mathrm{C}\right)$. The aorta was cannulated and perfused with a pressure of $60 \mathrm{~mm} \mathrm{Hg}$ The composition of the perfusion fluid was (mM) NaCl 130, $\mathrm{NaHCO}_{3} 20.1, \mathrm{KCl} 4.0$, $\mathrm{CaCl}_{2} 2.2, \mathrm{MgCl}_{2} 0.6, \mathrm{Na}_{2} \mathrm{HPO}_{4}$ 1.2, glucose 12 . The solution was saturated with a mixture of $95 \% \mathrm{O}_{2}$ and $5 \% \mathrm{CO}_{2}$. The $\mathrm{pH}$ was 7.35 and temperature was kept at $37 \pm 0.2^{\circ} \mathrm{C}$.

To create a thin two-dimensional layer of left ventricular epicardium, a cryoprocedure was performed as described previously. ${ }^{15}$ First, the cryoprobe (diameter $11 \mathrm{~mm}$ ) was inserted in the right ventricle and the free wall was completely cryoablated. Then, the heart was immersed in a tissue bath of $30^{\circ} \mathrm{C}$ and after inserting the cryoprobe in the left ventricle, coronary perfusion was interrupted for 7 minutes. This resulted in cryoablation of the septum and endocardial $4 / 5$ th of the free wall of the left ventricle. Only a thin sheet of left ventricular subepicardium (about $1 \mathrm{~mm}$ thick) was kept intact. In this surviving layer of perfused myocardium, both refractory period and conduction velocity were unchanged by the cryoprocedure. $^{15} \mathrm{~A}$ long linear epicardial lesion was made by radiofrequency (RF) ablation, by dragging a custom made electrode (length $12 \mathrm{~mm}$, diameter $0.35 \mathrm{~mm}$ ) from the posterior side of the left ventricular apex towards the mid portion of the anterior wall Repetitive bursts of RF-energy (2-5s, 12W, Medtronic Atakr generator) were applied unti a complete and transmural lesion $(2-3 \mathrm{~mm}$ wide) was created. The anterior tip of the RFlesion was extended by a $3-5 \mathrm{~mm}$ incision into the direction of the LAD. The lesion was oriented parallel to the direction of the subepicardial fibers. In the free wall of the left ventricle, the fibers gradually curve from the LAD to the apex (Fig 1). ${ }^{15}$

\section{Electrical Stimulation and High Density Mapping}

Two bipolar pacing electrodes were sutured on the epicardial surface of the left ventricle, one next to the origin of the LAD and another at the basal side of the RF-lesion (Fig 1). A computer-controlled custom made stimulator, delivering constant current biphasic square pulses of $2 \mathrm{~ms}$ duration, was used for regular pacing (stimulus strength twice diastolic threshold) and induction of premature beats ( $4 \mathrm{x}$ threshold). Stimulation at the LAD induced a planar wavefront propagating perpendicular to the fiber orientation. Pacing next to the lesion elicited a wavefront propagating parallel to the fiber orientation and making a sharp counterclockwise U-turn around the tip of the lesion. The orientation of the wavefront relative to the epicardial fiber orientation changed twice during the U-turn. First it changed from longitudinal to transverse and then from transverse to longitudinal again, when the wavefront made a full $180^{\circ}$ turn (Fig 1). Originally, we intended to study both clockwise and counterclockwise turning wavefronts. However, in most experiments it appeared that during pacing of the apical side of the lesion, probably due to the complex fiber architecture of the apex, the elicited activation wave was oriented oblique or even parallel to the lesion and consequently did not make a full $180^{\circ}$ turn. Therefore we limited our measurements to counterclockwise turning wavefronts. 

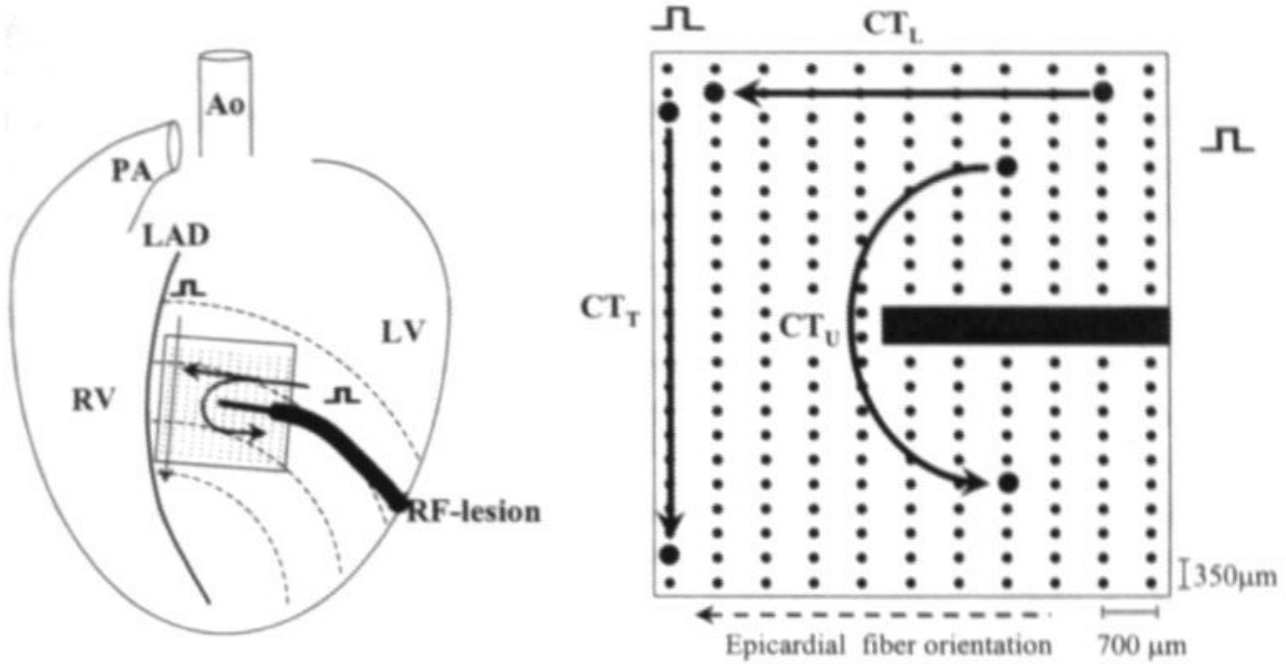

Figure 1. Left: The anatomical substrate for U-turn conduction. In a thin layer of Langendorff perfused rabbit sub-epicardium a linear RF lesion was made parallel to the epicandial fiber orientation (thick line). The RF-lesion was extended by a sharp incision (thin line). A high density mapping array was positioned with its center on the tip of the incision. The arrows indicate the direction of propagation during pacing at two different sites. Stimulation near the origin of the LAD induced a planar wavefront propagating perpendicular to the fiber orientation. Pacing at the basal side of the lesion elicited a wavefront which propagated parallel to the fiber orientation and then turning counterclockwise around the tip of the lesion. $L V=$ Left ventricle; $R V=$ Right ventricle Ao=Aorta; $L A D=L e f t$ anterior descending artery; $P A=P u l m o n a r y$ artery. Right: Measurement of conduction times with the high density mapping array. The black line indicates the location of the epicardial incision parallel to the epicardial fiber orientation. The dots represent the 240 electrodes of the mapping array. Conduction times were measured between pairs of electrodes selected from the mapping array. Longitudinal and $U$-turn conduction times $\left(C T_{L}\right)$ and $\left.C T_{U}\right)$ were measured during pacing at the basal side of the lesion. Transverse conduction time $\left(C T_{T}\right)$ was measured during pacing at the LAD.

High density mapping was performed using an array of 240 silver electrodes (diameter $150 \mu \mathrm{m}$ ). The interelectrode distance was $350 \mu \mathrm{m}$ in one direction (transverse to the fiber orientation) and $700 \mu \mathrm{m}$ in the other direction (longitudinal to the fiber orientation). The mapping electrode covered an area of $7.5 \times 7.5 \mathrm{~mm}$, and was positioned over the tip of the lesion. Unipolar electrograms $(n=240)$ were recorded simultaneously using the silver aortic cannula as indifferent electrode. After amplification (gain 300$)$ and filtering $(1-500 \mathrm{~Hz})$ the signals were multiplexed (sampling rate $1 \mathrm{kHz}$ ) and analog to digital converted ( 8 bits). The mapping system used for data acquisition, storage and analysis has been described previously. ${ }^{16}$ After each experiment the electrograms were played back from tape for analysis. An algorithm was used to detect the steepest negative deflection in each electrogram as the moment of local excitation. Color coded activation maps were plotted by the computer and isochrones were drawn manually at $5 \mathrm{~ms}$ intervals. If necessary, the maps were 


\section{Chapter 2}

edited by inspection of the individual electrograms and the pattern of activation around the recording site. Local conduction velocities were calculated normal to the isochrones. A conduction velocity of less than $5 \mathrm{~cm} / \mathrm{s}$ was taken as conduction block. To distinguish it from pseudoblock, a change in direction of propagation distal to the line of block was used as additional criterion. ${ }^{2}$ Conduction times and velocities during longitudinal $\left(\mathrm{CT}_{\mathrm{L}}, \theta_{\mathrm{V}}\right.$, transverse $\left(\mathrm{CT}_{\mathrm{T}}, \theta_{\mathrm{T}}\right)$ and $\mathrm{U}$-turn conduction $\left(\mathrm{CT}_{\mathrm{U}}, \theta_{\mathrm{U}}\right)$ were measured between pairs of electrodes from the mapping array as indicated in Fig 1. The distance between the electrodes for measurement of transverse conduction was $6.3 \mathrm{~mm}$ and for longitudinal conduction $5.8 \pm 0.8 \mathrm{~mm}$. The distance between the electrodes used for calculation of the U-turn conduction velocity $\left(\theta_{\mathrm{U}}\right)$, was determined by following the path of the activation wave around the pivot point normal to the isochrones. The conduction velocity at the pivot point itself was calculated from the activation times recorded at either side of the tip of the lesion.

\section{Experimental Protocol}

First the linear lesion was evaluated by mapping the activation across the lesion during slow pacing at the LAD. In case of incomplete block RF-energy was reapplied at the site of conduction until complete block was obtained. Then, longitudinal conduction along either side of the lesion and transverse conduction through the corridor between the lesion and the right ventricle was assessed during slow pacing. Preparations in which longitudinal conduction was $<50 \mathrm{~cm} / \mathrm{s}$ or transverse conduction was $<15 \mathrm{~cm} / \mathrm{s}$ were excluded from the study.

The effects of increased extracellular potassium and flecainide on longitudinal, transverse, and $\mathrm{U}$-turn conduction were compared by pacing from two different sites (next to the LAD and at the basal side of the lesion). The heart was paced at increasing rates until 1:1 capture failed $\left(\mathrm{F}_{\mathrm{Max}}\right)$ and premature beats were induced during regular pacing with a cycle length of $350 \mathrm{~ms}$.

Extracellular potassium was raised from 4 to 8,10 and $12 \mathrm{mmol} / \mathrm{l}$ in 11 hearts. After a change in potassium concentration the heart was paced during 10 minutes at a cycle length of $350 \mathrm{~ms}$ before measurements were made. In 9 hearts flecainide was administered in successive concentrations of 1 and $2 \mathrm{mg} /$. An equilibration period of 20 minutes was taken into consideration. At $1 \mathrm{mg} / \mathrm{l}$ of flecainide only the effects during slow pacing were measured, whereas at $2 \mathrm{mg} /$ also the effects during rapid pacing and premature beats were evaluated.

\section{Statistical Analysis}

The data are presented as mean \pm standard deviation. Conduction during control and different concentrations of potassium and flecainide was compared by a one-way ANOVA or the paired Student's t-test. Differences were considered statistically significant at p-values $<0.05$. 


\section{Results}

\section{High Density Mapping of Pivot Points}

Fig 2 shows an example of the different patterns of propagation at the tip of the lesion (longitudinal, transverse, counterclockwise, clockwise). Below each isochrone map the unipolar electrograms are shown recorded from the pivot point (box). A longitudinal wavefront elicited by dual site pacing at either side of the lesion propagated uniformly with a velocity of $64 \mathrm{~cm} / \mathrm{s}$. Since the two wavefronts arrived simultaneously at the tip of the lesion, no pivoting occurred. All electrograms around the lesion were of high amplitude and showed no signs of fragmentation. A transverse wavefront, elicited by pacing at the LAD, conducted with a velocity of $32 \mathrm{~cm} / \mathrm{s}$ and made a $90^{\circ}$ turn around the lesion. This $90^{\circ}$ turn was associated with some fragmentation of the unipolar electrograms at the site of divergence. When the impulse made a full $180^{\circ}$ turn (clock- or counterclockwise) the degree of fragmentation was more marked. As illustrated by the local clustering of isochrones, the local conduction velocity at the pivot point itself was relatively slow $(16 \mathrm{~cm} / \mathrm{s}$ between the electrodes at the right hand corners of the box). Note that during clock- and counterclockwise

Longitudinal
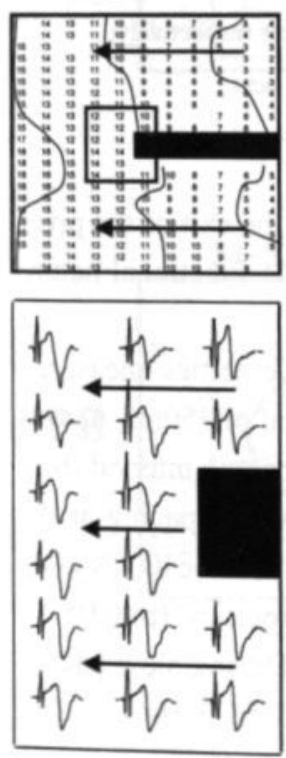

Transverse
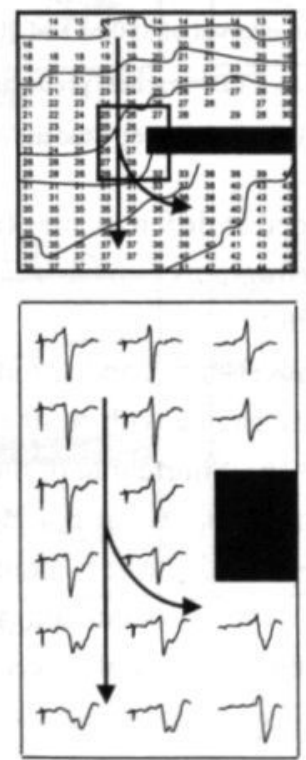

Counterclockwise
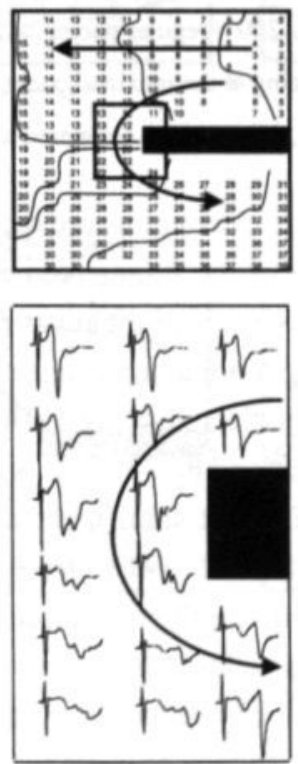

Clockwise
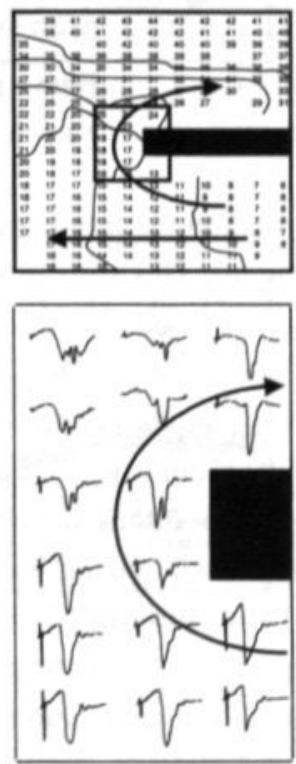

Figure 2. High density maps of different patterns of activation (longitudinal, transverse, counterclockwise, clockwise) during regular pacing with a cycle length of $350 \mathrm{~ms}$. The thick line represents the end of the linear lesion. Activation times are given in milliseconds with the moment of stimulation taken as $t=0$. Isochrones are drawn at $5 m$ s intervals. Arrows indicate the direction of propagation. The unipolar electrograms recorded around the pivot point (box) are given below the maps. Multicomponent electrograms of low amplitude were exclusively recorded during $U$-turn conduction (counterclockwise or clockwise) and were located at the exit of the pivot point. 
Table 1. Effects of rate and premature beats.

\begin{tabular}{|c|c|c|c|c|}
\hline Pacing & $\mathrm{N}$ & $\Theta_{L}$ & $\Theta_{\mathrm{T}}$ & $\Theta_{U}$ \\
\hline S1-S1 350 & 16 & $70 \pm 12$ & $29 \pm 9$ & $33 \pm 7$ \\
\hline S1-S1 350 & 10 & $76 \pm 10$ & $26 \pm 6$ & $36 \pm 7$ \\
\hline S1-S1 200 & 10 & $\begin{array}{l}73 \pm 14 \\
(-4 \pm 9 \%)\end{array}$ & $\begin{array}{c}25 \pm 5 \\
(-3 \pm 8 \%)\end{array}$ & $\begin{array}{c}34 \pm 9 \\
(-4 \pm 9 \%)\end{array}$ \\
\hline S1-S1 350 & 8 & $65 \pm 11$ & $32 \pm 8$ & $32 \pm 6$ \\
\hline Fmax & 8 & $\begin{array}{c}56 \pm 12 * \\
(-15 \pm 10 \%)\end{array}$ & $\begin{array}{c}26 \pm 8^{* *} \\
(-17 \pm 7 \%)\end{array}$ & $\begin{array}{c}26 \pm 5 * \\
(-20 \pm 6 \%)\end{array}$ \\
\hline S1-S1 350 & 13 & $71 \pm 11$ & $30 \pm 8$ & $33 \pm 6$ \\
\hline EPB & 13 & $\begin{array}{c}48 \pm 10^{* *} \\
(-32 \pm 15 \%)\end{array}$ & $\begin{array}{c}26 \pm 8^{\circ} \\
(-11 \pm 13 \%)\end{array}$ & $\begin{array}{c}24 \pm 6^{* *} \\
(-26 \pm 17 \%)\end{array}$ \\
\hline
\end{tabular}

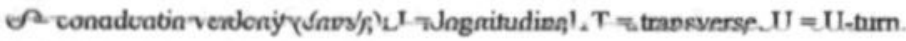

S1-S1 $350 / 200=$ regular pacing with an interval of $350 \mathrm{~ms}$ and $200 \mathrm{~ms}$ respectively;

Fmax $=$ pacing at the maximal pacing rate; $E P B=$ earliest premature beat.

$\bullet=p<0.05, * *=p<0.01$ compared to S1-S1 350 (paired Student's T-test).

rotation the fragmented electrograms are recorded at different sites (at the exit of the pivot point). This shift in site of the fragmented electrograms emphasizes the functional nature of the conduction disturbances at the pivot point.

Table 1 gives the longitudinal, transverse and U-turn conduction velocities measured between the electrodes indicated in Fig 1. During pacing with an interval of $350 \mathrm{~ms}, \theta_{\mathrm{L}}$ was $70 \pm 12 \mathrm{~cm} / \mathrm{s}, \theta_{\mathrm{T}} 29 \pm 9 \mathrm{~cm} / \mathrm{s}$ and $\theta_{\mathrm{U}} 33 \pm 7 \mathrm{~cm} / \mathrm{s}(\mathrm{n}=16)$. Shortening of the pacing interval from 350 to $200 \mathrm{~ms}(\mathrm{n}=10)$ did not significantly change $\theta_{\mathrm{L}}, \theta_{\mathrm{T}}$ or $\theta_{\mathrm{U}}$. However, pacing at the maximal pacing rate $(\mathrm{S} 1-\mathrm{S} 1 \mathrm{141} \pm 19 \mathrm{~ms}, \mathrm{n}=8)$ and earliest premature beats (V1-V2 $155 \pm 14 m s, n=13$ ) significantly decreased all three conduction velocities $(\mathrm{p}<0.05$ or $\mathrm{p}<0.01$ ). No preferential effect on U-turn conduction was observed. During slow pacing the local conduction velocity at the pivot point itself was $15 \pm 5 \mathrm{~cm} / \mathrm{s}(\mathrm{S} 1-\mathrm{S} 1350 \mathrm{~ms}, \mathrm{n}=16)$.

\section{Effects of High Potassium}

Fig. 3 shows the effects of high extracellular potassium on U-turn conduction both during slow pacing, rapid pacing and early premature beats. During pacing with a cycle length of $350 \mathrm{~ms}$, an increase in $\mathrm{K}^{*}$ from 4 to 10 and $12 \mathrm{mmol} / 1$ resulted in progressive prolongation of the U-turn conduction time from 17 to 24 and $51 \mathrm{~ms}$. At $12 \mathrm{mmol} / \mathrm{l}$ a clear crowding of isochrones occurred at the pivot point, corresponding with an average conduction velocity during pivoting of $8 \mathrm{~cm} / \mathrm{s}$. During rapid pacing (interval $200 \mathrm{~ms}$ ) the effects of high potas- 


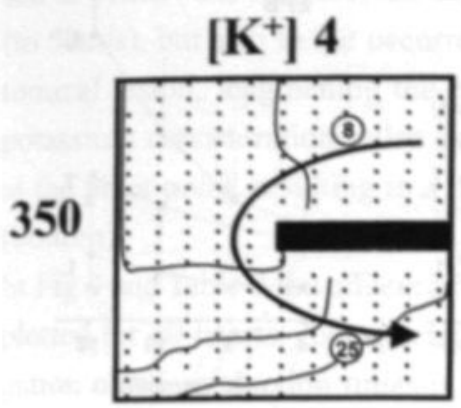

$17 \mathrm{~ms}$

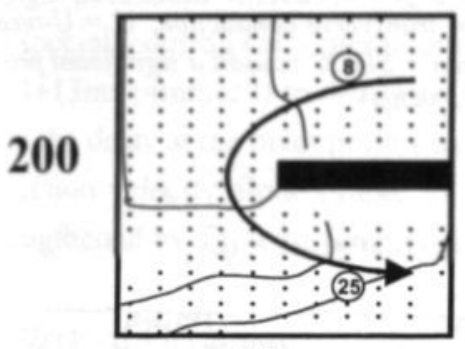

$17 \mathrm{~ms}$

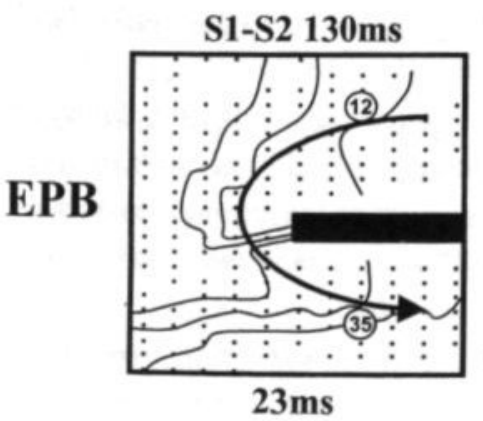

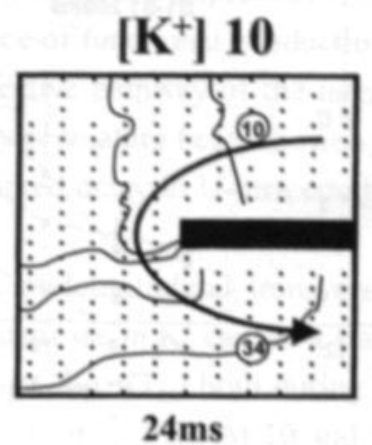
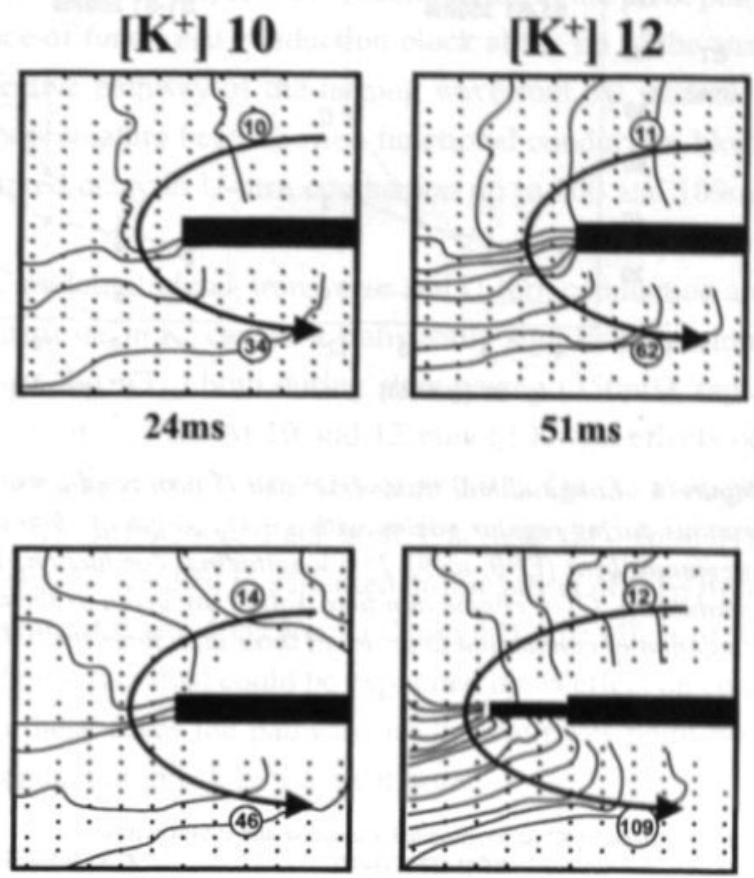

$32 \mathrm{~ms}$

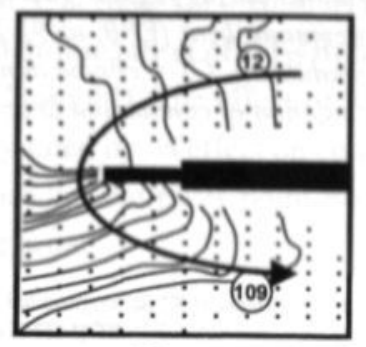

$97 \mathrm{~ms}$

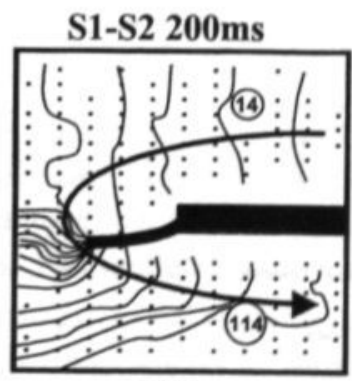

$100 \mathrm{~ms}$

Figure 3. Activation maps of a counterclockwise U-turn at increasing potassium concentrations during regular pacing (cycle length 350 and 200ms) and the earliest premature beat (EPB). The black dots indicate sites at which activation times could be assigned to the recorded electrograms. Isochrones are drawn at 5 ms intervals. The moment of stimulation was taken as $t=0$. The conduction time of the U-turn was measured between the encircled sites proximal and distal to the pivot point. Infusion of potassium resulted in a progressive delay in $U$-turn conduction by preferential slowing of conduction (crowding of isochrones) and functional conduction block at the pivot point (thick lines). 


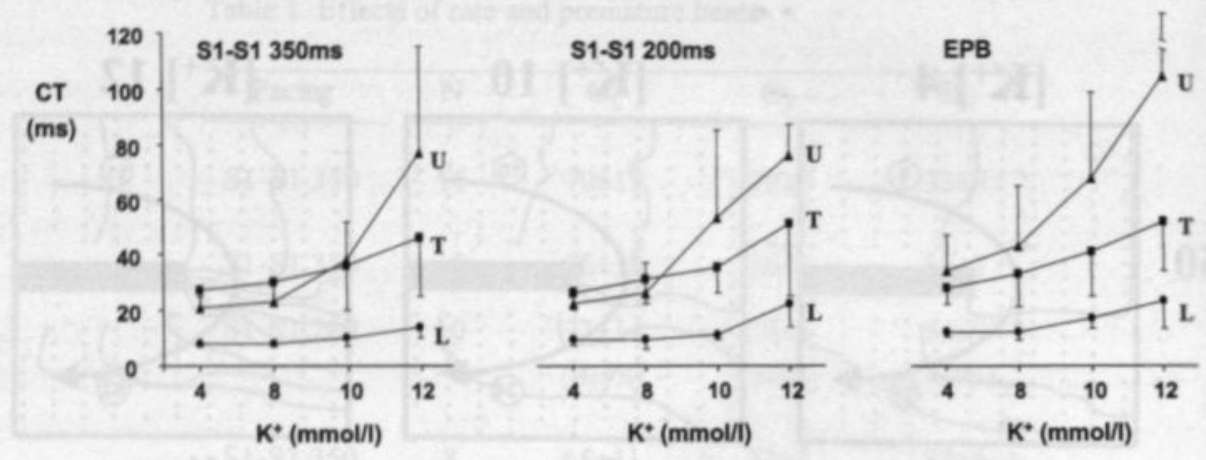

Figure 4. Longitudinal, transverse, and U-turn conduction times at increasing potassium concentrations during regular pacing with a cycle length of $350 \mathrm{~ms}(n=11), 200 \mathrm{~ms}(n=10)$ and the earliest premature beat $(E P B, n=9), L=$ longitudinal conduction; $T=$ transverse conduction; $U=U$-turn conduction; $C T=$ conduction time. Values are given as the mean $\pm S D . K^{*}$ caused a significant pro. longation of conduction times in all three directions $(p<0.05$, ANOVA).

Table 2. Effects of $\mathrm{K}^{*}$ on longitudinal, transverse and $\mathrm{U}$-tum conduction.

\begin{tabular}{|c|c|c|c|c|c|c|c|c|c|c|c|c|}
\hline \multirow[b]{2}{*}{$K^{+}(\operatorname{mmol})$} & \multicolumn{4}{|c|}{ SISIT350ms (-II) } & \multicolumn{4}{|c|}{$8131200 \mathrm{~m}(-10)$} & \multicolumn{4}{|c|}{ EPB (0-9) } \\
\hline & 4 & 8 & 10 & 12 & 4 & 8 & 10 & 12 & 4 & 8 & 10 & 12 \\
\hline \multicolumn{13}{|l|}{ Lengitudinal } \\
\hline $\mathrm{CT}_{\mathrm{L}}(\mathrm{ms})$ & $8+1$ & $8 \div 2$ & $10 \pm 3$ & $14 \pm 4$ & $9 \pm 2$ & $9 \pm 3$ & $11 \pm 2$ & $22 \pm 8$ & $12 \pm 2$ & $12+3$ & $17 \pm 4$ & $23 \pm 10$ \\
\hline$\theta_{\mathrm{L}}(\mathrm{cm} / \mathrm{h})$ & $75 \div 11$ & $73 \div 14$ & $58 \pm 10$ & $43 \pm 8$ & $73 \pm 14$ & $70 \pm 17$ & $S 4 \pm 10$ & $32 \pm 12$ & $51 \pm 10$ & $51 \pm 12$ & $38 \pm 9$ & $32 \pm 10$ \\
\hline$\Delta \mathrm{CT}_{\mathrm{L}}$ & - & $1.0 \pm 0.1$ & $1.3 * 0.2$ & $1.8 \pm 0.4$ & - & $1.0 \pm 0.1$ & $1.4 \pm 0.2$ & $2.8 \pm 0.9$ & - & $1.0 \pm 0.2$ & $1.4 \pm 0.3$ & $1.9 \pm 0.8$ \\
\hline \multicolumn{13}{|l|}{ Trasuvene } \\
\hline$C T_{T}(m s)$ & $27 \pm 7$ & 3048 & $36 \div 16$ & $46 \pm 21$ & $26 \pm 6$ & $31 \neq 9$ & $35 * 9$ & $51 \pm 27$ & $28 \pm 6$ & $33 \pm 12$ & $41 \pm 16$ & $52 \pm 18$ \\
\hline$\theta_{Y}(\mathrm{cmb})$ & $25 \pm 6$ & $22 * 6$ & $20 \pm 6$ & $15 \pm 5$ & $25 * 5$ & $22 \pm 6$ & 1945 & $15 \pm 6$ & $23 \pm 4$ & $21 \pm 7$ & $17 \pm 5$ & $13 \pm 4$ \\
\hline$\Delta \mathrm{CT}_{\mathrm{T}}$ & - & $1.0 \pm 0.2$ & $1.3 \pm 0.2$ & $1.8 \pm 0.5$ & - & $1.1 \pm 0.2$ & $1.4 \pm 0.2$ & $22 \pm 0.9$ & - & $1.1 \pm 0.2$ & $1.5 \pm 0.3$ & $2.0 \pm 0.6$ \\
\hline Blbck incidence & o/11 & or & on1 & 210 & ono & OK & 110 & a/3 & 09 & O6 & 29 & $3 / 9$ \\
\hline \multicolumn{13}{|l|}{ Uturn } \\
\hline $\mathrm{CT}_{\mathrm{u}}(\mathrm{ms})$ & $21 \pm 4$ & $23 * 7$ & $38+14$ & $77 \pm 38$ & $22 \pm 6$ & $26 \div 11$ & $53 * 32$ & $76 \pm 11$ & $34 \pm 13$ & $43 \pm 22$ & $68+31$ & $105 \pm 56$ \\
\hline$\theta_{u}(\mathrm{cmin})$ & $35 * 7$ & $32 \pm 9$ & $19: 6$ & $15 * 2$ & $34 \pm 9$ & $30 \pm 11$ & $19 \pm 5$ & $12 \pm 3$ & $26: 6$ & $19 \pm 7$ & $19: 3$ & $13 \pm 1$ \\
\hline$\Delta \mathrm{CT}_{\mathrm{v}}$ & - & $1.1 \pm 0.2$ & $1.8 \pm 0.4^{* 1}$ & $3.6 \pm 1.2^{*-7 t}$ & - & $1.1 \pm 0.2$ & $2.4 \pm 0.8^{* \prime}$ & $4.2 \pm 1.0$ & - & $15 \pm 1.0$ & $2.1 \pm 0.9^{*} . t$ & $3.3 \pm 15^{\prime \prime}$ \\
\hline$\Delta \theta_{0}$ & - & $1.1 \pm 0.2$ & $1.7 \pm 0.3$ & $2.4 \pm 0.3$ & - & $1.1 \pm 0.2$ & 1910.5 & $24 \pm 0.3$ & - & $1.5 \pm 0.6$ & $1.5 * 0.3$ & $2.3 \pm 0.8$ \\
\hline Bbok ixidene & on1 & as & 1/1 & $7 n 0$ & on10 & 0.6 & $4 / 10$ & 3/3 & 29 & $1 / 6$ & 89 & 99 \\
\hline Bbek kngh (mm) & 0 & 0 & 0.7 & $>1.8 * 1.0$ & 0 & 0 & $>1.9 \pm 1.2$ & $0.9 \div 0.4$ & $0.7 \pm 0$ & 0.7 & $>2.1 \pm 0.9$ & $>2.4 \pm 0.7$ \\
\hline N delay by black & - & 0 & $4 \pm 15$ & $34: 29$ & - & 0 & $21=30$ & $25 * 10$ & - & $5 \pm 16$ & $51 \pm 24$ & $43 \pm 15$ \\
\hline
\end{tabular}

S1-\$1 350/200 - regular pacing with an interval of $350 \mathrm{~ms}$ and $200 \mathrm{~ms}$ respectively; EPB = carliest premature beat CT = conduction time; $\theta=$ conduction velocity; $\Delta C T=$ factor of increase in conduction time; $\Delta \theta=$ factor of decrease in conduction velocity. Block = functional conduction block at the end of the anatomical lesion.

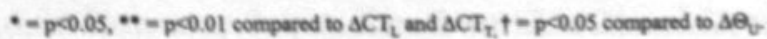


sium were even more pronounced and at $12 \mathrm{mmol} / \mathrm{K} \cdot$ the U-turn conduction time increased to $97 \mathrm{~ms}$. This was due, not only to a further depression of conduction at the pivot point (to $5 \mathrm{~cm} / \mathrm{s}$ ), but also to the occurrence of functional conduction block at the tip of the anatomical lesion, lengthening the effective pathway of the turning wavefront. At increased potassium concentrations, also early premature beats showed functional conduction block at the pivot point, resulting in a marked delay in U-turn conduction up to 100 and $109 \mathrm{~ms}$ (bottom).

In Fig 4 and Table 2 the effects of $\mathrm{K}^{\prime}$ on longitudinal, transverse and $\mathrm{U}$-turn conduction are plotted for all hearts. As expected, increase in $\mathrm{K}^{*}$ caused a statistically significant prolongation of all conduction times $\left(\mathrm{CT}_{\mathrm{L}}, \mathrm{CT}_{\mathrm{T}}, \mathrm{CT}_{\mathrm{U}}\right)$ both during slow pacing $(350 \mathrm{~ms})$, rapid pacing $(200 \mathrm{~ms})$ and early premature beats (EPB). At 10 and $12 \mathrm{mmol} / 1 \mathrm{~K}^{*}$ the effects on $\mathrm{CT}_{U}$ were significantly higher than on $\mathrm{CT}_{\mathrm{L}}$ and $\mathrm{CT}_{\mathrm{T}}(\mathrm{p}<0.05$ or $\mathrm{p}<0.01)$. On the average, high potassium increased the $\mathrm{CT}_{\mathrm{U}} 1.8$ times more than both $\mathrm{CT}_{\mathrm{L}}$ and $\mathrm{CT}_{\mathrm{T}}(\mathrm{p}<0.01)$. Especially during early premature beats, $\mathrm{K}^{*}$ resulted in a marked prolongation of $\mathrm{CT}_{U}$ from $34 \pm 13 \mathrm{~ms}(4 \mathrm{mmol} / \mathrm{l})$ to $68 \pm 31 \mathrm{~ms}(10 \mathrm{mmol} / 1)$ and $105 \pm 56 \mathrm{~ms}(12 \mathrm{mmol} / 1)$. The effect of $\mathrm{K}^{*}$ on the delay at the pivot point was often larger than could be explained by its effect on conduction velocity alone (Table 2 ). In these cases the pathway around the pivot point was lengthened by a line of functional conduction block at the pivot point.

\section{Effects of Flecainide}

Fig 5 shows an example of the effects of flecainide on U-turn conduction. During slow pacing $(350 \mathrm{~ms})$ flecainide caused a dose-dependent increase in U-turn conduction time from 19 to $28 \mathrm{~ms}(1 \mathrm{mg} / \mathrm{l})$ and $36 \mathrm{~ms}(2 \mathrm{mg} / \mathrm{l})$. During pacing at the maximal pacing frequency $\left(\mathrm{F}_{\max }\right)$ the effects of flecainide were more pronounced. At a concentration of $1 \mathrm{mg} / \mathrm{l}$ flecainide prolonged the U-turn conduction time from 26 to $48 \mathrm{~ms}$. The local conduction velocity at the exit of the pivot point decreased to $4 \mathrm{~cm} / \mathrm{s}$. At $2 \mathrm{mg} / \mathrm{l}$ a line of functional conduction block occurred at the pivot point, resulting in a lengthening of the pathway of the turning wavefront and a total U-turn conduction time of $58 \mathrm{~ms}$. Flecainide also induced functional conduction block of turning premature beats (lower panels). Local crowding of isochrones shows that conduction at the exit of the pivot point became as slow as $2 \mathrm{~cm} / \mathrm{s}$. The delay at the pivot point during premature beats of 52 and $77 \mathrm{~ms}$ again was caused by a combination of preferential slowing of conduction and lengthening of the turning pathway by a line of functional conduction block.

In Fig 6 and Table 3 the effects of flecainide are given for all hearts. During control, transverse conduction was faster $(32 \pm 8 \mathrm{~cm} / \mathrm{s})$ than in the potassium group $(25 \pm 6 \mathrm{~cm} / \mathrm{s} ; \mathrm{p}<0.05)$. Longitudinal and U-turn conduction were not different. Since each heart served as its own control and the potassium and flecainide groups were not directly compared, the difference in baseline transverse conduction velocity do not affect the results. As expected, flecainide caused a dose-dependent increase in all conduction times $(\mathrm{p}<0.05)$. During slow pacing flecainide $(2 \mathrm{mg} / 1)$ increased $\mathrm{CT}_{\mathrm{U}}$ by a factor of $1.9 \pm 0.4$, whereas $\mathrm{CT}_{\mathrm{L}}$ and $\mathrm{CT}_{\mathrm{T}}$ increased by a factor of $1.5 \pm 0.2$ and $1.6 \pm 0.3(\mathrm{p}<0.01)$. On the average, flecainide increased 


\section{Control}

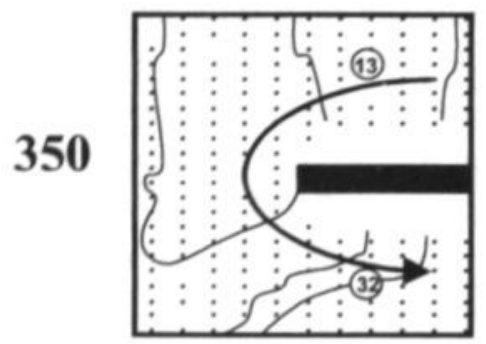

$19 \mathrm{~ms}$
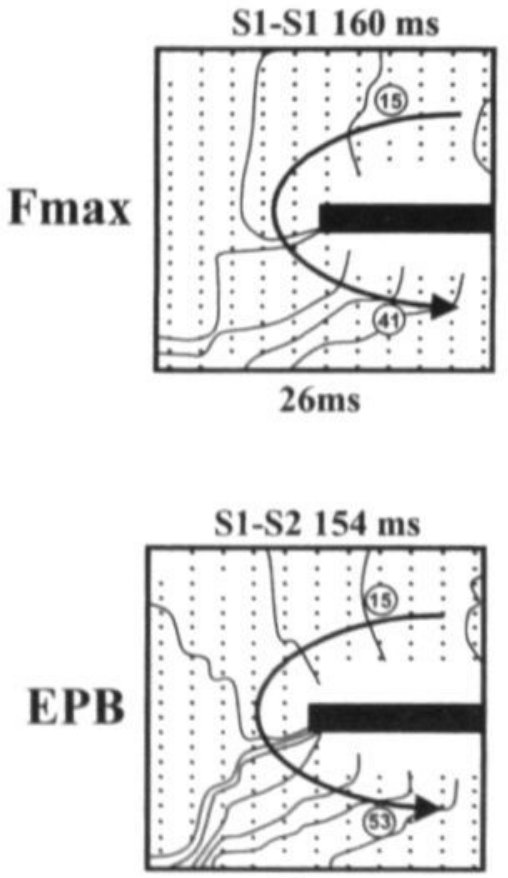

$38 \mathrm{~ms}$

Flecainide $1 \mathrm{mg} / \mathrm{l}$ Flecainide $2 \mathrm{mg} / \mathrm{l}$

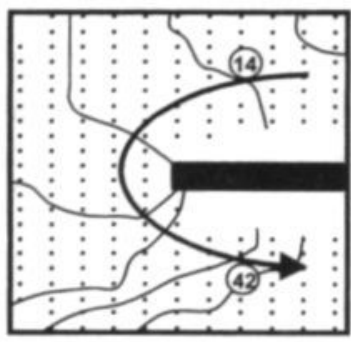

$28 \mathrm{~ms}$

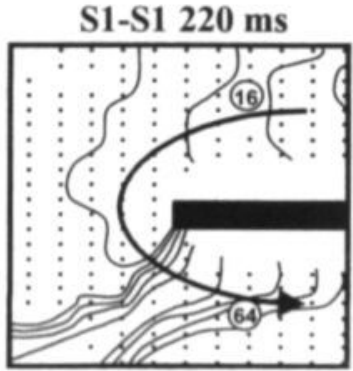

$48 \mathrm{~ms}$

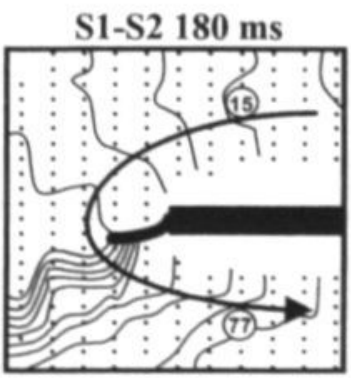

$52 \mathrm{~ms}$

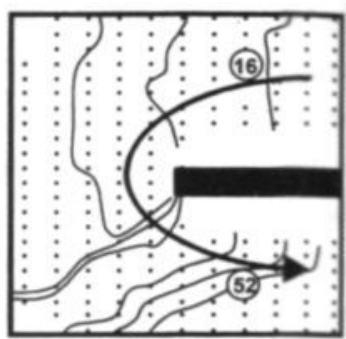

$36 \mathrm{~ms}$

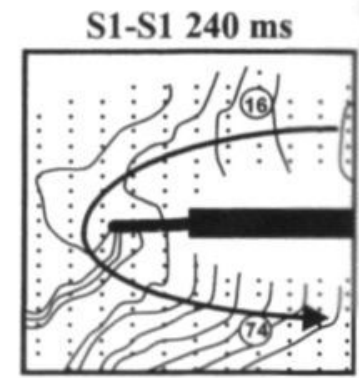

$58 \mathrm{~ms}$

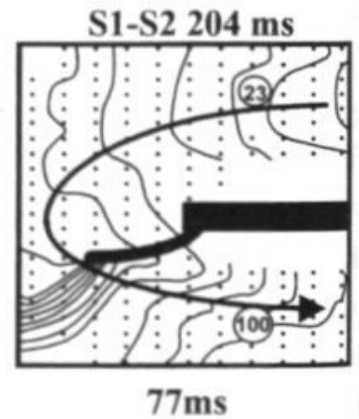

Figure 5. Activation maps of U-furn conduction at increasing concentrations of flecainide during pacing with a cycle length of $350 \mathrm{~ms}$, during pacing at the maximal nate (Fmax) and during the ear. liest premature beat (EPB). The black dots indicate sites at which activation times could be assigned to the reconded electrognams. Isochrones are drawn at 5 ms intervals. The moment of stimulation was taken as $t=0$. The $U$-turn conduction time was measured between the encircled sites proximal and distal to the pivot point. Infusion of flecainide resulted in a dose-dependent slowing of conduction and preferential prolongation of $U$-turn conduction time. During Fmax (flecainide $2 \mathrm{mg} /$ ) and early premature beats (flecainide 1 and $2 \mathrm{mg} /$ ) functional conduction block appeared at the pivot point (thick lines). These lines of functional conduction block shifted the actual turning point away from the anatomical lesion, effectively lengthening the pathway of the U-furn. 


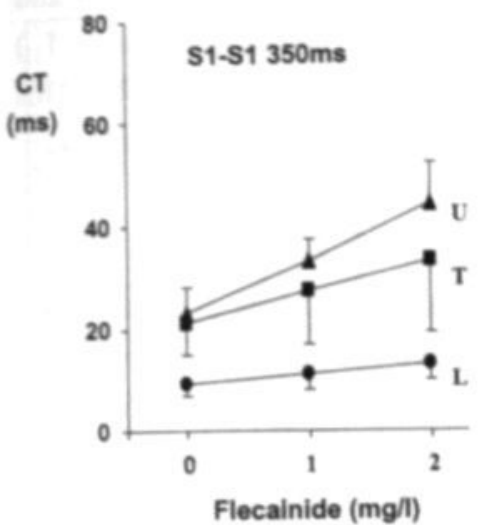

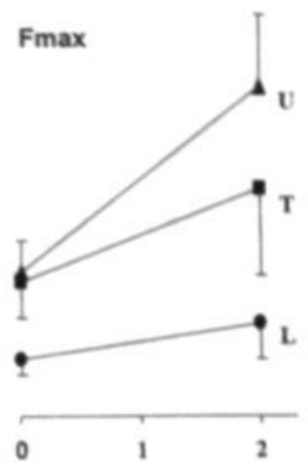

Flecainide (mg/)

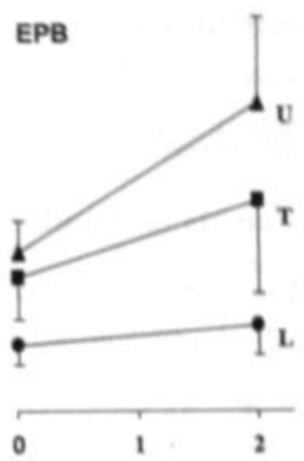

Flecainide $(\mathrm{mg} / \mathrm{l})$

Figure 6. The effects of flecainide on longitudinal, transverse, and U-turn conduction during slow pacing with a cycle length of $350 \mathrm{~ms}(n=9)$, pacing at the maximal pacing rate (Fmax, $n=8)$ and the earliest premature beat (EPB, $n=8) . L=$ longitudinal conduction; $T=$ transverse conduction: $U=$ $U$-hurn conduction; $C T=$ conduction time. Values are given as mean $\pm S D$. Flecainide caused a significant prolongation of conduction times in all three directions $(p<0.05$, ANOVA or paired Student's t-test).

Table 3. Effects of flecainide on longitudinal, transverse and U-turn conduction.

\begin{tabular}{|c|c|c|c|c|c|c|c|}
\hline \multirow[b]{2}{*}{ Flecainide (mg/) } & \multicolumn{3}{|c|}{ S1-S1 350ms (n-9) } & \multicolumn{2}{|c|}{ Fmax $(\mathrm{n}-8)$} & \multicolumn{2}{|c|}{ EPB $(a-8)$} \\
\hline & 0 & 1 & 2 & 0 & 2 & 0 & 2 \\
\hline \multicolumn{8}{|l|}{ Longitudinal } \\
\hline$C T_{L}$ (ms) & $9 \pm 2$ & $11 \pm 3$ & $13 \pm 3$ & $11 \pm 3$ & $18 \pm 7$ & $13 \pm 4$ & $17 \pm 6$ \\
\hline$\Theta_{\mathrm{L}}(\mathrm{cm} / \mathrm{s})$ & $67 \pm 11$ & $57 \pm 10$ & $46 \pm 8$ & $56 \pm 12$ & $36 \pm 10$ & $46 \pm 10$ & $37 \pm 9$ \\
\hline$\Delta \mathrm{CT}_{\mathrm{L}}$ & - & $1.2 \pm 0.2$ & $1.5 \pm 0.2$ & - & $1.6 \pm 0.2$ & - & $1.3 \pm 0.2$ \\
\hline \multicolumn{8}{|l|}{ Transverse } \\
\hline$C T_{\text {(ms) }}$ & $21 \pm 6$ & $27 \pm 10$ & $33 \pm 14$ & $26 \pm 7$ & $44 \pm 17$ & $26 \pm 8$ & $41 \pm 18$ \\
\hline$\Theta_{T}(\mathrm{~cm} / \mathrm{s})$ & $32 \pm 8$ & $27 \pm 10$ & $22 \pm 8$ & $26 \pm 8$ & $17 \pm 8$ & $27 \pm 10$ & $19 \pm 10$ \\
\hline$\Delta \mathrm{CT}_{\mathrm{T}}$ & - & $1.2 \pm 0.2$ & $1.6 \pm 0.3$ & - & $1.7 \pm 0.4$ & - & $1.6 \pm 0.4$ \\
\hline Block incidence & $0 / 9$ & $0 / 9$ & $0 / 9$ & $0 / 9$ & $2 / 8$ & $0 / 8$ & $1 / 8$ \\
\hline \multicolumn{8}{|l|}{ U-turn } \\
\hline $\mathrm{CT}_{\mathrm{u}}(\mathrm{ms})$ & $23 \pm 5$ & $33 \pm 4$ & $44 \pm 8$ & $28 \pm 6$ & $64 \pm 14$ & $31 \pm 6$ & $60 \pm 17$ \\
\hline$\Theta_{u}(\mathrm{~cm} / \mathrm{s})$ & $32 \pm 6$ & $21 \pm 3$ & $17 \pm 2$ & $26 \pm 5$ & $14 \pm 4$ & $23 \pm 5$ & $14 \pm 4$ \\
\hline$\Delta \mathrm{CT}_{\mathrm{u}}$ & - & $1.4 \pm 0.2^{*}$ & $1.9 \pm 0.4^{\circ}$ & - & $2.3 \pm 0.5^{* * t}$ & - & $1.9 \pm 0.6^{\circ}, t$ \\
\hline$\Delta \boldsymbol{\theta}_{u}$ & - & $1.4 \pm 0.2$ & $1.9 \pm 0.2$ & - & $1.9 \pm 0.5$ & - & $1.6 \pm 0.3$ \\
\hline Block meidence & $0 / 9$ & $0 / 9$ & $0 / 9$ & $0 / 9$ & $7 / 8$ & $0 / 8$ & $5 / 8$ \\
\hline Bbck kngth (mm) & 0 & 0 & 0 & 0 & $>1.2 \pm 0.5$ & 0 & $>1.1 \pm 0.6$ \\
\hline$\%$ deby by bbck & - & 0 & 0 & - & $39 \pm 24$ & - & $30 \pm 28$ \\
\hline
\end{tabular}

S1-S1 $350 / 200=$ regular pacing with an interval of $350 \mathrm{~ms}$ and $200 \mathrm{~ms}$ respectively; $\mathrm{EPB}=$ earliest premature beat. $C T=$ conduction time; $\Theta=$ conduction velocity; $\Delta C T=$ factor of increase in conduction time; $\Delta \Theta=$ factor of decrease in conduction velocity. Block $=$ functional conduction block at the end of the anatomical lesion.

$\bullet=p<0.05, \cdots=p<0.01$ compared to $\Delta C T_{L}$ and $\Delta C T_{T_{i}} \dagger=p<0.05$ compared to $\Delta \Theta_{U}$. 
the $\mathrm{CT}_{\mathrm{U}} 1.4$ times more than both $\mathrm{CT}_{\mathrm{L}}$ and $\mathrm{CT}_{\mathrm{T}}(\mathrm{p}<0.01)$. Again, both during $\mathrm{F}_{\mathrm{ms}}$ and early premature beats the effects of flecainide $(2 \mathrm{mg} / \mathrm{l})$ on U-turn conduction time $\left.\mathrm{CT}_{\mathrm{U}}\right)$ was higher than could be explained by the depression of the conduction velocity $\left(\theta_{U}\right)$ This was due to lengthening of the U-turn pathway by a line of functional conduction blck.

\section{Functional Conduction Block at the Pivot Point}

Fig 7 shows in more detail the occurrence of functional conduction block at the antomical pivot point during propagation of premature beats $\left(\mathrm{K}^{*} 10 \mathrm{mmol} / \mathrm{l}\right)$. The high ensity maps of the U-turn show that with increasing prematurity a longer line of functione conduction block occurred at the pivot point. At a coupling interval of $160 \mathrm{~ms}$ the trning wavefront was blocked along electrodes A-C over a distance of $1.4 \mathrm{~mm}$. At an S1-S2interval of $150 \mathrm{~ms}$ the premature wavefront was blocked along electrodes A-E $(2.8 \mathrm{~mm}$. The corresponding U-turn conduction times increased from $28 \mathrm{~ms}$ at a coupling interval f 200 $\mathrm{ms}$ (no block) to 36 and $79 \mathrm{~ms}$ respectively. At the bottom the unipolar electrograms(A-F) recorded along the functional line of block are shown. During a premature beat vith a coupling interval of $200 \mathrm{~ms}$ (no block) the electrograms were activated in the same squence as during regular pacing (S1). Only the electrogram recorded from the tip of theinatomical lesion (A) showed a double potential reflecting the dissociation in activation at either side of the lesion. During the premature beat with a coupling interval of $160 \mathrm{~ms}$ double potentials were now also recorded from sites B, C and D. At the same time the sequence of activation of sites A - C was reversed. Thus, the anatomical pivot point at site $\mathrm{A}$ was shifted to a functional pivot point at electrode D. Shortening of the coupling interval of the premature beat to $150 \mathrm{~ms}$ shifted the functional pivot point even further away from the anatomical pivot point and the sequence of activation was inversed at sites $\mathrm{A}$ to $\mathrm{F}$.

In Table 2 and 3 the incidence of functional conduction block at the pivot point are given. Conduction block at the pivot point occurred far more frequently during U-turn conduction than during transverse conduction when the impulse made only a $90^{\circ}$ turn. During slow pacing (interval $350 \mathrm{~ms}$ ), only at very high $\mathrm{K}^{*}$ concentrations lines of functional conduction block contributed to the U-turn delay (Table 2). Rapid pacing (200ms interval) increased the incidence of functional block at the pivot points. Also during early premature beats, lines of functional conduction block occurred more frequently at increasing $\mathrm{K}^{+}$ concentration. The length of the lines of block varied between 0.7 and $>3.5 \mathrm{~mm}$ (outside mapping area). About half of the increase in the $\mathrm{CT}_{U}$ of premature beats from $34 \pm 13 \mathrm{~ms}$ to $68 \pm 31(10 \mathrm{mmol} / \mathrm{l})$ and $105 \pm 56 \mathrm{~ms}(12 \mathrm{mmol} /)$, was due to the lengthening of the turning pathway ( $51 \pm 24 \%$ and $43 \pm 15 \%$ respectively).

Likewise, also during administration of flecainide $(2 \mathrm{mg} / \mathrm{l})$ lines of functional conduction block occurred both during rapid pacing and early premature beats (Table 3 ). The resulting prolongation of the pathway of the U-turn accounted for $39 \pm 24 \%$ (Fmax) and $30 \pm 28 \%$ (earliest premature beat) of the total increase in U-turn conduction time. 


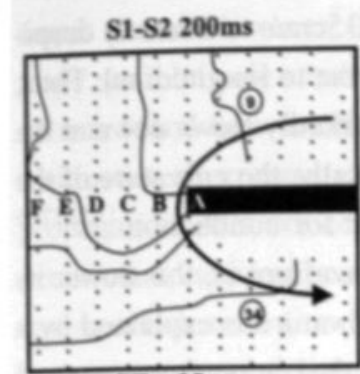

$\mathrm{CT}_{\mathrm{v}}: 25 \mathrm{~ms}$

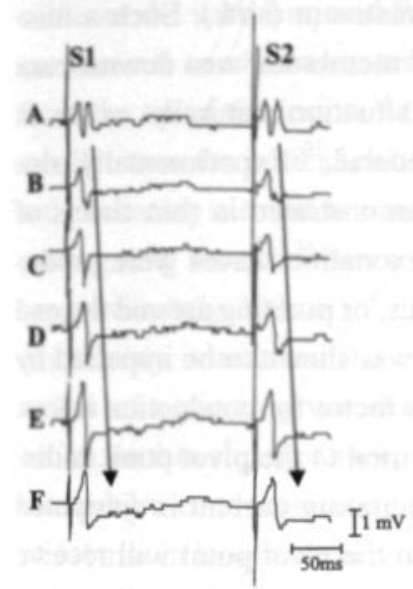

S1-S2 $160 \mathrm{~ms}$

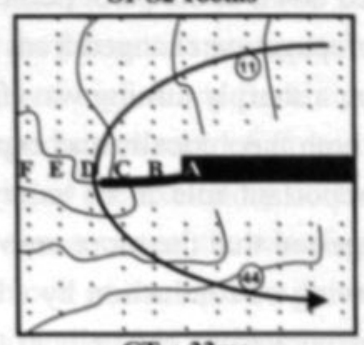

$\mathrm{CT}_{\mathrm{v}}: 33 \mathrm{~ms}$

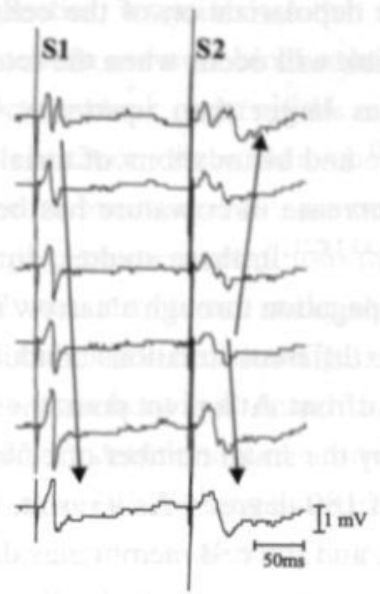

$51-52150 \mathrm{~ms}$

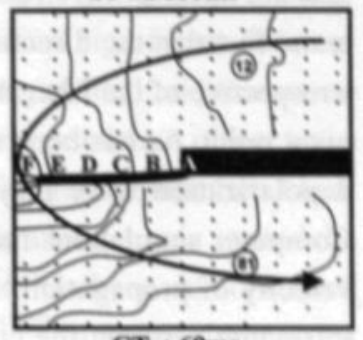

$\mathrm{CT}_{\mathrm{v}}: 69 \mathrm{~ms}$

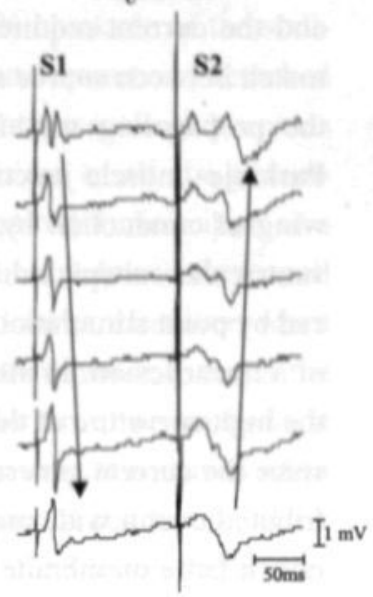

Figure 7. Functional conduction block at a $[\mathrm{K}+]$ of $10 \mathrm{mmol} / \mathrm{l}$ during $U$-turn conduction of premature beats (coupling interval $200 \mathrm{~ms}$ (left), $160 \mathrm{~ms}$ (middle), and $150 \mathrm{~ms}$ (right). The black dots indicate sites at which activation times could be assigned to the recorded electrograms. Isochrones are drawn at 5 ms intervals. The moment of stimulation was taken as $t=0$. $U$-turn conduction time was measured between the encircled sites. Below the maps the electrograms recorded from the pivot point (A-F) are shown. Arrows indicate the direction of propagation. Decreasing the coupling interval of the premature stimulus (S1-S2) from 200 to 160 to $150 \mathrm{~ms}$ progressively increased the U-turn conduction time from 23 to 34 and $69 \mathrm{~ms}$. During the early premature beats with a coupling interval of 160 and $150 \mathrm{~ms}$, a line of functional conduction block occurred at the pivot point (thick lines). The extension of the line of block can be measured by the occurrence of double potentials at electrodes A-F.

\section{Discussion}

\section{Characteristics of Conduction Around a Pivot Point}

During a full $180^{\circ}$ turn around a lesion parallel to the fiber orientation, the wavefront changed its direction relative to the fiber orientation twice, first from parallel to perpendicular, and then from perpendicular to parallel again. The conduction velocity decreased from a longitudinal conduction velocity of $70 \pm 12 \mathrm{~cm} / \mathrm{s}$ to a local conduction velocity at the pivot point of $15 \pm 5 \mathrm{~cm} / \mathrm{s}$. Since the conduction velocity of a transverse planar wavefront was still $29 \pm 9 \mathrm{~cm} / \mathrm{s}$, the observed slowing in conduction at the pivot point could not be explained on the basis of tissue anisotropy alone. In guinea pig ventricle, Girouard et $\mathrm{al}^{13}$ studied propagation around a linear lesion oriented perpendicular to the epicardial fibers. They found 


\section{Chapter 2}

that the turning wavefront slowed down at the pivot point (from $35 \mathrm{~cm} / \mathrm{s}$ to $20 \mathrm{~cm} / \mathrm{s}$ ) $\mathrm{despi}$ te the fact that the direction of propagation changed from transverse to longitudinal. Thus, irrespective of the fiber direction, a sharply turning wavefront markedly slows down at the pivot point. As has been shown both theoretically and experimentally, the curvature of the depolarization wave plays an important role in its safety factor for conduction. ${ }^{11,12,17-18}$ Computer simulations have suggested that the more convex a wavefront is, the slower its velocity of propagation. ${ }^{17,20}$ Slowing of conduction by a high curvature is explaineq by a mismatch between the current generated by the cells at the depolarization front (squrce) and the current required for depolarization of the cells downstream (sink). Such a mis. match between source and sink will occur when the total cell membrane area downstream the propagating wavefront is larger than upstream. This situation naturally exists at Purkinje- muscle junctions, ${ }^{21}$ and bifurcations of atrial trabeculae. ${ }^{10}$ Experimentally, slowing of conduction by an increase in curvature has been demonstrated in thin shets of ventricular subepicardium. ${ }^{11,13,14,22}$ In these studies, curved excitation waves were broduced by point stimulation, propagation through a narrow isthmus, or pivoting around the end of a linear lesion. In all these different situations conduction was shown to be impaired by the high curvature of the wavefront. At a pivot point the safety factor for conduction is low. since the curfent genefated by the small number of cells proximal to the piyot point is distributed over a wide angle of 180 degrees. As a result, the excitatory current is dissipated over a large membrane area, and the cell membranes distal to the pivot point will receive less depolarizing current per surface area. As has been shown by microelectrode recordings ${ }^{23}$ and optical mapping, ${ }^{13}$ this reduction in excitatory current is associated with a slow and notched upstroke of the action potential. The degree of dissipation of excitatory current is determined by the tissue anisotropy at the pivot point. When, like in our experiments, the line of block is oriented parallel to the fiber orientation, a sudden drop in axial resistance occurs at the exit of the pivot point. Consequently, at this point a sudden drain of excitatory current occurs along the longitudinal axis of the fibers. Thus, during a longitudinal U-turn, the safety factor for conduction will be lowest at the exit of the pivot point. This is demonstrated by the crowding of isochrones and the fragmented electrograms recorded at the exit of the U-turn (see Fig 2).

\section{Preferential Depression of Conduction Around a Pivot Point}

The main finding of this study was that blockade of the rapid sodium channels by high potassium or flecainide increased the conduction time of a U-turn 1.4 (flecainide) to 1.8 $\left(\mathrm{K}^{*}\right)$ times more than the conduction times during longitudinal or transverse planar wavefronts. As shown by high density mapping this preferential depression of U-turn conduction was located at the exit of the pivot point (Figs 3 and 5). The fact that the exit of the Uturn was most vulnerable to a general reduction in generation of excitatory current supports the concept that the safety factor for conduction is lowest at that site. Preferential impairment of conduction by class I drugs has also been demonstrated in uniform aniso- 
tropic tissue. However, the differences in safety factor for conduction by uniform anisotropy are relatively small. ${ }^{24-30}$ In the present experiments no statistical significant difference was found between the effects of high $\mathrm{K}$ or flecainide on longitudinal and transverse conduction. In contrast, U-turn conduction was 1.6 times more depressed than planar wave propagation. At a critical lowering of the excitatory current preferential conduction block occurred at the pivot point. As a consequence, the wavefront made a longer turn around the anatomical lesion. Conduction block at the tip of a linear lesion has been demonstrated both in computer simulations and in isolated cardiac tissue. ${ }^{14,19,31,32}$ In a two-dimensional cable model with Luo and Rudy kinetics, it was shown that at $75 \%$ blockade of the sodium channel conductance, turning wavefronts were blocked at the pivot point and detached from the tip of the lesion. ${ }^{14}$ Conduction block occurs if the radius of a wavefront becomes smaller than the critical radius for excitation. If the radius becomes too small, the generated excitatory current is insufficient to excite a minimum area required for initiation of a propagating wave. ${ }^{33,34}$ Since under physiological conditions the critical radius is very small (approximately $300 \mu \mathrm{m}){ }^{34}$ normally wavefronts can make sharp U-turns. However, when excitability is reduced the critical radius for excitation gets larger. When it exceeds the radius of a pivoting wavefront, the wavefront will detach from the tip of an anatomical lesion. In thin slices of sheep epicardium detachment of a turning wavefront occurred when the sodium conductance was reduced to $30 \%$ by tetrodotoxin. ${ }^{14}$ Lines of conduction block of 5-6mm in length occurred, producing vortex shedding at the tip of the lesion. In the present study, the lines of functional conduction block at a pivot point induced by high potassium and flecainide varied between $0.7 \mathrm{~mm}$ and $>3.5 \mathrm{~mm}$. Rather then producing reentrant VT, the major effect of these lines of block was that they lengthened the pathway of the turning wavefront. The resulting lengthening of the U-turn accounted for about $40 \%$ of the delay at the pivot points.

\section{Role of Pivot Points in Reentrant Arrhythmias}

Mapping studies in dogs have shown that ventricular tachycardia after myocardial infarction is based on reentrant excitation in the epicardial borderzone around a line of functional conduction block. ${ }^{2,3}$ Since the lines of block are mostly oriented parallel to the fibers, the pivot points of these circuits are similar to the ones studied in the present study. Coromilas et $\mathrm{al}^{35}$ found that at a plasma concentration of $1-4 \mathrm{mg} / \mathrm{L}$ flecainide prolonged VT cycle length in the epicardial borderzone from 171 to $210 \mathrm{~ms}$. This increase in VT cycle length by $40 \mathrm{~ms}$ was primarily due to depression of transverse conduction. Flecainide also increased the size of the reentrant circuits by lengthening of the central line of functional conduction block. In our study, during rapid pacing flecainide $(2 \mathrm{mg} / \mathrm{L})$ exhibited the same effects. However, our data suggest that the impaired conduction at the pivot point is not primarily caused by tissue anisotropy but is mainly due to the process of turning itself. Difficulty in making a sharp U-turn will create a delay in excitation of the myocardium beyond the pivot point. In case of a functional reentrant circuit, this will widen the excita- 


\section{Chapter 2}

ble gap of the tachycardia. Indeed, in the canine epicardial borderzone, the increase in VT cycle length by flecainide must have caused a widening of the excitable gap, since only minor effects on the ventricular refractory period were found. ${ }^{35}$ In patients with VT in the chronic phase of a myocardial infarction, class IC drugs prolong the VT cycle length and widen the excitable gap. ${ }^{36,37}$ It is not known whether these effects on clinical VT should be explained by a preferential effect on pivoting wavefronts. During ventricular fibrillation, multiple wavelets have been shown to reenter randomly through the ventricles around ares of functional conduction block. ${ }^{6,38}$ Slowing of the rate of ventricular fibrillation by class I drugs ${ }^{39,40}$ might primarily be due to conduction delay at the pivot points of the multiple reentering wavelets. The recent finding of Kwan et al ${ }^{41}$ that slowing of the rate of ventricular fibrillation by procainamide is associated with an increase in the size of the reentrant circuits from 13.3 to $38.7 \mathrm{~mm}^{2}$ supports this hypothesis. Lowering of the excitability also increased the rotation period and the size of spiral waves. ${ }^{42}$ As during a U-turn, the tip of the spiral wave made a wider turn around its central core.

Preferential delay at pivot points may also play an important role in the antiarrhythmic effects of class I drugs on atrial arrhythmias. In the canine sterile pericarditis model of atrial flutter, the impulse circulates in a functional reentrant circuit in the free wall of the right atrium. 'As shown by Ortiz et al ${ }^{43}$ the class IC drug moricizine terminates atrial flutter by conduction block at one of the pivot points of this intra-atrial circuit. Also atrial fibrillation (AF) can be terminated by class IC drugs. ${ }^{44}$ This anti-fibrillatory effect is associated with a dose dependent slowing of the rate of fibrillation and progressive organization of activation. ${ }^{45,46} \mathrm{~A}$ widening of the excitable gap during chronic $\mathrm{AF}$ by class I drugs has recently been demonstrated in the goat. ${ }^{47}$ These observations can be explained by the concept that class I drugs preferentially delay sharply turning wavefronts. If the multiple reentering wavelets are delayed at their pivot points, widening of the excitable gap and prolongation of the AF cycle length will occur. Preferential depression of U-turning wavelets may also explain the progressive organization of electrical activation. If $\mathrm{U}$-turns are more depressed than propagation of planar waves, planar waves will become more prominent. However, although the concept of preferential blockade of U-turns offers an attractive explanation for the temporal and spatial effects of class IC drugs on atrial and ventricular fibrillation, this is still a hypothesis which remains to be proven.

\section{Limitations of the Study}

Our attempts to produce U-turning wavefronts, as they may occur in clinical reentrant arrhythmias, is still clearly an oversimplification. First, we have studied U-turn conduction in a 2-dimensional subepicardial layer of the rabbit left ventricle. In such a layer of uniform anisotropic myocardium, the fibers are nicely oriented parallel to each other. This is in contrast to the arrhythmogenic substrate of chronic myocardial infarction. This substrate has a complex 3-dimensional architecture, in which strands of surviving tissue are separated by scar tissue. Also in the atria, the arrangement of the cardiac fibers is much more 
complex than in our preparation. In a more complex tissue structure, the behaviour of $U$ turning wavefronts might be quite different. Second, we studied U-turn conduction around a linear anatomical lesion. In contrast, during reentrant arrhythmias lines of conduction block are often functional in nature. Lowering the safety factor for conduction might have different effects on pivoting around a line of functional block. Third, the linear lesion was only made parallel to the fiber orientation and the directional effect of the line of block relative to the fiber orientation was not addressed. However, since Girouard et al $^{13}$ showed that the safety factor for conduction was also depressed during transversely oriented Uturns, we think that the role of anisotropy is not of major importance. Finally, lowering of the safety factor for conduction was accomplished by high potassium and flecainide. It is known that high potassium not only modifies the fast inward current but also affects $\mathrm{K}^{\text {* }}$ conductances and ionic pumps. Therefore, it can not be excluded that the effects of potassium on other transmembrane currents contributed to the preferential effect on U-turn conduction. The concentration of flecainide used in this study ( 1 and $2 \mathrm{mg} / \mathrm{l}$ ) is above the clinically recommended range of plasma levels of $0.2-0.4 \mathrm{mg} / \mathrm{l}$. Therefore it is not certain whether flecainide preferentially delays pivoting wavefronts during clinical reentrant arrhythmias. 


\section{References}

1. Page P, Plumb VJ, Okumura K, et al. A new model of atrial flutter. J Am Coll Cardiol 19863:872. 879.

2. Dillon SM, Allessie MA, Ursell PC, et al. Influences of anisotropic tissue structure on rentrant circuits in the epicardial border zone of subacute canine infarcts. Circ Res 1988;63:182-06.

3. El Sherif N, Smith RA, Evans K. Canine ventricular arrhythmias in the late myocardialinfarction period. 8. Epicardial mapping of reentrant circuits. Circ Res 1981;49:255-65.

4. Allessie MA, Lammers WJEP, Bonke FIM, et al. Experimental evaluation of Moe's rultiple wavelet hypothesis of atrial fibrillation. In Zipes DP, Jalife J, eds. Cardiac Arrhythmia. New York: Grune \& Stratton. 1985:265-276.

5. Konings KTS, Kirchhof CJHJ, Smeets JRLM,et al. High-density mapping of electricall induced atrial fibrillation in humans. Circulation 1994;89:1665-1680.

6. Janse MJ, van Capelle FJ, Morsink H, et al. Flow of "injury" current and patterns of excitationduring early ventricular arrhythmias in acute regional myocardial ischemia in isolated porcine ancianine hearts. Evidence for two different arrhythmogenic mechanisms. Circ Res 1980;47: 151-65.

7. Pertsov AM, Davidenko JM, Salomonsz R, et al. Spiral waves of excitation underlie rentrant activity in isolated cardiac muscle. Circ Res 1993;72:631-50.

8. Ikeda T, Uchida T, Hough D, et al. Mechanism of spontaneous termination of functionaleentry in isolated canine right atrium. Evidence for the presence of an excitable but nonexcitd core. Circulation 1996;94:1962-73.

9. Sano T, Takayama N, Shimamoto T. Directional difference of conduction velocity in the ardiac ventricular syncytium studied by microelectrodes. Circ Res 1959;7:262-268.

10. Snach MS. Miller WTd. Dolber PC. et al. The functional role of structural complexitic in the propagation of depolarization in the atrium of the dog. Cardiac conduction disturbances due to discontinuities of effective axial resistivity. Circ Res 1982;50:175-91.

11. Cabo C, Pertsov AM, Baxter WT, et al. Wave-front curvature as a cause of slow conduction and block in isolated cardiac muscle. Circ Res 1994;75:1014-28.

12. Fast VG, Kleber AG. Role of wavefront curvature in propagation of cardiac impulse. Cardiovasc Res 1997;33:258-71.

13. Girouard SD, Pastore JM, Laurita KR, et al. Optical mapping in a new guinea pig model of ventricular tachycardia reveals mechanisms for multiple wavelengths in a single reentrant circuit. Cinculation 1996;93:603-13.

14. Cabo C, Pertsov AM, Davidenko JM, et al. Vortex shedding as a precursor of turbulent electrical activity in cardiac muscle. Biophys $J$ 1996;70:1105-11.

15. Schalij MJ, Lammers WJEP, Rensma PL, et al. Anisotropic conduction and reentry in perfused epicardium of rabbit left ventricle. Am J Physiol 1992;263:H1466-H1478.

16. Allessie MA, Hoeks APG, Schmitz GML, et al. On-line mapping system for the visualization of the electrical activation of the heart. Int J Candiac Imag 1986;2:59-63.

17. Zykov VS. Analytical evaluation of the dependence of the speed of an excitation wave in twodimensional excitable medium of the curvature of its front. Biophysics 1980;1980:906-911.

18. Foerster P, Muller SC, Hess B. Curvature and propagation velocity of chemical waves. Science 1988;241:685-687.

19. Agladze K. Keener JP, Muller SC, et al. Rotating spiral waves created by geometry. Science 1994:264:

20. Zykov VS, Simulation of wave processes in excitable media. 1987, Manchester: Manchester University Press.

21. Mendez C, Mueller WJ, Merideth J, et al. Interaction of transmembrane potentials in canine Purkinje fibers and at Purkinje fiber-muscle junctions. Circ Res 1969:34:361-372.

22. Knisley SB, Hill BC. Effects of bipolar point and line stimulation in anisotropic rabbit epicardium: assessment of the critical radius of curvature for longitudinal block. IEEE Trans Biomed Eng 1995:42:957-66.

23. Wit AL, Allessie MA. Functional models of reentry: A comparison of anisotropic and leading circle reentry. In: Waldo AL, Toulboul P, eds. Atrial flutter: Advances in mechanisms and management. New York: Futura Publishing Company; 1996:103-119.

24. Kadish AH, Spear JF, Levine JH, et al. The effects of procainamide on conduction in anisotropic 
canine ventricular myocardium. Circulation 1986;74:616-25.

25. Spach MS, Dolber PC, Heidlage JF. Influence of the passive anisotropic properties on directional differences in propagation following modification of the sodi um conductance in human atrial mus cle. A model of reentry based on anisotropic discontinuous propagation. Circ Res 1988;62:811-32.

26. Boersma LVA, Brugada J, Schalij MJ, et al. The effects of $\mathrm{K}+$ on anisotropic conduction in sheets of perfused rabbit ventricular epicardium. $J$ Candiovasc Electrophysiol 1991;2:492-502.

27. Brugada J, Mont L, Boersma L, et al. Differential effects of heptanol, potassium, and tetrodotoxin on reentrant ventricular tachycardia around a fixed obstacle in anisotropic myocardium. Cinculation 1991;84:1307-18.

28. Delgado C, Steinhaus B, Delmar M, et al. Directional differences in excitability and margin of safety for propagation in sheep ventricular epicardial muscle. Cinc Res 1990;67:97-110.

29. lida M, Kodama I, Toyama J. Negative dromotropic effects of class I antiarrhythmic drugs in anisotropic ventricular muscle. Candiovase Res 1996;31:640-50.

30. Lacroix D, Delfaut P, Adamantidis M, et al. Differential effects of quinidine, flecainide, and cibenzoline on anisotropic conduction in the isolated porcine heart. $J$ Candiowase Electrophysiol 1998;9:55-69.

31. Pertsov AM, Panfilov AV, Medvedeva FU. Instabilities of autowaves in excitable media associated with critical curvature phenomenon. Biofizika 1983;28:100-102.

32. Girouard SD, Rosenbaum DS. Wavefront pivoting causes functional path length extension in an anatomically defined reentrant circuit. PACE 1997;20:1051 (abstract).

33. Fozzard HA, Schoenberg M. Strength-duration curves in cardiac Purkinje fibres: effects of liminal length and charge distribution. J Physiol Lond 1972;226:593-618.

34. Lindemans FW, Denier Van der Gon JJ. Current thresholds and liminal size in excitation of heart muscle. Cardiovasc Res 1978;12:477-85.

35. Coromilas J, Saltman AE, Waldecker B, et al. Electrophysiological effects of flecainide on anisotropic conduction and reentry in infarcted canine hearts. Circulation 1995;91:2245-63.

36. Callans DJ, Hook BG, Josephson ME. The mechanism of propafenone-induced slowing of ventricular tachycardia in man as defined by analysis of resetting response patterns. PACE 1991;14:2035-2041.

37. Naitoh N, Washizuka T, Takahashi K, et al. Effects of class I and III antiarrhythmic drugs on ventricular tachycardia-interrupting critical paced cycle length with rapid pacing. Jpn Circ J 1998;62:267-73.

38. Janse MJ, Wit AL. Electrophysiological mechanisms of ventricular arrhythmias resulting from myocardial ischemia and infarction. Physiol Rev 1989;69:1049-169.

39. Chorro FJ, Sanchez Munoz JJ, Sanchis J, et al. Modifications in the evolution of the dominant frequency in ventricular fibrillation induced by amiodarone, diltiazem, and flecainide. An experimental study. J Electrocardiol 1996;29:319-26.

40. Stewart AJ, Allen JD, Devine AB, et al. Effects of blockade of fast and slow inward current channels on ventricular fibrillation in the pig heart. Heart 1996;76:513-9.

41. Kwan YY, Fan W, Hough D, et al. Effects of procainamide on wave-front dynamics during ventricular fibrillation in open-chest dogs. Circulation 1998;97:1828-36.

42. Fast VG, Efimov IR, Krinsky VI. Transition from circular to linear rotation of a vortex in an excitable cellular medium. Phys Lett A 1990;151:157-161.

43. Ortiz J, Nozaki A, Shimizu A, et al. Mechanism of interruption of atrial flutter by moricizine. Electrophysiological and multiplexing studies in the canine sterile pericarditis model of atrial flutter. Circulation 1994;89:2860-9.

44. Crijns HJGM, Wijk vLM, Gilst vWH, et al. Acute conversion of atrial fibrillation to sinus rhythm: clinical efficacy of flecainide acetate. Comparison of two regimes. Eur Heart $J 1988$ ;1988:634-638.

45. Brugada J, Gursoy S, Brugada P, et al. Cibenzoline transforms random re-entry into ordered reentry in the atria. Eur Heart $J$ 1993;14:267-272.

46. Wang Z, Page P, Nattel S. Mechanisms of flecainide antiarrhythmic action in experimental atrial fibrillation. Circ Res 1992;71:271-287.

47. Wijffels MCEF, Dorland R, Kilian M, et al. Widening of the temporal excitable gap during AF by class I and III drugs. PACE 1998;21:840 (abstract). 
Chapter 2

$-60-$ 


\section{Chapter 3}

\section{Flecainide Widens the Excitable Gap at Pivot}

\section{Points of Premature Turning Wavefronts in Rabbit}

\section{Ventricular Myocardium}

Peter W. Danse, MD; Clifford J. Garratt, MD; Maurits A. Allessie, MD, PhD 
Chapter 3

$-62$. 


\section{Introduction}

Both atrial as well as ventricular tachyarrhythmias can be based on reentrant excitation around a line of conduction block. ${ }^{1,2}$ Class IC drugs slow the rate of these arrhythmias. It has been shown that flecainide prolongs the revolution time of functional reentrant circuits underlying ventricular tachycardia (VT) by depressing conduction at the pivot points of the circulating impulse. ${ }^{3}$ During atrial fibrillation (AF) multiple reentrant wavelets are present. ' Flecainide slows the rate of AF by increasing the size and decreasing the number of reentrant circuits. ${ }^{4}$ For some time, these antifibrillatory effects were thought to be due to a prolongation of the wavelength of refractoriness (conduction velocity $\mathrm{x}$ refractory period). ${ }^{45}$ However, Wijffels et al. ${ }^{6}$ recently demonstrated that class IC drugs did not prolong the wavelength during AF. Instead, the main reason for the slowing of the rate of AF was a marked widening of the temporal excitable gap. ${ }^{6}$ This raises the question how blockade of the rapid sodium channels can widen the excitable gap during functional reentry. A number of studies have indicated that at the pivot points of a reentrant circuit the safety factor for conduction is relatively low due to the high curvature of the wavefront. ${ }^{7.9}$ In a previous study in rabbit ventricle we have shown that flecainide preferentially slowed conduction around the end of a linear RF-lesion. ${ }^{9}$ In the present study we further explored the mechanisms by which such preferential slowing of conduction occurs. Furthermore, we directly evaluated the effect of flecainide on the excitable gap beyond the pivot point of premature turning wavefronts.

\section{Methods}

\section{Preparation}

Eight Flemish rabbits of either sex, weighing between 2.7 and $3.6 \mathrm{~kg}$ were used for this study. All experiments were carried out according to the guidelines of the Governmental Veterinar Committee of the Netherlands and approved by the Animal Investigation Committee of the University of Maastricht. After heparinization (1000 I.U.) and sedation $\left(5 \mathrm{mg} / \mathrm{kg}\right.$ fluanison and $0.1 \mathrm{mg} / \mathrm{kg}$ phentanyl $\left(\right.$ Hypnorm $\left.^{*}\right)$, the animals were killed by cervical dislocation. After a midsternal incision the heart was rapidly removed and placed in cold perfusion fluid $\left(10^{\circ} \mathrm{C}\right)$. The aorta was cannulated, and the coronary arteries were perfused with a pressure of $60 \mathrm{~mm} \mathrm{Hg}$. The composition of the perfusion fluid was $(\mathrm{mM}) \mathrm{NaCl}$ 130, $\mathrm{NaHCO}_{3} 20.1, \mathrm{KCl} 4.0, \mathrm{CaCl}_{2} 2.2, \mathrm{MgCl}_{2} 0.6, \mathrm{Na}_{2} \mathrm{HPO}_{4} 1.2$ and glucose 12. The solution was saturated with a mixture of $95 \% \mathrm{O}_{2}$ and $5 \% \mathrm{CO}_{2}$. The $\mathrm{pH}$ was 7.35 , the temperature was kept at $37 \pm 0.2{ }^{\circ} \mathrm{C}$.

To obtain a thin $(\sim 1 \mathrm{~mm})$ sheet of perfused left ventricular subepicardium a cryoprocedure was performed, as described previously. ${ }^{10} \mathrm{~A}$ long linear lesion (width $2 \mathrm{~mm}$ ) parallel to the epicardial fiber direction was made by radiofrequency (RF) ablation. To minimize the width of the tip of the lesion and to maximize the effect of curvature on propagation of the impulse around the lesion, one end of the RF-lesion was extended by a thin $3-5 \mathrm{~mm}$ long incision into the direction of the LAD. ${ }^{9}$ 


\section{High Density Mapping and Electrical Stimulation}

High density mapping was performed using an array of 240 silver electrodes (diaeter $150 \mu \mathrm{m})$. The interelectrode distance was $350 \mu \mathrm{m}$ transverse to the fiber orientationand $700 \mu \mathrm{m}$ in a longitudinal direction. The mapping electrode covered an area of $7.5 \times 7 . \mathrm{nm}$, and was positioned with its center on the tip of the lesion (Fig1). Unipolar electrogams $(n=240)$ were recorded simultaneously using the silver aortic cannula as indifferentlectrode. After amplification (gain 300$)$ and filtering $(1-500 \mathrm{~Hz}$ ) the signals were multipxed (sampling rate $1 \mathrm{kHz}$ ) and analog to digital converted ( 8 bits). The whole experimerwas recorded on video-tape. The mapping system used for data acquisition, storage and aalysis has been described previously."

Two bipolar pacing electrodes were sutured on the epicardial surface, one at either sle of the RF-lesion. Electrical stimulation was performed with a custom made constant-crent stimulator, delivering biphasic square pulses of $2 \mathrm{~ms}$ duration. During regular pacing stimulus strength of twice diastolic threshold was used and premature stimuli were delered with a strength of four times threshold. Pacing at one side of the lesion elicited a U-tming wavefront around the tip of the lesion either in a clockwise or counterclockwise dirtion (Fig1).

\section{Experimental Protocol}

An identical pacing protocol was carried out using pacing electrodes located at either side of the lesion. After a train of 20 basic stimuli (S1-S1 350ms) a single premature stimulus (S2) was given. The S1-S2 coupling interval was decreased in steps of $2 \mathrm{~ms}$ until the premature stimulus no longer captured the ventricle. The effective refractory period (ERP) was defined as the longest S1-S2 interval that failed to initiate a propagated response. V1V2 intervals (defined as the time window between the last basic beat and the premature beat at a given recording site) were measured both proximal and distal to the pivot point (black dots in Fig1). The excitable period proximal and distal to the pivot point was determined as the difference between the local V1-V2 interval and the ERP. Flecainide ( $2 \mathrm{mg} / \mathrm{l})$ was then added to the perfusion fluid and after 20 minutes the pacing protocol was repeated.

\section{Data Analysis}

After the experiment, all 240 electrograms were played back from tape and activation maps were generated by the computer, using the steepest negative deflection in the electrograms as the moment of activation. Isochrones were drawn manually at $5 \mathrm{~ms}$ intervals. Conduction velocity was calculated from the distance normal to the isochrones. Local conduction block was defined as a local conduction velocity of $<5 \mathrm{~cm} / \mathrm{s}$ and a change in direction of propagation distal to the line of block to differentiate it from slow conduction. ${ }^{12}$ The location of 

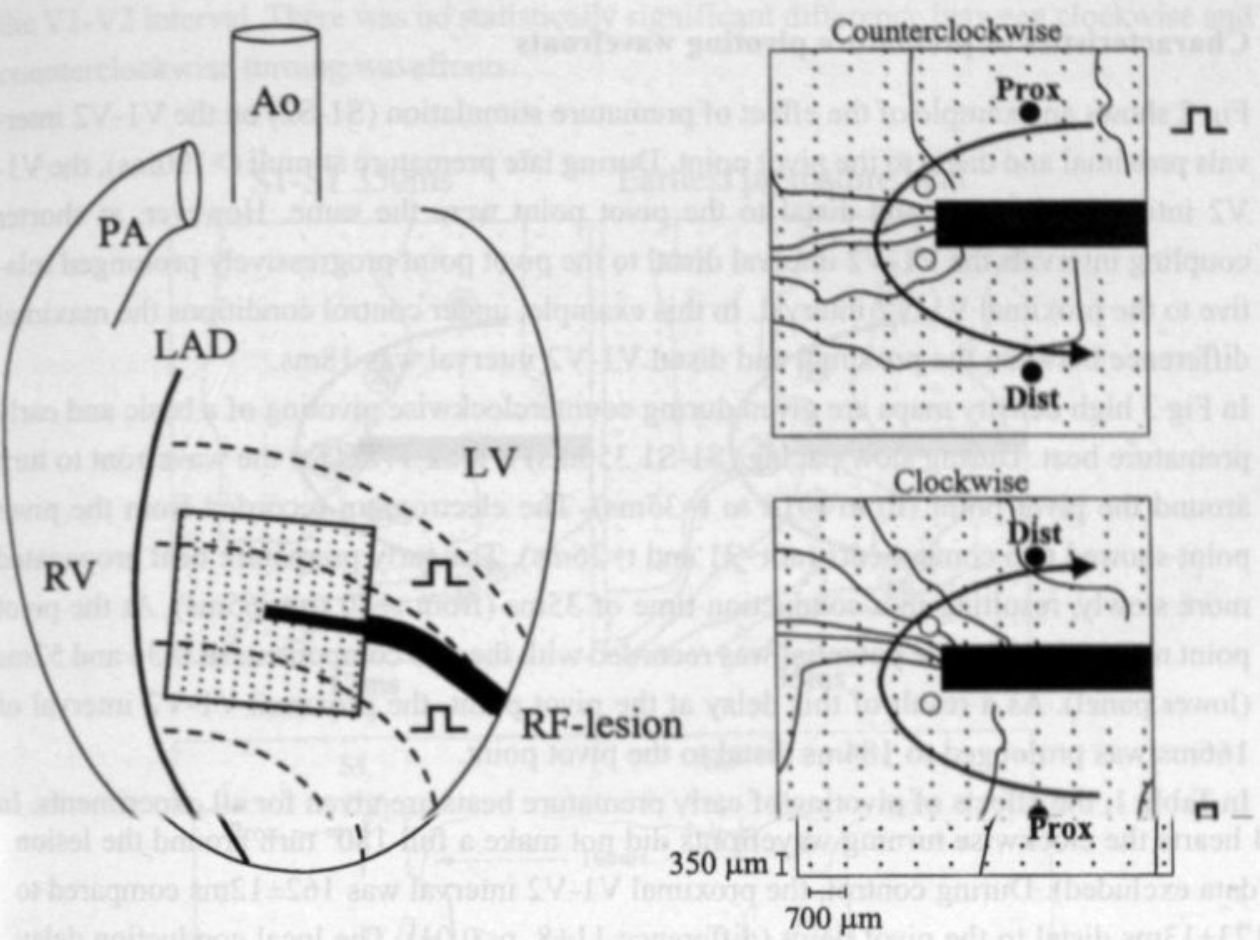

Figure 1. Left: Schematic drawing of the Langendorff perfused rabbit heart with a linear radiofrequency $(R F)$ lesion in the free wall of the left ventricle, parallel to the epicardial fiber orientation (thick line). The RF-lesion was extended by a short incision (thin line). A high density mapping array was positioned on the tip of the incision. The ventricle was paced at the lower or upper side of the lesion, resulting in either clockwise or counterclockwise $U$-turning wavefronts. $L V=l e f t$ ventricle; $R V=$ right ventricle; $A o=$ aorta $[L A D=$ left anterior descending artery; $P A=$ pulmonary artery. Right: Isochrone maps of a clockwise and a counterclockwise turning wavefront. The small dots indicate electrodes from which local unipolar electrograms were recorded. Isochrones were drawn manually at 5 msec intervals. The large black dots indicate the electrode sites at which the $V I-V 2$ intervals proximal (prox) and distal (dist) to the pivot point were measured. The open circles indicate the electrodes between which the local conduction delay at the pivot point was measured.

the anatomical lesion was determined by mapping during slow pacing. The conduction delay at the pivot point was measured between two electrodes at either end of the lesion 1.4 $\mathrm{mm}$ apart (open circles in Fig1). Only experiments were included in which the activation wave made a full $180^{\circ}$ turn around the lesion.

The data are presented as mean \pm standard deviation. Results were compared using the paired Student's t-test. Differences were considered statistically significant at $\mathrm{p}$-values $<0.05$. 


\section{Results}

\section{Characteristics of premature pivoting wavefronts}

Fig 2 shows an example of the effect of premature stimulation (S1-S2) on the V1-V2 itervals proximal and distal to the pivot point. During late premature stimuli $(>190 \mathrm{~ms})$, theVIV2 intervals proximal and distal to the pivot point were the same. However, at shrter coupling intervals the $\mathrm{V} 1-\mathrm{V} 2$ interval distal to the pivot point progressively prolonged elative to the proximal $\mathrm{V} 1-\mathrm{V} 2$ interval. In this example, under control conditions the maxmal difference between the proximal and distal V1-V2 interval was $18 \mathrm{~ms}$.

In Fig 3 high density maps are given during counterclockwise pivoting of a basic and arly premature beat. During slow pacing ( $\mathrm{S} 1-\mathrm{S} 1350 \mathrm{~ms})$ it took $17 \mathrm{~ms}$ for the wavefront toturn around the pivot point (from $t=18$ to $t=35 \mathrm{~ms}$ ). The electrogram recorded from the ivot point showed two components (at $\mathrm{t}=21$ and $\mathrm{t}=26 \mathrm{~ms}$ ). The early premature beat propaated more slowly, resulting in a conduction time of $35 \mathrm{~ms}$ (from $\mathrm{t}=30$ to $\mathrm{t}=65 \mathrm{~ms}$ ). At the sivot point now a clear double potential was recorded with the two components at $t=36$ and $2 \mathrm{~ms}$ (lower panel). As a result of this delay at the pivot point, the proximal V1-V2 interal of $166 \mathrm{~ms}$ was prolonged to $184 \mathrm{~ms}$ distal to the pivot point.

In Table 1, the effects of pivoting of early premature dieats are grivern fr"al layperimers. In 4 hearts the clockwise turning wavefronts did not make a full $180^{\circ}$ turn around the lesion (data excluded). During control, the proximal V1-V2 interval was $162 \pm 12 \mathrm{~ms}$ compared to $173 \pm 13 \mathrm{~ms}$ distal to the pivot point (difference $11 \pm 8, \mathrm{p}<0.01$ ). The local conduction delay at the pivot point increased from $11 \pm 5 \mathrm{~ms}$ during slow pacing to $18 \pm 9 \mathrm{~ms}$ during prematu-

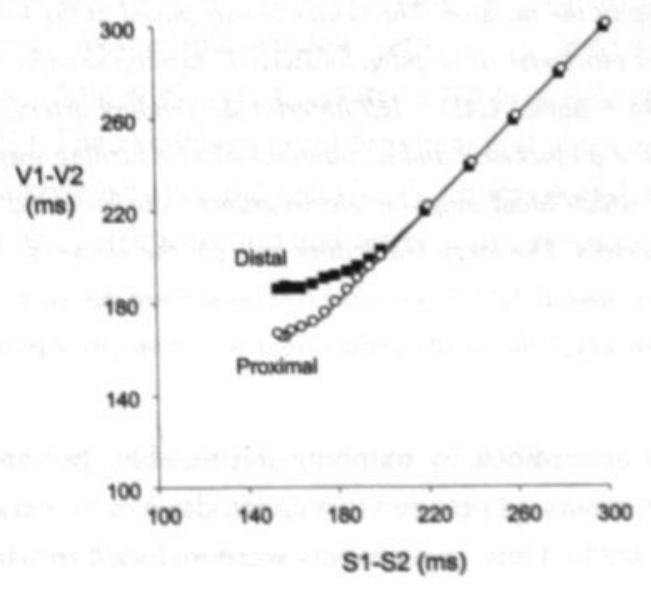

Figure 2. The effect of premature stimulation (SI-S2 intervals) on the VI-V2 intervals proximal and distal to the pivot point of a U-turning wavefront. At shorter $S I-S 2$ coupling intervals the VI-V2 interval distal to the pivot point became progressively prolonged relative to the proximal $V I-V 2$ interval. 
re stimulation $(p<0.01)$. This increase by $7 \pm 5 \mathrm{~ms}$ accounted for $64 \%$ of the lengthening of the V1-V2 interval. There was no statistically significant difference between clockwise and counterclockwise turning wavefronts.

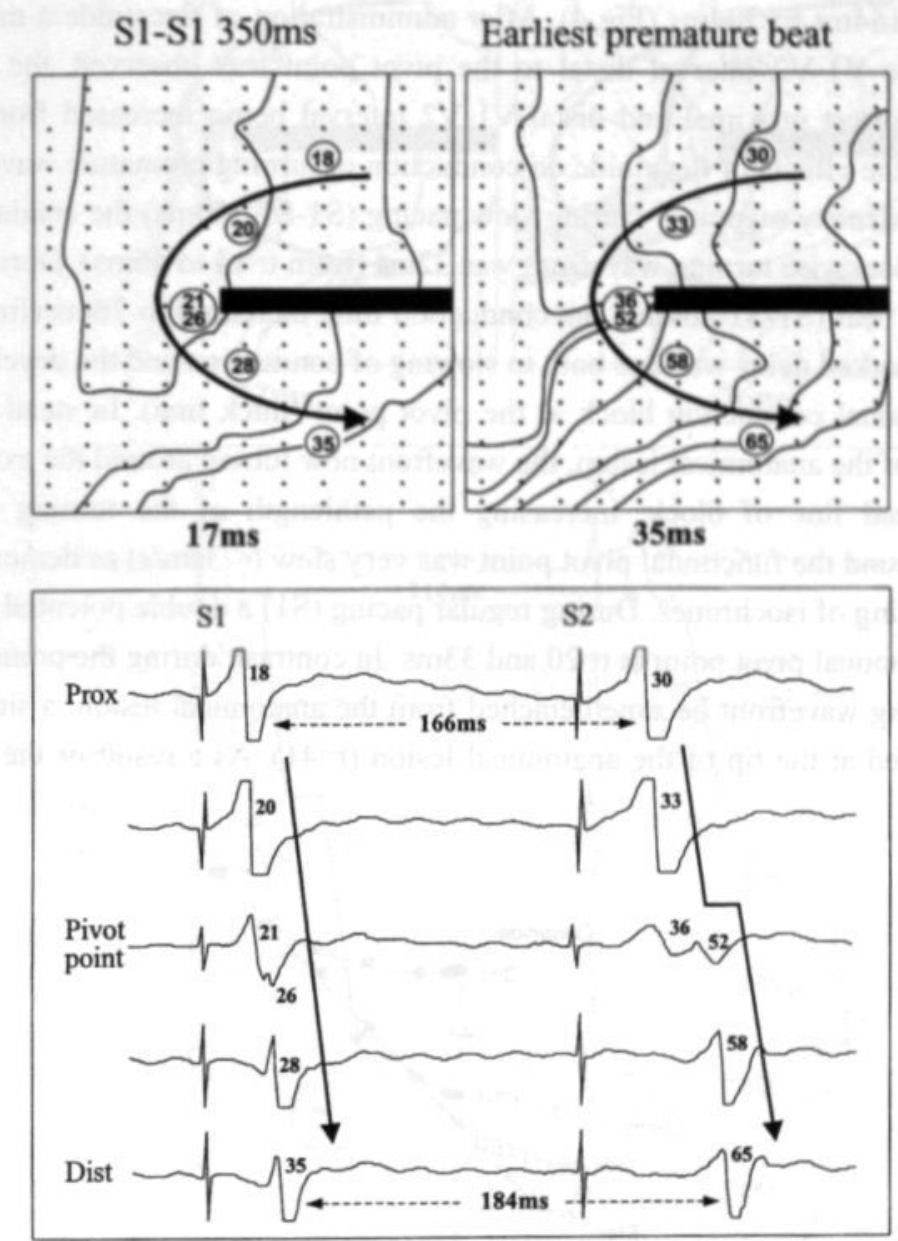

Figure 3. Top: High density maps of a counterclockwise turning wavefront during regular pacing (SI$S 1350 \mathrm{~ms}$ ) and the earliest premature beat (SI-S2 interval 156ms). The small dots indicate sites where the activation times were measured. The moment of stimulation is taken as $t=0$. Isochrones were drawn manually at 5 msec intervals. At five different sites around the pivot point the local activation times are given (encircled numbers). During regular pacing the conduction time around the lesion was $17 \mathrm{~ms}$ (from $t=18$ to $t=35 \mathrm{~ms}$ ). The earliest premature beat propagated more slowly around the pivot point from $t=30$ to $65 \mathrm{~ms}$. Bottom: Unipolar electrograms recorded at the five sites encircled in the maps. During regular pacing (SI), the electrogram at the pivot point showed a large potential at $t=21 \mathrm{~ms}$ and a small second component at $t=26 \mathrm{~ms}$. During propagation of the early premature beat (S2) the electrogram at the pivot point consisted of two small components at $t=36$ and $t=52 \mathrm{~ms}$. As a result of the local conduction delay at the pivot point the V1-V2 interval was prolonged to $184 \mathrm{~ms}$ distal to the pivot point. Prox $=$ proximal of the pivot point $;$ Dist $=$ distal to the pivot point. 


\section{Effects of flecainide on premature pivoting wavefronts}

Figures 4 and 5 show the effects of flecainide $(2 \mathrm{mg} / 1)$ on conduction of premature turning wavefronts. Flecainide prolonged the shortest S1-S2 interval that elicited a propagated response from $154 \mathrm{~ms}$ to $204 \mathrm{~ms}$ (Fig 4). After administration of flecainide a marked prolongation of the V1-V2 interval distal to the pivot point was observed, the difference between the shortest proximal and distal V1-V2 interval being increased from $18 \mathrm{~ms}$ to $44 \mathrm{~ms}$. In Fig 5 the effects of flecainide on conduction of turning premature wavefronts are shown by high density mapping. During slow pacing (S1-S1 350ms) the conduction time of the counterclockwise turning wavefront was $32 \mathrm{~ms}$ (from t=14 to $46 \mathrm{~ms}$ ). During the earliest premature beat (S1-S1 204ms) the conduction time increased to $76 \mathrm{~ms}$ (from $\mathrm{t}=28$ to $104 \mathrm{~ms}$ ). This marked delay was due both to slowing of conduction and the development of a line of functional conduction block at the pivot point (thick line). In stead of turning around the tip of the anatomical lesion, the wavefront now turned around the extended end of the functional line of block, increasing the pathlength of the turning wavefront. Conduction around the functional pivot point was very slow $(<3 \mathrm{~cm} / \mathrm{s})$ as demonstrated by the local crowding of isochrones. During regular pacing $(\mathrm{S} 1)$ a double potential was recorded at the anatomical pivot point at $\mathrm{t}=20$ and $33 \mathrm{~ms}$. In contrast, during the premature beat, when the turning wavefront became detached from the anatomical lesion, a single potential was recorded at the tip of the anatomical lesion $(t=41)$. As a result of the large con-

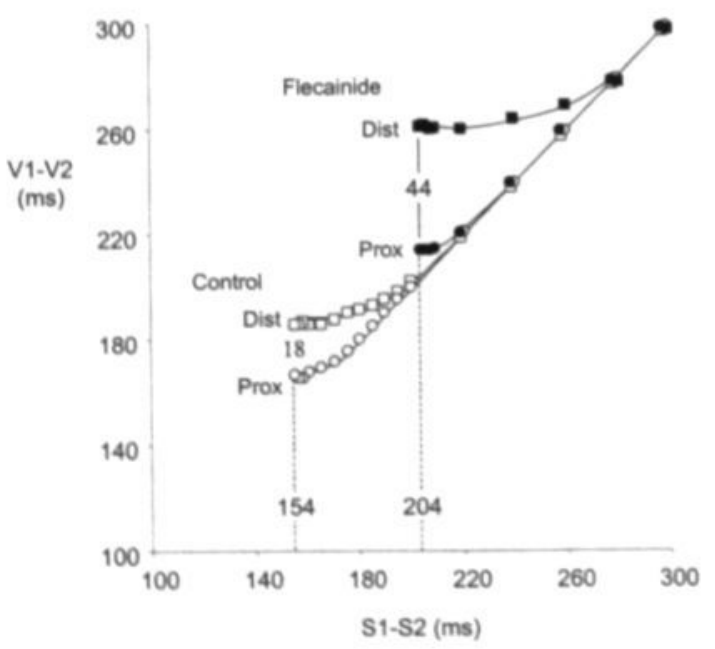

Figure 4. The effects of flecainide $(2 \mathrm{mg} / \mathrm{l})$ on the relation between the $S 1-S 2$ and $V I-V 2$ intervals praximal and distal to the pivot point. Flecainide prolonged the ERP (shortest S1-S2) from 154 to $204 \mathrm{msec}$ and increased the difference between the VI-V2 intervals distal and proximal to the pivot point. During control, the VI-V2 interval of the earliest premature beat was $184 \mathrm{~ms}$ distal to the pivot point compared to $166 \mathrm{~ms}$ proximal of the pivot point and (difference $18 \mathrm{~ms}$ ). During infusion of fle cainide, the distal $V 1-V 2$ interval was $260 \mathrm{~ms}$ and the proximal $V 1-V 2$ interval was $216 \mathrm{~ms}$ (difference $44 \mathrm{~ms})$. Prox $=$ proximal of the pinot point; Dist $=$ distal to the pivot point. 
S1-S1 350ms

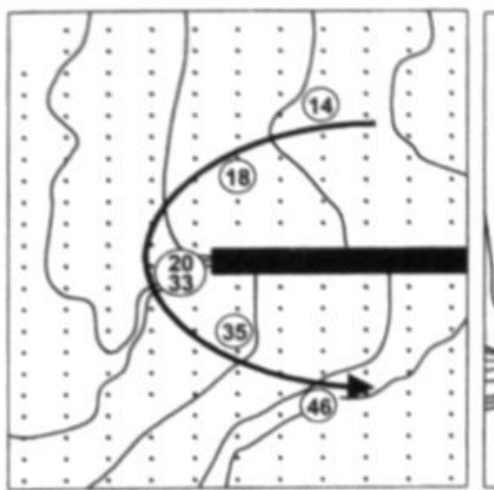

$32 \mathrm{~ms}$
Earliest premature beat

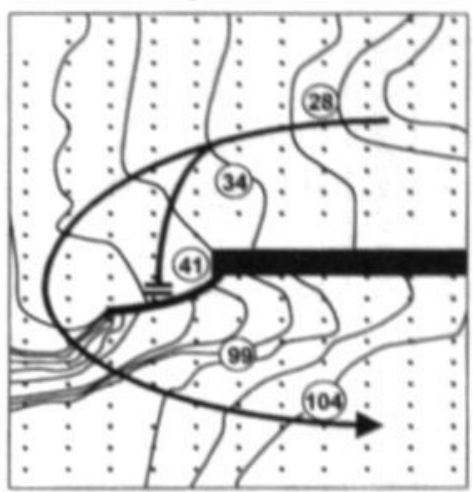

$76 \mathrm{~ms}$

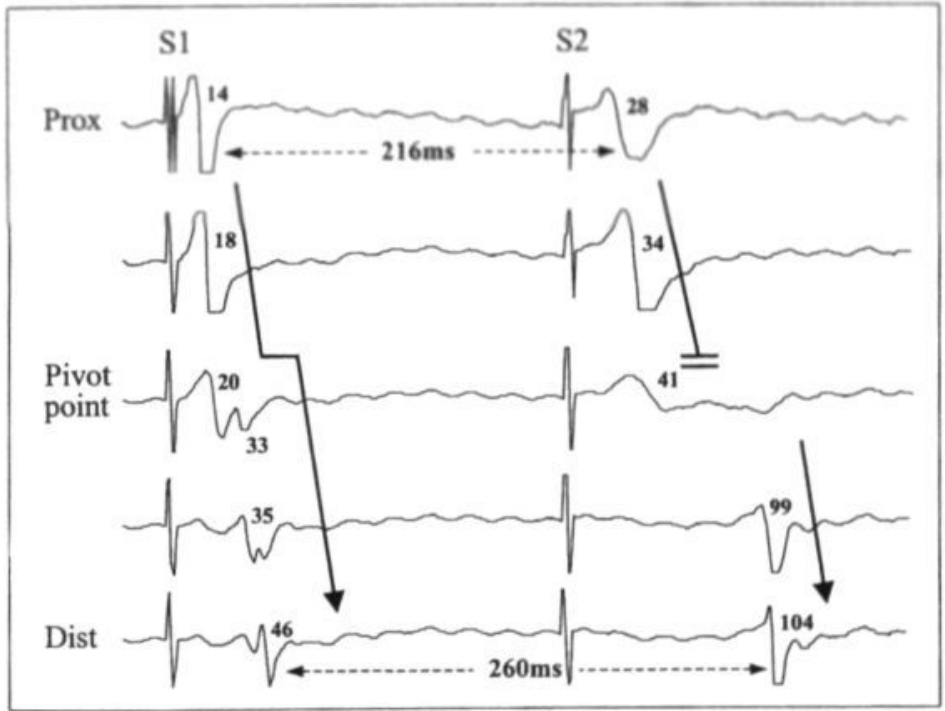

Figure 5. Top: High density maps of counterclockwise propagation during regular pacing (SI-SI $350 \mathrm{~ms})$ and the earliest premature beat after administration of flecainide $(2 \mathrm{mg} / \mathrm{l})$. Same experiment as Fig3. The small dots indicate electrodes where activation times were measured. The local moments of activation at five sites around the pivot point are indicated (encircled numbers; $t=0$ is moment of stimulation). Isochrones are drawn manaually at $5 \mathrm{msec}$ intervals. During regular pacing the conduction time around the lesion was $32 \mathrm{~ms}$ (from $t=14$ to $t=46 \mathrm{~ms}$ ). During pivoting of the earliest premature beat, a line of functional conduction block occurred at the tip of the anatomic lesion. The conduction velocity around the functional pivot point was $<3 \mathrm{~cm} / \mathrm{s}$ (dense crowding of isochrones). This resulted in a total increase in conduction time around the pivot point to $76 \mathrm{~ms}$ (from $t=28$ to $104 \mathrm{~ms}$ ). Bottom: Unipolar electrograms recorded from the five sites encircled in the maps. During regular pacing (SI) a double potential was recorded at the anatomical pivot point $(t=20 / 33)$. During premature stimulation (S2), when the turning wavefront became detached from the anatomical lesion, a single potential was recorded from the tip of the lesion $(t=41)$. Due to the large conduction delay at the pivot point the proximal V1-V2 interval of $216 \mathrm{~ms}$ increased to $260 \mathrm{~ms}$ distal to the pivot point. Prox = proximal of the pivot point; Dist $=$ distal to the pivot point. 
Table 1. Effects of flecainide on pivoting of the earliest premature beat

\begin{tabular}{|c|c|c|c|c|c|c|c|c|c|c|c|c|c|c|c|}
\hline & \multirow[b]{3}{*}{$\begin{array}{c}\text { U-tum } \\
\text { (N) }\end{array}$} & \multirow[b]{3}{*}{$\begin{array}{l}\text { ERP } \\
\text { (ms) }\end{array}$} & \multicolumn{6}{|c|}{ Control } & \multicolumn{7}{|c|}{ Flecainide $2 \mathrm{mg} /$} \\
\hline & & & \multicolumn{3}{|c|}{ V1-V2 (ms) } & \multicolumn{3}{|c|}{ Pivot Point Delay (ms) } & \multirow[b]{2}{*}{$\begin{array}{l}\text { ERP } \\
\text { (ms) }\end{array}$} & \multicolumn{3}{|c|}{$\mathrm{V}_{1}-\mathrm{V}_{2}$ (ms) } & \multicolumn{3}{|c|}{ Pivot Point Delay (ms) } \\
\hline & & & Prox & Dist & $\Delta$ & S1 & S2 & $\Delta$ & & Prox & Dist & $\Delta$ & S1 & s2 & $\Delta$ \\
\hline Total & 12 & $143 \pm 8$ & $162 \pm 12$ & $173 \pm 13^{* *}$ & $11 \pm 8$ & $11 \pm 5$ & $18 \pm 9$ & $7 \pm 5$ & $189+25^{t t}$ & $217 \pm 29$ & $244 \pm 36^{* *}$ & $27 \pm 16^{t t}$ & $23 \pm 6$ & $44 \pm 13$ & $21 \pm 12^{t t}$ \\
\hline CCW & 8 & $144 \pm 8$ & $162 \pm 12$ & $170 \pm 14^{\circ}$ & $8 \pm 7$ & $9 \pm 4$ & $13 \pm 5$ & $5 \pm 4$ & $191 \pm 21^{t t}$ & $220 \pm 18$ & $246 \pm 36^{* *}$ & $26 \pm 18^{t t}$ & $21 \pm 6$ & $40 \pm 14$ & $19 \pm 13^{t t}$ \\
\hline CW & 4 & $142 \pm 7$ & $160 \pm 12$ & $178 \pm 8^{* *}$ & $18 \pm 6$ & $16 \pm 5$ & $27 \pm 7$ & $11 \pm 3$ & $186 \pm 29^{t t}$ & $212 \pm 33$ & $241 \pm 43^{*}$ & $29 \pm 13$ & $27 \pm 2$ & $52 \pm 9$ & $25 \pm 9^{t}$ \\
\hline
\end{tabular}

$\mathrm{CCW}=$ counterclockwise, $\mathrm{CW}=$ clockwise. ERP $=$ effective refractory period, $\mathrm{V} 1-\mathrm{V} 2=\mathrm{V} 1-\mathrm{V} 2$ interval of the earliest premature beat, Prox $/$ Dist $=$ selected electrodes proximal respectively distal to the pivot point (see Fig1), PP = pivot point, $\mathrm{S} 1=$ regular pacing interval $350 \mathrm{~ms}, \mathrm{~S} 2=$ premature stimulation resulting in the earliest premature beat. ${ }^{*}=p<0.05, *=p<0.01$ dist versus $p r o x ;{ }^{\dagger}=p<0.05,{ }^{t \dagger}=p<0.01$ flecainide versus control. 
duction delay of the turning premature wavefront, the proximal V1-V2 interval of $216 \mathrm{~ms}$ was prolonged to $260 \mathrm{~ms}$ beyond the pivot point.

In Table 1 the effects of flecainide $(2 \mathrm{mg} / 1)$ on pivoting of the earliest premature beats are given for all experiments. Flecainide prolonged the ERP from $143 \pm 8 \mathrm{~ms}$ to $189 \pm 25 \mathrm{~ms}$ (p<0.01). The V1-V2 interval proximal to the pivot point was $217 \pm 29$ compared to $244 \pm 36 \mathrm{~ms}$ distal to the pivot point $(\mathrm{p}<0.01$ ). This difference of $27 \pm 16 \mathrm{~ms}$ was larger than the difference between the proximal and distal V1-V2 intervals during control $(11 \pm 8 \mathrm{~ms}$, p<0.01). The local conduction delay at the pivot point increased from $23 \pm 6$ during slow pacing to $44 \pm 13 \mathrm{~ms}$ during premature stimulation ( $<<0.01$ ). This increase by $21 \pm 12 \mathrm{~ms}$ accounted for $82 \%$ of the lengthening of the V1-V2 interval. No statistically significant differences were found between clockwise and counterclockwise rotation.

In Fig 6 the shortest attainable V1-V2 intervals proximal and distal to the pivot point are plotted for all experiments, both during control and after administration of flecainide. The temporal excitable gap was calculated as the difference between the shortest V1-V2 interval and the ERP. In the proximal limb of the turning wavefront the difference between the V1-V2 interval and the ERP was small. The slight prolongation of the V1-V2 interval compared to the S1-S2 interval is due to the latency between stimulus and response and a slight increase in conduction time of the premature impulse from the pacing to the recording site. The preferential conduction delay at the pivot point prolonged the shortest attainable V1V2 interval and increased the excitable gap distal to the pivot point. Administration of flecainide almost doubled the excitable gap distal to the pivot point from $30 \pm 11$ to $55 \pm 22 \mathrm{~ms}$

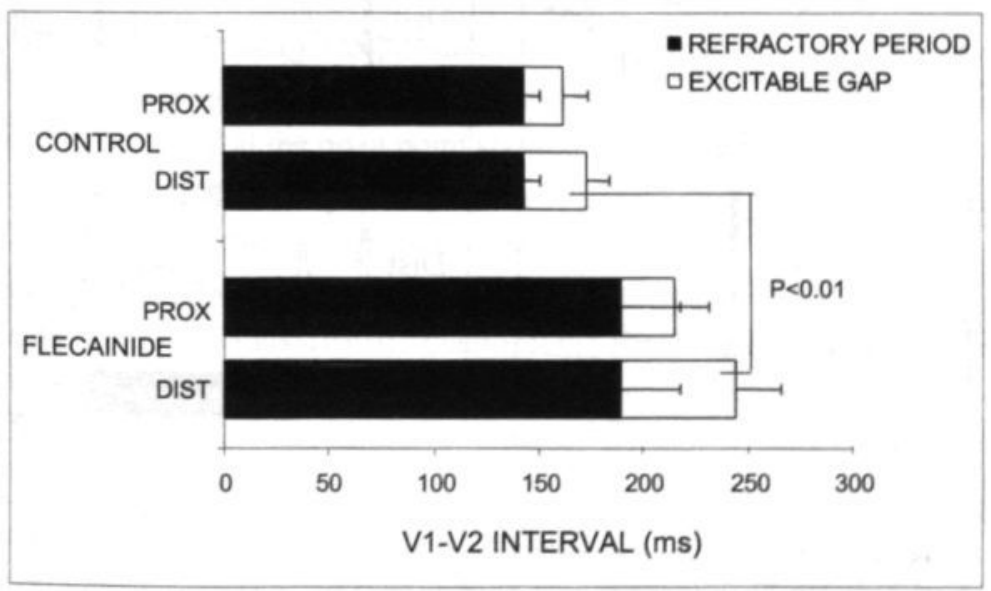

Figure 6. Effects of flecainide on the excitable gap proximal and distal to the pivot point. The filled bars represent the effective refractory period; the empty bars indicate the excitable gap. The sum of both bars equals the shortest attainable V1-V2 interval. Flecainide significantly increased the excitable gap distal to the pivot point from $30 \pm 11$ (control) to $55 \pm 22 \mathrm{~ms}$ (paired student's t-test). Prox = proximal of the pivot point; Dist $=$ distal to the pivot point. 
$(\mathrm{p}<0.01)$. To directly illustrate the presence of a large excitable gap distal to the pivot point, in one experiment an additional test stimulus was applied in the distal limb of the turning wavefront (Fig.7). In this experiment, the shortest V1-V2 interval was $230 \mathrm{~ms}$ proximal and $260 \mathrm{~ms}$ distal to the pivot point (left panel). During turning of the earliest possible premature beat, a test stimulus (S2*) was applied in the distal limb of the U-turn (right panel). Starting well within the refractory period, the V1-S2* interval was increased in steps of $2 \mathrm{~ms}$ until capture occurred. An S2* stimulus with a coupling interval of $190 \mathrm{~ms}$ did not capture and the whole area distal to the pivot point was activated by the counterclockwise premature wavefront induced at the other side of the lesion. However, when the V1-S2* coupling interval was increased to $200 \mathrm{~ms}$, the tissue distal to the pivot point was captured by the premature S2* stimulus. Now, part of the myocardium beyond the pivot point was activated before arrival of the counterclockwise turning wavefront. In this way, it was directly demonstrated that the excitable gap in the returning limb of the turning wavefront was as long as $60 \mathrm{~ms}$.
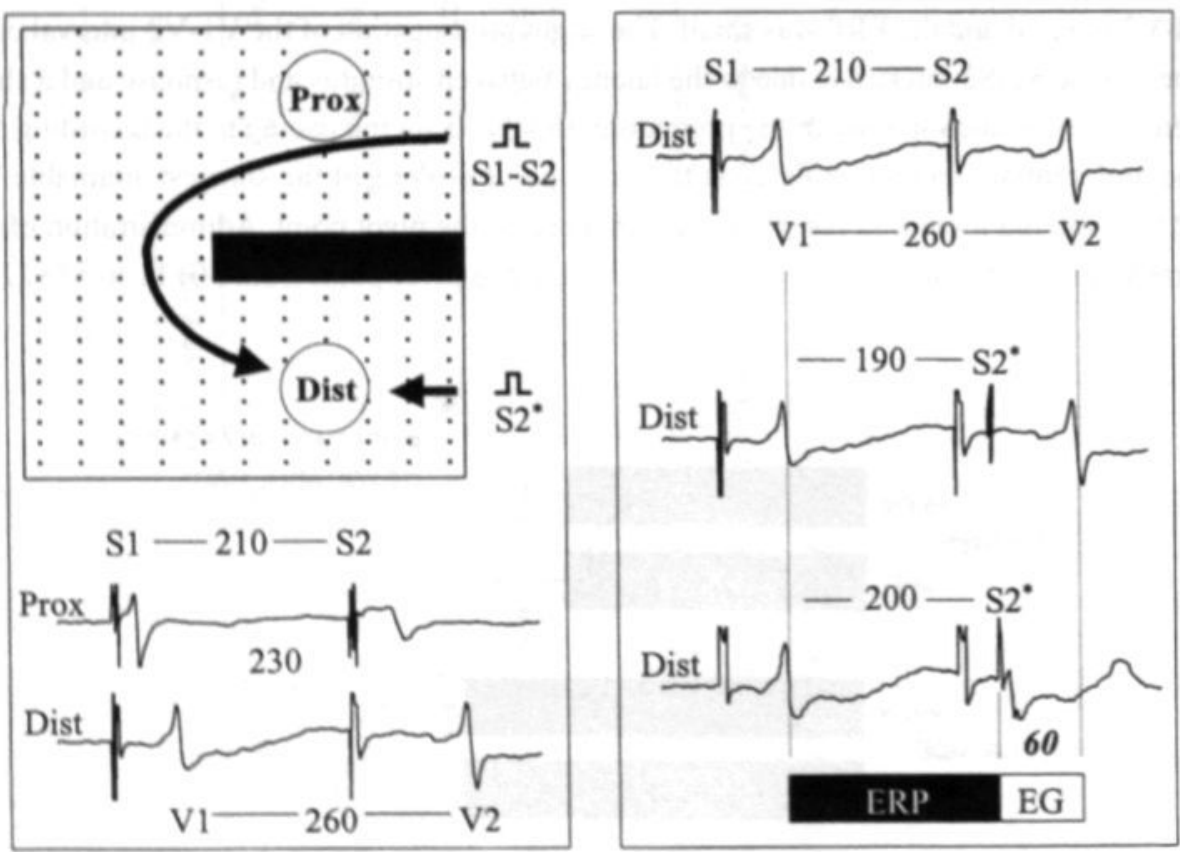

Figure 7. Demonstration of the presence of an excitable gap in the returning limb of a premature $U$ hurning wavefront. Left: A premature counterclockwise turning wavefront was induced by pacing at the upper side of the lesion. The shortest premature stimulus ( $S 1-S 2210 \mathrm{~ms}$ ) induced a premature beat with a Vl-V2 interval of $230 \mathrm{~ms}$ proximal and $260 \mathrm{~ms}$ distal to the pivot point. Right: Another premature stimulus was also applied at the lower side of the lesion (S2*). An S2* stimulus with a coupling intenval of $190 \mathrm{~ms}$ failed to capture the myocandium which was normally activated by the returning limb of the turning wavefront (distal VI-V2 intenval $260 \mathrm{~ms}$ ). When the coupling interval was lenghtened to $200 \mathrm{~ms}$, the tissue distal to the pivot point was captured by the $S 2 *$ stimulus long before arrival of the counterclockwise turning wavefront. The excitable gap (EG) in the returning limb of the premature turning wavefront was as long as $60 \mathrm{~ms}$. ERP = effective nefractory period. 


\section{Conduction Characteristics at the Pivot Point}

In Fig 8 the characteristics of delayed conduction around the pivot point are shown. During slow pacing in the absence of flecainide only a slight delay in conduction of $6 \mathrm{~ms}$ occurred at the pivot point (top panel). Almost all electrograms exhibited a single biphasic potential with a steep negative deflection. Only at the tip of the anatomic lesion the electrograms showed a small second component. In the lower left panel, pivoting of an early premature beat is shown. Now, some crowding of isochrones was observed between the tip of the lesion and the lower left corner of the map associated with a conduction delay between neighboring electrodes $(350 \mu \mathrm{m})$ of $11-16 \mathrm{~ms}$. All premature electrograms around the pivot point showed a double potential. Since in the time window between the components electrical activity could nowhere be recorded, this type of propagation was indicated as 'macroscopic discontinuous conduction'. After the delay, the tissue distal to the line of discontinuous conduction was activated almost simultaneously between $t=52$ and $t=54 \mathrm{~ms}$. The lower right panel shows the effects of flecainide. A line of functional conduction block with a length of $1.4 \mathrm{~mm}$ now occurred at the tip of the anatomical lesion (thick line), lengthening the pathway of the turning wavefront. At the pivot point a dense crowding of isochrones was observed with local conduction delays up to $30 \mathrm{~ms}$ between neighboring electrodes $(350 \mu \mathrm{m})$. The effective conduction velocity across this area of macroscopic discontinuous conduction was less than $3 \mathrm{~cm} / \mathrm{s}$ (pseudoblock). The electrograms were severely fractionated, the different components being separated by $14-30 \mathrm{~ms}$ (total duration $>40 \mathrm{~ms}$ ). In Table 2 the conduction characteristics at the pivot points are given for all experiments. During control (slow pacing with an interval of $350 \mathrm{~ms}$ ), in most cases ( 8 of 12) the impulse propagated slowly but smoothly around the lesion with a local conduction delay of only $6 \pm 1 \mathrm{~ms}$. In 4 experiments macroscopic discontinuous conduction occurred with a local delay of $17 \pm 2 \mathrm{~ms}$. Macroscopic discontinuous conduction was assigned to be present if: 1) the electrograms recorded at the pivot point showed a double potential, 2) the time window between the two components was more than $10 \mathrm{~ms}, 3$ ) no electrical activity was observed between the two components, 4) the tissue distal to the line of discontinuous conduction was activated almost simultaneously. Functional conduction block was not observed. During early premature beats (EPB), macroscopic discontinuous conduction occurred more frequently (conduction delay $20 \pm 9 \mathrm{~ms} ; \mathrm{n}=8$ ). In one experiment a short line of functional block was observed. After administration of flecainide, uniform slow conduction around the pivot point was no longer observed. Already during slow pacing, discontinuous conduction and functional conduction block occurred in respectively 9 and 3 of 12 cases. During early premature beats lines of functional conduction block occurred more frequently ( 8 of 12 cases). The length of the lines of functional block varied between 0.7 and $>2.8 \mathrm{~mm}$ (outside mapping area) with a mean of $>1.6 \pm 0.9 \mathrm{~mm}$. The conduction delay at the pivot point varied from $28 \pm 6 \mathrm{~ms}$ without and $53 \pm 9 \mathrm{~ms}$ with the occurrence of functional conduction block. 


\section{Chapter 3}

\section{Widening of the Excitable Gap by Flecainide}

The main finding of this study is that flecainide amplified the effects of pivoting of premature wavefronts. Due to a higher degree of macroscopic discontinuous propagation, the conduction delay at the pivot point increased from $18 \pm 9$ to $44 \pm 13 \mathrm{~ms}(\mathrm{p}<0.01)$. In many instances the premature wavefront actually seemed to come to a halt, to continue again after a pause of $15-30 \mathrm{~ms}$. After such a long local delay the tissue distal to this zone of discontinuous conduction was activated almost simultaneously (pseudoblock). ${ }^{12}$ The postponed activation might be explained by current flow from the cells proximal to the pivot point, which are already in their plateau phase, to the cells distal to the pivot point which are still repolarizing. Recent studies have provided evidence that the slow inward calcium current during the plateau phase may provide additional current for succesful propagation of high curvature wavefronts. ${ }^{18-21}$ Such a role of the calcium current may become especially important when the current generated by the rapid $\mathrm{Na}^{+}$channels is diminished, as for instance by flecainide. In 8 of 12 experiments the conduction delay at the pivot point was further enhanced by the occurrence of a line of functional conduction block, which lenghtened the pathway of the turning wavefront. The electrograms recorded at the pivot point were highly fractionated. Despite the high resolution of the mapping electrode $(350 \mu \mathrm{m})$, the exact distinction of areas of slow conduction and conduction block was often difficult due to the presence of electrotonic deflections in the local electrograms. Optical mapping with voltage-sensitive dyes earlier demonstrated the occurrence of functional conduction block at the tip of a linear lesion. In thin slices of sheep epicardium, reduction of tissue excitability by tetrodotoxin caused detachment of wavefronts from the tip of the incision and initiation of spiral waves. ${ }^{22}$

Due to an increase in the local conduction delay at the pivot point, flecainide widened the temporal excitable gap in the returning limb of premature turning wavefronts from $30 \pm 11$ to $55 \pm 22 \mathrm{~ms}$ ( $\mathrm{p}<0.01$ ). The question rises whether class I drugs will exert a similar action during functional reentrant arrhythmias. One may argue that conduction delay at one end of a line of functional block would give the other end of the line of block more time to recover, resulting in disappearance of part of the line of block. However, experimental studies on the effects of class IC drugs on functional reentrant circuits have shown that both in atrial and ventricular myocardium conduction was delayed at both ends of a line of functional conduction block. ${ }^{3,23}$ Apparently, under conditions of decreased excitability the size of a functional reentrant circuit is not mainly determined by the wavelength of refractoriness (conduction velocity $\mathrm{x}$ refractory period), but also by the curvature of the rotating wavefront. ${ }^{13}$ When tissue excitability is depressed, the curvature of the wavefront may prohibit an abrupt turn around the end of a line of block. Because the wavefront is 'forced' to make a wider turn with a lesser curvature, the tachycardia cycle length will prolong and the excitable gap will become wider. Indeed, in a canine model of reentrant ventricular tachycardia (VT), Coromilas et al. ${ }^{3}$ found that flecainide preferentially slowed conduction at the two pivot points of the central line of functional block and increased the size of the 
reentrant circuits. As a result, the VT cycle length prolonged from 171 to $210 \mathrm{~ms}$. Since flecainide had only minor effects on the refractory period, the temporal excitable gap during VT prolonged with about $40 \mathrm{~ms} .^{3}$ Ortiz et al. ${ }^{23}$ studied the effects of moricizine on atrial flutter due to functional reentry in the free wall of the canine right atrium. Also in the atrium, this class IC drug prolonged the reentrant cycle length mainly by slowing of conduction at the pivot points. We estimate that the observed increase in atrial flutter cycle length from $133 \pm 9$ to $172 \pm 27 \mathrm{~ms}$ was accompanied by a widening of the excitable gap of about $30 \mathrm{~ms} .{ }^{23}$ Flecainide also exerts a clear anti-arrhythmic effect on atrial fibrillation (AF) ${ }^{24}$ In a goat model of persistent $\mathrm{AF}$, Wijffels et al. ${ }^{6}$ recently showed that flecainide prolonged the AF cycle length from $91 \pm 8 \mathrm{~ms}$ to $134 \pm 8 \mathrm{~ms}$. This prolongation in AF cycle length was associated with a marked widening of the temporal excitable gap during AF. At high concentrations of a class I drug, about half of the AF cycle turned out to be excitable. ${ }^{6}$ Although our study was performed in ventricular myocardium, it may offer a possible explanation for the observed widening of the excitable gap during $\mathrm{AF}$. If flecainide prolongs the delay at pivot points of fibrillation waves, this is expected to widen the temporal excitable gap during atrial fibrillation. 


\section{References}

1. Allessie MA, Lammers WJEP, Bonke FIM, J. H. Experimental evaluation of Moe's multiple wavelet hypothesis of atrial fibrillation. In: Zipes DP, Jalife J, eds. Cardiac Arrhythmias. New York: Grune \& Stratton. 1985:265-276.

2. El Sherif N, Smith RA, Evans K. Canine ventricular arrhythmias in the late myocardial infaretion period. 8. Epicardial mapping of reentrant circuits. Circ Res. 1981;49:255-65.

3. Coromilas J, Saltman AE, Waldecker B, Dillon SM, Wit AL. Electrophysiological effects of flecainide on anisotropic conduction and reentry in infarcted canine hearts. Cinculation. 1995;91:2245-63.

4. Wang Z, Page P, Nattel S. Mechanisms of flecainide antiarrhythmic action in experimental atrial fibrillation. Circ Res. 1992;71:271-287.

5. Wang Z, Pelletier L, Talajic M, Nattel S. Effects of flecainide and quinidine on human atrial action potentials: Role of rate-dependence and comparison with guinea pig, rabbit, and dog tis. sues. Circulation. 1990;82:274-283.

6. Wijffels MCEF, Dorland R, Mast F, Allessie MA. Widening of the excitable gap during pharmacological cardioversion of atrial fibrillation in the goat. Effects of cibenzoline, hydroquinidine, flecainide and d-sotolol. Circulation. 2000;102:260-267.

7. Cabo C, Pertsov AM, Baxter WT, Davidenko JM, Gray RA, Jalife J. Wave-front curvature as a cause of slow conduction and block in isolated cardiac muscle. Circ Res. 1994;75:1014-28.

8. Girouard SD, Pastore JM, Laurita KR, Gregory KW, Rosenbaum DS. Optical mapping in a new guinea pig model of ventricular tachycardia reveals mechanisms for multiple wavelengths in a single reentrant circuit. Circulation. 1996;93:603-13.

9. Danse P, Garratt C, Mast F, Allessie M. Preferential depression of conduction around a pivot point in rabbit ventricular myocardium by potassium and flecainide. $J$ Cardiovascular Electrophysiology. 2000;11:262-73.

10. Schalij MJ, Lammers WJEP, Rensma PL, Allessie MA. Anisotropic conduction and reentry in perfused epicardium of rabbit left ventricle. Am J Physiol. 1992;263:H1466-H1478.

11. Allessie MA, Hoeks APG, Schmitz GML, Reneman RS. On-line mapping system for the visualization of the electrical activation of the heart. Int J Candiac Imag. 1986;2:59-63.

12. Dillon SM, Allessie MA, Ursell PC, Wit AL. Influences of anisotropic tissue structure on reentrant circuits in the epicardial border zone of subacute canine infarcts. Circ Res. 1988;63:182-206.

13. Fast VG, Kleber AG. Role of wavefront curvature in propagation of cardiac impulse. Cardiovasc Res. 1997:33:258-71.

14. Spach MS, Dolber PC. Relating extracellular potentials and their derivatives to anisotropic propagation at a microscopic level in human cardiac muscle. Evidence for electrical uncoupling of side-to-side fiber connections with increasing age. Circ Res. 1986;58:356-71.

15. Spach M. High resolution of cardiac electrical sources. Use of the derivatives of extracellular potential waveforms. J Electrocandiol. 1989;22 (Suppl):109-124.

16. Billette J. Atrioventricular nodal activation during premature stimulation of the atrium. $\mathrm{Am} J$ Physiol. 1987;252:H163-177.

17. Boersma L, Brugada J, Kirchhof C, Allessie M. Mapping of reset of anatomic and functional reentry in anisotropic rabbit ventricular myocardium. Circulation. 1994;89:852-62.

18. Sugiura $\mathrm{H}$, Johner $\mathrm{R}$. Action potential conduction between guinea pig ventricular cells can be modulated by calcium current. Am J Physiol. 1992;263:H1591-1604.

19. Joyner RW, Kumar R, Wilders R, Jongsma HJ, Verheijck EE, Golod DA, Van Ginneken AC, Wagner MB, Goolsby WN. Modulating L-type calcium current affects discontinuous cardiac action potential conduction. Biophys $J$. 1996;71:237-45.

20. Shaw RM, Rudy Y. lonic mechanisms of propagation in cardiac tissue. Roles of the sodium and L-type calcium currents during reduced excitability and decreased gap junction coupling. Cir Res. 1997;81:727-41.

21. Rohr S, Kucera JP. Involvement of the calcium inward current in cardiac impulse propagation: induction of unidirectional conduction block by nifedipine and reversal by Bay K 8644 . Biophys $\mathcal{L}$ 1997:72:754-66. 
22. Cabo C, Pertsov AM, Davidenko JM, Baxter WT, Gray RA, Jalife J. Vortex shedding as a precursor of turbulent electrical activity in cardiac muscle. Biophys $J$. 1996;70:1105-11.

23. Ortiz J, Nozaki A, Shimizu A, Khrestian C, Rudy Y, Waldo AL. Mechanism of interruption of atrial flutter by moricizine. Electrophysiological and multiplexing studies in the canine sterile pericarditis model of atrial flutter. Cinculation. 1994;89:2860-9.

24. Crijns HJGM, Wijk vLM, Gilst vWH, Kingma HJ, Van Gelder IC, Lie KI. Acute conversion of atrial fibrillation to sinus rhythm: clinical efficacy of flecainide acetate. Comparison of two regimes. Eur Heart J. 1988;1988:634-638. 
Chapter 3 
Chapter 4

\title{
Reentrant Ventricular Tachycardia in Isolated
}

\author{
Rabbit Hearts with a Healed
}

\author{
Myocardial Infarction
}

Peter W. Danse, MD; Mattias Duytschaever, MD; Jannie Ausma, PhD; Peter Kelderman, BS; Maurits A. Allessie, MD, PhD 
Chapter 4

As retcrad 3

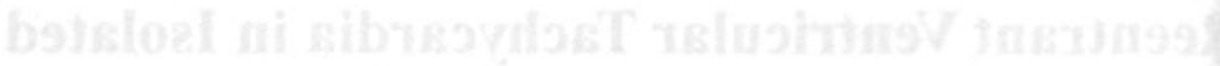

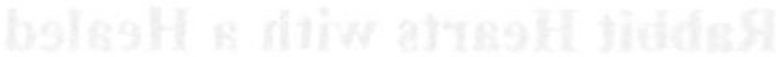

$-82$. 


\section{Introduction}

Since the early seventies, clinical electrophysiological studies have provided extensive evidence that ventricular tachycardia (VT) in the chronic phase of myocardial infarction is based on reentry. ${ }^{1,2}$ Catheter mapping has shown that these VT's usually arise from a subendocardial region. ${ }^{3}$ More detailed intraoperative mapping demonstrated that the endocardial origin of VT might be due to either a reentrant circuit in the endocardial borderzone itself, ${ }^{4,5}$ or to a macroreentrant circuit with an exit site towards the subendocardium. ${ }^{5}$ These anatomical circuits often comprise an area of slow conduction through the infarct, ${ }^{6}$ also known as 'slow conduction zone'? However, information on reentrant circuits causing VT in patients is limited since mapping can only be performed during relatively slow, hemodynamically stable VT. High resolution maps of complete reentrant circuits have only been obtained in a small subset of patients.

The most detailed information on reentrant circuits causing VT has been obtained from the canine model of 3-7 days old myocardial infarction. In this model of healing infarction, VT generally originates in the surviving epicardial border zone that overlies the infarcted area. ${ }^{89}$ Functional reentry circuits, either as a single loop, ${ }^{9}$ or in a figure-of-eight pattern, ${ }^{8}$ are the most common underlying mechanisms of VT. The nonuniform anisotropic structure of the border zone plays a key role in the course of these functional reentrant circuits. ${ }^{10}$ It is however unclear whether functional reentry is an important mechanism of VT in patients weeks to months after myocardial infarction. ${ }^{5,11}$

To facilitate further investigation on the mechanisms of reentrant VT occurring in the chronic phase of myocardial infarction, we developed a rabbit model of healed myocardial infarction in which reentrant VT can be induced and studied by high density mapping. In the epicardial borderzone of Langendorff perfused rabbit hearts with a 2-4 months old myocardial infarction, different types of reentrant VT were induced. As in humans, most VT's were based on anatomical reentry involving a zone of slow conduction through the scar. This rabbit model therefore offers a useful model to study the mechanisms of pathological conduction and reentry in healed myocardial infarction.

\section{Methods}

\section{Operation}

New Zealand rabbits, weighing between 3-4 kg, were used for this study. Myocardial infarction was produced by ligation of branches of the left anterior descending artery (LAD) and / or circumflex artery (RCX). All experiments were carried out according to the Dutch Law on Animal Experimentation and The European Directive for the Protection of Vertebrate Animals used for Experimental and other Scientific Purposes. The study protocol was approved by the Animal Investigation Committee of Maastricht University. The rabbits were anaesthetized with Hypnorm $0.5 \mathrm{ml} / \mathrm{kg}$ i.m (fentanyl citrate $0.315 \mathrm{mg} / \mathrm{ml}$, fluanisone $10 \mathrm{mg} / \mathrm{ml}$ ). After endotracheal intubation, the rabbits were ventilated with a mixture of $\mathrm{O}_{2}$ and $\mathrm{N}_{2} \mathrm{O}$ and halothane $1.5-2.5 \%$. A twelve lead electrocardiogram was 
recorded throughout the operation (Fig.1). A left thoracotomy was made through the fifth intercostal space, the lungs were held aside and the pericardium was opened. To produce an anterior myocardial infarction, a branch of the LAD or the RCX was selected for ligation. A suture was placed around the vessel, which could be tightened by a silicon tube. The selected artery was temporarily occluded, and the extent of ischemia was visually and electrocardiographically assessed for 5 minutes. In case ischemia was too extensive or severe ventricular arrhythmias occurred, the suture was removed. Otherwise, the artery was permanently ligated. If the ECG criteria for ischemia (ST-elevation $>2 \mathrm{~mm}$ in at least 3 precordial leads) were not met, another branch of the LAD or RCX was ligated. To prevent ventricular arrhythmias, lidocaine was infused throughout the procedure $(150 \mathrm{microgr} / \mathrm{kg} / \mathrm{min})$. In case ventricular arrhythmias occurred an additional bolus of $2 \mathrm{mg} / \mathrm{kg}$ lidocaine was given. After the procedure, the chest was closed and an intramuscular injection of ampicilline (250mg) and buprenofine $(0.04 \mathrm{mg} / \mathrm{kg})$ was given. The mortality rate during the operation was $15 \%$, mainly due to ventricular fibrillation. Post-operative mortality rate was $8 \%$.

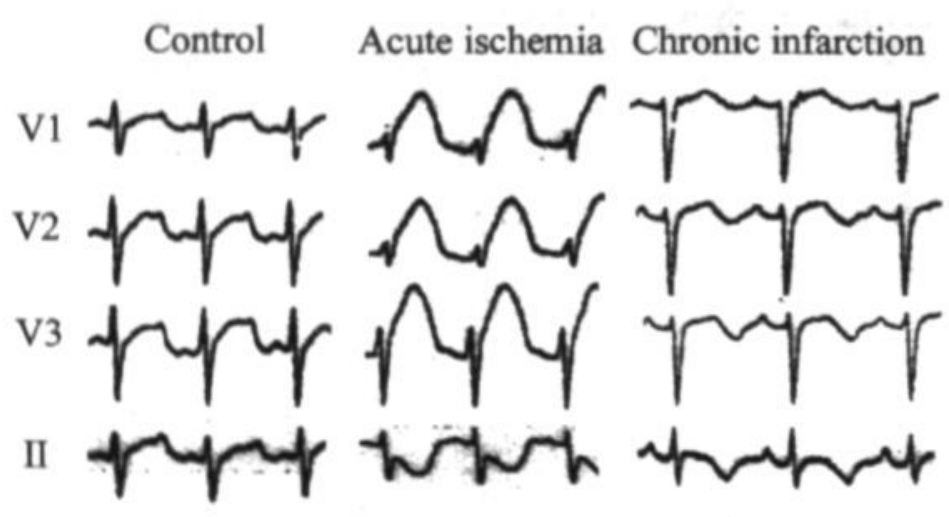

Figure 1. Three precondial leads (VI-V3) and lead II of a standand 12-lead surface ECG of the rabbit before, during, and 10 weeks after myocandial infarction. During acute ischemia, ST-elevation and peaked T-waves were observed in leads VI-V3 with reciprocal ST- depression in lead II. In the chronic phase of infarction, the anterior myocandial infarction could be recognized in leads VI-V3 by the reduced amplitude of the $R$-waves and biphasic $T$-waves.

\section{Isolated Preparation}

Two to four months after creating a myocardial infarction the rabbits were heparinized (1000 I.U.) and after sedation (Hypnorm $\mathbb{R}$ ) killed by cervical dislocation. The thorax was opened by a midsternal incision, and the heart was rapidly removed and placed in cold perfusion fluid $\left(10^{\circ} \mathrm{C}\right)$. The aorta was cannulated and perfused with a pressure of $60 \mathrm{~mm} \mathrm{Hg}$. The composition of the perfusion fluid was $(\mathrm{mM}) \mathrm{NaCl} 130, \mathrm{NaHCO}_{3} 20.1, \mathrm{KCl} 4.0$, $\mathrm{CaCl}_{2} 2.2, \mathrm{MgCl}_{2} 0.6, \mathrm{Na}_{2} \mathrm{HPO}_{4} 1.2$, glucose 12 . The solution was saturated with a mixture of $95 \% \mathrm{O}_{2}$ and $5 \% \mathrm{CO}_{2}$. The $\mathrm{pH}$ was 7.35 and temperature was kept at $37 \pm 0.2^{\circ} \mathrm{C}$. 


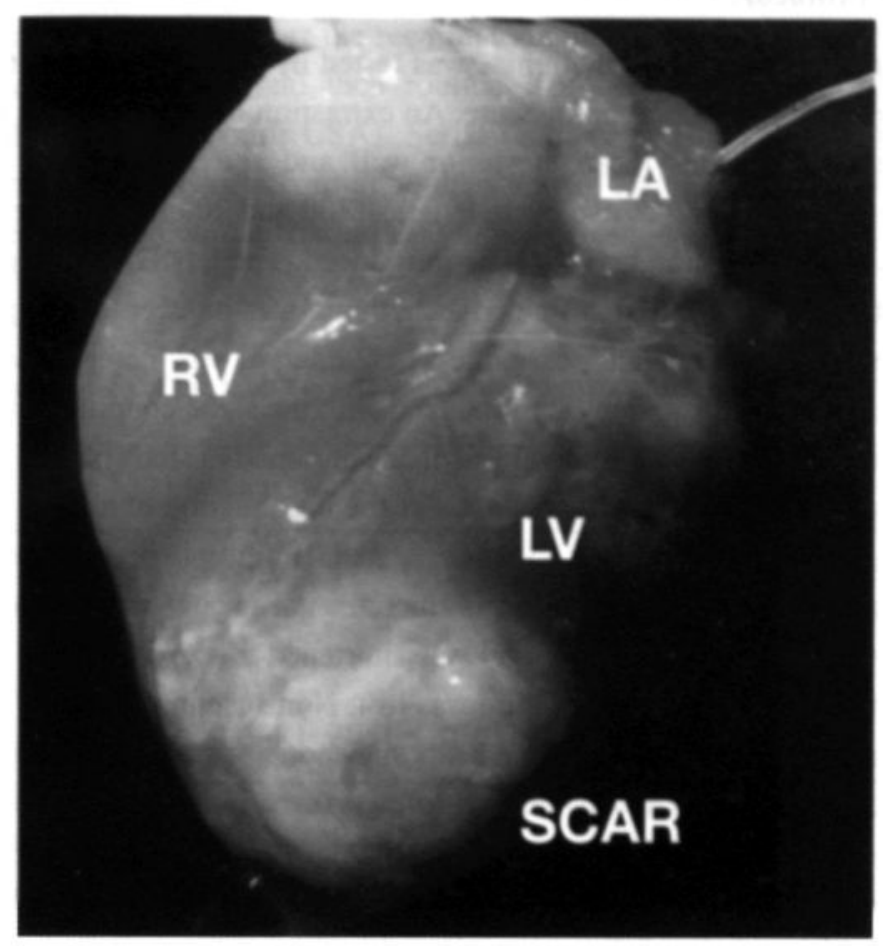

Figure 2. Photograph of the Langendorff perfused rabbit heart with a chronic myocardial infarction in the antero-apical region of the left ventricle. RV: right ventricle, $L V$ : left ventricle, LA: left atrium.

To create a thin layer of left ventricular subepicardium, a cryoprocedure was performed as described previously. ${ }^{12}$ First, the right ventricle was cryoablated by insertion of a cryoprobe (diameter $11 \mathrm{~mm}$ ) through the pulmonary artery and the right atrium. Then, the heart was immersed in a tissue bath of $37^{\circ} \mathrm{C}$ and the cryoprobe was inserted in the left ventricle for 10 minutes. As a result, the septum and endo- and midmyocardial layers of the free wall of the left ventricle were cryoablated. Only a thin sheet of left ventricular subepicardium (about $2 \mathrm{~mm}$ thick), including the healed myocardial infarction, was kept intact (Fig.2).

\section{Mapping and Stimulation}

The surface of the free wall of the left ventricle was mapped with a spoon-shaped mapping electrode containing 240 silver electrodes (diameter $0.3 \mathrm{~mm}$, spatial resolution $2.25 \mathrm{~mm}$ ). Unipolar electrograms were recorded simultaneously using the silver aortic cannula as indifferent electrode. After amplification (gain 300-2000) and filtering (bandwidth 1$500 \mathrm{~Hz}$ ) the signals were multiplexed, analog to digital converted ( 8 bits), and stored on videotape. Reference-electrodes were sutured on the left atrium and the posterior wall of the left ventricle. A computer-controlled custom-made stimulator was used for pacing with biphasic square pulses of $2 \mathrm{~ms}$ duration and four times diastolic threshold. 


\section{Experimental Protocol}

The inducibility of ventricular arrhythmias was tested by programmed electrical stimultion both before and after the cryoprocedure. An extrastimulus protocol was carried out t three epicardial pacing sites (base, posterior wall and apex). Premature stimuli wee applied during regular pacing at two cycle lengths ( 300 and $200 \mathrm{~ms})$. After every 20 basc stimuli (S1), a premature stimulus (S2) was introduced. The S1-S2 coupling interval ws decreased in steps of $5 \mathrm{~ms}$ until a sustained arrhythmia was induced or the premature \$mulus failed to capture. In the latter case, the S1-S2 interval was increased with $10 \mathrm{~ms}$ ad a second premature stimulus (S3) was introduced with the same coupling interval (S2-S) as the S1-S2 interval. The S2-S3 interval was then shortened in steps of $5 \mathrm{~ms}$ until a sustined arrhythmia occurred or capture was lost. For the introduction of a third premature smulus (S4), the same protocol as for $\mathrm{S} 3$ was repeated. If multiple premature stimuli faild to evoke a sustained ventricular arrhythmia, incremental pacing was performed. Aftera train of twenty stimuli, the pacing interval was shortened in steps of $10 \mathrm{~ms}$ until a sustined arrhythmia was induced or 1:1 capture was lost. Non sustained VT (NSVT) was deined as ventricular tachycardia of at least 3 beats and spontaneously terminating within les than 30 seconds. Sustained VT was defined as a regular monomorphic VT lasting forat least 30 seconds. Ventricular fibrillation (VF) was defined as a polymorphic ventricuar

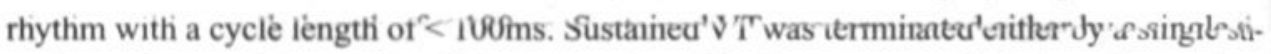
mulus or by overdrive pacing. VF was terminated by intracoronary infusion of potassium chloride.

The whole experiment was recorded on tape. After the experiment the electrograms were played back from tape for analysis. An algorithm was used to detect the steepest negative deflection in each electrogram as the moment of local activation. Color coded activation maps were generated automatically and edited when necessary. Isochrones were drawn manually at 10-ms intervals. Conduction velocity was measured from the distance between the isochrones. The circuit size of the reentrant circuits was measured by taking the shortest pathway of the circuit normal to the isochrones.

\section{Macroscopic and Microscopic Examination of the Infarcts}

A translucent copy of the spoon-shaped mapping array was used to evaluate the location of the epicardial scar relative to the mapping electrode. The infarcted area was drawn on a paper-copy of the mapping array and the size of the infarct was calculated by counting the number of electrodes on the scar. Since the surface of the mapping array (containing 240 equally spaced electrodes) covered an area of $11.2 \mathrm{~cm}^{2}$, the infarct size was calculated as the number of electrodes on the scar $/ 240 \times 11.2 \mathrm{~cm}^{2}$ (Table 1).

After the experimental procedure, the hearts were fixed by immersion in $10 \%$ phosphate buffered formalin. Seven hearts were selected for histological examination, based on the results of mapping. In 2 hearts the activation map during VT showed reentrant excitation 
around the scar, in 4 hearts the reentrant circuit comprised a segment of slow conduction through the scar, and in one heart the reentrant circuit was completely located within the scar. The scar was excised and then routinely processed and embedded in paraffin (Paraplast, Sherwood, Missouri, USA). Serial sections of $10 \mu \mathrm{m}$ were made and stained with haematoxylin and eosin according to the standard histological procedures. The serial sections were examined with a Nikon E800 light microscope.

Table 1. Characteristics of the rabbit hearts with a healed myocardial infarction ( $\mathrm{n}-62)$

\begin{tabular}{|c|c|c|c|c|c|c|}
\hline & \multicolumn{3}{|c|}{ Ligations (No.) } & \multicolumn{2}{|c|}{ Infarct size } & \multirow{2}{*}{$\begin{array}{r}\text { Infaret age } \\
\text { Weeks }\end{array}$} \\
\hline & Total & RCX & LAD & $\mathrm{cm}^{2}$ & $\%$ of LV & \\
\hline Range & $1-5$ & $0-5$ & $0-3$ & $0.7-4.7$ & 7.42 & $8-18$ \\
\hline Mean & $2.4 \pm 1.3$ & $2.0 \pm 1.1$ & $0.5 \pm 0.7$ & $2.0 \pm 0.8$ & $18 \pm 7$ & $13 \pm 3$ \\
\hline
\end{tabular}

RCX , LAD indicates side branches of respectively the circumflex and left anterior descending artery. $L V=$ left ventricle.

\section{Results}

\section{Inducibility of Ventricular Arrhythmias}

In Fig. 3 the inducibility of ventricular arrhythmias in 62 isolated hearts with a chronic infarction and 8 control hearts is shown both before and after the cryoprocedure. Before endocardial cryoablation (intact heart), the inducibility of VT, NSVT and VF was higher in the infarcted hearts than in controls. In intact control hearts sustained monomorphic VT could not be induced by programmed electrical stimulation. NSVT and VF could only be initiated by at least 3 premature beats or incremental pacing. In the infarcted hearts VT was induced in $8 \%$ of cases. NSVT and VF already occurred after 1 or 2 premature beats. VF was initiated by multiple premature stimuli in $47 \%$, compared to $13 \%$ in controls.

After the cryoprocedure, the inducibility of VF had decreased markedly. Instead, sustained VT was now initiated in $25 \%$ of controls and in $66 \%$ of infarcted hearts. In normal hearts VT could only be initiated by incremental pacing whereas in the infarcted hearts $35 \%$ of the VT's were induced by multiple premature beats. NSVT also occurred more often in the infarcted hearts than in controls ( $40 \%$ versus $22 \%$ ) and were induced by less aggressive pacing.

No correlation was found between the inducibility of VT and either the size $(\mathrm{p}=0.38)$ or age $(\mathrm{p}=0.82)$ of the myocardial infarctions. 

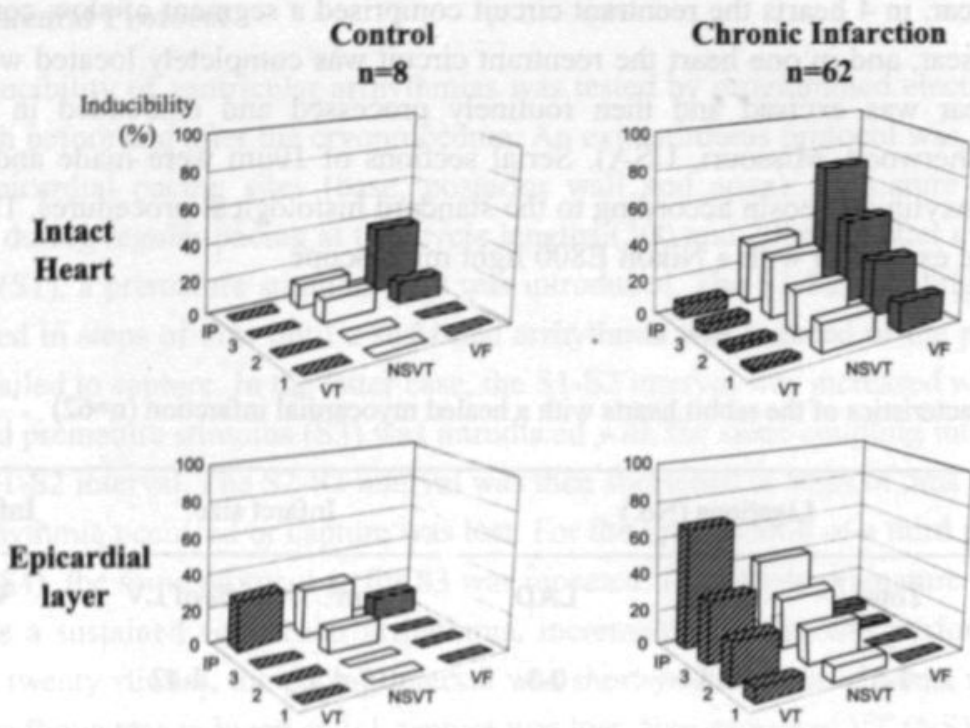

Figure 3. Inducibility of ventricular arrhythmias in 62 rabbit hearts with a chronic myocardial infarction and in 8 hearts without an infarct (controls), both before (intact heart) and after the cry. oprocedure (surviving epicardial layer). The cumulative inducibilty is shown after respectively one, two and three premature beats (1,2,3) and incremental pacing (IP). Both before and after the cryoprocedure, the inducibility of ventricular arrhythmias in the hearts with a chronic myocardial infarction was higher than in controls. In the intact heart, electrical stimulation induced $V F$ in $70 \%$ of infarcted hearts. Instead, in the epicardial layer a sustained VT was induced in $66 \%$ of hearts. $V T$ : ventricular tachycardia; NSVT: non sustained VT; VF: ventricular fibrillation.

\section{Epicardial Mapping of VT}

In 41 hearts with a chronic infarction, 67 different monomorphic VTs were induced. Most VTs continued for hours at a constant interval if not terminated by electrical stimulation. Mapping of the epicardial activation during VT revealed four different types of reentrant circuits. In 16\% ( $n=11)$ VT was based on reentry around the scar. The majority of VTs $(61 \%, n=41)$ were based on a reentrant circuit comprising a slow conduction zone through the infarct. In the other cases, the reentrant circuit was either located completely within $(12 \%, n=8)$ or outside the infarcted area $(10 \%, n=7)$.

\section{Reentry around the scar}

Fig. 4 shows an example of a reentrant VT around the infarct. The impulse rotated in a counterclockwise direction around the scar with a revolution time of $128 \mathrm{~ms}$. Due to the anisotropic properties of the subepicardium, the conduction velocity around the myocardial infarct varied. At the free wall of the left ventricle the impulse propagated parallel to the epicardial fiber orientation at a conduction velocity of $70 \mathrm{~cm} / \mathrm{s}$. In the corridor between the scar and the LAD the wavefront propagated perpendicular to the fibers at a reduced speed of $30 \mathrm{~cm} / \mathrm{s}$. Biphasic electrograms with a steep negative deflection and an isoelectri- 

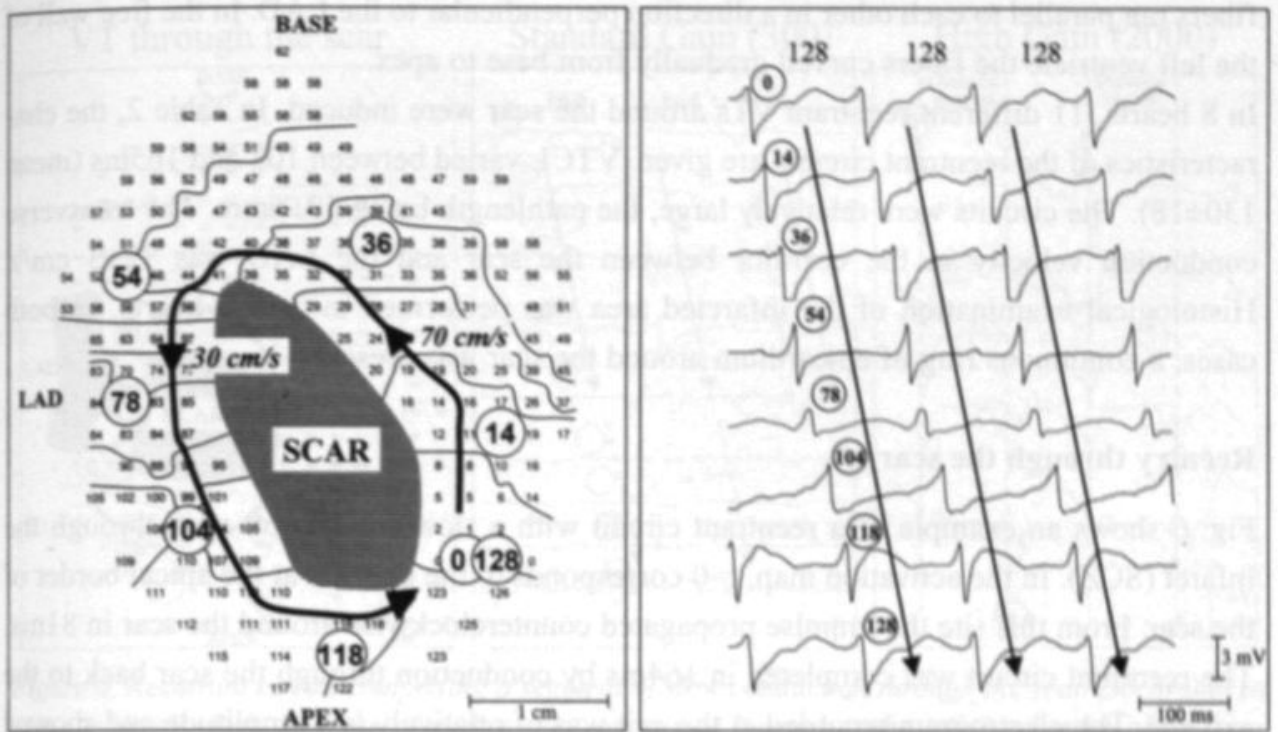

Figure 4. Reentrant VT around the scar. Numbers indicate local activation times in ms. Isochnones are dnawn at $10 \mathrm{~ms}$ intervals. At the free wall of the left ventricle the impulse propagated parallel to the epicandial fiber orientation with a conduction velocity of $70 \mathrm{~cm} / \mathrm{s}$. In the corridor between the scar and the left anterior descending artery (LAD) the wavefront propagated perpendicular to the fibers at a reduced speed of $30 \mathrm{~cm} / \mathrm{s}$.

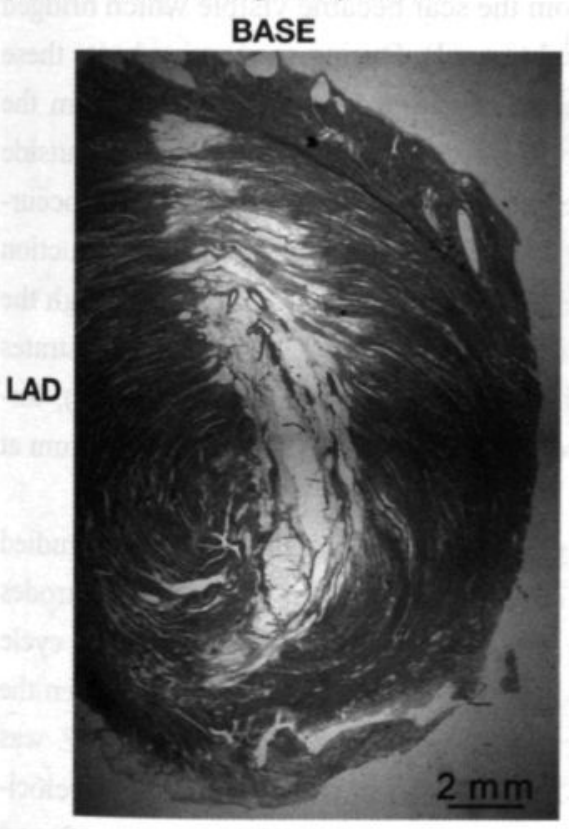

APEX
Figure 5. Photograph of the substrate of the VT around the scar, as shown in Fig. 4 (haematoxylin and eosin staining). In the center of the preparation scar tissue is visible as the lighter staining. The colored myocytes around the scar formed a continuous ring of viable myocardium. In the corridor between the scar and the LAD the fibers run parallel to the $A V$-groove. In the free wall, the fibers curve gradually from base to apex.

cal segment were recorded during the whole cycle of the VT. Histological examination of the left ventricle showed a continuous ring of ventricular myocardium around the fibrotic tissue of the scar, as illustated in Fig. 5. In the corridor between the scar and the LAD the 
fibers ran parallel to each other in a direction perpendicular to the LAD. In the free wall of the left ventricle the fibers curved gradually from base to apex.

In 8 hearts, 11 different reentrant VTs around the scar were induced. In Table 2, the characteristics of the reentrant circuits are given. VTCL varied between 108 and $165 \mathrm{~ms}$ (mean $130 \pm 18$ ). The circuits were relatively large, the pathlength being $59 \pm 6 \mathrm{~mm}$. The transverse conduction velocity in the corridor between the scar and the LAD was $32 \pm 3 \mathrm{~cm} / \mathrm{s}$. Histological examination of the infarcted area was performed in 2 of 8 hearts. In both cases, a continuous ring of epicardium around the scar was present.

\section{Reentry through the scar}

Fig. 6 shows an example of a reentrant circuit with a slow conduction zone through the infarct (SCZ). In the activation map, $\mathrm{t}=0$ corresponds to the exit site at the apical border of the scar. From this site the impulse propagated counterclockwise around the scar in $81 \mathrm{~ms}$. The reentrant circuit was completed in $164 \mathrm{~ms}$ by conduction through the scar back to the exit site. The electrogram recorded at the exit was of relatively low amplitude and showed a QS morphology (upper and lower electrogram in middle panel). During normal amplification of the electrograms (gain 300), the connecting pathway through the scar could not be detected (electrograms in grey area). Due to the apparent absence of electrical activity in the scar, a diastolic interval of $83 \mathrm{~ms}$ was present during the VT cycle of $164 \mathrm{~ms}$. However, at high gain $(2000 \mathrm{x})$ small potentials from the scar became visible which bridged the diastolic interval between $t=81$ and $164 \mathrm{~ms}$ (right panel). During successive beats these small potentials were fixed in time. The amplitude of the potentials recorded from the infarcted region was about $0.2 \mathrm{mV}$ compared to $1-3 \mathrm{mV}$ from the epicardial layer outside the scar. Assuming that conduction of the impulse between the entrance and exit site occurred along a straight line, the length of the SCZ was $12 \mathrm{~mm}$ and the apparent conduction velocity through the $\mathrm{SCZ}$ was $14 \mathrm{~cm} / \mathrm{s}$. The presence of a connecting pathway through the scar was confirmed by histological examination of the infarcted area. Fig. 7 demonstrates the presence of several isolated bundles surrounded by fibrotic scar tissue (arrows), forming an almost continuous tract of surviving myocytes between the viable myocardium at the upper and lower side of the infarcted area.

In three experiments, impulse propagation through the slow conduction zone was studied in more detail by a rectangular mapping array $(7.5$ by $7.5 \mathrm{~mm})$ containing 248 electrodes with an interelectrode distance of $500 \mu \mathrm{m}$. Fig. 8 shows an example. The VT with a cycle length of $128 \mathrm{~ms}$ was based on a clockwise reentrant loop comprising a SCZ between the inferior and superior border of the scar (upper left map). The length of the SCZ was $7.75 \mathrm{~mm}$ and the conduction time through the $\mathrm{SCZ}$ was $68 \mathrm{~ms}$ (apparent conduction velocity $11 \mathrm{~cm} / \mathrm{s})$. The mapping array was positioned on the scar between the entrance $(t=60)$ and exit $(t=0)$ of the SCZ (middle panel). The grey part of the map indicates the area of the infarction from which no electrical activity was recorded. The activation map of the SCZ shows that the entrance $(t=60)$ and exit $(t=0)$ were connected by several distinct pathways which converged into a common pathway towards the exit site. To localize and quantify the 
Activation map

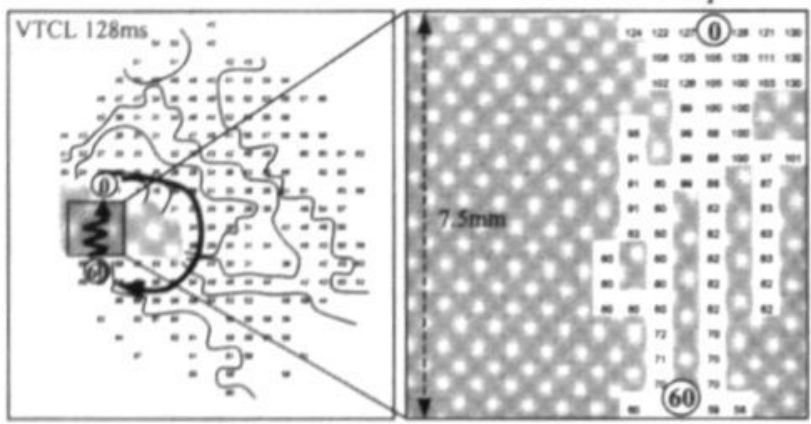

Phase map
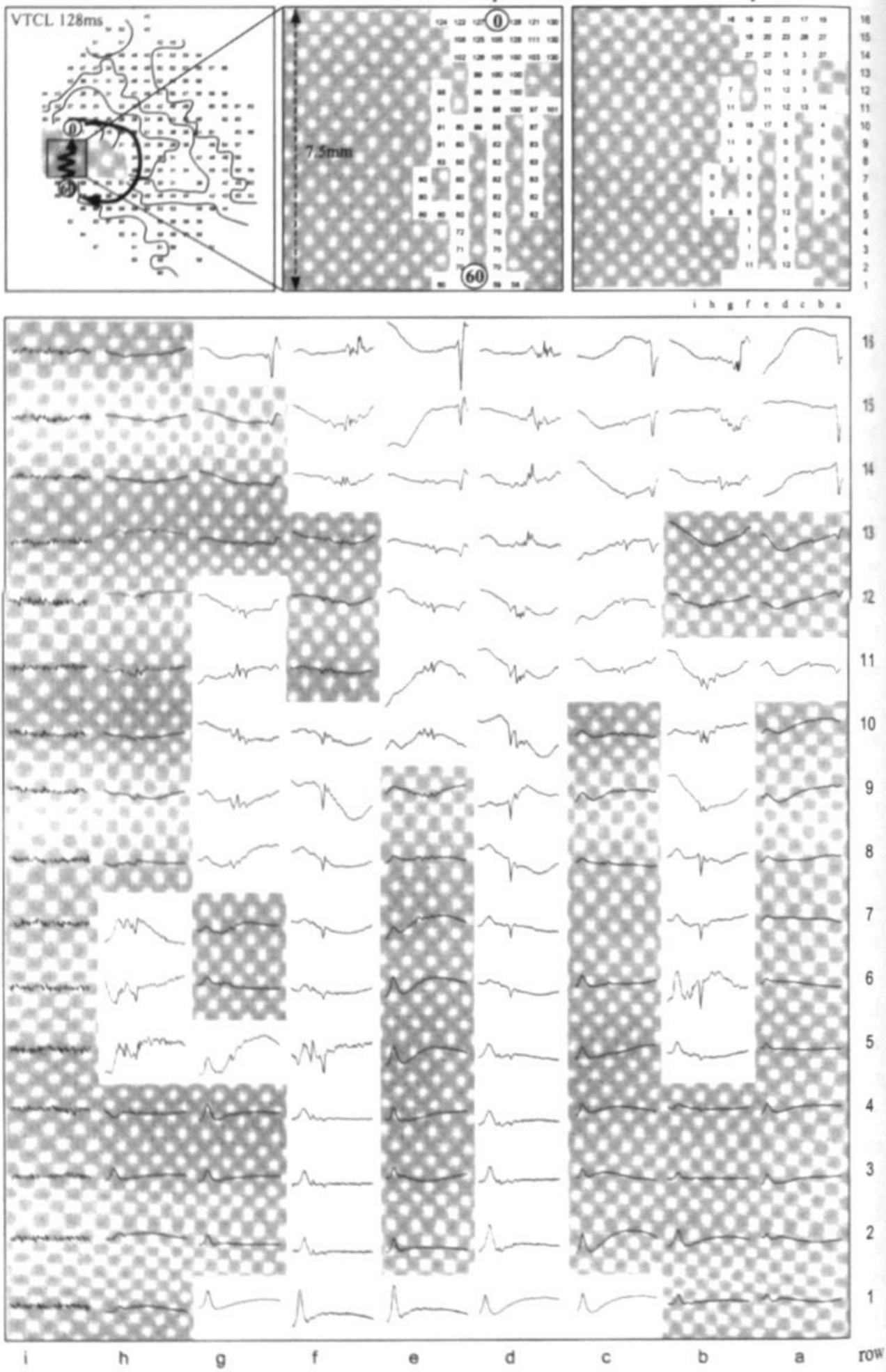
Left: Figure 8. High resolution mapping (interelectrode distance $500 \mu \mathrm{m}$ ) of the slow conduction zone (SCZ) during $V T$ with a cycle length of $128 \mathrm{~ms}$. The rectangular mapping array (7.5 by $7.5 \mathrm{~mm}$ ) was positioned between the entrance $(t=60)$ and exit $(t=0)$ of the $S C Z$ (upper left map). The high density activation map in the middle illustrates the routes of propagation between the entrance and exit site from $t=60$ to $t=128 \mathrm{~ms}$ ). For each rectangular arnay the largest local difference in activation time was plotted as a phase map (right panel). A large phase difference, indicating slow or discontimuous conduction, was found at the entrance and exit site of the SCZ and at branching points within the scar. Lower panel: Unipolar electrograms reconded from the SCZ (gain 2000x). The mumbers and letters correspond with the rows and collums of the phase map. Double potentials and fractionated electrognams were observed in the common pathway towands the exit (now 11-15) and at branching points.

spatial inhomogeneity in conduction, the maximal differences in activation time were calculated at each quadruplet of electrodes (phase map). Slow conduction, as indicated by a large local phase difference, occurred at the entrance and the exit of the SCZ and at branching points of the several pathways within the scar. At the exit, local differences in activation time as large as $28 \mathrm{~ms}$ were found, indicating a local conduction velocity of less than $2 \mathrm{~cm} / \mathrm{s}$. Electrical activation of the distinct pathways occurred almost simultaneously (phase $=0 \mathrm{~ms}$ ). The electrograms recorded from the SCZ are shown in the lower panel. At the entrance (row 1) a single positive deflection was recorded. At the starting point of the pathways through the scar (lane $\mathrm{d}$ and $\mathrm{f}$ ), the main positive deflection was followed by a second response of low amplitude (row 2-4). In both pathways, between the strands of electrically dead tissue (grey area), single potentials were observed. At branching points the electrograms were fractionated. In the common pathway towards the exit (row 11-15) double potentials and fractionated electrograms were recorded. At the exit (row 16), both single negative deflections and fragmented electrograms were recorded, suggesting dissociated conduction over (functionally) separated pathways.

In 26 hearts, 41 different VTs with a SCZ were induced. During all VTs, high amplification of electrograms recorded from the scar showed small diastolic potentials. The characteristics of the reentrant circuits are given in Table 2 . The large diversity in reentrant circuits is illustrated by the wide range in VTCL (103-274ms), circuit size (29-79mm), length of the SCZ (7-41 mm), apparent conduction velocity within the SCZ $(9-69 \mathrm{~cm} / \mathrm{s})$ and conduction time through the SCZ (13-244ms). In most cases, the conduction velocity through the SCZ $(20 \pm 10 \mathrm{~cm} / \mathrm{s})$ was slower than normal slow conduction transverse to the fibers as recorded during VTs around the scar $(32 \pm 3 \mathrm{~cm} / \mathrm{s}, \mathrm{p}<0.01)$. High resolution mapping $(500 \mu \mathrm{m})$ of the SCZ was performed in 3 experiments. In all cases, pathways of electrical activity within the scar could be demonstrated. Conduction through the infarct was largely inhomogeneous. The difference in activation times between adjacent electrodes varied from 0 (simultaneous excitation) to $40 \mathrm{~ms}$ (conduction velocity $1.25 \mathrm{~cm} / \mathrm{s}$ ). Histological examination of the infarcted area was performed in 4 of 26 hearts. In all cases, surviving muscle bundles were observed separated by connective tissue of the healed infarcts. 


\section{Reentry within the scar}

Fig. 9 shows the activation map of a VT with a cycle length of $112 \mathrm{~ms}$ originating from within the scar. The site of earliest activation was located at the left upper border of the scar (exit \#1 at $\mathrm{t}=0$ ). Two other exit sites were present, one at $\mathrm{t}=19 \mathrm{~ms}$ (exit \#2 at the right upper border of the infarct) and one at $\mathrm{t}=97 \mathrm{~ms}$ (exit \#3 at the inferior border). The two wavefronts emerging from the superior border of the scar collided at the base of the left ventricle at $t=27 \mathrm{~ms}$. At the site of collision the electrogram showed double potentials (middle panel) The dominant wave during VT originated from the right upper border of the scar and rota. ted clockwise around the infarct. However, instead of entering the infarcted area, it collided with the third wavefront emerging from the inferior border $(\mathrm{t}=113)$. Again, double potentials were recorded at the site of collision (middle panel). High gain recordings $(2000 \mathrm{x})$ from the scar showed highly fragmented low amplitude electrograms (right panel). Actually, the multiple components (arrows) recorded from the three electrodes in the center of the infarcted region covered the whole VT cycle length (continuous electrical activity). From the distance between the electrodes it was estimated that the reentrant circuit was confined to an area of about $7 \mathrm{~mm}^{2}$ with an estimated pathlength of $16 \mathrm{~mm}$. For reentry to occur in such a small area, the average conduction velocity must be less than $15 \mathrm{~cm} / \mathrm{s}$. Fig. 10 shows the anatomical substrate of this VT. In the infarcted region several small areas of surviving myocytes were observed (left panel). These viable bundles were usually in the proximity of a blood vessel. In the right panel, part of the infarcted area is shown at higher magnification. Two bundles with a different geometry can be seen. In one bundle, the myocytes were still closely packed and arranged in a longitudinal fashion, whereas in the other bundle the individual myocytes were separated by fibrotic tissue.

In 6 hearts, 8 different VTs originating from within the scar were induced (Table 2). In all cases, high amplification of the signals recorded from the scar revealed electrical activity during the whole VT cycle length. The VTs originating from within the scar were relatively fast (VTCL $120 \pm 9, \mathrm{n}=8)$. The estimated pathlength was relatively short $(20 \pm 5 \mathrm{~mm})$ and the estimated average conduction velocity around the circuit was $17 \pm 5 \mathrm{~cm} / \mathrm{s}$.

\section{Functional reentry outside the scar}

Fig. 11 shows an example of a functional reentrant circuit completely outside the infarcted region. The cycle length was very short with beat to beat alternation between 93 and $96 \mathrm{~ms}$. The impulse circulated in a counterclockwise direction around a small line of functional conduction block, oriented parallel to the epicardial fiber orientation. During pivoting around the ends of the line of block the conduction velocity was depressed. Especially at the pivot point near the LAD a marked crowding of isochrones was observed corresponding to a local conduction velocity of $16 \mathrm{~cm} / \mathrm{s}$. At the pivot points fragmented electrograms of low amplitude were recorded (at $\mathrm{t}=26$ and $81 \mathrm{~ms}$ in right panel). At the border of the infarct (asterisk) VT cycle length was $189 \mathrm{~ms}$ because the reentrant impulse was conducted in a $2: 1$ manner. 
VT within the scar

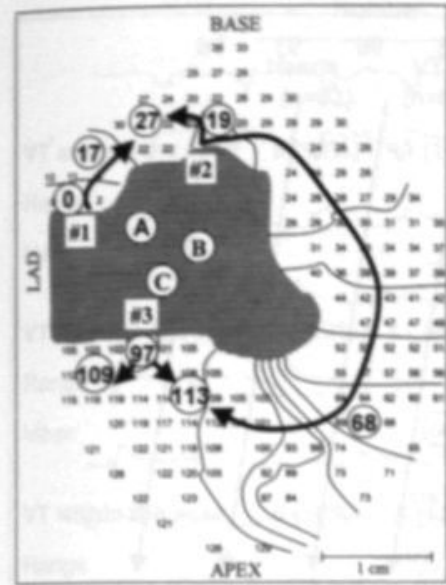

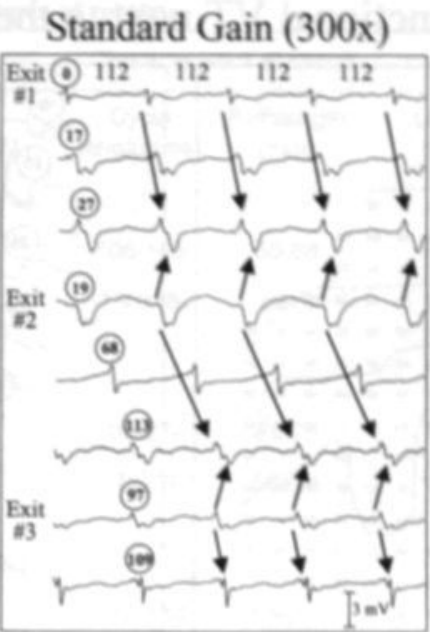

Figure 9. Reentry within the scar. Left: The site of earliest activation was located at the superior border of the scar $(t=0)$. Next to this exit site (HI), two more exit sites were present (H2 and $\# 3)$. The three wavefronts emerging from these exit sites collided in the free wall of the left ventricle at $t=27 \mathrm{~ms}$ (base) and $t=113 \mathrm{~ms}$ (apex). Middle: Unipolar electrognams reconded at normal gain (300x) anound the scar (location indicated by the encircled activation times). Right: At high gain settings (2000x) the electrograms recorded from within the scar showed a high degree of fragmentation. Small multiple deflections were present during the whole cycle length of the tachycardia (continuous electrical activity).
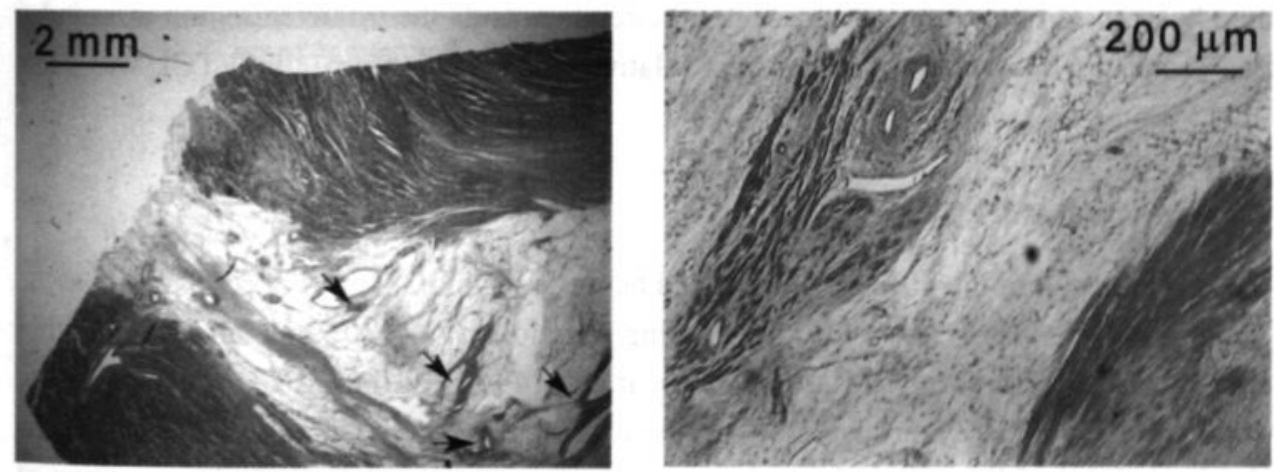

Figure 10. The substrate of the VT originating from within the scar shown in Fig.6. Left: In the infarcted region several small bundles of surviving myocytes can be seen (arrows). Right: Two bundles with a different kind of morphology at higher magnification. One bundle (lower right) consisted of myocytes closely packed in a longitudinal fashion. In the other bundle (upper left), each myocyte was surrounded by fibrotic tissue. Note that these myocytes were located in the proximity of small blood vessels. Haematoxylin and eosin staining. 


\section{Functional VT next to the scar}
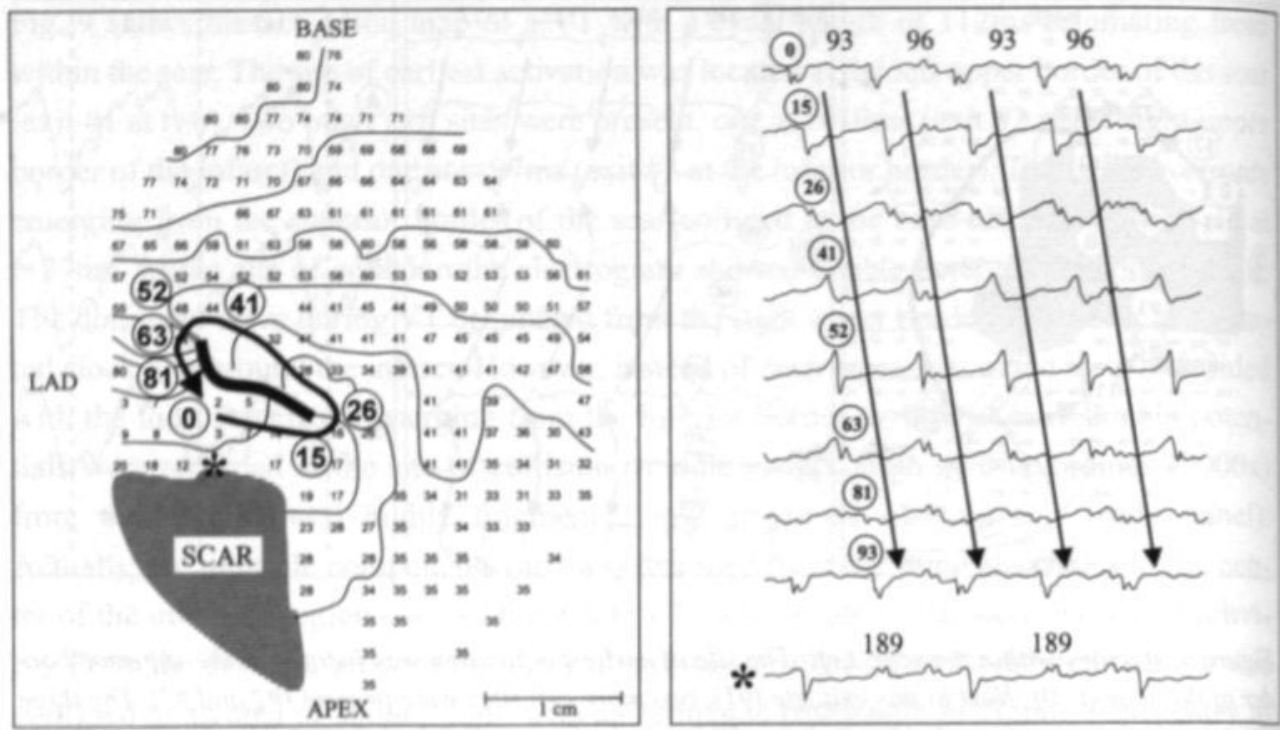

Figure 11. Functional reentry outside the scar. Left: The thick black line indicates the central line of functional conduction block parallel to the epicardial fiber orientation. Isochnones at $10 \mathrm{~ms}$ intervals. Right: Seven selected electrograms around the line of functional block (location indicated by encircled activation times). At either end of the line of functional block (pivot points) the electrograms were fractionated $(t=26, t=63 / 81)$. At the border of the scar 2:1 conduction block occurred (asterisk).

In 6 hearts, 7 different functional reentrant circuits outside the infarcted region were induced (Table 2). Because the circuits were relatively small $(24 \pm 6 \mathrm{~mm})$, the VTCL was short $(111 \pm 12 \mathrm{~ms})$.

\section{Slow versus Fast VT's}

The cycle length of the different VTs varied between 93 and $274 \mathrm{~ms}$. Fig. 12 shows that the mean VT cycle length was $111 \pm 12 \mathrm{~ms}$ during functional VT, $120 \pm 9 \mathrm{~ms}$ during VT within the scar, $130 \pm 18 \mathrm{~ms}$ during VT around the scar and $149 \pm 37 \mathrm{~ms}$ during VT involving a slow conduction zone (SCZ) through the scar. Fast VTs with a cycle length of less than $150 \mathrm{~ms}$ (horizontal dotted line) could be based on all four types of reentry. With the exception of two VTs around the scar, all "slow" VTs (CL $>150 \mathrm{~ms})$ were based on anatomically defined reentry comprising a $\mathrm{SCZ}$ through the scar.

The cycle length of the VTs around the scar varied between 108 and $165 \mathrm{~ms}$. These differences were mainly due to differences in length of the segment of slow transverse conduction around the scar. Fast VTs showed a relatively short segment of transverse conduction, whereas slow VTs comprised a longer segment of transverse conduction $\left(R^{2} 0.61, p<0.05\right)$. The cycle length of VT through the scar was mainly determined by the conduction time through the SCZ, as illustrated in Fig. 13. The conduction time through the SCZ was relatively short during fast VTs, whereas during slow VTs the conduction time through the 
Table 2. Characteristics of different types of reentry

\begin{tabular}{|c|c|c|c|c|c|c|c|}
\hline & \multicolumn{2}{|c|}{ Number } & \multicolumn{2}{|c|}{ Characteristics of circult } & \multicolumn{3}{|c|}{ Segment of slow conduction } \\
\hline & $\begin{array}{l}\text { Hearts } \\
(n=62)\end{array}$ & $\begin{array}{l}V T \\
(n=67)\end{array}$ & $\begin{array}{c}\text { Cycle } \\
\text { length (ms) }\end{array}$ & $\begin{array}{l}\text { Pathlength } \\
\text { (mm) }\end{array}$ & $\begin{array}{l}\text { Length } \\
(\mathrm{mm})\end{array}$ & $\begin{array}{l}\text { Conduction } \\
\text { velocity }(\mathrm{cm} / \mathrm{s})\end{array}$ & $\begin{array}{l}\text { Conduction } \\
\text { time (ms) }\end{array}$ \\
\hline$V T$ around the scar & $8(13 \%)$ & $11(16 \%)$ & & & & & \\
\hline Range & - & - & $108-165$ & $50-68$ & $11-20$ & $\theta, 28-35$ & $32-72$ \\
\hline Mean & - & - & $130 \pm 18$ & $59 \pm 6$ & $13 \pm 3$ & $\theta, 32 \pm 3$ & $48 \pm 17$ \\
\hline VT through the scar & $26(42 \%)$ & $41(61 \%)$ & & & & & \\
\hline Range & - & - & $103-274$ & $29-79$ & $7-41^{\prime}$ & $\theta_{n} 9-69^{\prime}$ & $13-244$ \\
\hline Mean & - & - & $149 \pm 37$ & $50 \pm 14$ & $16 \pm 8^{\prime}$ & $\theta_{w} 20 \pm 10^{\prime *}$ & $85 \pm 43^{*}$ \\
\hline$V T$ within the scar & $6(10 \%)$ & $8(12 \%)$ & & & & & \\
\hline Range & - & - & $110-134$ & $13-27^{2}$ & - & $\theta_{\omega} 11-25^{2}$ & - \\
\hline Mean & - & - & $120 \pm 9$ & $20 \pm 5^{2}$ & - & $\theta_{s e} 17 \pm 5^{2 *}$ & - \\
\hline Functional VT & $6(10 \%)$ & $7(10 \%)$ & & & & & \\
\hline Range & - & - & 94-130 & $18-32$ & - & - & - \\
\hline Mean & - & - & $111 \pm 12$ & $24 \pm 6$ & - & - & - \\
\hline NoVT & $21(34 \%)$ & - & - & - & - & - & - \\
\hline
\end{tabular}

$\Theta_{\mathrm{T}}$ indicates transverse conduction velocity, $\Theta_{\mathrm{M}}$ conduction velocity through the scar.

$1=$ estimated value assuming a straight conduction pathway through the scar.

${ }^{2}=$ estimated value assuming a circuit in between electrodes showing multicomponent electrograms which all together covered the whole VTCL (continuous electrical activity).

$\cdot=p<0.05$ versus VT around the scar (unpaired T-test).

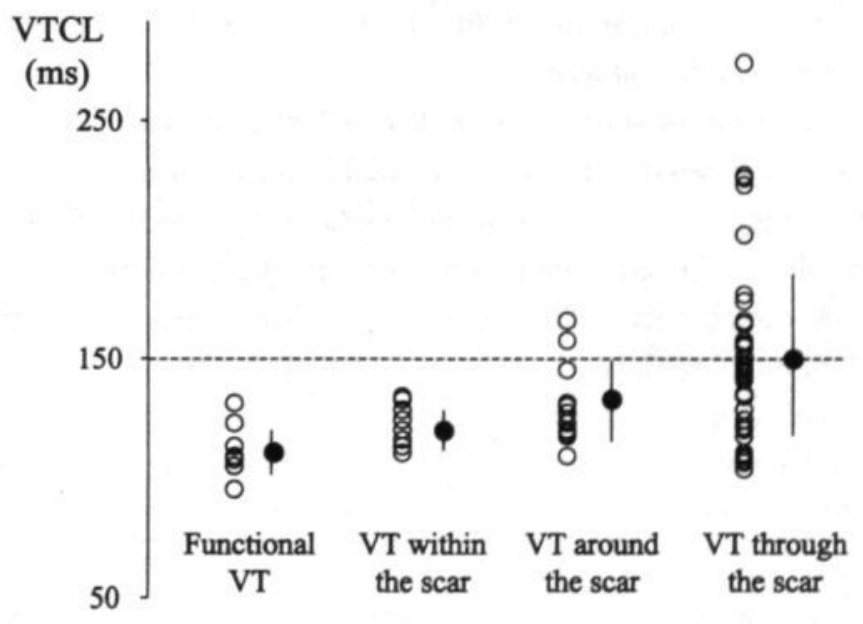

Figure 12. Cycle length of the different types of VT. The majority of the slow VTs (CL $>150 \mathrm{~ms}$, horizontal dotted line) were based on a reentrant circuit with a slow conduction zone through the scar. 


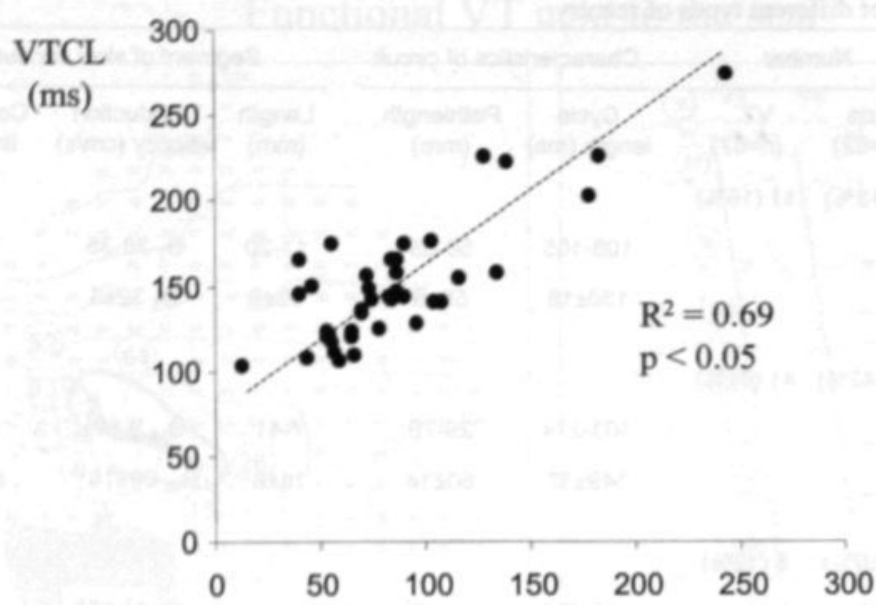

Conduction time through infarct (ms)

Figure 13. Relationship between the conduction time through the scar (abscissa) and VT cycle length (ondinate).

$\mathrm{SCZ}$ was much longer $\left(\mathrm{R}^{2} 0.69, \mathrm{p}<0.05\right)$. No correlation was found between the VTCL and the length of the $\mathrm{SCZ}\left(\mathrm{R}^{2} 0.23, \mathrm{p}=\mathrm{NS}\right)$. This can be explained by the large variation in conduction velocity through the infarct (range $9-69 \mathrm{~cm} / \mathrm{s}$ ).

\section{Different VT's in a Single Heart}

In 21 hearts, different VTs with varying morphology and/or cycle length were induced. This pleomorphism was due either to a different exit site $(n=5)$ or to a change in direction of rotation of the reentrant impulse $(n=9)$. In 7 hearts, VTs with a same morphology but different cycle length could be induced.

The upper two panels of Fig.14 show an example of VT pleomorphism due to a change in exit site. Both VTs were based on a reentrant circuit through the scar. The exit site $(t=0)$ of the VT with a cycle length of $110 \mathrm{~ms}$ was located at the lateral border of the infarct, whereas the exit of the slower VT (CL $146 \mathrm{~ms})$ was located more inferiorly. The electrograms in the upper and lower left corner of the map show a change from a QS morphology at the exit sites to an RS morphology after the exit site had shifted.

The two middle panels demonstrate pleomorphism of VT due to a change in direction of rotation. The cycle length of the clockwise $(222 \mathrm{~ms})$ and counterclockwise VT (226ms) were similar, indicating that the reentrant pathway during both VTs was the same. However, the morphology of the electrograms differed depending on the direction of rotation. During the clockwise VT a low amplitude negative potential was recorded at the exit site at the superior border of the scar and a high amplitude biphasic potential at the inferior border. During counterclockwise VT the exit site at the inferior border of the scar now showed a QS morphology. 

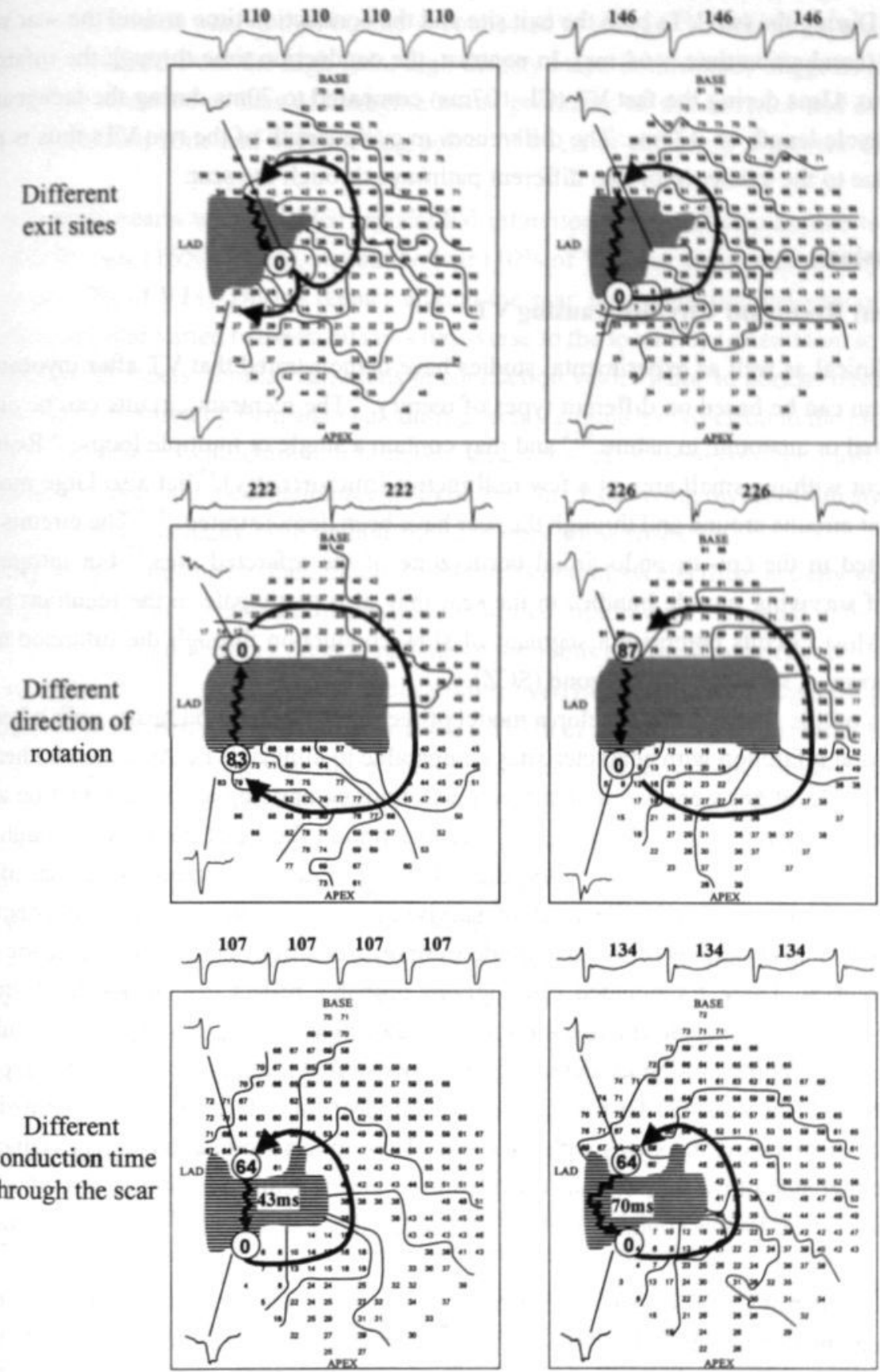

Figure 14 Three examples of VT pleomorphism. Isochrones at 10ms intervals. Zig-zag arrows indicate slow conduction through the scar. Top: Two VTs with different exit sites. Middle: Two VTs with different direction of the circulating impulse. Bottom: Two VTs with same exit site and direction of rotation but with different cycle length. The difference in VT cycle length $C L$ is probably due to the presence of two distinct pathways through the scar. 
The lower panels of Fig. 14 show two VTs with the same morphology but of different cycle length. During the two VTs both the exit site and the conduction time around the scar were similar (conduction time $=64 \mathrm{~ms}$ ). In contrast, the conduction time through the infarcted area was $43 \mathrm{~ms}$ during the fast VT (CL 107ms) compared to $70 \mathrm{~ms}$ during the tachycardia with a cycle length of $134 \mathrm{~ms}$. The differences in cycle length of the two VTs thus is probably due to the existence of two different pathways through the scar.

\section{Discussion}

\section{Different Reentrant Circuits Causing VT}

Both clinical as well as experimental studies have demonstrated that VT after myocardial infarction can be based on different types of reentry. ${ }^{13}$ The reentrant circuits can be either functional or anatomic in nature, ${ }^{9,14}$ and may contain a single or multiple loops. ${ }^{7,8}$ Reentry can occur within a small area of a few millimetres (microreentry), ${ }^{15}$ but also large macroreentrant circuits around and through the scar have been demonstrated. ${ }^{14.16}$ The circuits can be located in the epi- or endocardial borderzone of the infarcted area, ${ }^{17}$ but intramural tracts of surviving muscle bundles in the scar may also participate in the reentrant pathway. ${ }^{14}$ Most circuits comprise a segment of slow conduction through the infarcted area, also known as slow conduction zone (SCZ). ${ }^{\dagger}$

The aim of this study was to develop a model of reentrant VT in rabbit hearts with a healed myocardial infarction with characteristics comparable to clinical VTs. As in human hearts, most VTs (41 of 68 ) were based on a reentrant circuit comprising a slow conduction zone through the infarcted area. We were not able to pinpoint the exact pathways through the infarct in most experiments. However, the following arguments support that part of the reentrant circuit consisted of a tract of surviving myocytes in the infarcted area: (1) Fractionated electrograms of low amplitude were recorded from the scar, bridging the diastolic interval. These fractionated electrograms probably reflect discontinuous electrical activation of viable muscle fibers within the infarcted area. ${ }^{18-20}$ (2) In 3 experiments, ultrahigh density mapping of the infarcted region demonstrated the presence of electrical pathways through the scar. (3) Histological examination of the infarcted area confirmed the presence of surviving myocytes within the scar. These tracts seemed to connect viable tissue at either side of the infarct, thus completing an anatomically determined circuit. (4) In most cases the effective conduction velocity through the scar was slow (between 10 and 25 $\mathrm{cm} / \mathrm{s})$.

Similar reentrant circuits containing a tract of surviving myocytes within the scar have been demonstrated by de Bakker et al. in chronically infarcted hearts of patients. ${ }^{5.6}$ In their study, the effective conduction velocity through the infarct was about $20-30 \mathrm{~cm} / \mathrm{s}^{5}$. They showed that 'slow' conduction through the infarcted area actually was due to zigzag conduction at normal velocity over long pathways of surviving myocytes separated by connective tissue. ${ }^{20}$ Slow conduction through a myocardial infarction can also be caused by 
depressed excitability of the surviving myocytes, ${ }^{21}$ reduced cellular coupling, ${ }^{22}$ or source to sink mismatches when a thin bundle is connected to a larger volume of myocardium. ${ }^{23}$ The data obtained from the high gain, high density maps in this study suggests that slow conduction occurred at sites of changing tissue geometry, as the entrance and exit of the slow conduction zone and at branching points of tracts of surviving myocytes within the scar.

In the rabbit hearts with a healed myocardial infarction VT could also be due to reentry around the scar ( $16 \%$ of VTs), within the scar ( $10 \%$ of VTs), or functional reentry outside the scar ( $10 \%$ of VTs). During reentry around the scar, the conduction velocity of the circulating impulse varied between $30 \mathrm{~cm} / \mathrm{s}$ transverse to the local fiber orientation to $70 \mathrm{~cm} / \mathrm{s}$ parallel to the fibers. Similar variations in conduction velocity due to normal tissue anisotropy were measured by Brugada et al. during reenty around a cryolesion in the rabbit ventricle. ${ }^{24}$ In patients with chronic infarction and a ventricular aneurysm, the most obvious pathway for circulating excitation seems to be the rim of surviving myocardium around the scar, but this has actually been demonstrated in only a few cases.

During reentry confined to the infarcted area itself continuous electrical activity was recorded from the infarct. These circuits within the healed infarct were estimated to be as small as $5-10 \mathrm{~mm}^{2}$ (microreentry). Also in patients, continuous electrical activity can sometimes be recorded from a small area of endocardium overlying the infarct, suggesting microreentry as the underlying mechanism of $\mathrm{VT}^{25}$ Spach et al. calculated that when the myocardial fibers are separated by fibrotic tissue (non-uniform anisotropy) reentry can occur in areas as small as 1-4 mm ${ }^{2} .{ }^{26}$ Reentry on such a small scale is possible because the conduction velocity in nonuniform anisotropic myocardium may be as slow as $1-5 \mathrm{~cm} / \mathrm{s} .{ }^{10}$ Nonuniform anisotropic structure also seems to play a key role in functional reentrant VT in the epicardial borderzone of canine myocardial infarction. ${ }^{8,10}$ Schalij et al. ${ }^{12}$ showed that uniform anisotropy of normal ventricular myocardium is sufficient to cause functional reentrant VT. In our study, functional reentry was also observed occasionally in the noninfarcted part of the ventricle. As in the study of Schalij et al. ${ }^{12}$ the cycle length of these functional VTs was very short.

\section{Pleomorphism of VT}

In patients suffering from VT in the chronic phase of myocardial infarction, often multiple VT's with different morphologies can be induced. Catheter mapping during VT has shown that changes in QRS morphology are associated with a change in the site of earliest endocardial activation. ${ }^{27}$ Experimental studies using high density mapping have demonstrated that differences in exit site can be due either to different locations of the central common pathway or to a different direction of rotation of the reentrant impulse. ${ }^{28,29}$ In our study, these causes of pleomorphism were all observed (Fig.14). We further showed that also different VTs with a same morphology but with different cycle length could be indu- 
ced in the same heart. In these cases the location of the exit site remained the same, but two different pathways were present in the scar. Information about the presence of multiple pathways through the scar may be important for effective ablation of the arrhythmogenic substrate of VT.

\section{Benefits and Limitations of the Model}

The aim of this study was to develop a rabbit model of healed myocardial infarction to help elucidate the different mechanisms causing reentrant ventricular tachyarrhythmias after myocardial infarction in humans. The intrinsic limitation of this model off course is that it is not identical to the pathophysiological substrate of reentrant VT in humans: (1) The rabbit heart is much smaller than the human heart. (2) In the intact (three dimensional) rabbit heart with a healed myocardial infarction, VF rather than VT was induced by programmed electrical stimulation. Only after cryoablation of the complete right ventricle, the interventricular septum and the endo- and midmyocardial layers of the left ventricle, VT was induced in a substantial amount of hearts (66\%). (3) Due to the cryoprocedure, the complex 3 D architecture of chronic myocardial infarction is reduced. In patients, thin intramura strands of surviving muscle bundles in the infarct may be involved in the reentrant pathway. (4) Unlike the clinical substrate of VT, our preparations are not under the influence of coronary ischemia or variations in neurohumoral balance. ${ }^{30} \mathrm{~A}$ further limitation of the study was that in most experiments we were not abie to pinpoim the exact pathrway throught the infarct and that we have not determined the electrophysiological mechanisms of slow conduction in the infarcted area.

Since characteristics of VT after myocardial infarction have already been extensively studied in canine hearts with a chronic myocardial infarction, one can ask what the additional value of a rabbit model is. (1) Use of rabbit hearts is more practical in terms of costs, housing and laboratory equipment and therefore large series can be obtained more easily. (2) The Langendorff perfused preparations offer the possibility to study the mechanisms of both relatively slow and fast VTs, whereas detailed information on reentrant circuits in whole animals is limited to the slower hemodynamically tolerated VTs. (3) The thin layer of subepicardium allows two-dimensional (optical) mapping to study the reentrant circuit in great detail. (4) Reentrant VT in canine hearts has been mainly studied in the healing phase of infarction ( 3 to 5 days after infarction) because later after infarction VT is often no longer inducible. ${ }^{13}$ In contrast, the rabbit model consists of an epicardial borderzone containing an area of fully healed myocardial infarction (2-4 months old). In this phase, the surviving fibers in the infarcted area are more separated by connective tissue and the parallel orientation of the fibers has been lost. ${ }^{19}(5)$ Whereas in the epicardial borderzone of 3-5 days old canine infarction the reentrant circuits are usually functional in nature, in the rabbit model most VTs were based on an anatomically defined circuit. The different types of reentry are likely to respond differently to programmed electrical stimulation ${ }^{31}$ and antiarrhythmic drugs. ${ }^{32}$ 
As pointed out above, our rabbit model of healed myocardial infarction obviously is different from the substrate of clinical reentrant VT. Nevertheless, the histologic appearance of the resected infarcts in the rabbit bears close resemblance to human infarcts. The surviving myocytes in the infarcted area are clearly separated by connective tissue and formed continuous tracts which connected viable muscle at either side of the infarcted area. ${ }^{5.23}$ Therefore, we believe that this rabbit model of VT may be a useful tool to study the mechanisms of slow conduction and reentry in healed myocardial infarction which may help to understand the pathophysiological mechanisms of human VT. 


\section{References}

1. Wellens HJ, Schuilenburg RM, Durrer D. Electrical stimulation of the heart in patients with ventricular tachycardia. Circulation. 1972;46:216-26.

2. Wellens HJ, Lie KI, Durrer D. Further observations on ventricular tachycardia as studied by electrical stimulation of the heart. Chronic recurrent ventricular tachycardia and ventricular tachycardia during acute myocardial infarction. Circulation. 1974;49:647-53.

3. Josephson ME, Horowitz LN, Farshidi A, Spear JF, Kastor JA, Moore EN. Recurrent sustained ventricular tachycardia. 2. Endocardial mapping. Circulation. 1978;57:440-7.

4. Horowitz LN, Josephson ME, Harken AH. Epicardial and endocardial activation during sustained ventricular tachycardia in man. Circulation. 1980;61:1227-38.

5. de Bakker JM, van Capelle FJ, Janse MJ, Wilde AA, Coronel R, Becker AE, Dingemans KP, van Hemel NM, Hauer RN. Reentry as a cause of ventricular tachycardia in patients with chronic ischemic heart disease: electrophysiologic and anatomic correlation. Circulation. 1988;77:589-606.

6. de Bakker JM, van Capelle FJ, Janse MJ, van Hemel NM, Hauer RN, Defauw JJ, Vermeulen FE, Bakker de Wekker PF. Macroreentry in the infarcted human heart: the mechanism of ventricular tachycardias with a "focal" activation pattern. $J$ Am Coll Cardiol. 1991;18:1005-14.

7. Stevenson W, Khan H, Sager P, Saxon L, Middlekauff H, Natterson P, Wiener I. Identification of reentry circuit sites during catheter mapping and radiofrequency ablation of ventricular tachycardia late after myocardial infarction. Circulation. 1993;88:1647-70.

8. El Sherif N, Smith RA, Evans K. Canine ventricular arrhythmias in the late myocardial infarction period. 8. Epicardial mapping of reentrant circuits. Circ Res. 1981;49:255-65.

9. Wit AL, Allessie MA, Bonke Fl, Lammers W, Smeets J, Fenoglio JJ, Jr. Electrophysiologic mapping to determine the mechanism of experimental ventricular tachycardia initiated by premature impulses. Experimental approach and initial results demonstrating reentrant excitation. Am J Cardiol. 1982;49:166-85.

10. Dillon SM, Allessie MA, Ursell PC, Wit AL. Influences of anisotropic tissue structure on reentrant circuits in the epicardial border zone of subacute canine infarcts. Circ Res. 1988;63:182-206.

11. Almendral JM, Stamato NJ, Rosenthal ME, Marchlinski FE, Miller JM, Josephson ME. Resetting response patterns during sustained ventricular tachycardia: relationship to the excitable gap. Cinculation. 1986:74:722-30.

12. Schalij M, Lammers W, Rensma P, Allessie M. Anisotropic conduction and reentry in perfused epicardium of rabbit left ventricle. Am J Physiol. 1992;263:H1466-H1478.

13. Janse M, Wit A. Electrophysiosiological mechanisms of ventricular arrhythmias resulting from myocardial ischemia and infaretion. Physiol. Rev. 1989;69:1049-1169.

14. Bakker de J, Capelle van F, Janse M, Wilde A, Coronel R, Becker A, Dingemans K, Hemel van N, Hauer R. Reentry as a cause of ventricular tachycardia in patients with chronic ischemic heart disease: electrophysiologic and anatomic correlation. Circulation. 1988;77:589-606.

15. Josephson ME, Horowitz LN, Farshidi A, Spielman SR, Michelson EL, Greenspan AM. Sustained ventricular tachycardia: evidence for protected localized reentry. Am J Cardiol. 1978:42:416-24.

16. Miller J, Harken S, Hargrove W, Josephson M. Patterns of endocardial activation during sustained ventricular tachycardia. $J$ Am Coll Candiol. 1985;6:1280-1287.

17. Kaltenbrunner W, Cardinal R, Dubuc M, Shenasa M, Nadeau R, Tremblay G, Vermeulen M. Savard P, Page P. Epicardial and endocardial mapping of ventricular tachycardia in patients with healed myocardial infarction. Is the origin of the tachycardia always subendocardially localized? Cinculation. 1991:84:1058-1071.

18. Fenoglio JJ, Jr., Pham TD, Harken AH, Horowitz LN, Josephson ME, Wit AL. Recurrent sustained ventricular tachycardia: structure and ultrastructure of subendocardial regions in which tachycardia originates. Circulation. 1983:68:518-33 
19. Ursell PC, Gardner PI, Albala A, Fenoglio JJ, Jr., Wit AL. Structural and electrophysiological changes in the epicardial border zone of canine myocardial infarcts during infaret healing. Circ Res. 1985;56:436-51.

20. de Bakker JM, van Capelle FJ, Janse MJ, Tasseron S, Vermeulen J, de Jonge N, Lahpor JR. Slow conduction in the infarcted human heart. 'Zigzag' course of activation. Circulation. 1993;88:915-26.

21. Pu J, Boyden P. Alterations of Na+ currents in myocytes from epicardial border zone of infarcted heart. A possible mechanism for reduced excitability and postrepolarization refractoriness. Circ Res. 1997;81:110-119.

22. Peters NS, Coromilas J, Severs NJ, Wit AL. Disturbed connexin43 gap junction distribution correlates with the location of reentrant circuits in the epicardial border zone of healing canine infarets that cause ventricular tachycardia. Circulation. 1997;95:988-96.

23. de Bakker JM, Coronel R, Tasseron S, Wilde AA, Opthof T, Janse MJ, van Capelle FJ, Becker AE, Jambroes G. Ventricular tachycardia in the infarcted, Langendorff-perfused human heart: role of the arrangement of surviving cardiac fibers. $\mathrm{J} \mathrm{Am} \mathrm{Coll} \mathrm{Candiol.}$ 1990;15:1594-607.

24. Brugada J, Boersma L, Kirchhof C, Heynen V, Allessie M. Reentrant excitation around a fixed anatomical obstacle in uniform anisotropic ventricular myocardium. Circulation. 1991;84:1296-1306.

25. Josephson ME, Horowitz LN, Farshidi A. Continuous local electrical activity. A mechanism of recurrent ventricular tachycardia. Circulation. 1978;57:659-65.

26. Spach MS, Dolber PC, Heidlage JF. Influence of the passive anisotropic properties on directional differences in propagation following modification of the sodium conductance in human atrial muscle. A model of reentry based on anisotropic discontinuous propagation. Circ Res. 1988;62:811-32.

27. Josephson ME, Horowitz LN, Farshidi A, Spielman SR, Michelson EL, Greenspan AM. Recurrent sustained ventricular tachycardia. 4. Pleomorphism. Circulation. 1979;59:45968.

28. Boersma L, Brugada J, Kirchhof C, Allessie M. Entrainment of reentrant ventricular tachycardia in anisotropic rings of rabbit myocardium. Mechanisms of termination, changes in morphology, and acceleration. Circulation. 1993;88:1852-65.

29. Ciaccio E, Scheinman M, Fridman V, Schmitt H, Coromilas J, Wit A. Dynamic changes in electrogram morphology at functional lines of block in reentrant circuits during ventricular tachycardia in the infarcted canine heart: a new method to localize reentrant circuits from electrogram features using adaptive template matching. J Cardiovasc Electrophysiol. 1999;10:194-213.

30. Inoue H, Zipes D. Results of sympathetic denervation in the canine heart: Supersensitivity that may be arrhythmogenic. Circulation. 1987;75:877.

31. Boersma L, Brugada J, Kirchhof C, Allessie M. Mapping of reset of anatomic and functional reentry in anisotropic rabbit ventricular myocardium. Circulation. 1994;89:852-62.

32. The Sicilian Gambit: A new approach to the classification of antiarrhythmic drugs based on their actions on arrhythmogenic mechanisms. Task force of the working group on arrhythmias of the European Society of Cardiology. Circulation. 1991;84:1915-1923. 
Chapter 4 


\section{Chapter 5}

\section{Differentiation of the Substrate of VT by Resetting}

Peter W. Danse, MD; Matthias Duytschaever, MD; Maurits A. Allessie, MD, PhD 
Chapter 5

$-108-$ 


\section{Introduction}

In patients suffering from ventricular tachycardia (VT) after myocardial infarction, the response of VT to electrical stimulation is diverse. Some VTs can easily be terminated by premature stimuli while others can not or are even accelerated. ${ }^{1.3}$ The return cycle after a premature impulse that resets the tachycardia can be shorter, longer or equal to the cycle length of the VT. ${ }^{3-5}$ Usually, the reset curve has a flat part which is taken as evidence for an anatomic reentrant circuit with a fully excitable gap. ${ }^{3-6}$ However, since clinical studies are usually done without mapping the exact propagation of the reentrant impulse in the circuit, the properties of the reentrant circuit that determine the various responses of VT to premature stimuli are not completely understood.

To further explore the effects of premature stimulation on reentrant VT, high resolution mapping of the reentrant circuit during resetting has been performed in a number of experimental studies. ${ }^{7.9}$ In a rabbit model of anatomic reentrant VT, Haberl et al. recently reported a differential reset response depending on whether the area of slow conduction was caused by depression of the active membrane currents or by electrical uncoupling. ${ }^{10} \mathrm{We}$ developed a model of reentrant VT in Langendorff perfused layers of rabbit subepicardium containing an area of healed myocardial infarction. In some hearts VT was due to reentry around the scar, while in other hearts VT was based on a reentrant circuit comprising a slow conduction zone through the infarcted area. In this study, we investigated whether the reset response of a VT around the scar was different than that of a VT with a slow conduction zone through the scar and which properties of the reentrant circuit determine the response of VT to premature stimuli.

\section{Methods}

\section{Preparation}

In 19 Langendorff perfused rabbit hearts with a healed myocardial infarction (2-4 months old), a thin layer of left ventricular subepicardium was created by a cryoprocedure. The complete surgical procedure, the cryoprocedure, and the perfusion system have been described in detail in Chapter 4.

\section{Mapping and Stimulation}

The epicardium of the left ventricle was mapped with a spoon-shaped mapping array containing 240 silver electrodes (diameter $0.3 \mathrm{~mm}$ ) with an interelectrode distance of $2.25 \mathrm{~mm}$. Bipolar stimulation could be performed through any selected pair of electrodes in the electrode array. The on-line mapping system to record and analyze the data was described in Chapter 4 . Activation maps were generated by the computer. If necessary, the maps were edited by inspection of the individual electrograms and the pattern of activation around the recording site. Isochrones were drawn manually at $10-\mathrm{msec}$ intervals. Local conduction velocities were calculated normal to the isochrones. The circuit size of the reentrant circuits was measured by taking the shortest pathway of the circuit normal to the isochrones. 


\section{Experimental Protocol}

Sustained monomorphic VT was induced by programmed electrical stimulation using $1-3$ premature stimuli or incremental pacing. During VT, single premature stimuli $(4 \mathrm{x}$ threshold) were applied proximal to the area of slow conduction. An electrogram recorded adjacent to the pacing site was used to synchronize the stimulator. The last activation preceding the stimulus was defined as V1. The 2 beats following the premature stimulus were defined as V2 and V3. A complete reset curve was made by shortening the coupling interval between V1 and the stimulus (S) in steps of $2 \mathrm{~ms}$. The exact V1-S coupling interval was determined by correction for small differences in activation time between the pacing and sensing site. The excitable gap (EG) was measured as the range of coupling intervals that resulted in reset or termination of VT. The flat part of the reset curve was taken as the fully EG, whereas the partially EG was taken as the difference between the total EG and the fully EG.

In 8 hearts, the excitability threshold and the effective refractory period (ERP) were meas. ured at multiple sites within the scar, the borderzone of the infarct $(<1 \mathrm{~cm}$ from the scar) and the non-infarcted part of the left ventricle ( $>1 \mathrm{~cm}$ from the scar). During regular pacing (S1-S1) with an interval of 350 or $200 \mathrm{~ms}$, the ERP was measured by applying a single pre. mature stimulus (S2, 4x threshold) after every 20th basic interval. Starting well within the refractory period, the S1-S2 coupling interval was incremented in steps of $2 \mathrm{msec}$. The shortest $\mathrm{S} 1-\mathrm{S} 2$ interval that resulted in a propagated response was taken as the ERP.

\section{Statistical Analysis}

Results were compared using the unpaired Student's t-test and linear regression as indicated. P-values of less than 0.05 were taken as statistically significant.

\section{Results}

\section{Reset of VT around the scar}

Fig. I shows the activation map and the reset curve of a VT around the scar with a cycle length of $119 \mathrm{~ms}$. During reentrant excitation around the scar the conduction velocity varied in different parts of the circuit. At the free wall of the left ventricle the impulse propagated parallel to the epicardial fiber orientation with a conduction velocity of $70 \mathrm{~cm} / \mathrm{s}$. In the corridor between the scar and the LAD the wavefront propagated perpendicular to the fibers at a reduced speed of $30 \mathrm{~cm} / \mathrm{s}$. VT was reset by applying single premature stimuli proximal to the area of transverse conduction. The reset curve was almost completely flat. Only the earliest premature stimuli $(<76 \mathrm{~ms})$ caused a slight prolongation of the return cycle of the VT (V2-V3). After the earliest premature stimulus (V1-S $68 \mathrm{~ms}$ ) the return cycle was only $6 \mathrm{~ms}$ longer than the VTCL (V2-V3 $125 \mathrm{~ms}$ ). The fully excitable gap (EG) was $35 \mathrm{~ms}$ and the partially EG $10 \mathrm{~ms}$. The VT could not be terminated by a single premature stimulus. 


\section{VT through the scar}

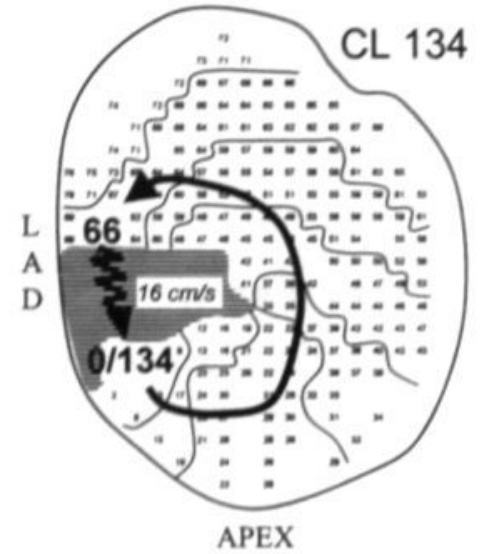

Reset of VT

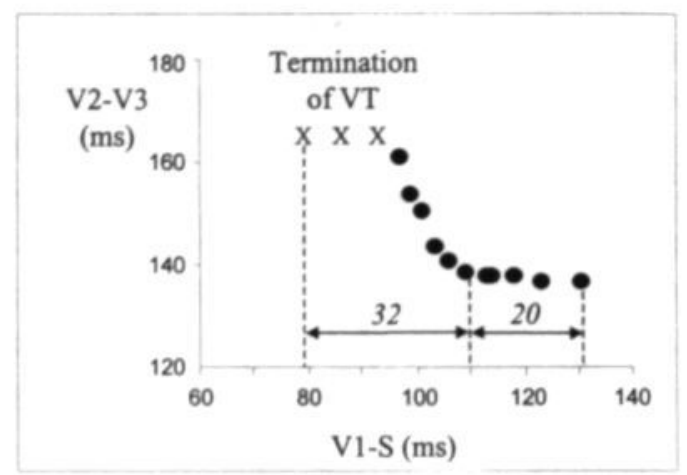

Figure 2. Left: Activation map showing a VT through the scar with a cycle length of $134 \mathrm{~ms}$. The site of earliest activation was located at the inferior border of the scar $(t=0)$. The conduction time through the scar between the entrance and the exit was $68 \mathrm{~ms}$ (from $t=66 \mathrm{~ms}$ to $t=134 \mathrm{~ms}$ ). The zigzagged arrow indicates slow conduction. Isochrones at IOms intervals. Right: Reset curve of the VT through the scar. Pacing was performed proximal to the slow conduction zone through the infarct. The coupling interval of the premature stimulus (VI-S) was plotted on the abscissa and the return cycles $\left(V_{2}-V_{3}\right)$ on the ordinate. Prolongation of the return cycle (V2-V3) started at a relatively long coupling interval (VI-S: 108ms) while premature stimuli with coupling intervals between 94 and $78 \mathrm{~ms}$ terminated the tachycardia. The fully EG was $20 \mathrm{~ms}$ and the partially EG $32 \mathrm{~ms}$.

through the SCZ increased from $68 \mathrm{~ms}$ during the tachycardia (V1) to $93 \mathrm{~ms}$ after premature stimulation (V2). Therefore, the prolongation of the return cycle by $26 \mathrm{~ms}$ was almost totally due to conduction delay within the SCZ $(25 \mathrm{~ms})$. This conduction delay caused longer V1-V2 intervals at the exit of the SCZ, as shown by the spatial distribution of the V1$\mathrm{V} 2$ intervals around the circuit (lower left panel). At the exit site the V1-V2 interval $(126 \mathrm{~ms})$ was almost equal to the normal VTCL $(134 \mathrm{~ms})$ and the premature impulse had lost almost all its prematurity. Consequently the tachycardia was reset by only $8 \mathrm{~ms}$. The V1-V2 intervals at the entrance and exit of the SCZ are plotted for all V1-S coupling intervals in the lower right panel. During premature stimulation with a coupling interval < $106 \mathrm{~ms}$, the V1-V2 interval at the exit progressively prolonged relative to the V1-V2 interval at the entrance. The shortest attainable V1-V2 interval at the entrance was $86 \mathrm{~ms}(64 \%$ of VTCL) compared to $109 \mathrm{~ms}$ at the exit site ( $81 \%$ of VTCL).

\section{Termination of VT}

Fig. 4 shows an example of termination of VT by a single premature stimulus. The tachycardia was based on a counterclockwise reentrant circuit comprising a long segment of slow conduction through the scar. From the exit site at the apical border of the scar, the impulse was conducted at high speed around the scar (from $t=0$ to $t=55 \mathrm{~ms}$ ) and then pro- 


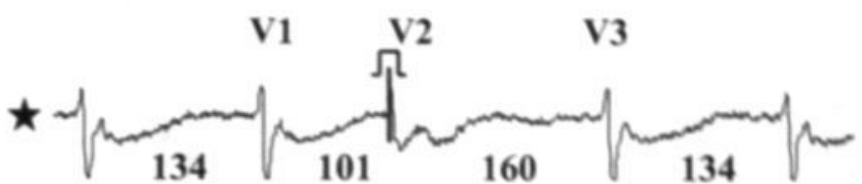

$V 1-S 96 m s$
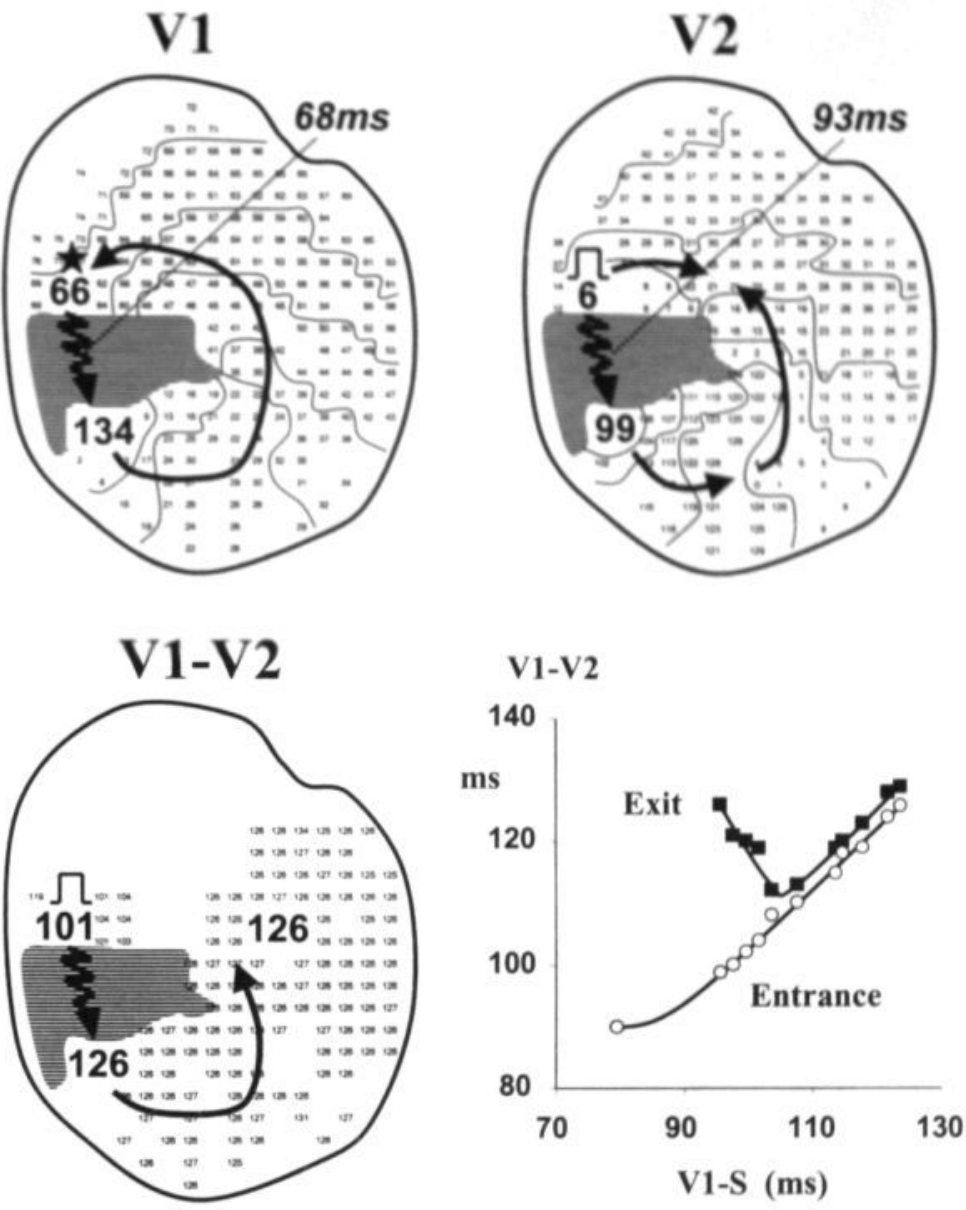

Figure 3. Reset of the VT through the scar (CL 134ms) by a premature stimulus with a coupling interval of $96 \mathrm{~ms}$. Same VT as shown in Fig.2. The premature stimulus shortened the V1-V2 interval at the pacing site to $101 \mathrm{~ms}$ with a prolongation of the V2-V3 interval to $160 \mathrm{~ms}$ (top). Two maps show the activation during VT (VI) and the premature impulse (V2). The conduction time through the infarct increased from $68 \mathrm{~ms}$ during $V T$ to $93 \mathrm{~ms}$ after premature stimulation proximal to the slow conduction zone. The VI-V2 interval map shows that the premature impulse (VI-V2: 101ms) had lost almost all its prematurity at the exit of the infarct (VI-V2: 126ms). Activation times are given in milliseconds and isochrones are drawn at $10 \mathrm{~ms}$ intervals. Arrows indicate the direction of propagation. The zigzagged arrow indicates slow conduction. Lower right panel: VI-V2 intervals at the entrance and exit of the infarct for all VI-S coupling intervals. At coupling intervals $<106 \mathrm{~ms}$, the VI-V2 interval at the exit progressively prolonged relative to the VI-V2 interval at the entrance. The shortest attainable VI$V 2$ interval at the exit of the infarct was $109 \mathrm{~ms}$ compared to $86 \mathrm{~ms}$ at the entrance. 


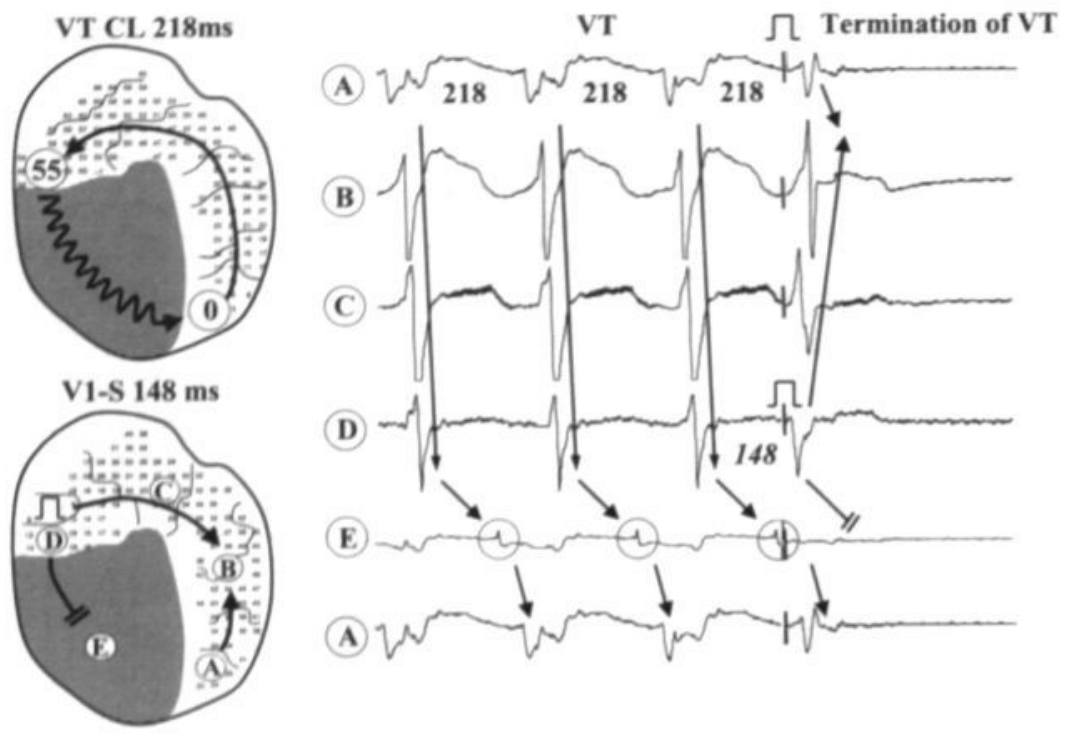

Figure 4. Termination of VT through the scar by a single premature stimulus. Left: Two maps show the activation during VT (CL 218ms) and the premature impulse (VI-S $148 \mathrm{~ms})$. The premature impulse was applied proximal to the slow conduction zone through the infarct. Activation times are given in milliseconds and isochrones are drawn at $10 \mathrm{~ms}$ intervals. Arrows indicate the direction of propagation, a zig-zagged arnow indicates slow conduction. Right: Unipolar electrograms recorded from 5 selected electrodes (location indicated on the map). Termination of VT was due to orthodromic conduction block of the paced impulse within the infarct while the antidromic wave collided with the counterclockwise circulating wave.

pagated slowly through the scar back to the exit site (from $t=55$ to $t=218 \mathrm{~ms}$ ). The electrogram recorded from the exit site showed a predominant negative deflection (site A). During fast propagation around the scar the electrograms were biphasic and of high amplitude (site B to D). A low amplitude potential was recorded from the scar (site E). VT was terminated by a single premature stimulus with a coupling interval of $148 \mathrm{~ms}$ delivered close to site D. The activation map of the premature impulse and the electrograms show that termination was due to orthodromic conduction block of the paced impulse within the SCZ while the antidromic wave collided with the circulating wave.

\section{Change in Morphology of VT}

Fig. 5 shows the reset curve of a VT with a cycle length of $111 \mathrm{~ms}$. After late premature stimuli the return cycle was not prolonged (flat part of curve). After early premature stimuli the return cycles were either slightly (up to $127 \mathrm{~ms}$ ) or markedly prolonged (up to $168 \mathrm{~ms}$ ). This dual response to early premature stimuli resulted in a 'split' reset curve which could be explained by the presence of two distinct pathways through the infarct. The VT was based on a reentrant circuit comprising a SCZ between the upper border $(t=0)$ and the low lateral border of the scar (upper map). Slight prolongation of the return cycle (V2-V3 

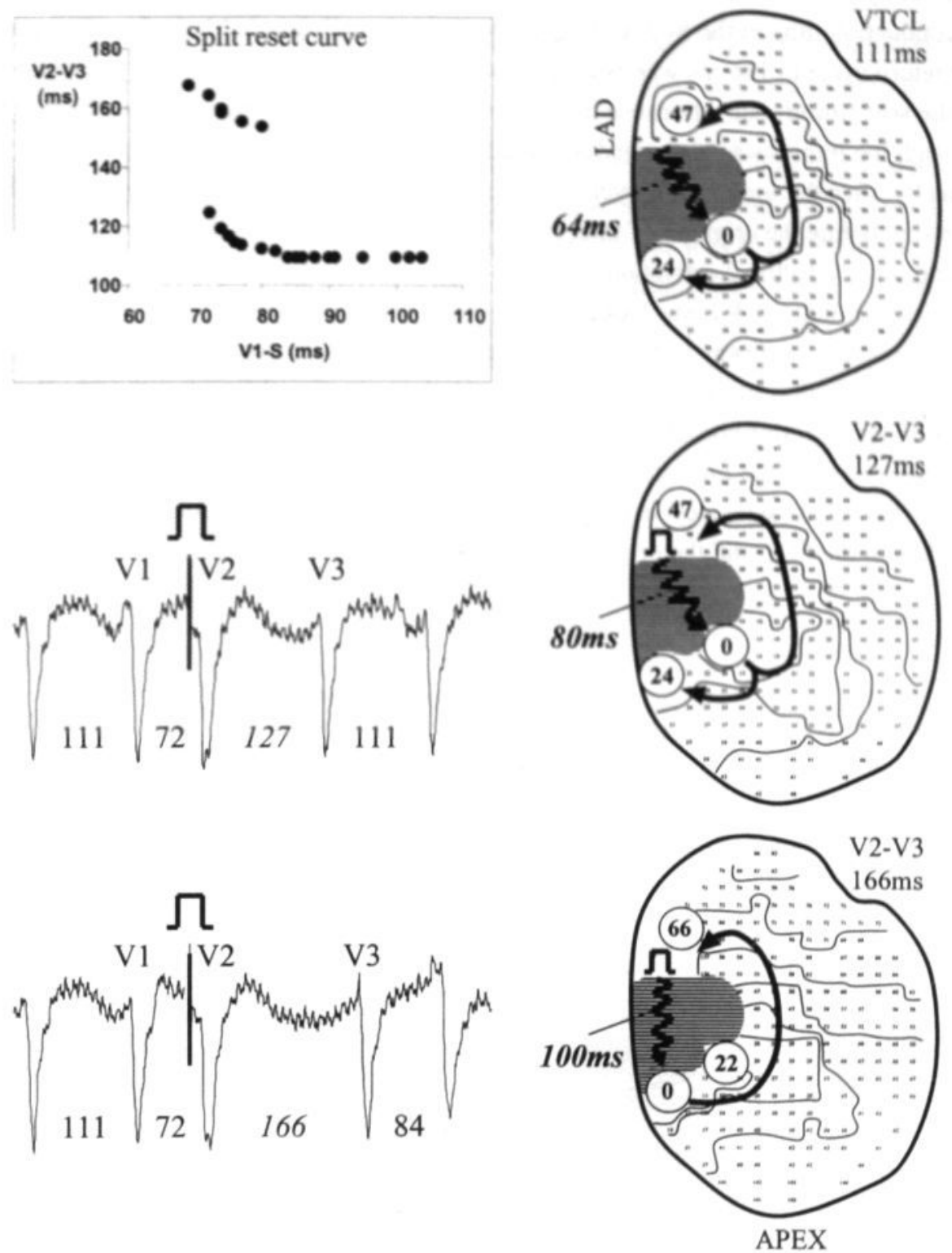

Figure 5. Left: Split reset curve. The return cycles (V2-V3) after early premature stimuli (V1-S) were either slightly (up to $127 \mathrm{~ms}$ ) or markedly prolonged (up to $168 \mathrm{~ms}$ ). The two electrograms illustrate the dual response to a premature stimulus with a coupling interval of $72 \mathrm{~ms}$. The V2-V3 intervals were respectively 127 and 166ms. Right: Three maps show the activation during VT (CL $111 \mathrm{~ms}$ ) and the return cycles of $127 \mathrm{~ms}$ and $166 \mathrm{~ms}$. Slight prolongation of the return cycle to $127 \mathrm{~ms}$ was due to an increase in the conduction time through the infarct from 64 to $80 \mathrm{~ms}$. Marked prolongation of the return cycle to $166 \mathrm{~ms}$ was associated with a shift from the exit site to the inferior border of the scar resulting in an increase in conduction time through the infarct to $100 \mathrm{~ms}$. Activation times are given in milliseconds and isochrones are drawn at $10 \mathrm{~ms}$ intervals. Arrows indicate the direction of propagation, zig-zagged arrows indicate slow conduction.. 
$127 \mathrm{~ms}$ ) by premature stimulation with a coupling interval of $72 \mathrm{~ms}$ was due to an increase in conduction time in the $\mathrm{SCZ}$ from $64 \mathrm{~ms}$ to $80 \mathrm{~ms}$ (middle map). Marked prolongation of the return cycle to $166 \mathrm{~ms}$ was associated with a shift of the exit site to the inferior border of the scar (lower map). Because the SCZ now was markedly longer, the conduction time through the infaret was prolonged to $100 \mathrm{~ms}$.

Directly after the long return cycle, two accelerated beats with intervals of 84 and $86 \mathrm{~ms}$ occurred before the original VT interval of $111 \mathrm{~ms}$ resumed. This is illustrated in Fig. 6 . The alterations in electrical activation underlying these accelerated beats are shown by the diagrams at the bottom. VT was based on a figure-of-eight like circuit with the exit site of the central common pathway $(\mathrm{t}=0)$ at the low lateral border of the scar. After the premature stimulus, conduction block occurred in the central common pathway and the impulse now exited at the inferior border of the infarct. Because the impulse could retrogradely invade the former exit at the low lateral border, a small reentrant circuit was started at the apical side of the infarct with a cycle length of 84 and $86 \mathrm{~ms}$. After two rotations the impulse was blocked in the $\mathrm{SCZ}$ and the original VT was restored.

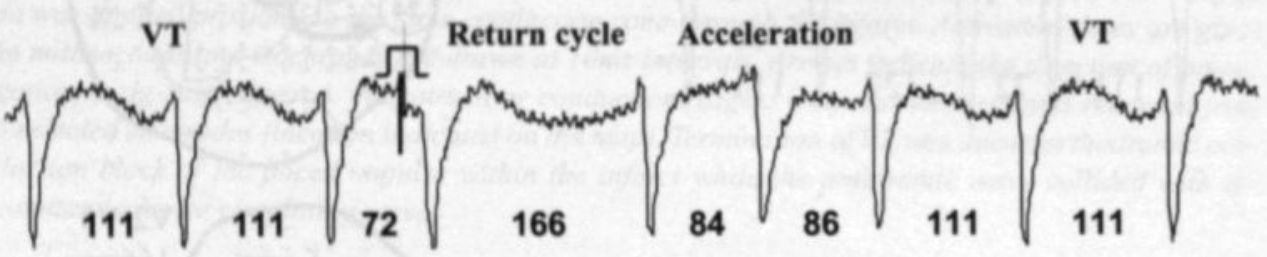

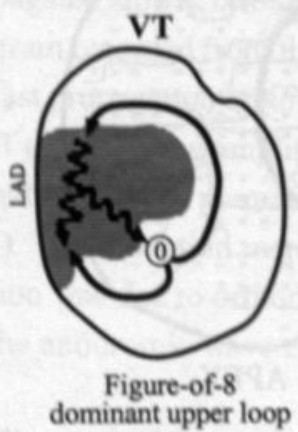

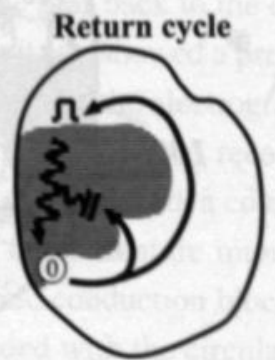

Block of paced impulse in central common pathway
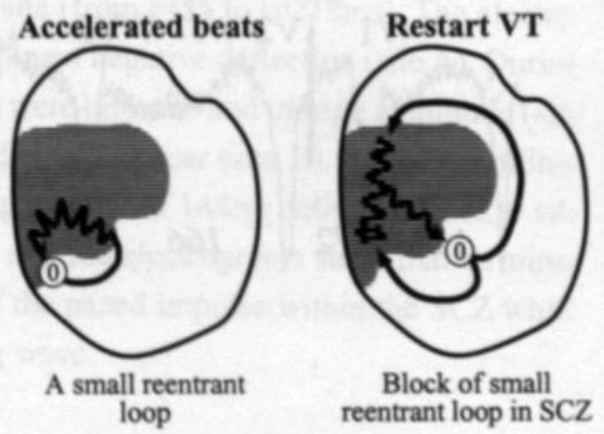

Figure 6. Accelenation of VT by a single premature impulse with a coupling interval of $72 \mathrm{~ms}$. The VT was based on a figure-of-eight like cincuit with an exit site $(t=0)$ at the low lateral bonder of the scar (VT). The premature stimulus caused conduction block in the central common pathway and the impulse now exited from the inferior border of the infarct (Return cycle). Because the impulse could netrognadely invade the former exit at the low lateral bonder, a small reentrant circuit was started at the apical side of the infarct (Accelerated beats). This small circuit was unstable and after two rotations conduction block occurred in the SCZ and the original VT was restoned (Restart VT). Arrows indicate the dinection of propagation, zig-zagged arnows indicate slow conduction. 


\section{All Experiments}

In 19 hearts, 21 different VTs were induced. In 5 cases VT was due to reentry around the scar, whereas in 16 cases the reentrant circuit comprised a slow conduction zone through the scar.

Fig. 7 shows that the EG was short during fast VTs, whereas slower VTs had a larger EG (left panel). This was the case both for VTs around the scar and through the scar $(\mathrm{p}<0.05)$. Only in case of reentry around the scar, the excitable gap was longer if the anatomic circuit was larger ( $p<0.01$, middle panel). The excitable gap during VT through the scar was mainly determined by the conduction time through the infarct ( $\mathrm{p}<0.05$, right panel).

Fig. 8 shows that the partially EG during VT around the scar was always $<15 \mathrm{~ms}$. Therefore, the reset curve of VTs around the scar was almost completely flat. In contrast, the reset curve of VTs through the scar was either mixed $(n=10)$ or completely sloped
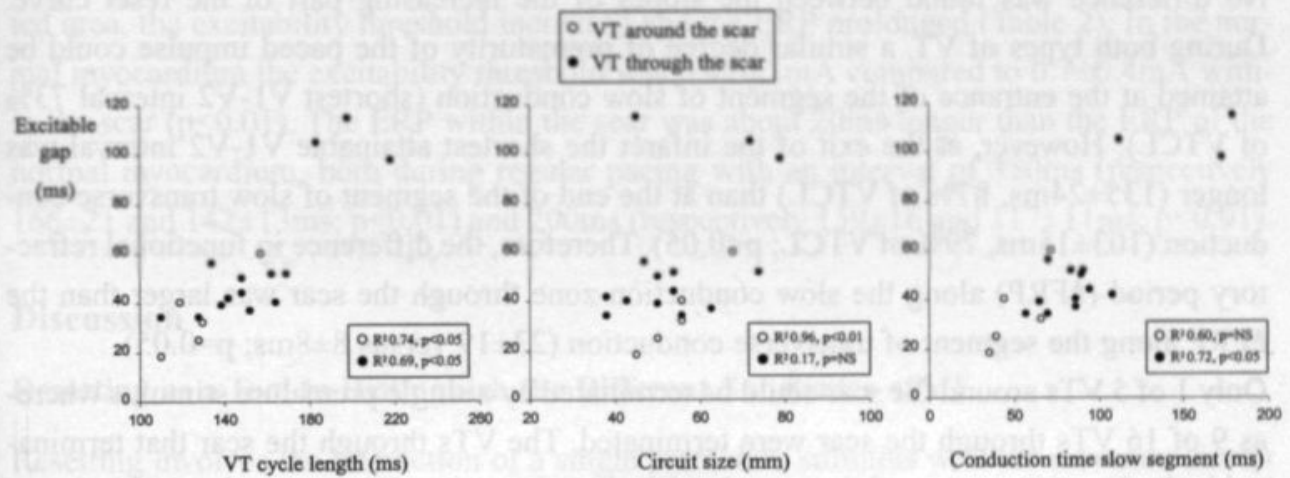

Figure 7. Graphs illustrating the correlation between the duration of the excitable gap and VT cycle length (left), size of the reentrant circuit (middle), and conduction time through the segment of slow conduction (right). In the lower right corners the correlation coefficients (R2) and level of significance $(P)$ are given both for VTs around (open circles) and through the scar (filled circles).

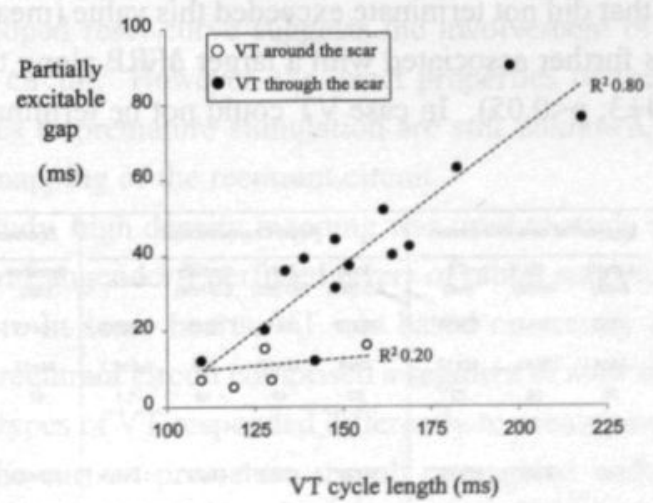

Figure 8. Correlation between the duration of the partially excitable gap and VT cycle length both for reentry around (open circles) and through the scar (filled circles). 
$(\mathrm{n}=6)$. The partially EG varied between $15 \mathrm{~ms}$ (VTCL $110 \mathrm{~ms}$ ) to as much as $90 \mathrm{~ms}$ (VTCL 204ms) $\left(\mathrm{R}^{2}=0.72\right.$, $\left.\mathrm{p}<0.05\right)$.

The quantitative differences between the reentrant circuits around and through the scar are given in Table 1. The VTs through the scar were slower (CL 156 $\pm 27 \mathrm{~ms}$ ) than the VTs around the scar (CL $129 \pm 18 \mathrm{~ms}, \mathrm{p}<0.05$ ), although the size of the reentrant circuits (respectively $53 \pm 13$ and $55 \pm 9 \mathrm{~mm}$ ) and the length of the segment of slow conduction (respectively $18 \pm 7$ and $15 \pm 5 \mathrm{~mm}$ ) were approximately the same. This was due to the fact that conduction through the infarct was slower than normal transverse conduction (respectively $20 \pm 6$ and $30 \pm 3 \mathrm{~cm} / \mathrm{s}, \mathrm{p}<0.01$ ). This resulted in a longer conduction time through the slow conducting segment $(97 \pm 35$ versus $52 \pm 16 \mathrm{~ms} ; \mathrm{p}<0.01)$. The EG during VT through the scar was longer than during VT around the scar (respectively $57 \pm 28$ and $35 \pm 16 \mathrm{~ms}, \mathrm{p}<0.05$ ). This was totally due to a larger partially EG (respectively $42 \pm 22$ and $10 \pm 5 \mathrm{~ms}, \mathrm{p}<0.05$ ) since the fully EG tended to be even shorter (respectively $15 \pm 13$ and $25 \pm 15 \mathrm{~ms}, \mathrm{p}=0.08$ ). No difference was found between the slopes of the increasing part of the reset curve. During both types of VT, a similar degree of prematurity of the paced impulse could be attained at the entrance of the segment of slow conduction (shortest V1-V2 interval 73\% of VTCL). However, at the exit of the infarct the shortest attainable V1-V2 interval was longer (135 $\pm 24 \mathrm{~ms}, 87 \%$ of VTCL) than at the end of the segment of slow transverse conduction $(103 \pm 15 \mathrm{~ms}, 79 \%$ of VTCL; $\mathrm{p}<0.05)$. Therefore, the difference in functional refractory period $(\triangle \mathrm{FRP})$ along the slow conduction zone through the scar was larger than the $\triangle F R P$ along the segment of transverse conduction $(23 \pm 19$ versus $8 \pm 8 \mathrm{~ms} ; \mathrm{p}=0.05$ ).

Only 1 of 5 VTs around the scar could be terminated by a single premature stimulus whereas 9 of 16 VTs through the scar were terminated. The VTs through the scar that terminated had a longer segment of slow conduction than those that did not terminate $(21 \pm 8$ versus $14 \pm 6 \mathrm{~mm} ; \mathrm{p}<0.05$ ). Consequently, these VTs also tended to be slower (CL $163 \pm 29$ versus $148 \pm 27 \mathrm{~ms} ; \mathrm{p}=0.1)$ and the excitable gap was larger $(72 \pm 33$ versus $42 \pm 9 \mathrm{~ms} ; \mathrm{p}<0.05$ ). The ability to terminate VT was associated with a steep slope of the increasing part of the reset curve. Seven of nine VT's that terminated had a slope steeper than -0.8 (mean $1.4 \pm 1.1$ ), while only 1 of 6 that did not terminate exceeded this value (mean $-0.6 \pm 0.2$ ). The ability to terminate VT was further associated with a larger $\triangle \mathrm{FRP}$ along the slow conduction zone $(31 \pm 25$ versus $14 \pm 3 ; \mathrm{p}<0.05)$. In case VT could not be terminated, the shortest

Table 1

\begin{tabular}{|c|c|c|c|c|c|c|c|c|c|c|c|c|c|c|c|}
\hline & \multirow[t]{2}{*}{ N } & \multicolumn{2}{|c|}{$v T$} & \multicolumn{3}{|c|}{ Sepment of stow conduction } & \multicolumn{4}{|c|}{ Reset Characteriabca } & \multicolumn{5}{|c|}{ Shortest V1.V2 interval, slow seoment } \\
\hline & & $\underset{(m)}{c}$ & crat & imin) & (oviv) & $\begin{array}{l}\text { CT } \\
\text { (me) }\end{array}$ & $\begin{array}{c}\text { Tota } \\
\text { EO (ma) }\end{array}$ & Eo (ma) & $\begin{array}{l}\text { Pataly } \\
\text { EO (mi) }\end{array}$ & siope & $\begin{array}{l}\text { Entrace } \\
\text { (ime) }\end{array}$ & sa & Ex & sa & $\underset{(m)}{S / \infty}$ \\
\hline VT around the scar & 8 & taveste & sses & ises & 3003 & Sante & $34+16$ & ase1s & tons & -8003 & esett & $n$ & 100e1s & $\pi$ & tent \\
\hline No teminabon & 4 & 12220 & ans & 164 & 3003 & 47413 & ans & 2012 & 804 & $0.5+02$ & Met13 & 76 & 9ente & 61 & Set \\
\hline Temination & 1 & 187 & 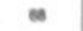 & 20 & a & $n$ & $\infty$ & 4 & 16 & -1.1 & $m$ & e & 116 & 74 & to \\
\hline VT throwh the scar & 16 & tseart & 2013 & sent & $20 n e$ & oness: & stear & $15 e 13$ & $\sin 2 x$ & -1.090 .9 & 113025 & $n$ & tasese & 87 & netr \\
\hline No temmination & 7 & 146027 & Stet2 & 1646 & sonet & ats & ans & $7 n$ & SSe14 & 0.6002 & 120028 & $\mathbf{\infty}$ & 13428 & $\infty$ & 1403 \\
\hline Teminabon & $\theta$ & reases & Sents & 2ten'? & 3046 & tobese? & rass' & zant? & soeat & -1.421 .17 & 106e2s & ss & 137224 & $\mathbf{M}$ & $31625 !$ \\
\hline
\end{tabular}

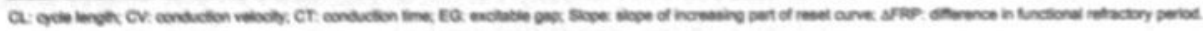

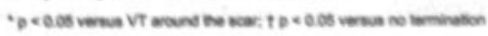




\begin{tabular}{lcccc}
\hline Table 2 & " sites & $\begin{array}{c}\text { Thr } \\
(\mathrm{mA})\end{array}$ & $\begin{array}{c}\text { ERP } \\
(\mathrm{ms})\end{array}$ & $\begin{array}{c}\text { ERP } \\
(\mathrm{ms})\end{array}$ \\
\hline Normal myocardium & 36 & $0.4 \pm 0.1$ & $142 \pm 13$ & $117 \pm 11$ \\
Borderzone & 20 & $0.5 \pm 0.3$ & $150 \pm 19$ & $121 \pm 16$ \\
Infarct & 24 & $0.7 \pm 0.4^{*}$ & $166 \pm 21^{*}$ & $139 \pm 16^{*}$ \\
\hline
\end{tabular}

attainable V1-V2 interval at the entrance of the slow conduction zone was only $80 \%$ of the VTCL. In 3 hearts the reset curve of the VT was split, indicating the presence of two different pathways through the scar.

In 8 hearts, the excitability threshold and the effective refractory period (ERP) were measured at multiple sites within the scar, the borderzone ( $<1 \mathrm{~cm}$ from the scar), and the normal myocardium ( $>1 \mathrm{~cm}$ from the scar). Going from the normal myocardium towards the infarcted area, the excitability threshold increased and the ERP prolonged (Table 2). In the normal myocardium the excitability threshold was $0.4 \pm 0$. $1 \mathrm{~mA}$ compared to $0.7 \pm 0.4 \mathrm{~mA}$ within the scar $(p<0.01)$. The ERP within the scar was about $20 \mathrm{~ms}$ longer than the ERP of the normal myocardium, both during regular pacing with an interval of $350 \mathrm{~ms}$ (respectively $166 \pm 21$ and $142 \pm 13 \mathrm{~ms} ; \mathrm{p}<0.01$ ) and $200 \mathrm{~ms}$ (respectively $139 \pm 16$ and $117 \pm 11 \mathrm{~ms} ; \mathrm{p}<0.01$ ).

\section{Discussion}

\section{Resetting as a Tool to Distinguish the Different Substrates of VT}

Resetting involves the interaction of a single premature stimulus with the reentrant circuit resulting in a less than compensatory pause. ${ }^{3-5}$ In patients with a healed myocardial infarction, three different reset patterns have been described. ${ }^{3-5} \mathrm{~A}$ flat reset curve is commonly associated with a large anatomic circuit containing a fully excitable gap. A mixed reset response (flat and sloped part) is expected in case of an anatomic circuit with a fully excitable gap and short coupled premature impulses propagating in relatively refractory tissue. A completely sloped reset curve suggests the involvement of a small anatomic or functional reentrant circuit. ${ }^{6}$ However, the exact properties of the circuit that determine the various responses to premature stimulation are still unknown, since clinical reset studies do not include mapping of the reentrant circuit.

In the present study, high density mapping was used to study the responses of VT to premature stimuli in Langendorff perfused layers of rabbit subepicardium with a healed myocardial infarction. In some hearts, VT was based on reentry around the scar whereas in other hearts the reentrant circuit comprised a segment of slow conduction zone through the scar. These two types of VT responded differently to premature stimuli. During VT around the scar, only the earliest premature stimuli propagated with a minor conduction delay through the circuit. Consequently, the reset curves were almost completely flat. In contrast, if the reentrant impulse propagated through the scar, the reset curve was either mixed or 
completely sloped. In such cases already late premature impulses were conducted with considerable delay through the slow conduction zone. As a result, the partially excitable gap was longer $(55 \pm 22 \mathrm{~ms})$ than during VTs around the scar $(10 \pm 5 \mathrm{~ms}, \mathrm{p}<0.01)$. VTs through the infarcted area could also be reset to a lesser extent (13\%) than VTs around the scar $(21 \%)$. In case of reentry around the scar, the length of the excitable gap depended on the size of the anatomic circuit. The excitable gap of VTs through the scar was mainly determined by the conduction time through the infarct.

Only 1 of 5 VTs around the scar could be terminated by a single premature stimulus, whereas 9 of 16 VTs through the scar were terminated. As in patients, ${ }^{11,12}$ termination was due to orthodromic block of the premature impulse in the slow conduction zone. Gottlieb et al. found that the slope of the reset curves of the VTs that terminated was steeper than those that did not terminate. ${ }^{13}$ We also found that the slope of the reset curve was a predictor of termination, indicating a large dispersion in functional refractory period between the entrance and exit of the slow conduction zone. In addition, we demonstrated that the ability to terminate VT was associated with the presence of a relatively long segment of slow conduction through the scar.

A 'split' reset curve indicated the presence of two distinct pathways through the scar with a different functional refractory period. The phenomenon of the split curve can be compared with the sudden increase in AV nodal conduction time after atrial premature beats with a short coupling interval. ${ }^{14}$ This sudden increase is interpreted as evidence of dual $\mathrm{AV}$ nodal pathways, reflecting unidirectional block in the fast pathway and conduction over the slow pathway having a shorter refractory period.

\section{Characterization of Slow Conduction by Resetting}

Many studies have shown that the reentrant circuit after myocardial infarction comprises an area of slow conduction, ${ }^{15-17}$ and that such a segment influences the reset response. 8.18 . ${ }^{20} \mathrm{Haberl}$ et al. demonstrated a differential effect of the area of slow conduction on the reset response of anatomic VT in the rabbit ventricle, depending on whether slow conduction was due to depression of the active membrane currents or caused by electrical uncoupling. ${ }^{10}$ Electrical uncoupling of part of the circuit by heptanol resulted in a mixed reset curve but early premature impulses failed to terminate VT. Depression of the active membrane properties by high extracellular potassium resulted in a completely sloped reset curve and, in most cases, termination of VT by premature stimuli.

In our study, the reset curves of the circuits comprising a slow conduction zone through the scar were either mixed $(n=10)$ or completely sloped $(n=7)$. In fact, there was a continuum in durations of the fully and partially excitable gap (Fig. 7 and 8). According to the findings of Haberl et. al., ${ }^{10}$ the fact that 9 of 16 VTs were terminated by a premature stimulus indicates that slow conduction through the scar was not solely due to cellular uncoupling. Depressed excitability of the surviving myocytes within the infarcted area with prolonged refractory periods must also play a role. Pu et al. ${ }^{21}$ demonstrated that ischemiainduced alterations in the $\mathrm{Na}^{*}$ channels indeed reduced the excitability of surviving myo- 
cytes in the epicardial borderzone of canine myocardial infarction and that the recovery of excitability was slower than repolarization of the cells (post-repolarization refractoriness). Similar characteristics have been demonstrated in the AV node. ${ }^{22}$ However, unlike the results of our and other studies on ventricular tachycardias, ${ }^{3.5}$ during AV nodal reentrant tachycardia the increase in the return cycle following early premature impulses is usually more than compensatory. ${ }^{23}$ Conduction of premature impulses in the atrioventricular node thus appears to be slowed to a greater extent than in chronically infarcted myocardium.

\section{Clinical Implications}

Programmed electrical stimulation during VT has been used to localize the site of origin of VT for radiofrequency (RF) ablation, ${ }^{24}$ and to provide insights into the therapeutic role of antiarrhythmic drugs and antitachycardia pacing. ${ }^{2,25}$ Differentiation of the substrate for VT might be of importance for the choice of antiarrhythmic therapy. In case of anatomical reentry around the scar, premature stimuli usually did not terminate VT. More aggressive anti-tachycardia pacing or defibrillation is probably needed to terminate this type of VT. RF-ablation will only be successful if the complete isthmus between the scar and an anatomical boundary is ablated. Termination and prevention of these VTs by class I and III anti-arrhythmic drugs is probably not successful, since all segments of the circuits usually have a large and fully excitable gap and a high safety factor for conduction.

In case of anatomical reentry with a segment of slow conduction through the scar, single premature stimuli terminated more than half of the VT's. The ability to terminate VT depended on the length of the zone of slow conduction, the slope of the reset curve, and the dispersion in functional refractory periods. This information can be used clinically to choose a more or less aggressive mode of anti-tachycardia pacing. RF-ablation of the slow conduction zone should abolish VT, but a 'split' reset curve can unveil the presence of more than one slow conducting pathway. Knowledge about the nature of slow conduction in the infarcted area may be helpful to guide anti-arrhythmic therapy.

\section{Limitations of the Study}

The major limitation of the study is that the rabbit model of reentrant VT is obviously different from the pathophysiological substrate of clinical reentrant VT. Most importantly, the normal complex 3-D architecture of the chronic myocardial infarction was largely modified by the cryoprocedure. A further limitation is that the spatial resolution of the mapping electrode was not sufficient to pinpoint the exact pathways through the infarct. The pacing site was always chosen proximal to the area of slow conduction. However, in the clinical setting the pacing site relative to the area of slow conduction varies which will influence the reset response. ${ }^{19,20,26}$ Therefore, the value of a certain reset response to identify the underlying substrate of VT in patients remains to be determined. 


\section{References}

1. Wellens HJ, Schuilenburg RM, Durrer D. Electrical stimulation of the heart in patients with ventricular tachycardia. Circulation. 1972;46:216-26.

2. Waldecker B, Brugada P, Zehender M, Stevenson W, Den Dulk K, Wellens HJ. Importance of modes of electrical termination of ventricular tachycardia for the selection of implantable antitachycardia devices. Am J Cardiol. 1986;57:150-5.

3. Almendral JM, Rosenthal ME, Stamato NJ, Marchlinski FE, Buxton AE, Frame LH, Miller JM, Josephson ME. Analysis of the resetting phenomenon in sustained uniform ventricular tachycardia: incidence and relation to termination. JAm Coll Candiol. 1986;8:294-300.

4. Almendral JM, Stamato NJ, Rosenthal ME, Marchlinski FE, Miller JM, Josephson ME. Resetting response patterns during sustained ventricular tachycardia: relationship to the excitable gap. Circulation. 1986;74:722-30.

5. Stamato NJ, Rosenthal ME, Almendral JM, Josephson ME. The resetting response of ventricular tachycardia to single and double extrastimuli: implications for an excitable gap. Am J Cardiol. 1987;60:596-601.

6. Josephson M. Response of sustained uniform ventricular tachycardia to stimulation. In: Josephson M, ed. Clinical Cardiac Electrophysiology. Philadelphia/London: Lea and Febiger: 1993:502-543.

7. El Sherif N, Gough WB, Restivo M. Reentrant ventricular arrhythmias in the late myocardial infarction period: 14. Mechanisms of resetting, entrainment, acceleration, or termination of reentrant tachycardia by programmed electrical stimulation. Pacing Clin Electrophysiol. 1987; 10:341-71.

8. Peters NS, Coromilas J, Hanna MS, Josephson ME, Costeas C. Wit AL. Characteristics of the temporal and spatial excitable gap in anisotropic reentrant circuits causing sustained ventricular tachycardia. Circ Res. 1998;82:279-93.

9. Boersma L, Brugada J, Kirchhof C, Allessie M. Mapping of reset of anatomic and functional reentry in anisotropic rabbit ventricular myocardium. Circulation. 1994;89:852-62.

10. Haberl K. Allessie M. Differential effects of a segment of slow conduction on reentrant ventricular tachycardia in the rabbit heart. Circulation. 1999;99:949-962.

11. Okumura K, Henthorn R, Epstein A, Plumb V, Waldo A. Further observations on transient entrainment: importance of pacing site and properties of the components of the reentrant circuit. Circulation. 1985;6:1293-1307.

12. Aizawa $\mathrm{Y}$, Niwano S, Chinushi M, al e. Incidence and mechanism of interruption of reentrant ventricular tachycardia with rapid ventricular pacing. Circulation. 1992;85:589-595.

13. Gottlieb CD, Rosenthal ME, Stamato NJ, Frame LH, Lesh MD, Miller JM, Josephson ME. A quantitative evaluation of refractoriness within a reentrant circuit during ventricular tachycardia. Relation to termination. Cinculation. 1990;82:1289-95.

14. Denes $\mathrm{P}, \mathrm{Wu}$ D, Dhingra $\mathrm{R}$. Demonstration of dual A-V nodal pathways in patients with paroxysmal supraventricular tachycardia. Circulation. 1973;48:549.

15. de Bakker JM, van Capelle FJ, Janse MJ, Wilde AA, Coronel R, Becker AE, Dingemans KP, van Hemel NM, Hauer RN. Reentry as a cause of ventricular tachycardia in patients with chronic ischemic heart disease: electrophysiologic and anatomic correlation. Circulation. 1988;77:589606.

16. de Bakker JM, van Capelle FJ, Janse MJ, van Hemel NM, Hauer RN, Defauw JJ, Vermeulen FE, Bakker de Wekker PF. Macroreentry in the infareted human heart: the mechanism of ventricular tachycardias with a "focal" activation pattern. J Am Coll Cardiol. 1991;18:1005-14.

17. Downar E, Kimber S, Harris L, et al. Endocardial mapping of ventricular tachycardia in the intact human heart. II. Evidence for multiuse reentry in a function sheet of surviviving myocardium. J Am Coll Candiol. 1992;20:869-878.

18. Rosenthal ME, Stamato NJ, Almendral JM, Gottlieb CD, Josephson ME. Resetting of ventricular tachycardia with electrocardiographic fusion: incidence and significance. Cinculation. 1988:77:581-8.

19. Stevenson W. Weiss J, Wiener I, Nademanee K. Wohlgelernter D, Yeatman L. Josephson M. Klitzner T. Resetting of ventricular tachycardia: implications for localizing the area of slow con- 
duction. JAm.Coll.Candiol. 1988;11:522-529.

20. Kay N, Epstein A, Plumb V. Resetting of ventricular tachycardia by single extrastimuli. Relation to slow conduction within the reentrant circuit. Circulation. 1990:81:1507-1519.

21. Pu J, Boyden P. Alterations of $\mathrm{Na}+$ currents in myocytes from epicardial border zone of infarcted heart. A possible mechanism for reduced axcitability and postrepolarization refractoriness. Cinc Res. 1997:81:110-119.

22. Merideth J, Mendez C, Mueller W. Electrical excitability of atrioventricular nodal cells. Cinc Res. 1968:23:69-85.

23. Bigger J, Goldreyer B. The mechanism of supraventricular tachycardia. Circulation. 1970;42:673-688.

24. Stevenson W, Khan H, Sager P, Saxon L, Middlekauff H, Natterson P, Wiener I. Identification of reentry circuit sites during catheter mapping and radiofrequency ablation of ventricular tachycardia late after myocardial infaretion. Circulation. 1993;88:1647-70.

25. The Sicilian Gambit: A new approach to the classification of antiarrhythmic drugs based on their actions on arrhythmogenic mechanisms. Task force of the working group on arrhythmias of the European Society of Cardiology. Circulation. 1991;84:1915-1923.

26. Rosenthal ME, Stamato NJ, Almendral JM, Marchlinski FE, Buxton AE, Miller JM, Josephson ME. Influence of the site of stimulation on the resetting phenomenon in ventricular tachycardia. Am J Candiol. 1986;58:970-6. 
Chapter 5

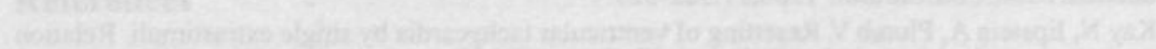


Chapter 6

Differential Effects of Overdrive Pacing on Reentrant VT with or without a Slow

Conduction Zone through Healed Myocardial Infarction 
Chapter 6

$-126$. 


\section{Introduction}

In patients with chronic ischemic heart disease ventricular tachycardia (VT) can often be entrained and terminated by rapid ventricular pacing which is regarded as evidence that reentry is the mechanism of VT. ${ }^{1-4}$ Because overdrive pacing terminates VT in a high percentage of patients, it is also widely used in the treatment of VT. ${ }^{5,6}$ However, acceleration of VT by overdrive pacing may also occur, ${ }^{5,7}$ often resulting in haemodynamic instability requiring instant cardioversion.

Direct evidence on the mechanisms responsible for termination and acceleration of VT by electrical stimulation stems from high density mapping studies in canine hearts with a 4-7 days old myocardial infarction. ${ }^{8-10}$ In this model of healing infarction, VT is generally due to functional reentry in the surviving epicardial borderzone that overlies the infarcted area. " However, the substrate for reentrant VT markedly changes as the infarct continues to heal. ${ }^{12-14}$ Because of alterations in anatomial and electrophysiological properties of the infarcted tissue, the mechanisms involved in termination and acceleration of VT by overdrive pacing may also change with time. So far, the effects of overdrive pacing during reentrant VT in the healed phase of myocardial infarction have not been studied by high density mapping. Furthermore, it is incompletely understood why some VTs are easily terminated by overdrive pacing, while other VTs can not be terminated or are accelerated by entrainment.

To further elucidate the mechanisms involved in termination and acceleration of VT after overdrive pacing, we performed high resolution mapping during overdrive pacing of VT in Langendorff perfused layers of rabbit subepicardium containing an area of healed (3 months old) myocardial infarction. Overdrive pacing always terminated VT if it was based on a reentrant circuit comprising a slow conduction zone through the infarct. On the other hand, VTs based on anatomical reentry around the infarct were most of the time accelerated. Termination of VT was due to orthodromic conduction block in the slow conduction zone. Prior to conduction block, the conduction time of the paced wavefronts through the slow conduction zone progressively increased. Insights in the mechanisms of pacingmediated termination and acceleration of reentrant VT may be used to classify the substrate of reentrant VT and to develop improved antitachycardia pacing algorithms.

\section{Methods}

\section{Preparation}

In 12 Langendorff-perfused rabbit hearts with a chronic myocardial infarction ( $12 \pm 3$ weeks old), a thin layer of left ventricular subepicardium was created by a cryoprocedure. The surgical procedure, the cryotechnique and the experimental set-up have been described in Chapter 4 . 


\section{Mapping and Stimulation}

The epicardium of the left ventricle was mapped with a spoon-shaped mapping array containing 240 silver electrodes (diameter $0.3 \mathrm{~mm}$ ) with an interelectrode distance of $2.25 \mathrm{~mm}$. The on-line mapping system to record and analyze the data is described in Chapter 4. Local conduction velocities were calculated normal to the isochrones. Bipolar stimulation could be performed with any selected pair of electrodes in the electrode spoon. Sustained monomorphic ventricular tachycardia (VT) was induced by programmed electrical stimulation using 1-3 premature stimuli or incremental pacing. Overdrive stimulation was performed by applying trains of 10 stimuli ( $4 \mathrm{x}$ threshold) with a fixed interstimulus interval proximal to the area of slow conduction. The first stimuli of the train did not always capture the ventricle since stimulation was started randomly. However, in all cases at least 8 of the 10 stimuli captured the ventricle. The cycle length of the train of stimuli was shortened in steps of $5 \mathrm{~ms}$ until the VT was terminated or accelerated or capture was lost.

\section{Statistical Analysis}

Results were compared using the unpaired Student's t-test. P-values of less than 0.05 were taken as statistically significant.

\section{Results}

\section{Characteristics of VT}

Overdrive pacing was performed during two different types of VT, which are illustrated in Fig. 1. In 5 hearts, VT was based on anatomical reentry around the scar. Due to the anisotropic properties of the myocardium, the conduction velocity varied in different parts of the circuit. At the base and the free wall, the reentrant impulse propagated parallel to the fibers with a velocity of $70 \pm 10 \mathrm{~cm} / \mathrm{s}$. In the corridor between the scar and the LAD, the impulse propagated transverse to the fibers with a reduced velocity of $30 \pm 3 \mathrm{~cm} / \mathrm{s}$. The unipolar electrograms recorded from different sites around the scar showed biphasic potentials during the whole VT cycle. VTCL ranged between 110 and $160 \mathrm{~ms}$ (mean $130 \pm 19 \mathrm{~ms}$ ). In 7 other hearts, VT was based on an anatomical reentrant circuit comprising a slow conduction zone through the scar. The effective conduction velocity through the scar, calculated from the straight distance between the entrance and exit of the scar and the conduction time through the scar, was $19 \pm 6 \mathrm{~cm} / \mathrm{s}$. Because during normal amplification of the electrograms (gain 300 ) no electrical activity was recorded from the scar, the VT cycle comprised a 'diastolic interval' (bottom panel). In these tachycardias, VTCL ranged from 110-196ms (mean $149 \pm 33 \mathrm{~ms}$ ) with a diastolic interval of $57-179 \mathrm{~ms}$ (mean $100 \pm 43=67 \%$ of VTCL).

\section{Overdrive pacing of VT around the scar}

Only 1 of 5 VTs could be terminated by overdrive pacing. This single case is shown in Fig 2. The electrogram at the top shows that overdrive pacing shortened the VTCL $(160 \mathrm{~ms})$ to 


\section{VT around the scar}

\section{VT through the scar}
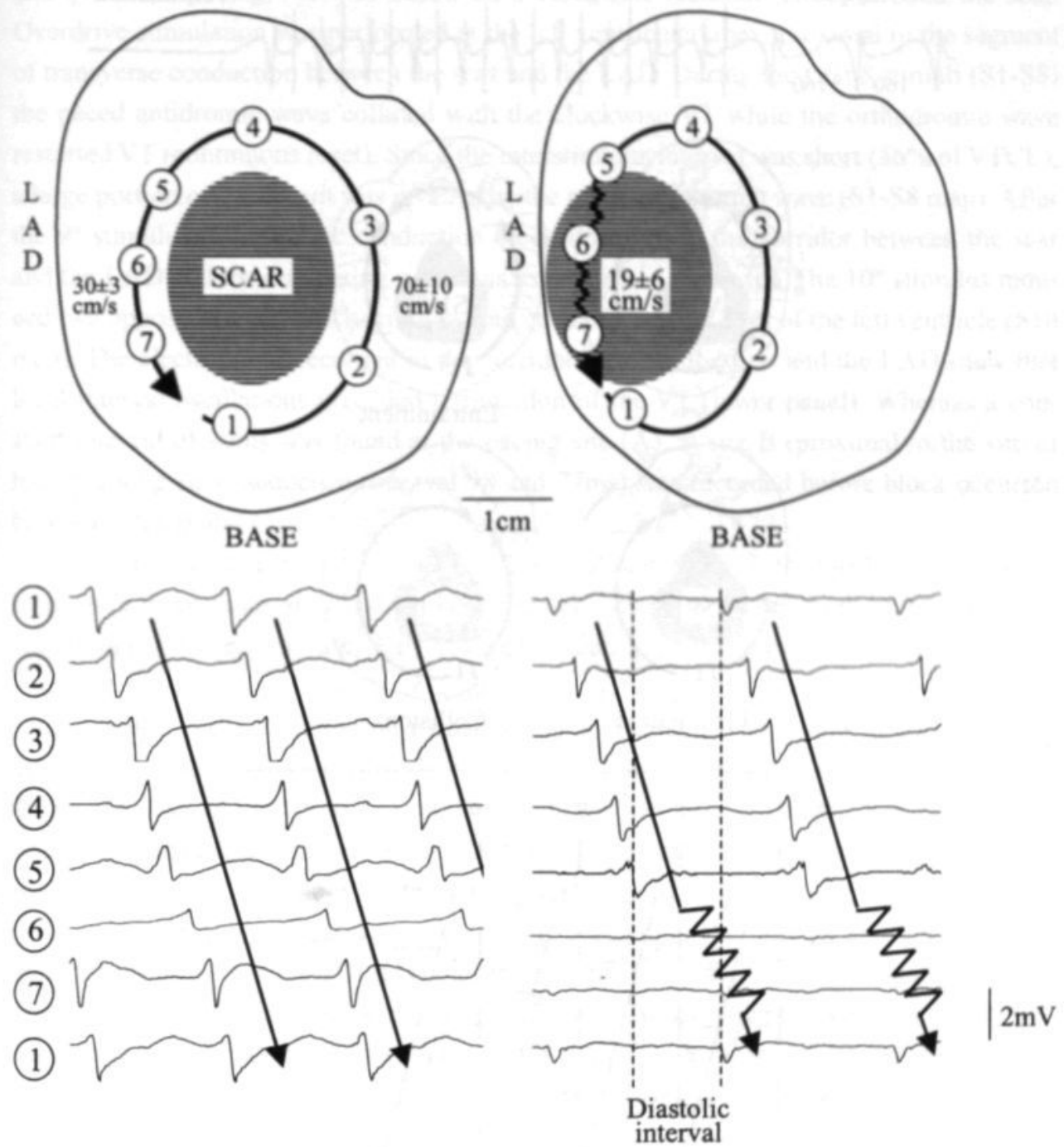

Figure 1. Two different kinds of VT, one based on reentry around the scar and one on circus movement through the scar (top). The unipolar electrograms are taken from representative experiments (bottom). The location of the selected electrograms is indicated on the maps. Left: During VT around the scar the conduction velocity varied in the different parts of the circuit depending on the direction of propagation relative to the epicardial fiber orientation. Conduction was slowest in the corridor between the scar and the left anterior descending artery (LAD), where the impulse propagated perpendicular to the fibers. During the whole VT cycle, biphasic electrograms were recorded from different sites around the scar. Right: Part of the reentrant circuit consisted of a slow conduction zone through the infarct (zig-zag arrow). The VT cycle comprised a 'diastolic interval' because at normal amplification of the electrograms (gain 300) no electrical activity was recorded from the scar. 
90
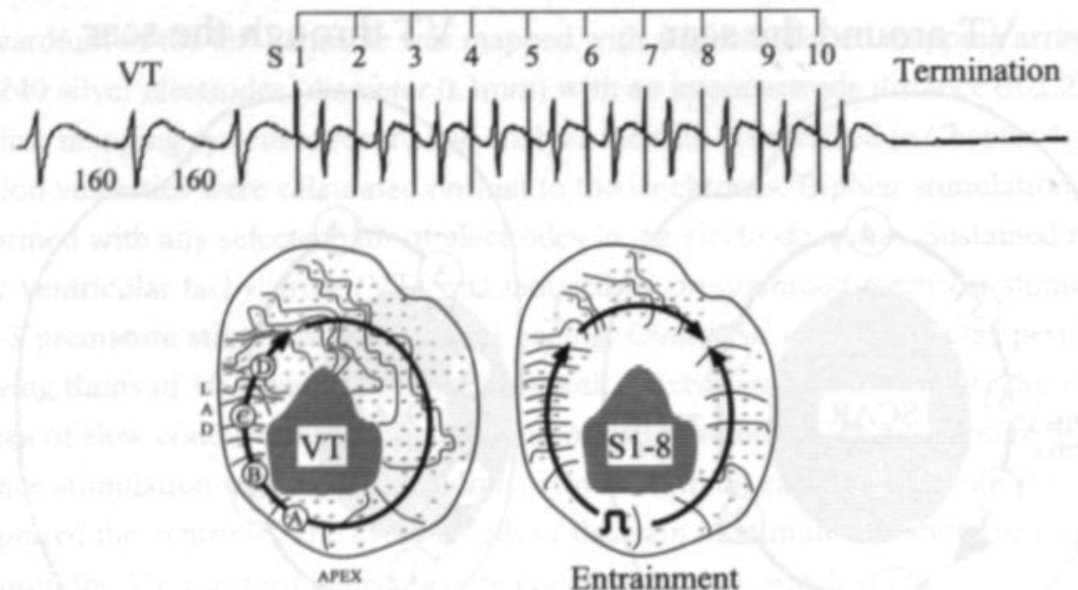

Entrainment

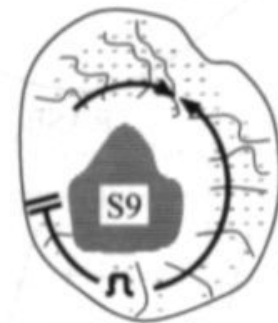

Termination

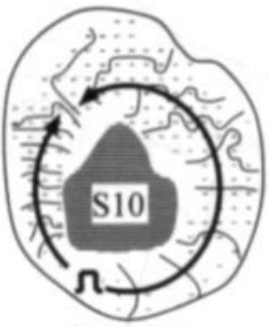

Collision

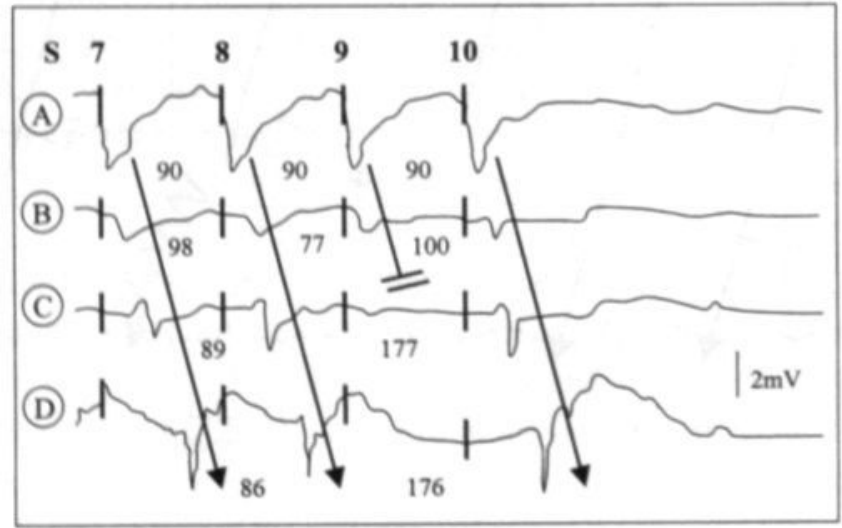

Figure 2. Termination of VT around the scar after ovendrive pacing with an interval of $90 \mathrm{~ms}$ (top). The VT was based on a clockwise circulating wave (upper left map). The first 8 stimuli (SI-S8) resulted in entrainment of VT (upper right map). VT was terminated by $S 9$ due to orthodromic conduction block in the corridor between the scar and the LAD (lower left map). After termination, two opposed paced wavefronts colliding at the base of the ventricle activated the myocardium around the scar (lower right map). The moment of stimulation is taken as $t=0$; isochrones are drawn at $10 \mathrm{~ms}$ intervals. Conduction block is indicated by double bars. The recondings sites of the 4 electrograms are indicated by A-D. Bottom: Whereas a constant interval of $90 \mathrm{~ms}$ was found at the pacing site $(A)$. praximal to the site of block (site B) a relatively long interval of $98 \mathrm{~ms}$ preceded a short interval of $77 \mathrm{~ms}$ before conduction block occurned. 
the cycle length of the overdrive stimuli $(90 \mathrm{~ms})$ and that VT was terminated after cessation of pacing. The activation maps show the electrical activation of the left ventricle during VT and overdrive pacing. VT was based on a clockwise reentrant circuit around the scar. Overdrive stimulation was performed at the left ventricular apex, proximal to the segment of transverse conduction between the scar and the LAD. During the first 8 stimuli (S1-S8) the paced antidromic wave collided with the clockwise VT while the orthodromic wave restarted VT (continuous reset). Since the interstimulus interval was short ( $56 \%$ of VTCL), a large portion of the circuit was invaded by the paced antidromic wave (S1-S8 map). After the $9^{\text {s }}$ stimulus orthodromic conduction block occurred in the corridor between the scar and the LAD and the circulating wave was extinguished ( $\mathrm{S} 9$ map). The $10^{\mathrm{*}}$ stimulus induced two opposed waves which collided with each other at the base of the left ventricle (SI0 map). The electrograms recorded in the corridor between the scar and the LAD show that local interval oscillations preceded termination of the VT (lower panel). Whereas a constant interval of $90 \mathrm{~ms}$ was found at the pacing site (A), at site B (proximal to the site of block) a long-short sequence (interval 98 and $77 \mathrm{~ms}$ ) was recorded before block occurred between sites $\mathrm{B}$ and $\mathrm{C}$.

Overdrive pacing accelerated 3 of 5 VTs around the scar. In Fig 3, the mechanisms of acceleration in these cases are illustrated by activation maps of the VT both before and after entrainment. In the first case (top) a large reentrant circuit around the scar with a cycle length of $132 \mathrm{~ms}$ was present. After entrainment, the VT interval was shortened to $106 \mathrm{~ms}$. This was due to the initiation of a smaller reentrant circuit with a slow conduction zone through the scar. Because part of the ventricle was now activated in a different direction, the morphology of the VT was also different. In the second case (middle panel), acceleration of VT (interval shortened from 110 to $74 \mathrm{~ms}$ ) was due to induction of a second wave in the same circuit (double wave reentry). Since the sequence of activation was not changed, the morphology of the VT remained almost the same. The interval of $74 \mathrm{~ms}$ was more than half of the original VTCL $(110 \mathrm{~ms})$ because the two waves were propagating in each other tail of refractoriness (slowing of conduction $\pm 30 \%$ ). In the third example (bottom), very rapid pacing (interval $52 \mathrm{~ms}$ ) during a VT with a cycle length of $121 \mathrm{~ms}$ caused ventricular fibrillation due to the induction of multiple wavelets outside the infarcted area.

\section{Overdrive pacing of VT through the scar}

All VTs through the scar $(n=7)$ could be terminated by overdrive pacing. An example is shown in Fig. 4. The electrogram at the top, recorded distal to the area of slow conduction, shows that the VT with a cycle length of $132 \mathrm{~ms}$ was terminated by overdrive pacing with a relatively long interstimulus interval of $105 \mathrm{~ms}$ ( $80 \%$ of VTCL). The first premature stimulus (S1) already captured the ventricle and shortened the cycle length to $118 \mathrm{~ms}$. After $\mathrm{S} 2$ the VT cycle was adjusted to the cycle length of the overdrive stimuli (105ms). After S3 the interval prolonged to $117 \mathrm{~ms}$ and after S4 only a small potential was observed. During S5-S10, the morphology of the electrogram was different. The maps show the changes in activation pattern of the left ventricle during overdrive pacing. The VT was based on a 


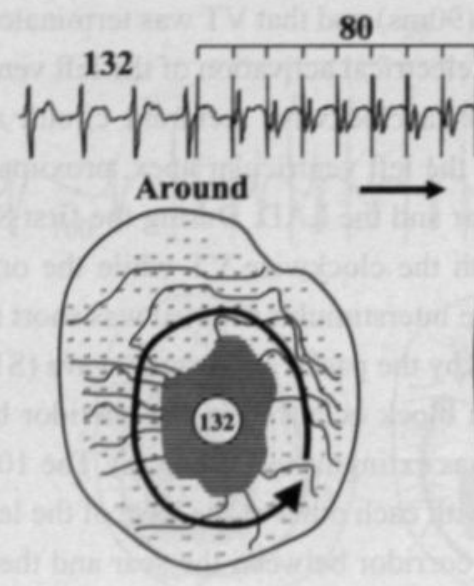

\section{6}

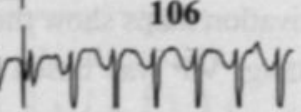

Through
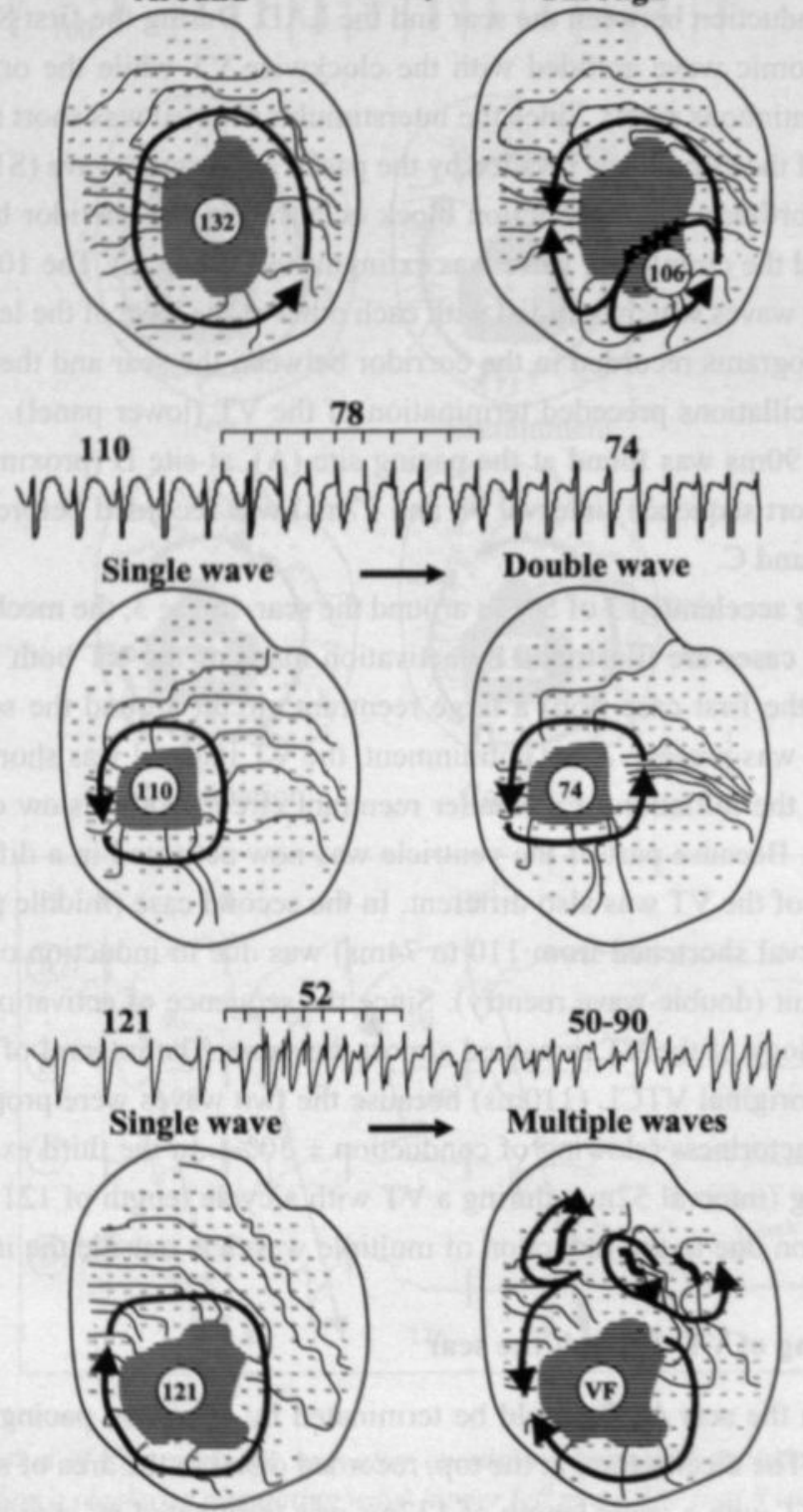

Figure 3. Various mechanisms of acceleration of VT by entrainment. Activation maps of VT before and after entrainment are shown. Isochrones at $10 \mathrm{~ms}$ intervals. Top: Before entrainment $V T$ was due to a large neentrant cincuit around the scar (CL $132 \mathrm{~ms})$. After entrainment a smaller reentrant circuit with a slow conduction zone through the scar was present (CL 106ms). Middle: Acceleration of VT from a VTCL of 110 to $74 \mathrm{~ms}$ by induction of double wave reentry. Bottom: Ovendrive pacing at a very high rate (SI-S1: $52 \mathrm{~ms})$ transformed the VT (CL 121 ms) into VF due to the induction of multiple wavelet reentry around functional lines of conduction block (CL. $50-90 \mathrm{~ms})$. 
counterclockwise reentrant circuit with a slow conduction zone through the infarcted area (VT). The exit site $(t=0)$ was located at the inferior border of the scar. Overdrive pacing was performed at the superior border of the scar, proximal to the slow conduction zone. During entrainment the paced antidromic wave collided with the counterclockwise VT while the orthodromic wave restarted VT (S1-3). Since the interstimulus interval was relatively long ( $80 \%$ of VTCL), only a small portion of the circuit was invaded by the paced antidromic wave. The orthodromic wave initiated by the 4 th stimulus was blocked within the scar, resulting in termination of the tachycardia (S4). After termination, the paced impulses now activated the whole free wall of the left ventricle in a clockwise direction (S5-10). In the lower panel, 4 electrograms are shown recorded from the segment of slow conduction. Electrogram A and D from the entrance and exit of the area of slow conduction were recorded at normal gain. The electrograms from the infarcted area itself were recorded with a gain of $1000 \mathrm{x}$. At the pacing site the ventricle was captured in a 1:1 manner with a constant interval of $105 \mathrm{~ms}$. At the exit of the area of slow conduction the interval increased from 105 to $117 \mathrm{~ms}$ before conduction block occurred (Wenkebach block). The electrograms recorded from the scar were fractionated and of low amplitude. The different components of the fractionated electrograms (small arrows) bridged the time window between the activation of the entrance and exit of the infaret. During S1-S3 small changes in morphology of the fractionated electrograms occurred. At the fourth stimulus which terminated the tachycardia, the morphology of the electrograms changed more markedly and became completely different after $\mathrm{S} 5$ when the ventricle was activated in opposite direction.

Sustained acceleration of VT through the scar after overdrive pacing was never observed. However, in two experiments a single accelerated beat occurred after entrainment. An example is given in Fig. 5. The VT had a cycle length of $112 \mathrm{~ms}$ and was due to figure of eight reentry with a counterclockwise loop through the scar. After entrainment with a cycle length of $80 \mathrm{~ms}$, a single accelerated beat with a cycle length of $77 \mathrm{~ms}$ and a completely different morphology was observed. The maps show the activation pattern of the left ventricle during VT and after the last stimulus (S10). During VT the exit site $(\mathrm{t}=0)$ was located at the lateral border of the scar. From this exit site, the impulse propagated both in a clockwise and counterclockwise direction around the scar to its inferior $(t=20)$ and superior border $(\mathrm{t}=49 \mathrm{~ms})$ respectively. The circuit was completed by a slow conduction zone between the superior and lateral border of the scar. After S10, the impulse first exited from the lateral border of the scar $(t=0)$ and the left ventricle was activated in a similar way as during the VT (middle map). Then, $97 \mathrm{~ms}$ after this impulse had exited, a second wave emerged from the infarcted area at the inferior border (right map). Most likely, two slow conducting pathways were present in the infarct. The train of overdrive stimuli must have caused such a large conduction delay in the second slow conduction zone, that it could excite the ventricle again after it was already activated by the other earlier exiting pathway. 

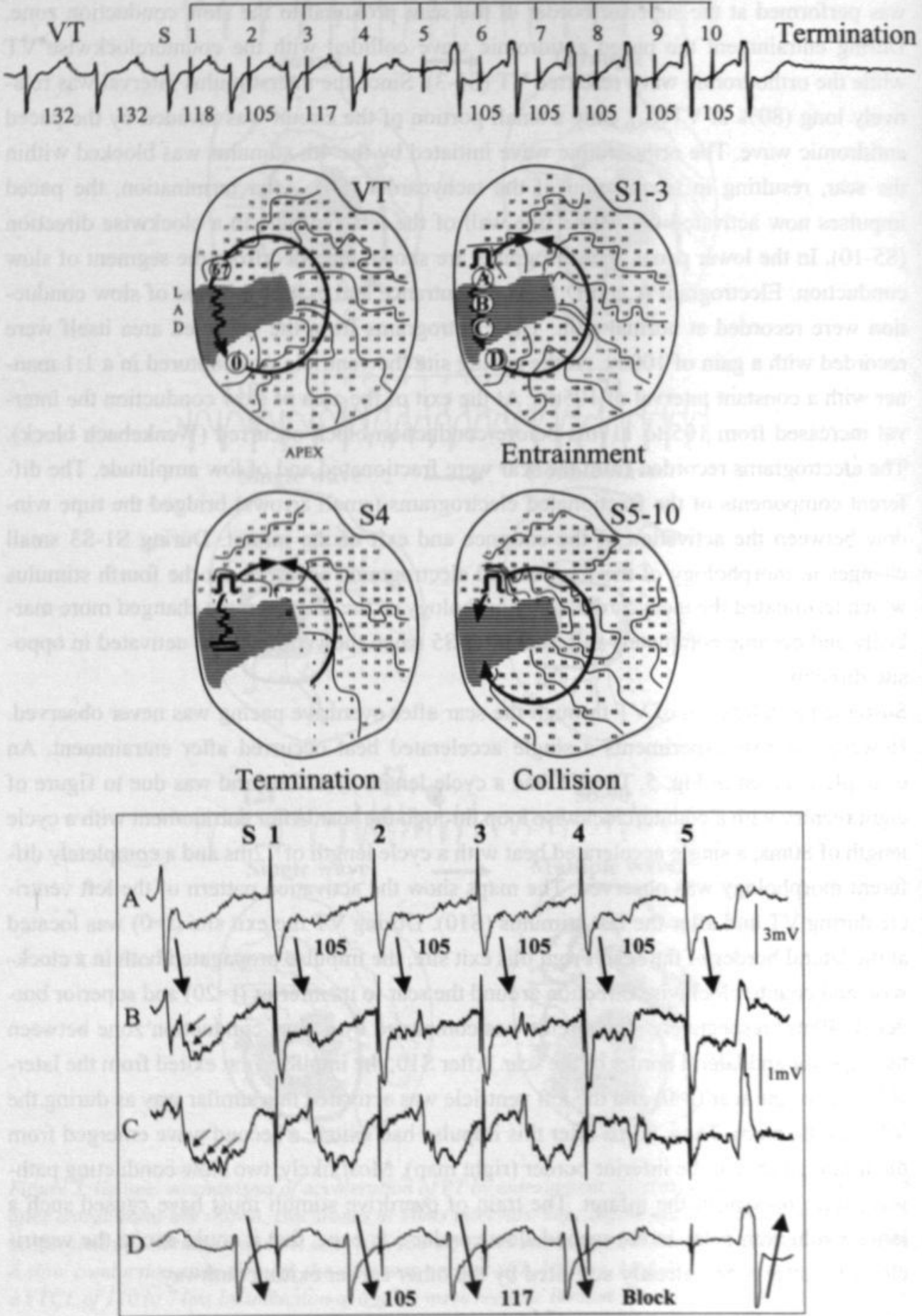
Left: Figure 4. Termination of VT through the scar after ovendrive pacing with an intenval of $105 \mathrm{~ms}$. The electrogram at the top was reconded distal to the slow conduction zone (site D in S1-3 map). The $V T$ was based on a counterclockwise cinculating wavefront with a slow conduction sone in the infarcted area (upper left map). In the VT map the exit site at the inferior bonder of the scar was taken as $t=0$. In the other maps, the moment of stimulation was taken as $t=0$. The first 3 stimuli (SI-3) nesulted in entrainment of VT (upper right map). At $\$ 4 V T$ was terminated because of orthodromic conduction block in the slow conduction zone (lower left map). After termination, the whole free wall of the left ventricle was activated in a clockwise direction. The two paced wavefronts collided within the infarcted area (lower right map). Isochrones are drawn at $10 \mathrm{~ms}$ intenvals; double bars indicate conduction block; the letters $A$ to $D$ indicate the recondings sites of the 4 electrognams presented at the bottom. Bottom: The entrance of the slow conduction zone $(A)$ was paced at a constant interval of $105 \mathrm{~ms}$. At the exit of the infarct (D) the interval increased from 105 to $117 \mathrm{~ms}$ before conduction block occurred (Wenckebach block). The individual components of the fractionated electrognams reconded from the scar $(B$ and $C$ ) bridge the time window between the electrical activation of the entrance and exit of the infarct.
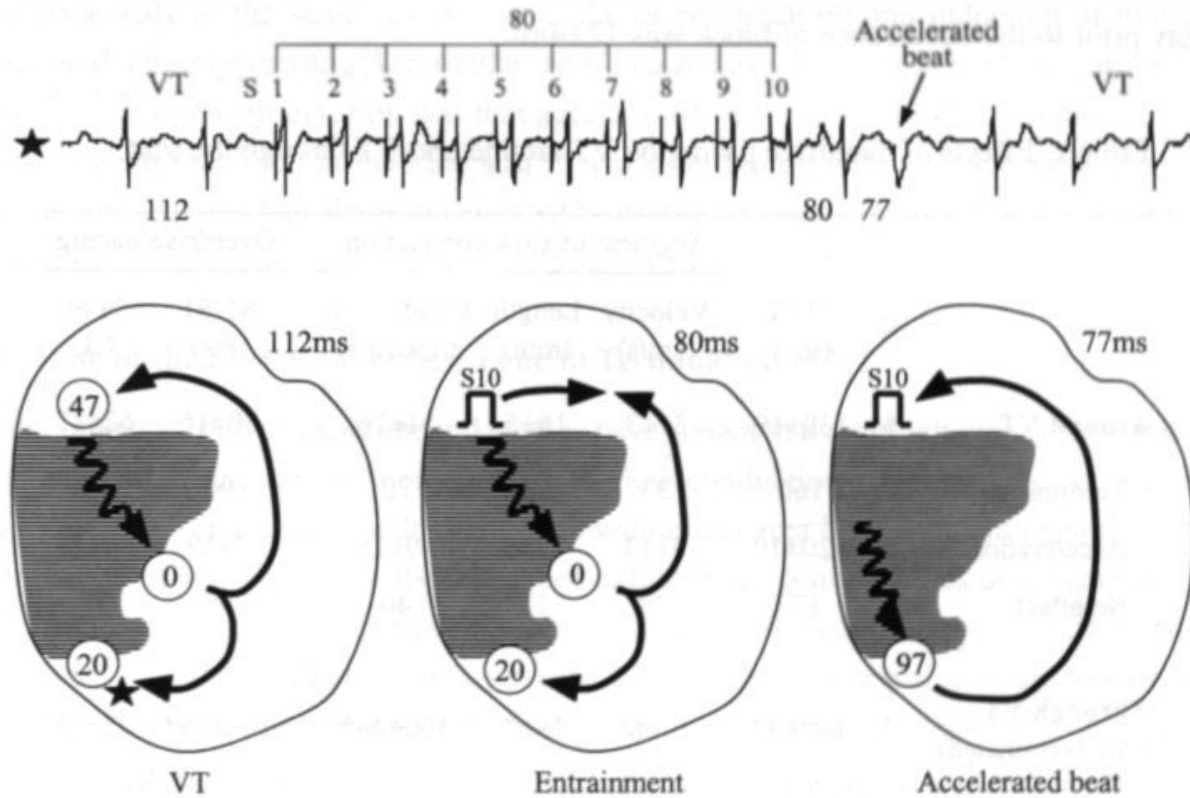

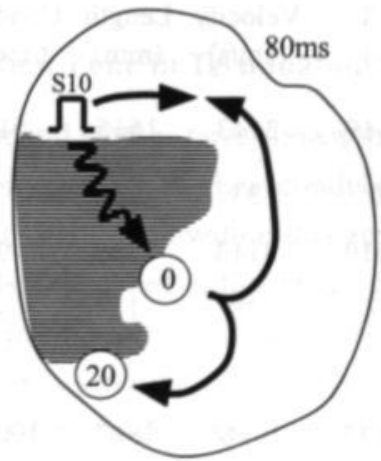

Entrainment

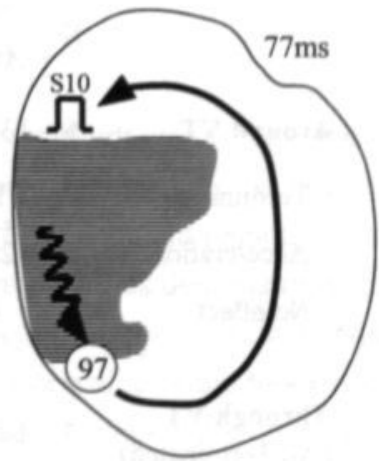

Accelerated beat

Figure 5. Occurrence of one accelerated beat after entrainment of VT. The maps show the activation during VT (cycle length $112 \mathrm{~ms}$ ), entrainment of VT (cycle length $80 \mathrm{~ms}$ ), and the accelerated beat (cycle length $77 \mathrm{~ms}$ ). The VT was based on a figure-of-eight like circuit with a slow central common pathway (zig-zag arrow) between the superior border of the scar $(t=47)$ and the exit at the lateral border $(t=0)$. After $S 10$, the orthodromic paced impulse firstly exited from the lateral border of the scar $(t=0)$ and the left ventricle was activated in a similar way as during VT (middle panel). Then, $97 \mathrm{~ms}$ after this impulse had exited, another wavefront started from the inferior border of the scar which excited the ventricle again (right panel). 


\section{All Experiments}

In Table 1 the differences between the reentrant circuits around the scar and the reentrant circuits through the scar are summarized. The VTs through the scar tended to be slower than the VTs around the scar (VTCL $149 \pm 33$ versus $130 \pm 19 \mathrm{~ms}$ ) because the conduction time through the segment of slow conduction was longer $(100 \pm 43$ versus $51 \pm 16 \mathrm{~ms}$, $p<0.01$ ). This was due to slower conduction through the scar compared to transverse con-

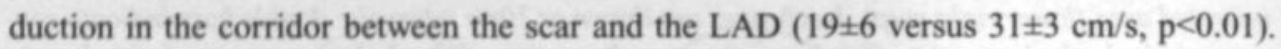
All VTs through the scar $(n=7)$ were terminated by overdrive pacing. On the average, the pacing interval resulting in termination of VT was $71 \pm 11 \%$ of the VTCL. The VTs around the scar could not be terminated by overdrive pacing with a similar stimulus interval. Overdrive pacing with a stimulus interval of $60 \pm 15 \%$ of the VTCL accelerated 3 of 5 VTs around the scar. Only one VT around the scar could be extinguished by overdrive pacing with an interval of $56 \%$ of the VTCL.

Termination of VT through the scar was always due to orthodromic conduction block in the infarcted area. Orthodromic block within the infarct occurred between the 1st and 5th captured beat (mean 2.4 \pm 1.8 ). In 5 of 7 cases the conduction time through the infarcted area increased before conduction block occurred (Wenkebach block). The average conduction delay prior to the occurrence of block was $12 \pm 4 \mathrm{~ms}$.

Table 1. Effects of overdrive pacing on VT around and VT through the scar

\begin{tabular}{|c|c|c|c|c|c|c|c|}
\hline & \multirow[b]{2}{*}{$\mathrm{N}$} & \multirow[b]{2}{*}{$\begin{array}{l}\text { VTCL } \\
\text { (ms) }\end{array}$} & \multicolumn{3}{|c|}{ Segment of slow conduction } & \multicolumn{2}{|c|}{ Overdrive pacing } \\
\hline & & & $\begin{array}{l}\text { Velocity } \\
(\mathrm{cm} / \mathrm{s})\end{array}$ & $\begin{array}{l}\text { Length } \\
\text { (mm) }\end{array}$ & $\begin{array}{l}\text { Conduction } \\
\text { time (ms) }\end{array}$ & $\begin{array}{l}\text { S1-S1 } \\
\text { (ms) }\end{array}$ & $\begin{array}{c}\% \text { of } \\
\mathrm{CL}\end{array}$ \\
\hline Around VT & 5 & $130 \pm 19$ & $31 \pm 3$ & $16 \pm 5$ & $51 \pm 16$ & $80 \pm 16$ & $62 \pm 12$ \\
\hline Termination & 1 & 160 & 33 & 23 & 70 & 90 & 56 \\
\hline Acceleration & 3 & $120 \pm 10$ & $31 \pm 3$ & $15 \pm 5$ & $49 \pm 15$ & $73 \pm 9$ & $60 \pm 15$ \\
\hline No effect & 1 & 127 & 28 & 11 & 40 & 90 & 71 \\
\hline $\begin{array}{l}\text { Through VT } \\
\text { (All Terminated) }\end{array}$ & 7 & $149 \pm 33$ & $19 \pm 6^{*}$ & $18 \pm 7$ & $100 \pm 43^{*}$ & $104 \pm 19^{*}$ & $71 \pm 11$ \\
\hline
\end{tabular}

* $\mathrm{p}<0.05$ vs around VT

\section{Discussion}

\section{Differential Effects of Overdrive Pacing on Reentrant VT}

Overdrive pacing of reentrant VT typically results in entrainment at slow pacing rates and in termination or acceleration at faster rates. ${ }^{2,15,16}$ Direct evidence for the mechanisms responsible for termination and acceleration by overdrive pacing has been provided by high 
density mapping studies using experimental models of reentrant VT. Termination of functional reentrant VT in the epicardial borderzone of canine myocardial infarction has been shown to be due to either orthodromic conduction block in the central common pathway or gradual diminishment of the lines of functional block. ${ }^{8.9}$ In rings of rabbit epicardium, termination of anatomic VT around a cryolesion was most frequently due to complete orthodromic conduction block, but partial orthodromic block resulting in reflection of an antidromic echo-wave could also occur (echo-wave termination). ${ }^{17}$ In the present study, we demonstrated that the ability to terminate VT mainly depended on whether the reentrant circuit comprised a slow conduction zone through the infarcted area. Whereas only 1 of 5 VTs around the scar could be terminated, all VTs based on a reentrant circuit partly consisting of a slow conduction zone through the infarct were terminated $(n=7)$. In all cases termination was due to orthodromic conduction block in the slow conduction zone, suggesting that the safety factor for conduction was lowest in this part of the circuit. The fact that most VTs around the scar could not be terminated by overdrive pacing indicates that all segments of the circuit had a high safety factor for conduction. Overdrive pacing at very rapid rates $(73 \pm 9 \mathrm{~ms}, 60 \pm 15 \%$ of VTCL) resulted in acceleration of these VTs. Different mechanisms of acceleration were found. Double wave reentry (two waves propagating simultaneously in the same circuit and in the same direction) and induction of multiple functional circuits causing ventricular fibrillation have been described in earlier studies. ${ }^{8,10,18,19}$ A new observation was that acceleration of VT could be due to a change from a macroreentrant circuit around the scar to a smaller circuit with a slow conduction zone through the scar and that single accelerated beats after entrainment of VT could result from dissociated conduction over two slow pathways within the infarcted area.

\section{The Role of the Slow Conduction Zone in Termination of VT}

Both clinical as well as experimental studies have shown that reentrant circuits causing VT after myocardial infarction often comprise a slow conduction zone through the infarcted area. ${ }^{12,14,20,21}$ Orthodromic conduction block within this area has been held responsible for termination of VT, ${ }^{3,6,8}$ as was also observed in this study. Some studies demonstrated that prior to conduction block clear oscillations in cycle length occur within the slow conduction zone. ${ }^{17,22}$ These oscillations may culminate in a last short interval, causing block of the circulating wave. In the present study, interval oscillations prior to block were observed in one experiment (Fig.2). However, since the exact local intervals are difficult to determine from the low amplitude and fractionated electrograms recorded from the infarcted area, it can not be excluded that oscillations in cycle length occurred within the slow conduction zone.

In patients with a healed myocardial infarction, Callans et al. ${ }^{23}$ showed that termination of VT by overdrive pacing was preceded by an increase in interval of successive paced beats. In our study, in 5 of 7 cases the return cycle after successive paced impulses prolonged before termination of VT. This was due to a progressive increase in conduction time through the infarct. Wenkebach-type of conduction block is a typical feature of tissue with 
decreased excitability such as the AV-node ${ }^{24}$ In chronically infarcted myocardium regions of low excitability may exist because of altered membrane properties or partial membrane depolarization. Pu et al. ${ }^{25}$ demonstrated that ischemia-induced alterations in the $\mathrm{Na}^{+}$channel reduced the excitability of surviving myocytes in the epicardial borderzone of canine myocardial infarction. In addition, the recovery of excitability was delayed beyond the repolarization phase of the action potential (post-repolarization refractoriness). Also geometrical factors such as paucity of intercellular connections ${ }^{26}$ and a complex network of small bundles separated by connective tissue ${ }^{27}$ may play a role in the occurrence of preferential conduction block within the infarcted area.

\section{Clinical Implications}

Clinically, termination of VT by overdrive pacing is possible in $60-95 \%$ of cases. ${ }^{5,7.28}$ The cycle length of the tachycardia appears to be a major determinant of this ability to terminate VT. ${ }^{7}$ Slow VTs are often terminated easily, whereas faster VTs are more difficult to terminate by pacing. VTs with a cycle length of less than $300 \mathrm{~ms}$ have an almost $40 \%$ chance to be accelerated by antitachycardia pacing. ${ }^{5,7}$ Our results may contribute to the understanding of this differential effect depending on cycle length. We also found that overdrive pacing terminated slow VTs more easily and that the risk of acceleration was higher in more rapid VTs. The average cycle length of the tachycardias that terminated was $150 \pm 30$ $(n=8)$ compared to $120 \pm 10 \mathrm{~ms}(\mathrm{n}=3)$ of those that accelerated $(\mathrm{p}<0.05)$. The VTs that terminated were based on a reentrant circuit comprising a slow conduction zone through the infarct $(\mathrm{n}=7)$ or a relatively long corridor of slow transverse conduction between the scar and the LAD $(n=1)$. The VTs that accelerated were based on a reentrant circuit around the scar with a relatively short segment of transverse conduction. As such, the response of VT to overdrive stimulation may be used as an indirect parameter to determine the substrate of $\mathrm{VT}$ in patients. However, extrapolation of our observation to the clinical situation should be performed with caution. The substrate for clinical VT has a complex 3-dimensional architecture and the response of VT to overdrive pacing depends on the way the reentrant circuit is connected to the rest of the ventricles and on the position of the pacing site relative to the area of slow conduction. ${ }^{16}$ Our experimental model consisted of a thin (2-dimensional) layer of subepicardium and overdrive pacing was performed closely proximal to the entrance of the area of slow conduction. 


\section{References}

1. Wellens HJ, Schuilenburg RM, Durrer D. Electrical stimulation of the heart in patients with ventricular tachycardia. Circulation. 1972;46:216-26.

2. Waldo A, Henthorn R, Plumb V, MacLean W. Demonstration of the mechanisms of transient entrainment and interruption of ventricular tachycardia by rapid atrial pacing. $\mathrm{J} \mathrm{Am} \mathrm{Coll}$ Candiol. 1984;3:422.

3. Okumura K, Olshansky B, Henthorn R, Epstein A, Plumb V, Waldo A. Demonstration of the presence of slow conduction during sustained ventricular tachycardia in man: use of transient entrainment of the tachycardia. Circulation. 1987;75:369-378.

4. Kay G, Epstein A, Plumb V. Incidence of reentry with an excitable gap in ventricular tachycardia: in a prospective evaluation utilizing transient entrainment. J.Am.Coll.Candiol. 1988;11:530538.

5. Waldecker B, Brugada P, Zehender M, Stevenson W, Den Dulk K, Wellens HJ. Importance of modes of electrical termination of ventricular tachycardia for the selection of implantable antitachycardia devices. Am J Candiol. 1986;57:150-5 .

6. Aizawa $\mathrm{Y}$, Niwano $\mathrm{S}$, Chinushi $\mathrm{M}$, et al. Incidence and mechanism of interruption of reentrant ventricular tachycardia with rapid ventricular pacing. Circulation. 1992;85:589-595.

7. Roy D, Waxman H, Buxton A, Marchlinski F, Cain M, Gardner M, Josepson M. Termination of ventricular tachycardia: Role of tachycardia cycle length. Am J Cardiol. 1982;50:1346.

8. el Sherif N, Gough WB, Restivo M. Reentrant ventricular arrhythmias in the late myocardial infaretion period: 14. Mechanisms of resetting, entrainment, acceleration, or termination of reentrant tachycardia by programmed electrical stimulation. Pacing Clin Electrophysiol. 1987;10:341-71.

9. Waldecker B, Coromilas J, Saltman AE, Dillon SM, Wit AL. Overdrive stimulation of functional reentrant circuits causing ventricular tachycardia in the infareted canine heart. Resetting and entrainment. Circulation. 1993;87:1286-305.

10. Dillon SM, Coromilas J, Waldecker B, Wit AL. Effects of overdrive stimulation on functional reentrant circuits causing ventricular tachycardia in the canine heart: mechanisms for resumption or alteration of tachycardia. J Cardiovasc Electrophysiol. 1993;4:393-411.

11. Wit AL, Allessie MA, Bonke FI, Lammers W, Smeets J, Fenoglio JJ, Jr. Electrophysiologic mapping to determine the mechanism of experimental ventricular tachycardia initiated by premature impulses. Experimental approach and initial results demonstrating reentrant excitation. $\mathrm{Am} \mathrm{J}$ Cardiol. 1982;49:166-85.

12. Ursell PC, Gardner PI, Albala A, Fenoglio JJ, Jr., Wit AL. Structural and electrophysiological changes in the epicardial border zone of canine myocardial infarcts during infarct healing. Circ Res. 1985;56:436-51.

13. Gardner PI, Ursell PC, Fenoglio JJ, Jr., Wit AL. Electrophysiologic and anatomic basis for fractionated electrograms recorded from healed myocardial infarcts. Circulation. 1985;72:596-611.

14. de Bakker JM, van Capelle FJ, Janse MJ, Wilde AA, Coronel R, Becker AE, Dingemans KP, van Hemel NM, Hauer RN. Reentry as a cause of ventricular tachycardia in patients with chronic ischemic heart disease: electrophysiologic and anatomic correlation. Circulation. 1988;77:589606.

15. Waldo A, Henthorn R. Use of transient entrainment during ventricular tachycardia to localize a critical area in the reentry circuit for ablation. Pace. 1989;12:231-244.

16. Okumura K, Henthorn R, Epstein A, Plumb V, Waldo A. Further observations on transient entrainment: importance of pacing site and properties of the components of the reentrant circuit. Circulation. 1985;6:1293-1307.

17. Boersma L, Brugada J, Kirchhof C, Allessie M. Entrainment of reentrant ventricular tachycardia in anisotropic rings of rabbit myocardium. Mechanisms of termination, changes in morphology, and acceleration. Circulation. 1993;88:1852-65.

18. Brugada J, Boersma L, Kirchhof C, Brugada P, Havenith M, Wellens HJ, Allessie M. Doublewave reentry as a mechanism of acceleration of ventricular tachycardia. Circulation. 1990;81:1633-43. 
19. Brugada J, Brugada P, Boersma L, Mont L, Kirchhof C, Wellens HJ, Allessie MA. On the mechanisms of ventricular tachycardia acceleration during programmed electrical stimulation. Circulation. 1991;83:1621-9.

20. El Sherif N, Scherlag BJ, Lazzara R, Hope RR. Reentrant ventricular arrhythmias in the late myocardial infarction period. 1. Conduction characteristics in the infarction zone. Circulation. 1977;55:686-702.

21. Dillon SM, Allessie MA, Ursell PC, Wit AL. Influences of anisotropic tissue structure on reentrant circuits in the epicardial border zone of subacute canine infarcts. Circ Res. 1988;63:182206.

22. Frame L, Simson M. Oscillations of conduction, action potentials duration, and refractoriness. A mechanism for spontaneous termination of reentrant tachycardias. Circulation. 1988;78:1277-1287.

23. Callans DJ, Hook BG, Mitra RL, Josephson ME. Characterization of return cycle responses predictive of successful pacing-mediated termination of ventricular tachycardia. J Am Coll Candiol. 1995;25:47-53.

24. Merideth J, Mendez C, Mueller W. Electrical excitability of atrioventricular nodal cells. Cinc Res. 1968;23:69-85.

25. Pu J, Boyden P. Alterations of $\mathrm{Na}$ + currents in myocytes from epicardial border zone of infareted heart. A possible mechanism for reduced excitability and postrepolarization refractoriness. Circ Res. 1997;81:110-119.

26. Peters NS, Coromilas J, Severs NJ, Wit AL. Disturbed connexin43 gap junction distribution correlates with the location of reentrant circuits in the epicardial border zone of healing canine infarcts that cause ventricular tachycardia. Circulation. 1997;95:988-96.

27. de Bakker JM, Coronel R, Tasseron S, Wilde AA, Opthof T, Janse MJ, van Capelle FJ, Becker AE, Jambroes G. Ventricular tachycardia in the infareted, Langendorff-perfused human heart: role of the arrangement of surviving cardiac fibers. J Am Coll Cardiol. 1990;15:1594-607.

28. Saksena S, Chandran $\mathrm{P}$, Shah $\mathrm{Y}$, al e. Comparative efficacy of transvenous cardioversion and pacing in patients with sustained ventricular tachycardia: A prospective, randomized, crossover study. Circulation. 1985;72:153-160. 


\section{Chapter 7}

Differential Effects of Anti-Arrhythmic Drugs on Various Types of Reentrant VT in Rabbit Hearts with a Healed Myocardial Infarction 


\section{Chapter 7}

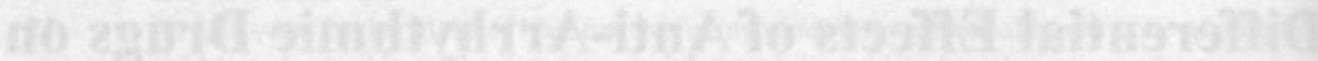

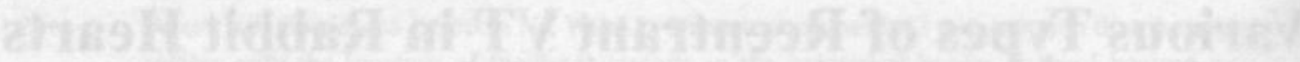

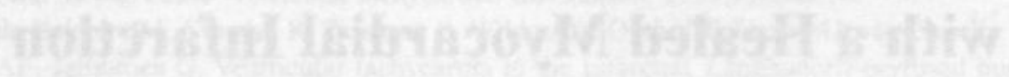

$-142-$ 


\section{Introduction}

Despite continuing concerns over their efficacy and safety, antiarrhythmic drugs remain an important therapeutic option for patients with chronic ischemic heart disease suffering from ventricular tachyarrhythmias. ${ }^{1-4}$ The choice for a particular antiarrhythmic agent depends on the underlying mechanism of the arrhythmia. ${ }^{5}$ Many studies have shown that ventricular tachycardia (VT) after myocardial infarction is based on reentry and that the reentrant circuits often comprise a zone of slow conduction within the infarcted area. ${ }^{6-10}$ However, the exact nature of slow conduction through the infarct and how it is influenced by antiarrhythmic drugs is still incompletely understood. Since the electrophysiological properties of the arrhythmogenic substrate may vary from patient to patient, ${ }^{11,12}$ understanding of the effects of antiarrhythmic drugs on various substrates of reentrant VT might be useful to guide antiarrhythmic therapy.

We developed a model of reentrant VT in Langendorff perfused subepicardium of the rabbit heart containing an area of healed ( 3 months old) myocardial infaretion. In this model, VT could be based either on reentry around the scar, reentry within the scar, or, most frequently, on a reentrant circuit containing a segment of slow conduction zone through the scar. To gain more insights into the effects of anti-arrhythmic drugs on these different types of reentrant VT and to better understand how they effect conduction in the infarcted myocardium, high density mapping of the reentrant circuits was performed during infusion of flecainide (sodium channel blockade), verapamil (calcium channel blockade) and d-sotalol (potassium channel blockade). Our results show that flecainide preferentially depressed conduction in the area of slow conduction within the infarct. Consequently, reentry through the scar was terminated by a much lower concentration of flecainide than reentry around the infarcted area. Changes in morphology of VT during infusion of flecainide were mainly due to changes in exit site of the reentrant circuit. $\mathrm{d}$-Sotalol hardly affected the reentrant circuits at therapeutic concentrations, whereas verapamil terminated only 1 of 3 VTs.

\section{Methods}

\section{Preparation}

In Langendorff perfused rabbit hearts with a healed ( $12 \pm 3$ weeks old) myocardial infarction, a thin layer of left ventricular subepicardium was created by a cryoprocedure. Details of the surgical procedure, the perfusion system and the cryoprocedure have been descibed in Chapter 4.

\section{Recording and Stimulation}

The epicardium of the left ventricle was mapped with a spoon-shaped mapping array containing 240 silver electrodes (diameter $0.3 \mathrm{~mm}$ ) with an interelectrode distance of $2.25 \mathrm{~mm}$. The on-line mapping system to record and analyze the data is described in Chapter 4. Local conduction velocities were calculated normal to the isochrones. Bipolar stimulation could be performed through any selected pair of electrodes in the spoon electrode. 


\section{Experimental Protocol}

Sustained monomorphic ventricular tachycardia (VT) was induced by programmed electrical stimulation using 1-3 premature stimuli or incremental pacing. Flecainide, d-sotalol and verapamil were dissolved in Tyrode and added to the perfusion fluid by an infusion pomp. The concentration of flecainide was raised in steps of $1 \mathrm{mg} / \mathrm{l}$ until VT was terminated. d-Sotalol was tested at concentrations of $10,20,40$ and $80 \mathrm{mg} / 1$ and verapamil at 0.1 , $0.2,0.5$ and $1.0 \mathrm{mg} / \mathrm{l}$. At each concentration, an equilibrium time of 15 minutes was taken into account before the concentration was increased.

\section{Statistical Analysis}

The data are presented as mean \pm standard deviation. Differences between VT around the scar and VT through the scar were compared with the unpaired Student's t-test. Conduction during control and different concentrations of flecainide were compared by a one-way ANOVA or the paired Student's t-test. Differences were considered statistically significant at p-values $<0.05$.

\section{Results}

\section{Effects of Flecainide}

VT around the scar. Fig. 1 shows the effects of flecainide on a VT based on reentry around the scar. During control, the wavefront circulated in a counterclockwise direction around the scar with a cycle length of $158 \mathrm{~ms}$. In the corridor between the scar and the LAD slow conduction occurred transverse to the fiber orientation while at the base and the free wall longitudinal conduction was much faster (Chapter 4). Flecainide progressively prolonged the VTCL from $158 \mathrm{~ms}$ (control) to $396 \mathrm{~ms}(4 \mathrm{mg} / \mathrm{l})$ and $502 \mathrm{~ms}(6 \mathrm{mg} / \mathrm{l})$. The activation maps show that during infusion of flecainide the number of isochrones increased markedly, due to a strong depression of conduction. At $6 \mathrm{mg} / 1$, more than 6 isochrones could be present between two adjacent electrodes (conduction velocity less than $5 \mathrm{~cm} / \mathrm{s}$ ). Also, small local lines of functional conduction block occurred. Despite this strong depression of conduction, the VT continued with a cycle length more than 3 times longer as during control. Finally VT terminated by conduction block between site $\mathrm{D}$ and $\mathrm{E}$ in the corridor between the scar and the LAD.

Right: Figure 1. Effects of flecainide on reentrant VT around the scar. The four maps show the activation pattern of VT during control, after administration of 4 and $6 \mathrm{mg} / \mathrm{l}$ of flecainide and during termination of the VT. During control the counterclockwise circulating wave propagated around the scar with a cycle length of $158 \mathrm{~ms}$ (upper left). During 4 and $6 \mathrm{mg} /$ of flecainide, the VT cycle length increased to respectively 396 (upper right) and $502 \mathrm{~ms}$ (lower left), due to a strong depression of conduction (crowding of isochrones). At $6 \mathrm{mg} /$, small lines of functional conduction block occurred (thick lines). At this high concentration, complete conduction block between sites $D$ and $E$ in the corridor behween the scar and the LAD finally terminated the VT (lower right). The five electrograms at the bottom were neconded at sites $A-E$, as indicated in the lower right activation map. Activation times are given in milliseconds. Isochrones are drawn at $10 \mathrm{~ms}$ intervals, double bars indicate conduction block. 
Effects of Flecainide on VT around the scar

Control

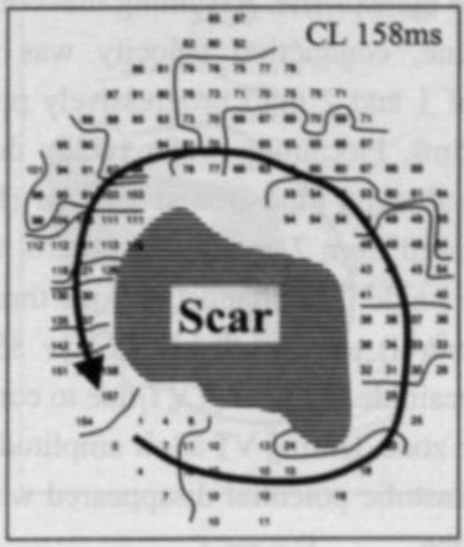

$6 \mathrm{mg} / \mathrm{l}$

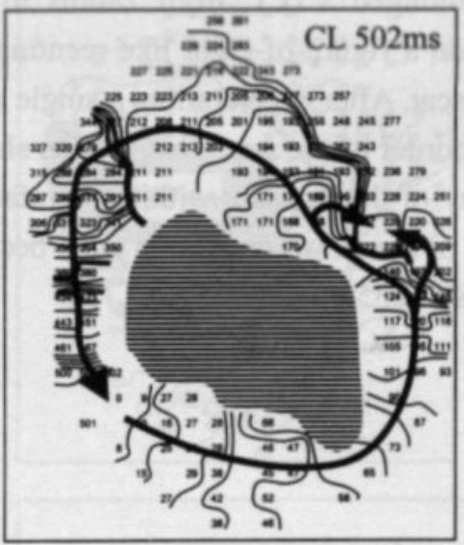

$4 \mathrm{mg} / \mathrm{l}$

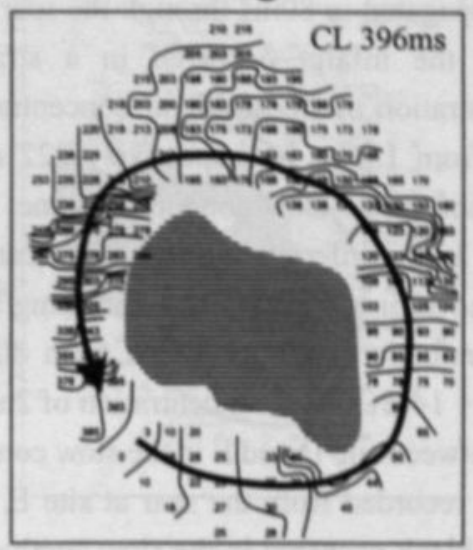

Termination $(6 \mathrm{mg} / \mathrm{l})$

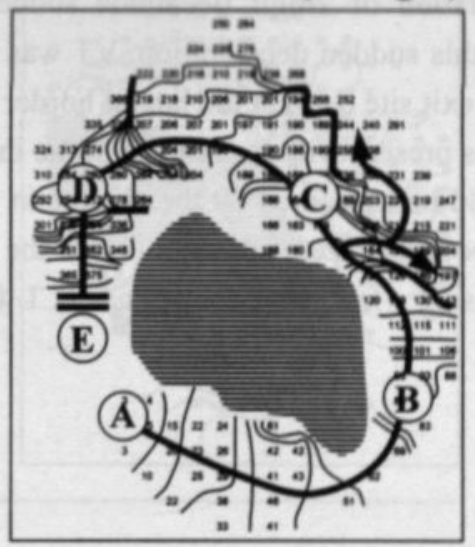

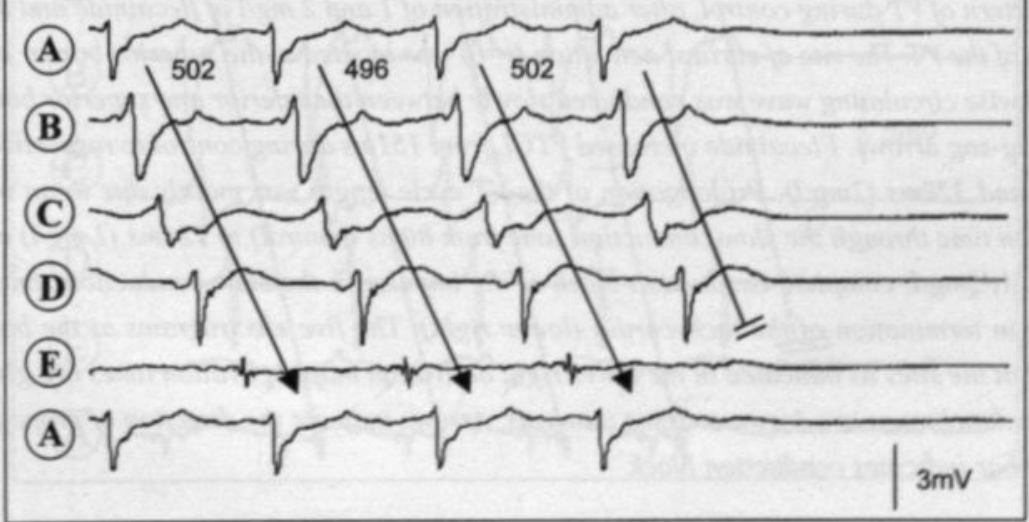




\section{Chapter 7}

VT through the scar. Fig. 2 shows the effects of flecainide on VT based on a clockwise reentrant circuit with an area of slow conduction through the scar. The VT cycle length was $151 \mathrm{~ms}$. The site of earliest activation $(\mathrm{t}=0)$ was located at the superior border of the scar. From this exit site the impulse rotated around the scar to its inferior border in $71 \mathrm{~ms}$ and then propagated in $80 \mathrm{~ms}$ through the scar back to the exit site. Assuming that conduction through the infarct occurred in a straight line, conduction velocity was $17 \mathrm{~cm} / \mathrm{s}$. Administration of flecainide at concentrations of 1 and $2 \mathrm{mg} / 1$ progressively prolonged VTCL from $151 \mathrm{~ms}$ to respectively 222 and $315 \mathrm{~ms}$. Flecainide preferentially depressed conduction in the slow conduction zone. The conduction time around the scar (from the exit site to the inferior border of the scar) increased from $71 \mathrm{~ms}$ during control to 93 (+ $31 \%)$ and $125 \mathrm{~ms}(+76 \%)$ at 1 and $2 \mathrm{mg} / \mathrm{l}$ of flecainide. The conduction time through the slow conduction zone increased from $80 \mathrm{~ms}$ (control) to respectively $124(+55 \%)$ and $197 \mathrm{~ms}(+146 \%)$. At a concentration of $2 \mathrm{mg} / \mathrm{l}$, flecainide terminated VT due to conduction block between site D and $\mathrm{E}$ in the slow conduction zone. During VT a low amplitude potential was recorded from the scar at site E. This diastolic potential disappeared when conduction block occurred in the slow conduction zone.

Fig. 3 shows the effects of flecainide on another VT through the scar. In this example, at a concentration of $2 \mathrm{mg} / \mathrm{l}$ flecainide suddenly prolonged VTCL from $280 \mathrm{~ms}$ to $350 \mathrm{~ms}$. Before this sudden deceleration, VT was based on a figure-of-eight like reentrant circuit with an exit site $(\mathrm{t}=0)$ at the lateral border of the scar. After deceleration, a single reentrant loop was present with its exit site at the inferior border of the scar. This sudden slowing of VT could be explained by the change in pathway of the impulse within the infarct. As a result, both the size of the circuit and the length of the slow conduction zone became larger, causing a marked increase in VTCL from 280 to $350 \mathrm{~ms}$.

Right: Figure 2. Effects of flecainide on reentrant VT through the scar. The four maps show the activation pattern of VT during control, after administration of $I$ and $2 \mathrm{mg} / \mathrm{lof}$ flecainide and during termination of the VT. The site of earliest activation $(t=0)$ was located at the superior border of the scar. The clockwise circulating wave was conducted slowly between the inferior and superior border of the infarct (zig-zag arrow). Flecainide increased VTCL from $151 \mathrm{~ms}$ during control to respectively $227 \mathrm{~ms}$ $(l \mathrm{mg} / \mathrm{l})$ and $322 \mathrm{~ms}(2 \mathrm{mg} /)$. Prolongation of the VT cycle length was mainly due to an increase in conduction time through the slow conduction zone from $80 \mathrm{~ms}$ (control) to $124 \mathrm{~ms}$ (I mg/l) and $197 \mathrm{~ms}$ $(2 \mathrm{mg} / \mathrm{l})$. At $2 \mathrm{mg} /$, complete conduction block of the impulse in the slow conduction zone occurred resulting in termination of the tachycardia (lower right). The five electrograms at the bottom were reconded at the sites as indicated in the lower right activation map. Activation times are given in milliseconds. Isochrones are drawn at $10 \mathrm{~ms}$ intervals. Arrows indicate the direction of propagation and a double bar indicates conduction block. 
Effects of Flecainide on VT through the scar

\section{Control}

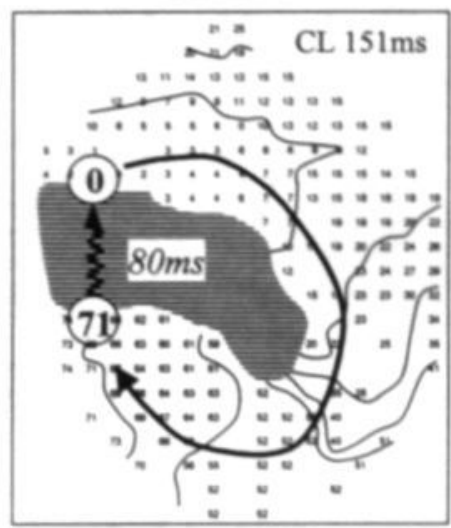

$2 \mathrm{mg} / \mathrm{l}$

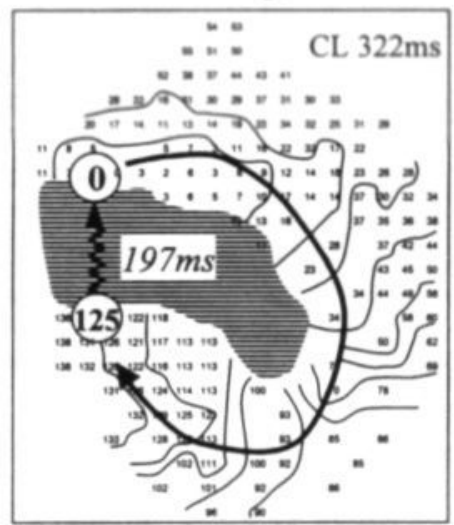

$1 \mathrm{mg} / 1$

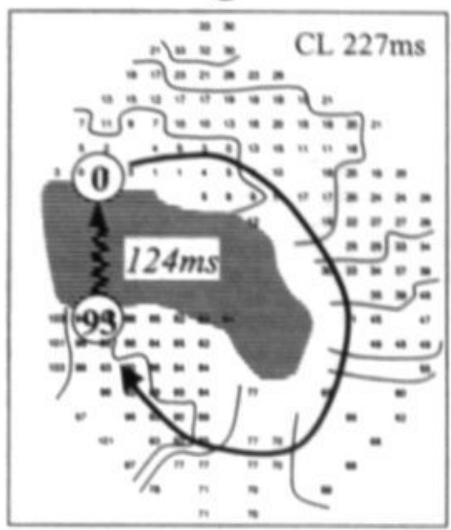

Termination $(2 \mathrm{mg} / \mathrm{l})$

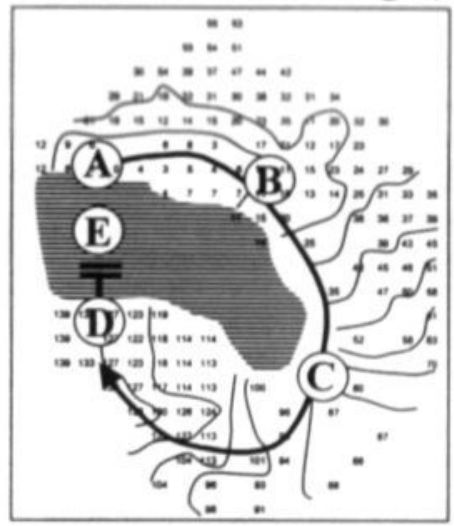

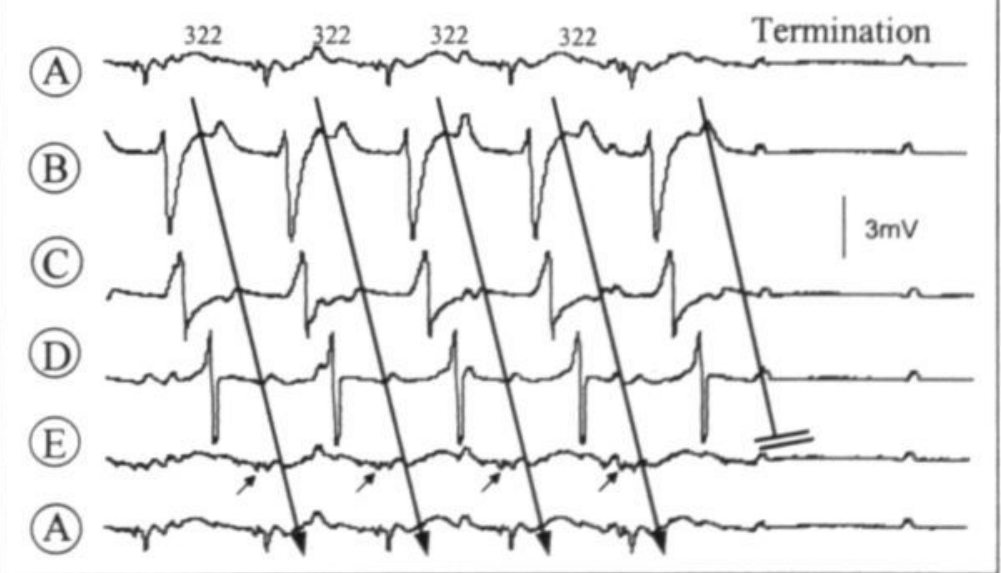




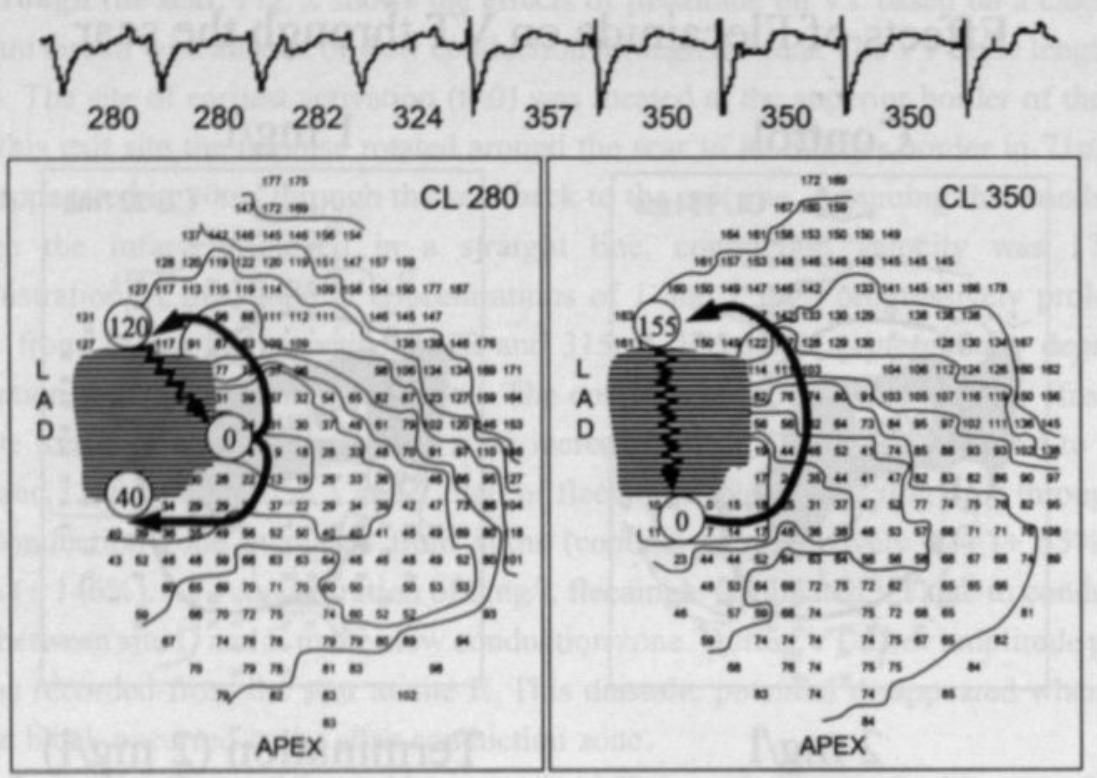

Figure 3. Sudden change in morphology of $V T$ after administration of $2 \mathrm{mg} / \mathrm{lof}$ flecainide. The maps show the activation pattern of the VT before (VTCL 280ms) and after (VTCL 350ms) deceleration. During the $280 \mathrm{~ms}$ cycle, the site of earliest activation $(t=0)$ was located at the lateral border of the scar. From this exit site, both a clockwise and a counterclockwise wavefront propagated around the scar to respectively its inferior $(t=40)$ and superior border $(t=120)$. The dominant counterclockwise loop was completed by a slow conduction zone through the scar (zig-zag arrow). During the $350 \mathrm{~ms}$ cycle, the site of earliest activation was located at the inferior border of the scar. The now single counterclockwise loop comprised a slow conduction zone between the superior and inferior border of the scar. Note that isochrones are drawn at $20 \mathrm{~ms}$ intervals.

VT within the scar. Fig. 4 shows the effects of flecainide on a VT due to reentry within the scar. The reentrant circuit was located within the scar because multiple exit sites were present and the electrograms recorded from the scar showed continuous electrical activity. In this example, one exit site was located close to the $\operatorname{LAD}(\# 1, t=0)$, a second exit site was located at right upper border of the scar $(\# 2, t=14)$ and a third exit occurred at the inferior border of the scar $(\# 3, t=104)$. The wavefronts emerging from the different exit sites collided with each other in the myocardium around the infarct. Infusion of flecainide markedly changed the morphology of the VT. At $2 \mathrm{mg} /$ the exit site near the LAD had disappeared and the VT was now based on a small counterclockwise loop at the base of the left ventricle comprising a slow conduction zone through the infarct. At a flecainide concentration of $3 \mathrm{mg} /$, the exit site at the right upper border of the scar was also blocked leaving only a single exit at the inferior border of the scar. As a result, the VT was now based on a large counterclockwise circuit comprising a slow conduction zone between the superior and inferior border of the scar. 


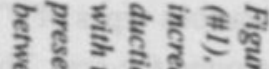

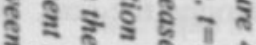
궁ำ क

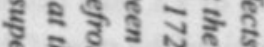

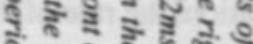
รี่

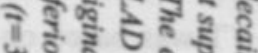
นัำ के क्षे ता के के है के के है क्ष सร ฐ ํำำำ के ริ

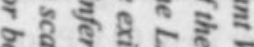
년ㄷำ

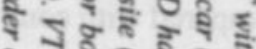
ใ ₹ ริ ริ

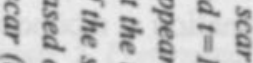
Iำ สิ อ 연 $\Rightarrow$

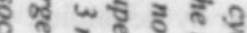
ร 8 कै ปै ₹ हु) ㅇำ ริธ ริำ ร. फ्. ส 3 ส 3 ป

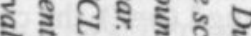
ริ $า 7$ ถิ 실 ह कू จ ปิ ริ ปี ถิำ 근

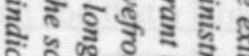

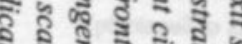
3 ล วิ

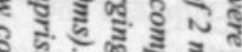
ริ

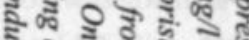

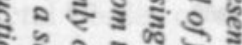

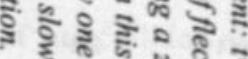
8 \& 늘 ำำำำ ․․ हूई है ह

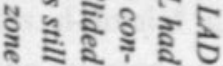

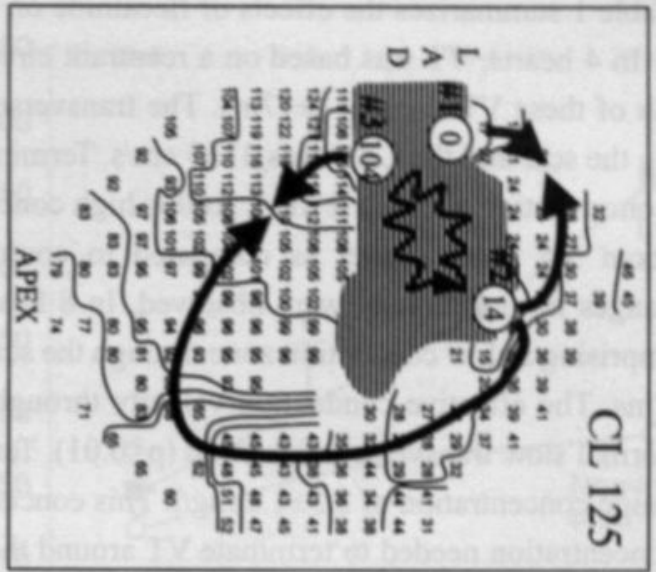

常

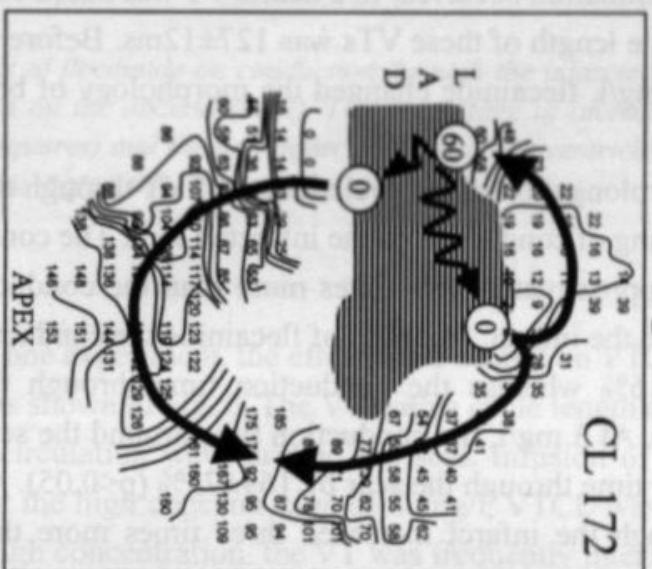

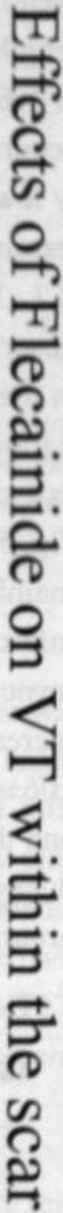

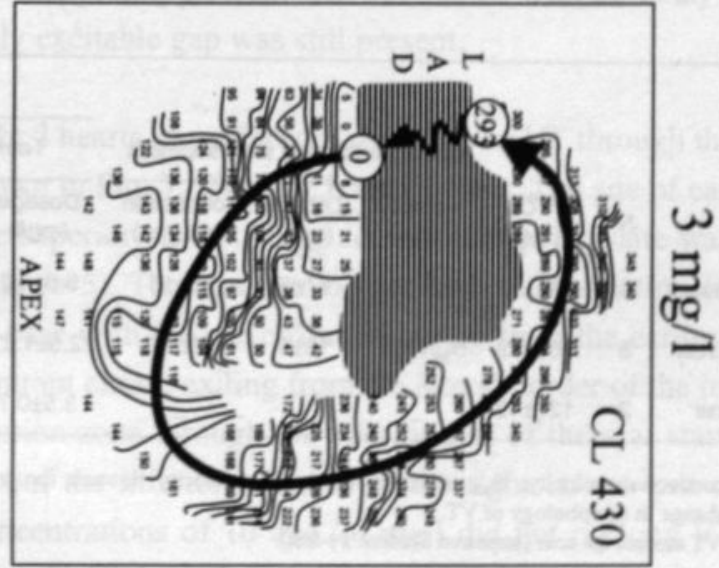




\section{Chapter 7}

All experiments. Table 1 summarizes the effects of flecainide on the various types of VT for all experiments. In 4 hearts, VT was based on a reentrant circuit around the scar. The average cycle length of these VTs was $134 \pm 17 \mathrm{~ms}$. The transverse conduction velocity in the corridor between the scar and the LAD was $31 \pm 3 \mathrm{~cm} / \mathrm{s}$. Termination of VT only occurred at a flecainide concentration of $5.0 \pm 1.2 \mathrm{mg} /$. At this high concentration, the rate of the tachycardia was about 3.5 times slower as compared to control (CL $451 \pm 80$ versus $134 \pm 17 \mathrm{~ms}$ ). No changes in morphology were observed. In 8 hearts, VT was based on a reentrant circuit comprising a slow conduction zone through the scar. The average VT cycle length was $150 \pm 22 \mathrm{~ms}$. The effective conduction velocity through the infarct was slower $(17 \pm 6 \mathrm{~cm} / \mathrm{s})$ than normal slow transverse conduction $(\mathrm{p}<0.01)$. Termination of VT already occurred at a flecainide concentration of $2.5 \pm 1.2 \mathrm{mg} /$. This concentration was significantly lower than the concentration needed to terminate VT around the scar $(p<0.01)$. Prior to termination, the rate of the tachycardia was about 2 times slower as compared with control (CL $334 \pm 119$ versus $150 \pm 22 \mathrm{~ms}$ ). In 2 of 8 hearts a change in morphology of VT was observed before termination occurred. In 2 hearts VT was based on a reentrant circuit within the scar. The cycle length of these VTs was $127 \pm 12 \mathrm{~ms}$. Before termination at a concentration of $3.5 \pm 0.3 \mathrm{mg} /$, flecainide changed the morphology of both VTs by a shift of the exit site.

Fig. 5 shows that prolongation of the cycle length of VT through the scar by flecainide was mainly due to slowing of conduction in the infarcted area. The conduction time through the infarct increased approximately two times more than the conduction time in the normal myocardium around the infarct. At $2 \mathrm{mg} / \mathrm{l}$ of flecainide the conduction time around the scar increased by $58 \pm 16 \%$ whereas the conduction time through the infarct increased by $106 \pm 43 \%(\mathrm{p}<0.05)$. At $3 \mathrm{mg} / \mathrm{l}$, the conduction time around the scar increased by $75 \pm 10 \%$ and the conduction time through the scar by $169 \pm 75 \%(\mathrm{p}<0.05)$. At $4 \mathrm{mg} / \mathrm{l}(\mathrm{n}=2)$, the conduction time through the infarct increased three times more than the conduction time around the scar (respectively $259 \pm 47 \%$ and $85 \pm 10 \%$ ).

Tabel 1.

\begin{tabular}{|c|c|c|c|c|c|c|c|c|}
\hline & \multirow[b]{3}{*}{$\mathbf{N}$} & \multirow[b]{3}{*}{$\begin{array}{l}\text { VTCL } \\
\text { (ms) }\end{array}$} & & & & \multicolumn{3}{|c|}{ Effects of flecainide } \\
\hline & & & \multicolumn{3}{|c|}{ Characteristics of slow segment } & \multicolumn{2}{|c|}{ Termination } & \multirow{2}{*}{$\frac{\Delta \text { Morphology }}{N}$} \\
\hline & & & $\begin{array}{l}\text { Velocity } \\
\text { (cm/s) }\end{array}$ & $\begin{array}{l}\text { Length } \\
(\mathrm{mm})\end{array}$ & $\begin{array}{l}\text { Conduction } \\
\text { time (ms) }\end{array}$ & $\begin{array}{c}\text { Dosage } \\
\text { (mg/) }\end{array}$ & $\begin{array}{l}\text { VTCL } \\
\text { (ms) }\end{array}$ & \\
\hline$V T$ around the scar & 4 & $134 \pm 17$ & $\theta, 31 \pm 3$ & $17 \pm 5$ & $55 \pm 15$ & $5.0 \pm 1.2$ & $451 \pm 80$ & $0 / 4$ \\
\hline VT through the scar & 8 & $150 \pm 22$ & $\theta_{n=1} 17 \pm 6^{*}$ & $15 \pm 5$ & $87 \pm 23^{\circ}$ & $2.5 \pm 1.2^{*}$ & $334 \pm 119$ & $2 / 8$ \\
\hline$V T$ within the scar & 2 & $127 \pm 12$ & _- & - & - & $3.5 \pm 0.7$ & $376 \pm 133$ & $2 / 2$ \\
\hline
\end{tabular}

$\Theta_{\text {Y: }}$ transverse conduction velocity; $\Theta_{\text {se: }}$ effective conduction velocity through the myocartial infarction. $\Delta$ Morphology: change in morphology of VT.

- p<0.01 versus VT around the scar (unpaired Student's t-test). 


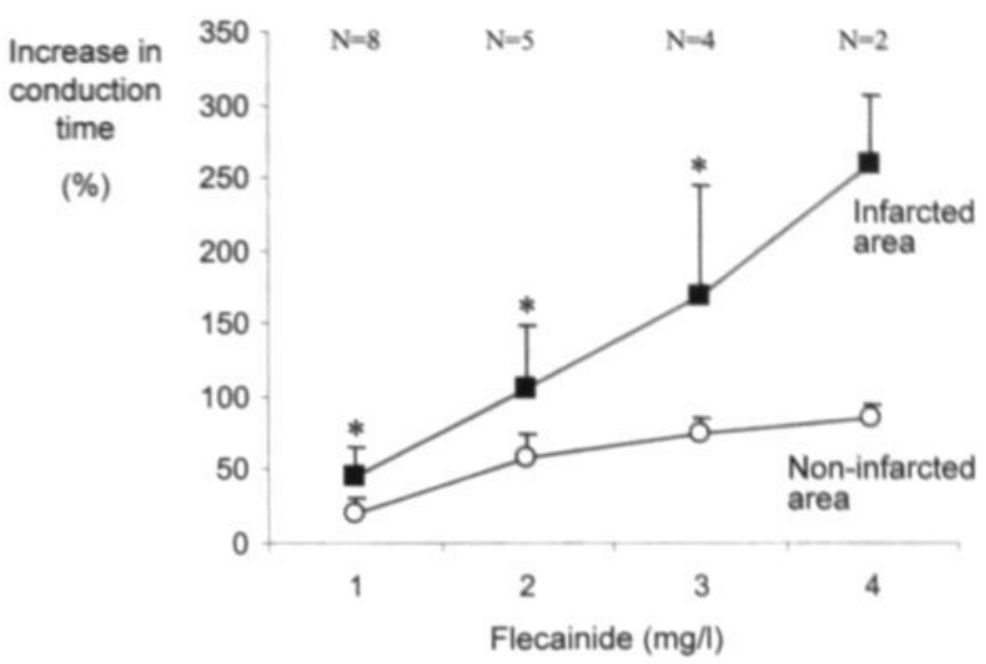

Figure 5. Preferential effect of flecainide on conduction through the infarcted area. The concentration of flecainide is plotted on the abcissa $(\mathrm{mg} / \mathrm{l})$. The percentage of increase in conduction time through the infarct (filled squares) and the non-infarcted part of the ventricle (open circles) during $V T$ is plotted on the ondinate. $\bullet<<0.05$.

\section{Effects of d-Sotalol}

VT around the scar. In one experiment, the effects of d-sotalol on VT around the scar was tested. This experiment is shown in Fig. 6. The VT with a cycle length of $176 \mathrm{~ms}$ was based on a counterclockwise circulating wave around the scar. Infusion of d-sotalol had little effect on VTCL. Even at the high concentration of $80 \mathrm{mg} / \mathrm{l}$, VTCL was prolonged by only $10 \mathrm{~ms}(186 \mathrm{~ms})$. At this high concentration, the VT was frequently interrupted by spontaneously occurring premature beats with an interval of $114 \mathrm{~ms}$ which originated from the base of the ventricle. The cycle length following the premature beat was similar to the VTCL (186ms), indicating that the premature beat was conducted with no delay around the circuit and that a large fully excitable gap was still present.

VT through the scar. In 2 hearts, the effects of d-sotalol on VT through the scar were tested. One example is shown in Fig. 7. The VTCL was $141 \mathrm{~ms}$. The site of earliest activation $(\mathrm{t}=0$ ) was located at the superior border of the scar. A second exit site was located at the lateral border of the scar $(t=5)$. The counterclockwise wave originating from the second exit site collided at the base with the wavefront emerging from the earliest site of activation. The clockwise reentrant circuit exiting from the lateral border of the infarct was completed by a slow conduction zone through the inferior part of the scar starting at $t=37 \mathrm{~ms}$. The conduction time from the inferior entrance to the right lateral exit of the scar was $109 \mathrm{~ms}$. d-Sotalol in concentrations of 10 and $20 \mathrm{mg} / \mathrm{l}$ did not prolong VT cycle length. During infusion of $40 \mathrm{mg} /$, the cycle length of the reentrant tachycardia increased from 

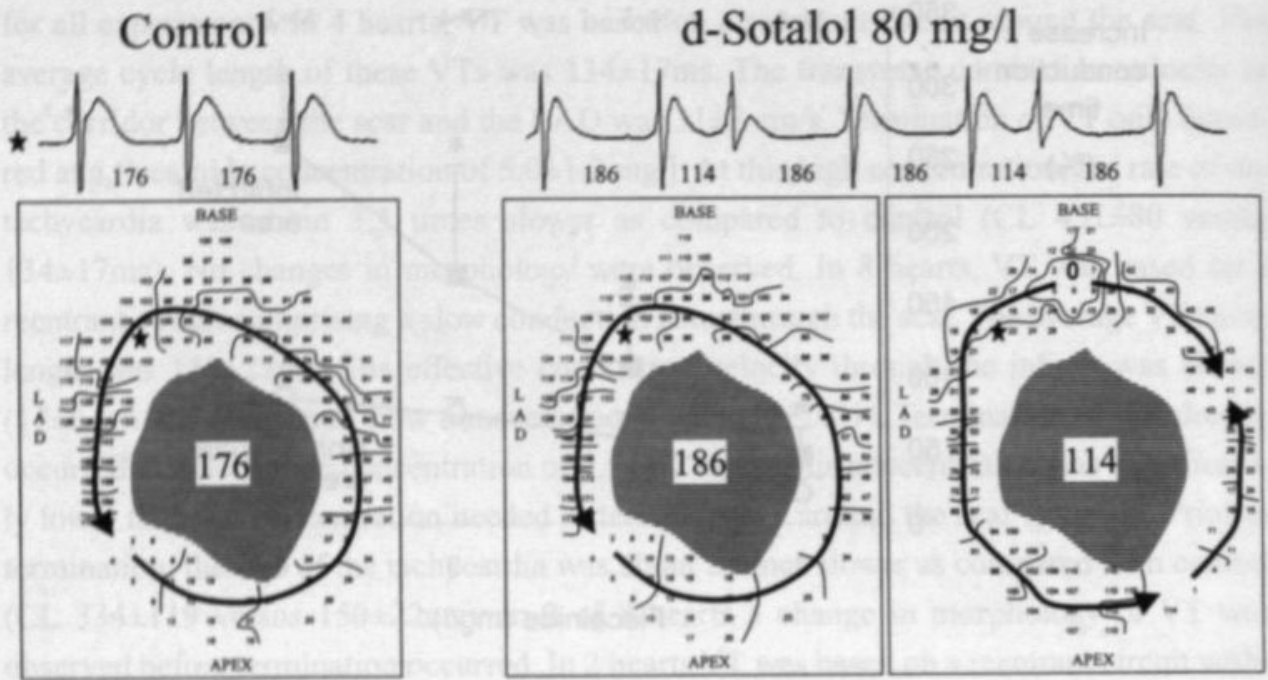

Figure 6. Effects of d-sotalol on reentrant VT around the scar. During control VT cycle length was regular with an interval of $176 \mathrm{~ms}$. During infusion of $d$-Sotalol $(80 \mathrm{mg} / \mathrm{l}) V T$ cycle length increased to $186 \mathrm{~ms}$. Premature beats with an interval of $114 \mathrm{~ms}$ were now frequently observed. VT was based

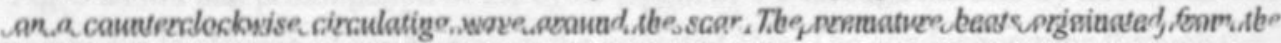
base of the ventricle. The return cycle after the premature beats was similar to the VTCL (186ms), indicating that even at this high concentration of d-Sotalol a large excitable gap was still present. Isochrones at $10 \mathrm{~ms}$ intervals.

\section{Control}
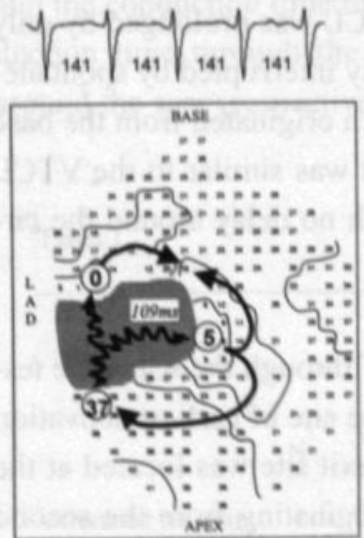

\section{d-Sotalol $40 \mathrm{mg} / 1$}
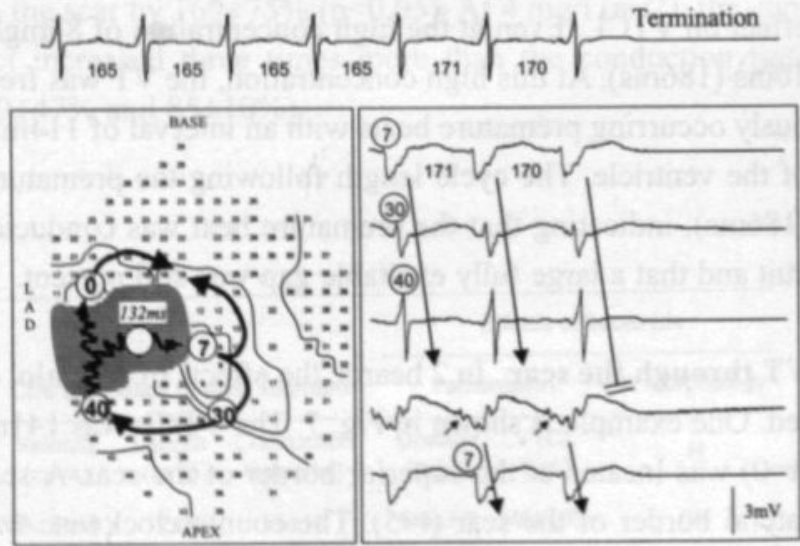

Figure 7. Effects of d-sotalol on reentrant VT through the scar. The four electrograms were reconded at the encircled sites on the activation map. Termination of VT was due to conduction block in the infarcted area. Activation times are given in milliseconds. Isochrones are drawn at 10ms intervals. Arrows indicate the dinection of propagation, zig-zag arnows indicate paths of slow conduction. Double bar indicates conduction block. See text for further description. 
141 to $165 \mathrm{~ms}$. This prolongation of VTCL by $24 \mathrm{~ms}$ was due to an increase in conduction time through the scar from 109 to $133 \mathrm{~ms}$. Termination of VT occurred when VTCL further prolonged to $170 \mathrm{~ms}$ and was due to conduction block in the infarcted area, as shown by the electrograms. During VT a small potential was recorded from the scar before the lateral border of the scar was activated at $\mathrm{t}=7 \mathrm{~ms}$ (diastolic potential). Termination of VT was associated with the disappearance of this diastolic potential. In the other heart, the effect of d-sotalol on VT was similar. At $20 \mathrm{mg} /$, VTCL increased from 172 (control) to $194 \mathrm{~ms}$ before conduction block occurred in the slow conduction zone resulting in termination of VT.

\section{Effects of Verapamil}

The effects of verapamil were studied in three hearts in which a VT through the scar was induced. In two hearts, a very high dosage of verapamil $(1.0 \mathrm{mg} / \mathrm{l})$ neither slowed nor terminated the tachycardia. In one case, infusion of verapamil at a concentration of $0.1 \mathrm{mg} / \mathrm{l}$ resulted in alternation of VT cycle length and termination of VT. This is illustrated in Fig. 8. During control, VT cycle length was regular with an interval of $168 \mathrm{~ms}$. The exit site of the VT was located at the base of the left ventricle. The clockwise reentrant loop origina-
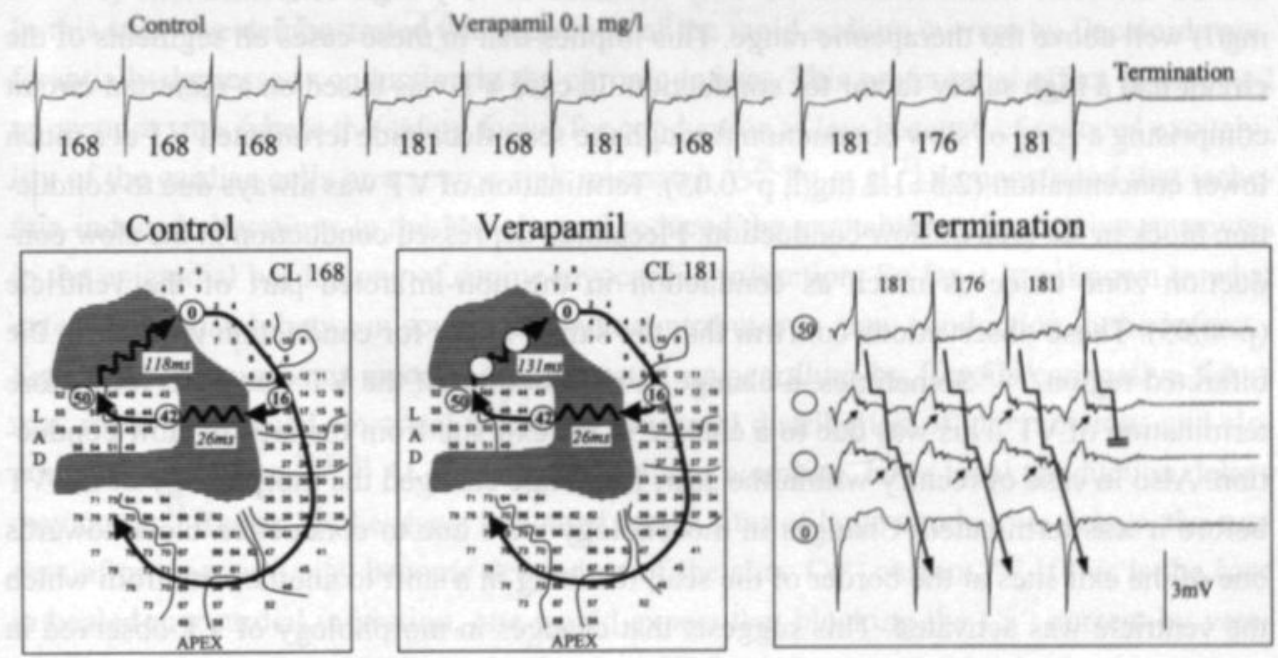

Figure 8. Effects of verapamil on reentrant VT through the scar. Infusion of verapamil $(0.1 \mathrm{mg} / \mathrm{l})$ resulted in alternation of VT cycle length and termination of VT (top). The activation maps show that the VT was based on a clockwise reentrant loop originating from the base of the ventricle comprising two successive zones of slow conduction through the scar. The difference in activation pattern between control and verapamil was an alternation in conduction time through the second zone of slow conduction between 118 and $131 \mathrm{~ms}$. The four electrograms were recorded at the encircled sites indicated on the activation map. Termination of VT was due to conduction block in the second zone of slow conduction. Activation times are given in milliseconds. Isochrones are drawn at $10 \mathrm{~ms}$ intervals. Arrows indicate the direction of propagation, zig-zag arrows indicates slow conduction. Double bar indicates conduction block. 
ting from this site comprised two successive zones of slow conduction through the scar. The conduction time through the first zone was $26 \mathrm{~ms}$ (from $\mathrm{t}=16$ to $42 \mathrm{~ms}$ ) and $118 \mathrm{~ms}$ through the second zone (from $\mathrm{t}=50$ to $168 \mathrm{~ms}$ ). During infusion of verapamil $(0.1 \mathrm{mg} / \mathrm{l})$ VTCL started to alternate between 168 and $181 \mathrm{~ms}$. The activation pattern during the $168 \mathrm{~ms}$ cycle was exactly the same as during control (not shown). The cause for the alternation between 168 and $181 \mathrm{~ms}$ was alternation of the conduction time through the second zone of slow conduction between 118 and $131 \mathrm{~ms}$. Termination of VT was due to conduction block in this second area of slow conduction.

\section{Discussion}

\section{Effects of Antiarrhythmic Drugs on Reentrant VT}

Antiarrhythmic drugs exert their effect either by slowing and terminating ventricular arrhythmias or by preventing their inducibility. Slowing of conduction and termination of VT is generally assumed to result from an increase in refractoriness or depression of conduction. $^{5,13-15}$ In the present study, in all hearts the class Ic drug flecainide markedly slowed conduction of the reentrant wavefront, thus increasing the cycle length of VT. The efficacy to terminate VT depended on the nature of the reentrant circuit. In case of reentry around the scar, termination of VT only occurred at very high concentrations $(5.0 \pm 1.2$ $\mathrm{mg} /$ l) well above the therapeutic range. This implies that in these cases all segments of the circuit had a high safety factor for conduction. In case VT was based on a reentrant circuit comprising a zone of slow conduction through the scar, flecainide terminated VT at a much lower concentration $(2.5 \pm 1.2 \mathrm{mg} / \mathrm{l}, \mathrm{p}<0.05)$. Termination of VT was always due to conduction block in the area of slow conduction. Flecainide depressed conduction in the slow conduction zone twice as much as conduction in the non-infarcted part of the ventricle $(p<0.05)$. These observations confirm that the safety factor for conduction is lower in the

infarcted region. ${ }^{16,17}$ Sometimes, a change in morphology of the VT was observed before termination of VT. This was due to a change in the exit site from the area of slow conduction. Also in case of reentry within the scar, flecainide changed the morphology of the VT before it was terminated. Changes in morphology were due to conduction block towards one of the exit sites at the border of the scar, resulting in a shift to another site from which the ventricle was activated. This suggests that changes in morphology of VT observed in patients may equally be due to exit block. ${ }^{18}$

The class III antiarrhythmic drug d-sotalol hardly affected VT at therapeutic concentrations. In case of VT around the scar, a slight increase in VT cycle length at high concentrations of d-sotalol could not be explained by a shortening of the excitable gap. Early premature wavefronts could still propagate without any slowing of conduction around the circuit. In case of reentry through the scar, d-sotalol slightly prolonged VTCL and terminated VT at concentrations above $20 \mathrm{mg} /$. Termination was due to conduction block in the slow conduction zone. Since we did not measure the refractory period before and after infusion of d-sotalol, it remains uncertain whether whether termination of VT was due to 
closing of the excitable gap. Some studies have demonstrated that sotalol at high concentration reduces the upstroke velocity of the action potential $\left(\mathrm{V}_{\max }\right) \cdot{ }^{19.20}$ Such a class I effect of d-sotalol might explain the slowing and termination of VT.

In 2 of 3 hearts, infusion of verapamil did not affect VT. In one case, verapamil terminated VT by conduction block in the slow conduction zone, suggesting that in this case the inward calcium current participated in conduction through the infarct. Also in patients, only a small percentage of VTs respond to administration of verapamil. ${ }^{21,22}$

\section{Effects of Antiarrhythmic Drugs on the Slow Conduction Zone}

In patients with VT after myocardial infarction, the reentrant circuit usually incorporates a slow conduction zone through the infarct. ${ }^{9,10}$ Some studies have suggested that antiarrhythmic drugs may especially affect the slow conduction zone, providing a preferential site for conduction block and termination of VT. ${ }^{16,17}$ However, the exact nature of slow conduction and how it is affected by anti-arrhythmic drugs is still largely unknown. Slow conduction in the infarcted area can be due to decreased excitability of the surviving myocytes, ${ }^{23}$ reduced cellular coupling, ${ }^{24}$ zig-zag conduction in the complex network of surviving myocytes, ${ }^{25}$ or a mismatch between the current generated and the current needed for excitation. $^{26-28}$

In this study we demonstrated that reduction of the rapid sodium current by flecainide preferentially depressed conduction in the chronic infarct. This preferential effect is expected to occur at sites where the safety factor for conduction is low because of reduced excitability of the cardiac cells or a source-sink mismatch. ${ }^{27.29} \mathrm{Pu}$ et al. ${ }^{23}$ demonstrated that ischemia-induced alterations in the $\mathrm{Na}^{+}$channel reduced the excitability of surviving myocytes in the epicardial borderzone of canine myocardial infarction. So far it is unknown to what extent a mismatch between source and sink contributes to slow conduction in the infarct. Separation of surviving myocytes in infarcted myocardium by fibrous connective tissue may result in reduced electrical coupling, abnormal distribution of gap junctions and slowing of conduction. ${ }^{24,30,31}$ At sites of poor cellular coupling, large local conduction delays may occur. ${ }^{32}$ Recent studies have indicated that at sites of large conduction delays, the success of propagation may become dependent of the slow $\mathrm{Ca}^{*}$ current. ${ }^{313}$. If this is the case in healed myocardial infarction, one would expect that blocking the $\mathrm{Ca}^{*}$ current by verapamil would depress or block conduction in the infarcted area, resulting in slowing and termination of VT. In our study, in 1 of 3 experiments verapamil slowed the rate and terminated VT by depressing conduction in the slow conduction zone. This suggests that in this experiment the $\mathrm{Ca}^{*}$ current was critical for succesfull propagation through the infarcted area. Surprisingly, Cabo et al. recently showed that increasing the L-type calcium current by Bay-Y5959 caused slowing of conduction and conduction block in canine hearts with a healing myocardial infarction. ${ }^{36}$ This was explained by a decrease in gap junctional conductance consequent to an increase in intracellular calcium. On the other hand, Bay-Y5959 also improved conduction of premature impulses so that lines of unidirectional block 
necessary for VT initiation were not formed. ${ }^{36}$ The various effects of all these pharmacologic agents on conduction through a chronic myocardial infarction indicates that several electrophysiological alterations may contribute to abnormal conduction within the infarcted area. Further knowledge on the exact nature of slow conduction in infarcted tissue might help to direct antiarrhythmic drug therapy with a much higher success rate.

\section{References}

1. Echt D, Liebson P, Mitchell L, al e. Mortality and morbidity in patients receiving encainide, flecainide or placebo. The Cardiac Arrhythmia Suppression Trial. N Engl J Med. 1991;327:227.

2. Waldo A, Camm J, de Ruyter $\mathrm{H}$, al e. Effect of d-sotalol on mortality in patients with left ventricular dysfunction after recent and remote myocardial infarction. Lancet. 1996;348:7.

3. Julian D, Camm A, Frangin G, al e. Randomised trial of effect of amiodarone on mortality in patients with left-ventricular dysfunction after recent myocardial infarction: EMIAT. Lancet. 1997;349:667.

4. Cairns J, Connolly S, Roberts R, Gent M. Randomised trial of outcome after myocardial infaretion in patients with frequent or repetitive ventricular premature depolarisations: CAMIAT. Canadian Amiodarone Myocardial Infarction Arrhythmia Trial Investigators. Lancet. 1997;349 (9053):675-82.

5. The Sicilian Gambit: A new approach to the classification of antiarrhythmic drugs based on their actions on arrhythmogenic mechanisms. Task force of the working group on arrhythmias of the European Society of Cardiology. Circulation. 1991;84:1915-1923.

6. El Sherif N, Scherlag BJ, Lazzara R, Hope RR. Re-entrant ventricular arrhythmias in the late myocardial infarction period. 1. Conduction characteristics in the infarction zone. Circulation. 1977;55:686-702.

7. Wit AL, Allessie MA, Bonke FI, Lammers W, Smeets J, Fenoglio JJ, Jr. Electrophysiologic mapping to determine the mechanism of experimental ventricular tachycardia initiated by premature impulses. Experimental approach and initial results demonstrating reentrant excitation. Am J Candiol. 1982;49:166-85.

8. Dillon SM, Allessie MA, Ursell PC, Wit AL. Influences of anisotropic tissue structure on reentrant circuits in the epicardial border zone of subacute canine infarcts. Circ Res. 1988;63:182-206.

9. de Bakker JM, van Capelle FJ, Janse MJ, Wilde AA, Coronel R, Becker AE, Dingemans KP, van Hemel NM, Hauer RN. Reentry as a cause of ventricular tachycardia in patients with chronic ischemic heart disease: electrophysiologic and anatomic correlation. Circulation. 1988;77:589-606.

10. Stevenson W, Khan H, Sager P, Saxon L, Middlekauff H, Natterson P, Wiener I. Identification of reentry circuit sites during catheter mapping and radiofrequency ablation of ventricular tachycardia late after myocardial infarction. Circulation. 1993;88:1647-70.

11. Bakker de J, Capelle van F, Janse M, Wilde A, Coronel R, Becker A, Dingemans K, Hemel van $\mathrm{N}$, Hauer R. Reentry as a cause of ventricular tachycardia in patients with chronic ischemic heart disease: electrophysiologic and anatomic correlation. Circulation. 1988;77:589-606.

12. Janse M, Wit A. Electrophysiosiological mechanisms of ventricular arrhythmias resulting from myocardial ischemia and infaretion. Physiol. Rev. 1989;69:1049-1169.

13. Stamato NJ, Frame LH, Rosenthal ME, Almendral JM, Gottlieb CD, Josephson ME. Procainamide-induced slowing of ventricular tachycardia with insights from analysis of resetting response patterns. Am J Candiol. 1989;63:1455-61

14. Callans DJ, Hook BG, Josephson ME. The mechanism of propafenone-induced slowing of ven tricular tachycardia in man as defined by analysis of resetting response patterns. PACE. 1991;14:2035-2041.

15. Coromilas J, Saltman AE, Waldecker B, Dillon SM, Wit AL. Electrophysiological effects of flecainide on anisotropic conduction and reentry in infarcted canine hearts. Circulation. 1995;91:2245-63. 
16. Kadish $\mathrm{AH}, \mathrm{Spear} \mathrm{JF}$, Levine $\mathrm{JH}$, Moore EN. The effects of procainamide on conduction in anisotropic canine ventricular myocardium. Cinculation. 1986;74:616-25.

17. Kay G, Epstein A, Plumb V. Preferential effect of procainamide on the reentrant cireuit of ventricular tachycardia. JAm Coll Candiol. 1989;14:382-390.

18. Callans D, Marchlinski F. Characterization of spontaneous termination of sustained ventricular tachycardia associated with coronary artery disease. Am J Candiol. 1991;1991:50-54.

19. Carmeliet E. Electrophysiologic and voltage clamp analysis of sotalol effects in cardiac muscle and Purkinje fibers. J Pharmacol Exp Ther. 1985;232:77-85.

20. Nakaya H, Kimura S, Nakao Y, Kanno M. Effects of nipradilol (K-351) on the electrophysiological properties of canine cardiac tissues: comparison with propanolol and sotalol. Eur $J$ Pharmacol. 1984;104:335-344.

21. Wellens HJ, Bar FW, Lie KI, Duren DR, Dohmen HJ. Effect of procainamide, propranolol and verapamil on mechanism of tachycardia in patients with chronic recurrent ventricular tachycardia. Am J Candiol. 1977;40:579-85.

22. German L, Packer D, Bardy G, Gallagher J. Ventricular tachycardia induced by atrial stimulation in patients without symptomatic cardiac disease. Am J Candiol. 1983;52:1202-1207.

23. Pu J, Boyden P. Alterations of $\mathrm{Na}+$ currents in myocytes from epicardial border zone of infareted heart. A possible mechanism for reduced excitability and postrepolarization refractoriness. Circ Res. 1997;81:110-119.

24. Peters NS, Coromilas J, Severs NJ, Wit AL. Disturbed connexin43 gap junction distribution correlates with the location of reentrant circuits in the epicardial border zone of healing canine infarcts that cause ventricular tachycardia. Circulation. 1997;95:988-96.

25. de Bakker JM, van Capelle FJ, Janse MJ, Tasseron S, Vermeulen JT, de Jonge N, Lahpor JR. Slow conduction in the infarcted human heart. 'Zigzag' course of activation. Cinculation. 1993;88:915-26.

26. de Bakker JM, Coronel R, Tasseron S, Wilde AA, Opthof T, Janse MJ, van Capelle FJ, Becker AE, Jambroes G. Ventricular tachycardia in the infarcted, Langendorff-perfused human heart: role of the arrangement of surviving cardiac fibers. JAm Coll Cardiol. 1990;15:1594-607.

27. Fast VG, Kleber AG. Role of wavefront curvature in propagation of cardiac impulse. Cardiovasc Res. 1997;33:258-71.

28. Kucera JP, Kleber AG, Rohr S. Slow conduction in cardiac tissue, II: effects of branching tissue geometry. Circulation. 1998.

29. Danse P, Garratt C, Mast F, Allessie M. Preferential depression of conduction around a pivot point in rabbit ventricular myocardium by potassium and flecainide. $J$ Cardiovascular Electrophysiology. 2000;11:262-73.

30. Ursell PC, Gardner PI, Albala A, Fenoglio JJ, Jr., Wit AL. Structural and electrophysiological changes in the epicardial border zone of canine myocardial infarcts during infarct healing. Circ Res. 1985;56:436-51.

31. Gardner PI, Ursell PC, Fenoglio JJ, Jr., Wit AL. Electrophysiologic and anatomic basis for fractionated electrograms recorded from healed myocardial infarcts. Circulation. 1985;72:596-611.

32. Rohr S, Kucera JP, Kleber AG. Slow conduction in cardiac tissue, I: effects of a reduction of excitability versus a reduction of electrical coupling on microconduction. Circ Res. 1998;83:781-94.

33. Joyner RW, Kumar R, Wilders R, Jongsma HJ, Verheijck EE, Golod DA, Van Ginneken AC, Wagner MB, Goolsby WN. Modulating L-type calcium current affects discontinuous cardiac action potential conduction. Biophys $J$. 1996;71:237-45.

34. Rohr S, Kucera JP. Involvement of the calcium inward current in cardiac impulse propagation: induction of unidirectional conduction block by nifedipine and reversal by Bay K 8644 . Biophys J. 1997;72:754-66.

35. Wagner M, Wang Y, Kumar R, Golod D, Goolsby W, Joyner R. Measurements of calcium transients in ventricular cells during discontinuous action potential conduction. Am J Physiol Heart Circ Physiol. 2000;278:H444-51.

36. Cabo C, Schmitt H, Wit A. New mechanism of antiarrhythmic drug action: increasing L-type calcium current prevents reentrant ventricular tachycardia in the infarcted canine heart. Cinculation. 2000;102:2417-25. 
Chapter 7

$-158$. 
Chapter 8

Synthesis 
Chapter 8

8 7oforat?

$-160-$ 


\section{U-turn Blockade as a Novel Concept of Anti-Arrhythmic Drug Action}

Antiarhythmic drugs exert their beneficial effect either by slowing or terminating cardiac arrhythmias or by preventing their inducibility. The choice for a particular antiarrhythmic drug depends on the underlying mechanism of the arrhythmia.' Both atrial as well as ventricular tachyarrhythmias are often based on reentry. In reentry, the circulating impulse travels over a route that leads back to its point of origin. The shortest pathlength that can sustain reentry is determined by the product of the refractory period and the conduction velocity, the so-called wavelength of refractoriness, describing the distance that the activation front travels during the refractory period of the cardiac cells. ${ }^{2}$ If the pathlength of a potential circuit is smaller than the wavelength, the circulating impulse will traverse the circuit and return to its starting point in a time shorter than the refractory period, forcing it to impinge on still-refractory tissue and die out. The concept of the wavelength has long time been used (and still serves) as a paradigm for our understanding of the action of antiarrhythmic drugs. ${ }^{3}$ Drugs that prolong the wavelength of refractoriness should abolish reentrant circuits, whereas drugs that shorten the wavelength should have proarrhythmic effects. However, Wijffels et al. ${ }^{4}$ recently showed that class I antiarrhythmic drugs slowed and terminated atrial fibrillation (AF) although they did not prolong the wavelength during AF. Instead, the main reason for the slowing of the rate of AF was a marked widening of the excitable gap. ${ }^{4}$ Thus, surprisingly, it seems that the wavelength of refractoriness is not the critical parameter for the antifibrillatory effects of class I antiarrhythmic drugs. What then explains their antiarrhythmic effects?

In this thesis, we have shown that class I drugs act as 'U-turn blockers'. In Chapter 2 we demonstrated that in a thin sheet of left ventricular subepicardium of the rabbit heart, a general reduction of the inward sodium current by infusion of potassium or flecainide depressed conduction of U-turning wavefronts around a thin linear lesion about 1.6 times more than conduction of planar waves. This preferential effect was due to slow discontinuous conduction and functional conduction block at the pivot point. Especially during high frequency stimulation or early premature beats lines of functional conduction block occurred at the tip of the anatomical lesion, forcing the pivoting wave to make a wider turn with lesser curvature. In Chapter 3 we demonstrated that due to preferential conduction delay at the pivot point flecainide prolonged the excitable period in the descending limb of a premature U-turn.

Class I drugs act as preferential 'U-turn blockers' because the safety factor for conduction during wavefront pivoting is lower than during propagation of planar waves. At a pivot point, the wavefront curvature increases abruptly. Due to the high curvature, the excitatory current generated by the turning wavefront (source) is distributed over a larger area and consequently, the cells distal to the pivot point (sink) will receive less current per $\mathrm{mm}^{2}$ membrane area. ${ }^{5,6}$ Under normal conditions a high wavefront-curvature only causes a small local delay in conduction since cardiac cells generate a large surplus of excitatory current. ${ }^{6}$ However, when the inward $\mathrm{Na}^{*}$ current is reduced by class I drugs, the excitatory current 


\section{Chapter 8}

generated at the pivot point may become insufficient to depolarise the descending limb of the U-turn resulting in large local conduction delays and U-turn block.

The U-turn blocking effect of class I drugs may be influenced by tissue architecture. Our study was performed in a thin sheet of left ventricular subepicardium ( $\pm 1 \mathrm{~mm}$ thick), in which the muscle fibers are oriented parallel to each other (uniform anisotropy). The Uturning wavefronts rotated around a line of block which was made parallel to the fiber orientation. At the exit of such a U-turn the impulse changes its direction relative to the fibers from transverse to parallel. At this point, a sudden drain of excitatory current occurs owing to reduced axial resistence in the longitudinal direction. ${ }^{7}$ Thus, next to increased wavefront curvature, tissue anisotropy may create an additional current sink that further depresses conduction of a pivoting wave and makes the U-turn more vulnerable for the action of class I drugs. It is not possible from our data to distinguish the relative contributions of wavefront curvature and tissue anisotropy to altered current loading at pivot points. Girouard et al. ${ }^{8}$ studied propagation around a linear lesion oriented perpendicular to the epicardial fibers. Also during such a U-turn, conduction slows down at the pivot point. Unfortunately, the effects of class I drugs on these U-turns were not studied. Other studies demonstrated that a close, inverse correlation exists between the curvature of a pivoting wavefront and the degree of slowing of conduction, independent of a specific fiber orientation. ${ }^{10}$ Thus, although tissue anisotropy may play a role in the occurrence of source-sink imbaiances at pivot points, the influence of increased wavefront curvature on conduction of pivoting waves seems to be far stronger than the influence of anisotropy. The influence of more complex 3-dimensional tissue architecture (such as the atria) on source-sink imbalances is still largely unknown.

Not only class I drugs may act as U-turn blockers. Recent studies have demonstrated that at sites of large conduction delay due to high wavefront curvature, the local current for propagation is not only carried by $\mathrm{Na}^{+}$ions but also by flow of $\mathrm{Ca}^{++}$ions during the plateau phase. ${ }^{11,12}$ Such a role of the calcium current may become especially important when the current generated by the rapid $\mathrm{Na}^{+}$channels is diminished, as for instance by flecainide. Under these circumstances, it is expected that $\mathrm{Ca}^{+*}$ channel blockers such as verapamil may also act as U-turn blockers. In this view, amiodarone might also exert a U-turn blocking effect since it reduces both the inward $\mathrm{Na}^{+}$and $\mathrm{Ca}^{+}$current. So far, no data are available to support these hypotheses.

Another hypothesis that still needs to be proven is whether class I antiarrhythmic drugs indeed act as U-turn blockers during atrial fibrillation. Previous studies have shown that slowing of the rate of fibrillation by class I drugs is associated with an increase in the size of the reentrant circuits, ${ }^{13}$ a widening of the excitable gap, ${ }^{4}$ and progressive organization of activation. ${ }^{14}$ Recent work using a computer model of $\mathrm{AF}$ that is based on realistic atrial cellular ionic properties suggests that $\mathrm{Na}^{*}$ blockade may terminate $\mathrm{AF}$ by causing the spiral wave activity that maintains AF to die out despite a decrease in the wavelength of refractoriness. ${ }^{15}$ All these observations can be explained by the concept that class I drugs prefe- 
rentially delay sharply turning wavefronts. If during $\mathrm{AF} U$-turns are more depressed than propagation of planar waves, planar waves will become more prominent which may lead to a progressive organization of electrical activation. Conduction block at pivot points will force the wavefronts to make wider turns with lesser curvature, resulting in an increase of the size of the reentrant circuits, prolongation of the AF cycle length and widening of the excitable gap. Therefore, the concept of preferential blockade of U-turns offers an attractive explanation for the temporal and spatial effects of class I drugs on AF.

\section{Reentrant Ventricular Tachycardia after Myocardial Infarction}

In the past three decades, many clinical as well as experimental studies have been undertaken to unravel the mechanisms of ventricular tachycardia occurring in the chronic phase of myocardial infarction. The main findings of these studies were that VT after myocardial infarction is based on reentry which can be either anatomic or functional in nature, and that the reentrant circuits usually comprise a segment of slow conduction through the infarcted area (for review see reference ${ }^{16}$ ). Slow conduction through the infarct can be due to zigzag conduction with normal velocity over long meandering tracts of surviving myocytes, ${ }^{17}$ depressed excitability of the surviving myocytes, ${ }^{18}$ and reduced cellular coupling. ${ }^{19}$ It was demonstrated that the slow conduction zone is the critical component of the reentrant circuit and is usually the site of termination of VT bv either bacine ${ }^{20,21}$ or antiarrhvthmic drugs. ${ }^{22}$ Studies on the therapy of VT after myocardial infarction have revealed that the occurrence of VT can be prevented by surgical excision of the infarcted area, ${ }^{23}$ radiofrequency- or cryoablation of the slow conduction zone, ${ }^{24,25}$ or by changing the electrophysiological properties of the arrhythmogenic substrate by antiarrhythmic drugs. ${ }^{26,27}$ However, since all these therapeutic strategies have a high failure rate, nowadays most patients suffering from ventricular tachyarrhythmias after myocardial infarction receive an implantable cardioverter defibrillator (ICD), especially when the VTs are hemodynamically unstable or left ventricular function is depressed. ${ }^{28.29}$ The ICD is highly effective in terminating ventricular tachyarrhythmias and aborting sudden cardiac death. ${ }^{30}$ Therefore, one may argue that the introduction of the ICD has abolished the need for further studies on the mechanisms and treatment of VT. However, the ICD does not cure patients from having tachyarrhythmias and frequent painful (and sometimes inappropriate) shocks may severely affect their quality of life. Furthermore, because of its high costs, in many countries ICD therapy is limited to a highly selective subgroup of patients. ${ }^{31}$ Therefore, to optimise the treatment for individual patients, further studies are still needed to better understand the mechanisms of post-infarction VT. Information on the architecture of chronic myocardial infarction might help to increase the success rate of ablation therapy. ${ }^{32,33}$ Further knowledge on the electrophysiological alterations within the infarcted area might help to direct antiarrhythmic drug therapy with a much higher success rate.

In this thesis, we have studied the mechanisms of reentrant VT in Langendorff perfused layers of subepicardium of the rabbit heart containing an area of healed myocardial infarc- 


\section{Chapter 8}

tion. Although this experimental model is obviously different from the pathophysiological substrate of reentrant VT in humans, the reentrant circuits causing VT had characteristics similar to those causing VT in patients with chronic myocardial infarction. The following similarities were observed: (1) The VTs were usually based on an anamic circuit involving a zone of slow conduction through the infarct; ${ }^{34}$ (2) The slow conduction zone consisted of surviving myocytes separated by connective tissue which formed continuous tracts connecting viable muscle at either side of the infarcted area; ${ }^{17.34,35}$ (3) During reentry low amplitude fractionated electrograms were recorded from the segment of slow conduction through the infarct (diastolic potentials); ${ }^{34,36,37}$ (4) In a minority of hearts reentry occurred around the scar or within a small area of the infarct; ${ }^{34}$ (5) The reentrant circuits could contain a single loop or multiple loops; ${ }^{38}$ (6) In some hearts, VTs with a different morphology and / or cycle length could be induced; ${ }^{39}(7)$ The reentrant circuits could often be reset over a large range of premature coupling intervals, indicating the presence of a large excitable gap; ${ }^{40}(8)$ The reset curves were either flat, completely sloped, or mixed (flat and sloped part $) ;^{40}$ (9) The slow conduction zone was the critical component of the reentrant circuits being the site of termination of VT by either pacing or antiarrhythmic drugs. ${ }^{20-}$

${ }^{22}$ Because of these similarities with clinical VT, we believe that this new model of reentrant VT is a useful tool to study the pathophysiological mechanisms of reentry and slow conduction in chronic myocardial infarction, as it may occur in patients.

Whereas detailed information on reentrant circuits in humans and whole animals is limited to the slower hemodynamically tolerated VTs, the Langendorff perfused preparations offered the possibility to study the mechanisms of both relatively slow and fast VTs. Slow VTs were based either on a large macroreentrant circuit around the scar or an anatomic circuit comprising a slow conduction zone through the scar. During slow VTs, the conduction time through the infarct was relatively long (long diastolic interval). In contrast to recent findings of Ciaccio et al. in canine hearts with a healing myocardial infarction, ${ }^{32}$ no correlation was found between the cycle length of the VT and the length of the segment of slow conduction through the infarct. This could be explained by the large variation in conduction velocity through the infarct among the different hearts (range $9-69 \mathrm{~cm} / \mathrm{s}$ ). Fast VTs were based on either a small reentrant circuit completely located within the scar, reentry around the scar, or reentry through the scar with a short diastolic interval.

Clinically, the responses of VT to programmed electrical stimulation have widely been used to localize the site of origin of VT, ${ }^{38}$ to determine the excitable gap in the reentrant circuit, ${ }^{40}$ and to provide insights into the therapeutic role of antiarrhythmic drugs and antitachycardia pacing. ${ }^{41,42}$ As in many previous electrophysiological studies we found that premature impulses could reset, terminate or accelerate $\mathrm{VT}^{43-45} \mathrm{~A}$ new finding was that the response of VT to electrical stimulation could differentiate the underlying arrhythmogenic substrate. In case of a reentrant circuit around the scar, only the earliest premature stimuli propagated with a minor conduction delay through the circuit. Consequently, the reset curves were almost completely flat. Furthermore, the VTs around the scar could usually not 
be terminated by either a single premature stimulus or overdrive pacing by a train of 10 premature stimuli. Instead, overdrive pacing with high frequencies usually accelerated these VTs. In contrast, if the reentrant circuit comprised a slow conduction zone through the scar, the reset curve was either mixed or completely sloped. In such cases already late premature impulses were conducted with considerable delay through the slow conduction zone. Early premature stimuli terminated VT through the scar in about $60 \%$ of cases and overdrive pacing terminated all of these VTs. The ability to terminate VT through the scar by a single premature stimulus was associated with a long segment of slow conduction through the scar and a large difference in functional refractory period between the infarct and the surrounding myocardium. We further showed that resetting of VT by premature stimuli could 'unmask' the presence of two potential slow conduction zones within the infarct. In these circumstances a sudden change in the return cycle was observed after early premature stimuli, reflecting orthodromic conduction block in the slow pathway of the original reentrant circuit and conduction over the second 'hidden' slow pathway having a shorter refractory period. This dual response of VT to premature stimuli resulted in a 'split' reset curve.

Premature stimulation during VT has also been used to determine the width and nature of the excitable gap within the reentrant circuit. ${ }^{43}$ Up to now, a wide excitable gap was commonly associated with a large anatomic circuit. ${ }^{43}$ However, in our study we demonstrated that only in case of reentry around the scar the duration of the excitable gap depended on the size of the circuit. The duration of excitable gap during reentry involving a slow conduction zone through the scar was mainly determined by the conduction time through the infarct. During this type of reentry the partially excitable gap was usually longer than the fully excitable gap, since already late premature impulses were conducted with delay through the slow conduction zone. It must be emphasized that the width of the fully and partially excitable gap in reentrant circuits is not constant but may vary considerably due to variations in conduction velocity of the circulating impulse, as was demonstrated by Girouard et al. ${ }^{8}$

Next to programmed electrical stimulation, infusion of antiarrhythmic drugs may provide information on the pathophysiological substrate of VT. We demonstrated that the concentration of flecainide needed to terminate VT based on a reentrant circuit comprising a slow conduction zone through the scar was only half of the concentration needed to terminate VT based on reentry around the scar. Furthermore, in some cases a change in morphology of the VT could be observed during infusion of flecainide, providing evidence for the presence of a second slow conduction zone. Thus, although nowadays it is considered malpractice to prescribe flecainide to patients with a previous myocardial infarction, ${ }^{46}$ administration of this drug in the electrophysiology laboratory can be a useful tool to characterize the substrate for VT and to unmask hidden pathways through the scar. 


\section{Mechanisms of Slow Conduction Through the Infaret}

Many clinical as well as experimental studies have shown that the reentrant circuits causing VT after myocardial infarction usually comprise an area of slow conduction through the infarct and that this slow conduction zone is the critical component of the reentrant circuit. ${ }^{16.38}$ Previous studies in Langendorff perfused human hearts with a chronic myocardial infarction and in canine hearts with a healing myocardial infarction have suggested that slow conduction can be due to 'zig-zag' conduction in the complex network of surviving fibers, ${ }^{17}$ reduced gap-junctional coupling between the individual myocytes, ${ }^{19}$ or decreased excitability of the myocytes themselves. ${ }^{18} \mathrm{~A}$ more recent study in cultures of neonatal myocytes showed that current-to-load mismatches may occur at branching sites of muscle fibers, which may cause slowing of conduction. ${ }^{47}$ Such mismatches can also be expected to occur in infarct scars, in which the surviving tissue forms cell islands interconnected by cell strands. ${ }^{17,35,48}$ However, the exact effects of these structural and electrophysiological alterations within the infarcted area on impulse propagation are still largely unknown. In this thesis, we attempted to determine the key parameters for slow conduction through the infarcted area. We found some arguments that current-to-load mismatches within the infarct importantly contribute to slow conduction. Firstly, ultra-high density mapping of the infarcted area (interelectrode distance $500 \mu \mathrm{m}$ ) showed that slow conduction within the scar especially seemed to occur at branching sites of tracts of surviving myocytes. The conduction velocity at branching sites could be as slow as $<5 \mathrm{~cm} / \mathrm{s}$, whereas electrical activation of the connecting strands occurred almost simultaneously. Secondly, due to the imbalance between source and sink at branching points, these sites were expected to be more vulnerable for the action of class I drugs. We demonstrated that flecainide indeed preferentially depressed conduction through the infarct. It must be noted however that preferential slowing of conduction by class I drugs is also expected to occur at sites where the safety factor for conduction is low because of reduced excitability of the cardiac cells. Pu et al. ${ }^{18}$ demonstrated that surviving myocytes within the infarcted indeed have a reduced excitability due to ischemia-induced alterations in the Na channel. However, since very slow conduction $(<10 \mathrm{~cm} / \mathrm{s})$ has never been observed as a result of $\mathrm{Na}^{+}$blockade alone, ${ }^{49}$ reduced excitability of the surviving myocytes does not seem to be the main cause of slow conduction through the infarct. Very slow conduction $(1-5 \mathrm{~cm} / \mathrm{s})$ has been demonstrated in tissue with a high degree of cellular uncoupling. ${ }^{49}$ In these circumstances the activation front follows a meandering pathway (zig-zag conduction) and conduction is sustained by sequentially activated patches of tissue, each of which consists of a few cells being activated simultaneously. ${ }^{40.50}$ Many studies have suggested that a reduction of cellular coupling and altered distribution of the gap junctions between the surviving myocytes (gap junctional remodeling) plays a seminal role in slow conduction through chronic myocardial infarction. ${ }^{19,48.51}$ However, Jongsma et al. showed that gap junctional remodeling only gave rise to small to moderate changes in conduction velocity. ${ }^{52}$ Recent work of Haberl et al. ${ }^{53}$ also suggested that reduced cellular coupling can not be the only cause of slow conduction through the infarct. In a rabbit model of anatomic reentrant VT around a cryolesion, a seg- 
ment of slow conduction was created by local infusion of heptanol resulting in electrical uncoupling of part of the circuit. It was demonstrated that even very early premature impulses still propagated through the slow conduction zone and did not terminate the tachycardia. ${ }^{53}$ Since VTs in chronically infarcted myocardium often can be terminated by premature stimuli, this implicates that slow conduction through scar tissue can not solely be due to cellular uncoupling. Thus, depressed excitability of the surviving myocytes, discontinuous tissue geometry or dispersion of refractoriness may also play a role. Future lines of research are needed to fully characterize the electrophysiological properties of the slow conduction zone. If it would be possible to exactly localize the complete tract of slow conduction, unmask hidden pathways within the scar, and identify the key parameters for slow conduction in individual patients, antiarrhythmic therapy might be applied with a much higher success rate.

\section{References}

1. The Sicilian Gambit: A new approach to the classification of antiarrhythmic drugs based on their actions on arrhythmogenic mechanisms. Task force of the working group on arrhythmias of the European Society of Cardiology. Cinculation. 1991;84:1915-1923.

2. Smeets JLRM. Wave length of the cardiac impulse and reentrant arrhythmias. In: Maastricht, The Netherlands: University of Limburg; 1983.

3. Spinelli W, Hoffman BF. Mechanisms of termination of reentrant atrial arrhythmias by class I and class III antiarrhythmic agents. Circ Res. 1989;65:1565-79.

4. Wijffels MCEF, Dorland R, Mast F, Allessie MA. Widening of the excitable gap during pharmacological cardioversion of atrial fibrillation in the goat. Effects of cibenzoline, hydroquinidine, flecainide and d-sotolol. Circulation. 2000;102:260-267.

5. Zykov VS. Analytical evaluation of the dependence of the speed of an excitation wave in two-dimensional excitable medium of the curvature of its front. Biophysics. 1980;1980:906-911.

6. Fast VG, Kleber AG. Role of wavefront curvature in propagation of cardiac impulse. Cardiovasc Res. 1997;33:258-71.

7. Spach M, Miller W. The discontinuous nature of propagation in normal canine cardiac muscle. Evidence for recurrent discontinuities of intracellular resistance that affect the membrane currents. Circ Res. 1981;48:39-54.

8. Girouard SD, Pastore JM, Laurita KR, Gregory KW, Rosenbaum DS. Optical mapping in a new guinea pig model of ventricular tachycardia reveals mechanisms for multiple wavelengths in a single reentrant circuit. Circulation. 1996;93:603-13.

9. Cabo C, Pertsov AM, Baxter WT, Davidenko JM, Gray RA, Jalife J. Wave-front curvature as a cause of slow conduction and block in isolated cardiac muscle. Circ Res. 1994;75:1014-28.

10. Fast VG, Kleber AG. Cardiac tissue geometry as a determinant of unidirectional conduction block: assessment of microscopic excitation spread by optical mapping in patterned cell cultures and in a computer model. Cardiovasc Res. 1995;29:697-707.

11. Joyner RW, Kumar R, Wilders R, Jongsma HJ, Verheijck EE, Golod DA, Van Ginneken AC, Wagner MB, Goolsby WN. Modulating L-type calcium current affects discontinuous cardiac action potential conduction. Biophys J. 1996;71:237-45.

12. Shaw RM, Rudy Y. lonic mechanisms of propagation in cardiac tissue. Roles of the sodium and L-type calcium currents during reduced excitability and decreased gap junction coupling. Circ Res. 1997;81:727-41.

13. Kwan YY, Fan W, Hough D, Lee JJ, Fishbein MC, Karagueuzian HS, Chen PS. Effects of procainamide on wave-front dynamics during ventricular fibrillation in open-chest dogs. Circulation. 1998;97:1828-36.

14. Brugada J, Gursoy S, Brugada P, Atie J, Guiraudon G, Andries E. Cibenzoline transforms random re-entry into ordered re-entry in the atria. Eur Heart J. 1993;14:267-272. 


\section{Chapter 8}

15. Kneller J, Zou R, Vigmond EJ, Wang Z, Leon LJ, Nattel S. Cholinergic atrial fibrillation in a computer model of a two dimensional sheet of canine atrial cells with realistic ionic properties. Circulation. Res. 2002;90:E73-87.

16. Janse M, Wit A. Electrophysiosiological mechanisms of ventricular arrhythmias resulting from myocardial ischemia and infarction. Physiol. Rev. 1989;69:1049-1169.

17. de Bakker JM, van Capelle FJ, Janse MJ, Tasseron S, Vermeulen JT, de Jonge N, Lahpor JR. Slow conduction in the infarcted human heart. 'Zigzag' course of activation. Circulation. 1993;88:915-26.

18. Pu J, Boyden P. Alterations of $\mathrm{Na}+$ currents in myocytes from epicardial border zone of infarcted heart. A possible mechanism for reduced excitability and postrepolarization refractoriness. Circ Res. 1997:81:110-119.

19. Peters NS, Coromilas J, Severs NJ, Wit AL. Disturbed connexin43 gap junction distribution correlates with the location of reentrant circuits in the epicardial border zone of healing canine infarcts that cause ventricular tachycardia. Circulation. 1997;95:988-96.

20. Okumura K, Olshansky B, Henthorn R, Epstein A, Plumb V, Waldo A. Demonstration of the presence of slow conduction during sustained ventricular tachycardia in man: use of transient entrainment of the tachycardia. Circulation. 1987;75:369-378.

21. Aizawa Y, Niwano S, Chinushi M, al e. Incidence and mechanism of interruption of reentrant ventricular tachycardia with rapid ventricular pacing. Circulation. 1992;85:589-595.

22. Kay G, Epstein A, Plumb V. Preferential effect of procainamide on the reentrant circuit of ventricular tachycardia. J Am Coll Cardiol. 1989;14:382-390.

23. Boineau J, Cox J. Rationale for a direct surgical approach to control ventricular arrhythmias: Relation of specific intraoperative techniques to mechanism and location of the arrhythmic circuit. Am J Cardiol. 1982;49:381-396.

late after myocardial infarction. J Cardiovasc Electrophysiol. 1997;8:1309-19.

Caceres J, Akhtar M, Werner P, al e. Cryoablation of refractory sustained ventricular tachycardia due to coronary artery disease. Am J Cardiol. 1989;63:296-300.

6. Julian D, Camm A, Frangin G, al e. Randomised trial of effect of amiodarone on mortality in patients with left-ventricular dysfunction after recent myocardial infarction: EMIAT. Lancet. 1997;349:667.

7. Cairns J, Connolly S, Roberts R, Gent M. Randomised trial of outcome after myocardial infarction in patients with frequent or repetitive ventricular premature depolarisations: CAMIAT. Canadian Amiodarone Myocardial Infarction Arrhythmia Trial Investigators. Lancet. 1997;349 (9053):675-82.

28. Connolly S, Hallstrom A, Cappato R, al e. Meta-analysis of the implantable cardioverter defibrillator secondary prevention trials. AVID, CASH and CIDS studies. Eur Heart J. 2000;21:2071.

29. Block M, Breithardt G. The implantable cardioverter defibrillator and primary prevention of sudden death: the Multicenter Automatic Defibrillator Implantation Trial and the Coronary Artery Bypass Graft (CABG)-Patch Trial. Am J Cardiol. 1999;83:74D-78D.

30. Lehmann M, Steinman R, Schuger C, Jackson K. The automatic implantable cardioverter-defibrillator as antiarrhythmic treatment modality of choice for survivors of cardiac arrest unrelated to acute myocardial infarction. Am J Cardiol. 1988;62:803-5.

31. Zipes D. Implantable cardioverter-defibrillator: A Volkswagen or a Rolls Royce. How much will we pay to save a life? Cinculation. 2001;103:1372-1374.

32. Ciaccio EJ, Costeas C, Coromilas J, Wit AL. Static relationship of cycle length to reentrant circuit geometry.Circulation. 2001;104:1946-51.

33. de Chillou C, Lacroix D, Klug D, Magnin-Poull I, Marquie C, Messier M, Andronache M, Kouakam C, Sadoul N, Chen J, Kacet S. Isthmus characteristics of reentrant ventricular tachycardia after myocardial infarction. Cinculation. 2002;105:726-731.

34. de Bakker JM, van Capelle FJ, Janse MJ, Wilde AA, Coronel R, Becker AE, Dingemans KP, van Hemel NM, Hauer RN. Reentry as a cause of ventricular tachycardia in patients with chronic ischemicheart disease: electrophysiologic and anatomic correlation. Circulation. 1988;77:589-606. 
35. de Bakker JM, Coronel R, Tasseron S, Wilde AA, Opthof T, Janse MJ, van Capelle FJ, Becker AE, Jambroes G. Ventricular tachycardia in the infarcted. Langendorff-perfused human heart: role of the arrangement of surviving cardiac fibers. J Am Coll Cantiol. 1990;15:1594-607.

36. de Bakker JM, van Capelle FJ, Janse MJ, van Hemel NM, Hauer RN, Defauw J, Vermeulen FE, Bakker de Wekker PF. Macroreentry in the infarcted human heart: the mechanism of ventricular tachycardias with a "focal" activation pattern. J Am Coll Candiol. 1991;18:1005-14.

37. Downar E, Harris L, Mickleborough L, Shaikh N, Parson I. Endocardial mapping of ventricular tachycardia in the intact human ventricle: evidence for reentrant mechanisms. $J \mathrm{Am}$ Coll Candiol. 1988;11:783-791.

38. Stevenson W, Khan H, Sager P, Saxon L, Middlekauff H, Natterson P, Wiener I. Identification of reentry circuit sites during catheter mapping and radiofrequency ablation of ventricular tachycardia late after myocardial infarction. Circulation. 1993;88:1647-70.

39. Josephson ME, Horowitz LN, Farshidi A, Spielman SR, Michelson EL, Greenspan AM. Recurrent sustained ventricular tachycardia. 4. Pleomorphism. Circulation. 1979;59:459-68.

40. Almendral JM, Stamato NJ, Rosenthal ME, Marchlinski FE, Miller JM, Josephson ME. Resetting response patterns during sustained ventricular tachycardia: relationship to the excitable gap. Circulation. 1986;74:722-30.

41. Callans DJ, Hook BG, Josephson ME. The mechanism of propafenone-induced slowing of ventricular tachycardia in man as defined by analysis of resetting response patterns. PACE. 1991:14:2035-2041.

42. Waldecker B, Brugada P, Zehender M, Stevenson W, Den Dulk K, Wellens HJ. Importance of modes of electrical termination of ventricular tachycardia for the selection of implantable antitachycardia devices. Am J Candiol. 1986;57:150-5.

43. Almendral JM, Rosenthal ME, Stamato NJ, Marchlinski FE, Buxton AE, Frame LH, Miller JM, Josephson ME. Analysis of the resetting phenomenon in sustained uniform ventricular tachycardia: incidence and relation to termination. J Am Coll Cardiol. 1986;8:294-300.

44. el Sherif N, Gough WB, Restivo M. Reentrant ventricular arrhythmias in the late myocardial infarction period: 14. Mechanisms of resetting, entrainment, acceleration, or termination of reentrant tachycardia by programmed electrical stimulation. Pacing Clin Electrophysiol. 1987;10:341-71.

45. Waldecker B, Coromilas J, Saltman AE, Dillon SM, Wit AL. Overdrive stimulation of functional reentrant circuits causing ventricular tachycardia in the infarcted canine heart. Resetting and entrainment. Circulation. 1993;87:1286-305.

46. CAST Investigators. Preliminary report: effect of encainide and flecainide on mortality in a randomized trial of arrhythmia suppression after myocardial infarction. $N$ Engl $J$ Med. 1989;321:406-412.

47. Kucera JP, Kleber AG, Rohr S. Slow conduction in cardiac tissue, II: effects of branching tissuc geometry. Circulation. 1998.

48. Ursell PC, Gardner PI, Albala A, Fenoglio JJ, Jr., Wit AL. Structural and electrophysiological changes in the epicardial border zone of canine myocardial infarcts during infarct healing. Circ Res. 1985;56:436-51.

49. Rohr S, Kucera JP, Kleber AG. Slow conduction in cardiac tissue, I: effects of a reduction of excitability versus a reduction of electrical coupling on microconduction. Circ Res. 1998;83:781-94.

50. Spach MS, Josephson ME. Initiating reentry: the role of nonuniform anisotropy in small circuits. J Cardiovasc Electrophysiol. 1994;5:182-209.

51. Dillon SM, Allessie MA, Ursell PC, Wit AL. Influences of anisotropic tissue structure on reentrant circuits in the epicardial border zone of subacute canine infarcts. Circ Res.

1988:63:182-206.

52. Jongsma H, Wilders R. Gap junctions in cardiovascular disease. Circ Res. 2000;86:1193-7.

53. Haberl K, Allessie M. Differential effects of a segment of slow conduction on reentrant ventricular tachycardia in the rabbit heart. Circulation. 1999:99:949-962. 
Chapter 9

\section{Summary and Conclusions}


Chapter 9

$-172$ 


\section{Summary}

In patients with chronic ischemic heart disease ventricular tachyarrhythmias are a major cause of mortality. ${ }^{1}$ Electrophysiological studies have demonstrated that reentry is the underlying mechanism of these arrhythmias. ${ }^{2}$ Surviving myocardial fibers in the infarcted region are crucial for the genesis of reentrant tachyarrhythmias. ${ }^{3}$ Studies in dogs have shown that VT usually originates from the thin surviving epicardial borderzone overlying the myocardial infarction. ${ }^{4}$ Early in the healing process the fibers in the epicardial borderzone are still orientated parallel to each other but are separated by edema or connective tissue. ${ }^{5}$ Because of differences in conduction parallel and transverse to the fibers (anisotropy), functional reentrant circuits can be induced around lines of functional conduction block (anisotropic reentry). ${ }^{4,6,7}$ Reentrant excitation around an anatomical obstacle like a large myocardial scar or a ventricular aneurysm has also been demonstrated to be a mechanism of VT (anatomic reentry). ${ }^{8}$ Part of the anatomic circuit may consist of a tract of surviving myocytes embedded in scar tissue, forming a continuous electrical pathway through the infarct. ${ }^{8}$

Both functional (or anisotropic) as well as anatomical circuits usually comprise a zone of slow conduction. During anisotropic reentry the circulating impulse propagates perpendicular to the fibers in part of the circuit. ${ }^{6}$ Due to directional differences in resistance, the conduction velocity perpendicular to the fibers is three times slower than the conduction velocity parallel to the fiber orientation. ${ }^{9}$ Slow conduction in anatomical circuits has been attributed to 'zig-zag' conduction in the network of surviving fibers, ${ }^{10}$ increased gap-junctional resistance between the myocytes, ${ }^{11}$ or reduced excitability of the myocytes. ${ }^{12}$ Recent studies have emphasized the role of a high wavefront curvature in slowing of conduction. ${ }^{13}$ The objectives of this thesis were 1) to characterize the conduction properties of pivoting wave fronts with a high curvature in the subepicardium, 2) to study the characteristics of reentrant VT in rabbit hearts with a healed myocardial infarction, and 3) to characterize the conduction properties of the chronically infarcted myocardium.

\section{Conduction around a Pivot Point}

The studies were performed in isolated Langendorff perfused rabbit hearts. The right ventricle, the interventricular septum, and the endo- and midmyocardial layers of the free wall of the left ventricle were ablated by a cryoprocedure, only leaving a thin sheet of left ventricular subepicardium intact. In the epicardial layer, the fibers are arranged in a longitudinal fashion. A thin linear lesion was made parallel to the fiber orientation by radiofrequency (RF) ablation. The RF-lesion was extended by a short incision. Electrical stimulation next to the lesion elicited a wavefront which made a sharp U-turn around the tip of the lesion. A high density mapping electrode ( 240 electrodes, resolution $350-700 \mu \mathrm{m}$ ) was used for detailed analysis of the activation pattern of the U-turn.

In Chapter $\mathbf{2}$ we demonstrated that the conduction velocity of the impulse decreased considerably during pivoting around the tip of the lesion. The fast longitudinal conduction 


\section{Chapter 9}

velocity of $70 \mathrm{~cm} / \mathrm{s}$ along the lesion slowed down at the pivot point to $15 \mathrm{~cm} / \mathrm{s}$. Since the conduction velocity perpendicular to the fibers was $30 \mathrm{~cm} / \mathrm{s}$, slow conduction at the pivot point could not be explained by an increase in electrical resistance alone. The high curvature of the pivoting wavefront must also play a role. A general reduction of the inward sodium current by infusion of potassium or flecainide depressed conduction of the pivoting wavefronts about 1.6 times more than conduction of planar waves. This preferential effect was due to discontinuous conduction and functional conduction block at the pivot point. Especially during high frequency stimulation or early premature beats lines of functional conduction block occurred at the tip of the anatomical lesion. Because the wavefront was now forced to make a wider turn around the lesion, the conduction delay at the pivot point increased markedly.

In Chapter 3 we demonstrated that the preferential depression of conduction at the pivot point resulted in prolongation of the shortest attainable coupling interval of a premature beat distal to the pivot point (distal V1-V2 interval). Since the distal V1-V2 interval was longer than the refractory period a clear excitable gap was created in the descending limb of the U-turn. Infusion of flecainide prolonged the excitable period in the descending limb of a premature U-turn from 30 to $55 \mathrm{~ms}$. The widening of the excitable period due to preferential conduction delay at pivot points may explain the antiarrhythmic effects of the class I drugs.

\section{Reentrant VT in Rabbit Hearts with a Healed Myocardial Infarction}

To study the mechanismen of VT in rabbit hearts with a healed myocardial infarction, a myocardial infarction was produced surgically by ligation of side-branches of the left coronary artery. The peri-operative mortality was $23 \%$. About three months after the operation, the rabbit hearts were excised and connected to a Langendorff perfusion system. The characteristics of the model are described in Chapter 4. In hearts with a healed myocardial infarction ventricular tachyarrhythmias were induced more easily and more frequently than in control hearts. After the cryoprocedure (described above) sustained monomorphic VT could be induced in $70 \%$ of the infarcted hearts compared to $25 \%$ in controls. In the epicardial layers of 41 hearts with a healed myocardial infarction 68 different VTs were induced. The activation patterns during VT were studied by a spoon shaped mapping array molded to the epicardial surface, containing 248 electrodes with an interelectrode distance of $2.25 \mathrm{~mm}$. Four different types of reentrant circuits were observed: 1) anatomic reentry around the scar $(16 \%), 2)$ anatomic reentry comprising a segment of slow conduction through the scar $(61 \%), 3)$ reentry within the scar $(13 \%)$, and 4$)$ functional reentry outside the infarct $(10 \%)$. In some hearts VTs with a different morphology could be induced. This pleomorphism was due to different exit sites of the reentrant impulse from the infarct or to a different direction of rotation. Also different VTs with the same morphology but with a different cycle length could be induced. This was due to a change in conduction time of the reentrant impulse through the infarcted area. Histologic examination of the hearts showed 
that in case of reentry around the scar a continuous ring of normal epicardium was present around the scar. In case of reentry through the scar several isolated bundles surrounded by fibrotic tissue were found in the infarcted area which formed an almost continuous tract of surviving myocytes from one end of the infarct to the other side. Also in case of reentry within the scar surviving myocytes were embedded in the fibrotic tissue of the myocardium.

Although the cycle length of the different types of VT varied considerably, on average the tachycardias comprising a segment of slow conduction through the scar had the slowest rate. The cycle length of these VTs was mainly determined by the conduction time of the circulating impulse through the infaret. The conduction time through the infarct resulted in a 'diastolic' interval, since during normal amplification of the electrograms electrical activity was not recorded from the scar. However, at high gain (up to 4000x) small potentials became visible, completely bridging the diastolic interval. The effective conduction velocity through the infarct was usually less than $20 \mathrm{~cm} / \mathrm{s}$, which was slower than conduction parallel $(70 \mathrm{~cm} / \mathrm{s})$ and perpendicular to the fiber orientation $(32 \mathrm{~cm} / \mathrm{s})$. In a few hearts the electrical activation of the infarcted area was studied by ultra high resolution mapping (resolution $500 \mu \mathrm{m}$ ). The differences in activation time between adjacent electrodes varied between 0 and $40 \mathrm{~ms}$ (local conduction velocity about $1 \mathrm{~cm} / \mathrm{s}$ ). Long local conduction delays in the infarct especially occurred at sites of changing tissue geometry such as the entrance and exit of the slow conduction zone and at branching points of tracts of surviving myocytes.

In Chapter 5 and 6 we tested the effects of programmed electrical stimulation on VT. Both during reentry around the scar as well as during reentry through the scar a large excitable gap was present. During VT around the scar, the duration of the excitable gap mainly depended on the size of the anatomic circuit whereas during VT through the scar the excitable gap was mainly determined by the conduction time through the segment of slow conduction. Because late premature beats already conducted with considerable delay through the slow conduction zone, the partial excitable gap during VT through the scar was longer than during VT around the scar. Early premature stimuli frequently terminated VT through the scar by causing conduction block in the segment of slow conduction. The ability to terminate VTs through the scar by single premature stimuli was associated with a long segment of slow conduction, a steep slope of the reset curve and a large difference in functional refractory period between the normal myocardium and the infarct. VTs around the scar usually could not be terminated by single premature stimuli. The different types of VT also responded differently to overdrive pacing. Whereas VTs through the scar were always terminated by overdrive pacing, in contrast VTs around the scar were usually accelerated. Termination of VT through the scar was due to conduction block in the area of slow conduction and was often preceded by an increase in conduction time through this zone (Wenkebach block). Acceleration and / or changes in morphology of VT by programmed electrical stimulation were due to changes in exit site of the reentrant circuits, induction of 


\section{Chapter 9}

double wave reentry or ventricular fibrillation.

In Chapter 7 we tested the effects of antiarrhythmic drugs on the different types of reentrant VT. The class Ic drug flecainide markedly slowed the rate of all types of VT by a strong depression of conduction. The efficacy to terminate VT depended on the type of reentry. The concentration of flecainide needed to terminate a VT through the scar was half the concentration required to terminate a VT around the scar. Termination of VT through the scar was always due to conduction block in the slow conduction zone. Flecainide depressed conduction in the slow conduction zone twice as much as conduction in the noninfarcted part of the ventricle. At therapeutic concentrations the class III drug d-sotalol hardly affected VT. The calcium channel blocker verapamil terminated 1 of 3 VTs.

\section{Conclusions}

Conduction properties of U-turning wavefronts and the mechanisms of reentrant VT and slow conduction in healed myocardial infarction were studied in Langendorff perfused thin layers of subepicardium of the rabbit heart by high density mapping. A reduction of the rapid $\mathrm{Na}^{\prime}$ current by high potassium or flecainide preferentially depressed conduction of U-turning wavefronts by causing discontinuous conduction and functional conduction block at the pivot points. The preferential conduction delay at the pivot point created an excitable gap in the distal limb of the U-turn. In the rabbit model of healed myocardial infarction different types of reentrant VT could be induced with similar characteristics as clinical VTs. Most circuits comprised a zone of slow conduction through the scar but VT could also be based on reentry around the scar. These two types of VT could be distinguished by their response to programmed electrical stimulation and antiarrhythmic drugs. Conduction through the infarct was slow and discontinuous. The results of ultra-high density mapping of the slow conduction zone showed that abnormal conduction especially occurred at branching sites of strands of surviving myocytes. The effects of premature stimulation and antiarrhythmic drugs on conduction in the slow conduction suggested that slow conduction through the infarcted area was not solely due to reduced cellular coupling between the surviving myocytes. A source to sink mismatch at sites of changing tissue geometry and reduced excitability of the surviving myocytes may contribute to slowing of conduction in a chronic myocardial infarction. 


\section{References}

1. Multicenter Postinfarction Research Group: Risk stratification and survival after myocardial infarction. N. Engl. J Med. 1983;309:331.

2. Janse M, Wit A. Electrophysiosiological mechanisms of ventricular arrhythmias resulting from myocardial ischemia and infarction. Physiol. Rev. 1989;69:1049-1169.

3. Gardner P, Ursell P, Pham TD, Fenoglio J, Wit A. Experimental chronic ventricular tachycardia: anatomic and electrophysiologic substrates. In: Josephson M, Wellens H, eds. Tachycardias: Mechanisms, Diagnosis, Treatment. Philadelphia: Lea and Febiger; 1983:29-60.

4. Wit AL, Allessie MA, Bonke FI, Lammers W, Smeets J, Fenoglio JJ, Jr. Electrophysiologic mapping to determine the mechanism of experimental ventricular tachycardia initiated by premature impulses. Experimental approach and initial results demonstrating reentrant excitation. Am J Candiol. 1982;49:166-85.

5. Ursell PC, Gardner PI, Albala A, Fenoglio JJ, Jr., Wit AL. Structural and electrophysiological changes in the epicardial border zone of canine myocardial infarcts during infaret healing. Cine Res. 1985;56:436-51.

6. Dillon SM, Allessie MA, Ursell PC, Wit AL. Influences of anisotropic tissue structure on reentrant circuits in the epicardial border zone of subacute canine infarcts. Cinc Res. 1988;63:182-206.

7. el Sherif N, Gough WB, Zeiler RH, Hariman R. Reentrant ventricular arrhythmias in the late myocardial infarction period. 12. Spontaneous versus induced reentry and intramural versus epicardial circuits. J Am Coll Candiol. 1985;6:124-32.

8. de Bakker JM, van Capelle FJ, Janse MJ, Wilde AA, Coronel R, Becker AE, Dingemans KP, van Hemel NM, Hauer RN. Reentry as a cause of ventricular tachycardia in patients with chronic ischemic heart disease: electrophysiologic and anatomic correlation. Circulation. 1988;77:589-606.

9. Sano T, Takayama N, Shimamoto T. Directional difference of conduction velocity in the cardiac ventricular syncytium studied by microelectrodes. Circulation Research. 1959;7:262-268.

10. de Bakker JM, van Capelle FJ, Janse MJ, Tasseron S, Vermeulen JT, de Jonge N, Lahpor JR. Slow conduction in the infarcted human heart. 'Zigzag' course of activation. Circulation. 1993;88:915-26.

11. Peters NS, Coromilas J, Severs NJ, Wit AL. Disturbed connexin43 gap junction distribution correlates with the location of reentrant circuits in the epicardial border zone of healing canine infarcts that cause ventricular tachycardia. Circulation. 1997;95:988-96.

12. Pu J, Boyden P. Alterations of $\mathrm{Na}+$ currents in myocytes from epicardial border zone of infarcted heart. A possible mechanism for reduced excitability and postrepolarization refractoriness. Circ Res. 1997;81:110-119.

13. Fast VG, Kleber AG. Role of wavefront curvature in propagation of cardiac impulse. Cardiovasc Res. 1997;33:258-71. 


\section{Samenvatting}

Hartritmestoornissen zijn een belangrijke doodsoorzaak bij patienten die een hartinfarct doorgemaakt hebben. Deze ritmestoornissen zijn gekenmerkt door een snelle hartfrequentie en zijn afkomstig uit de hartkamers, een situatie die wordt aangeduid als kamertachycardie. Kamertachycardieën die optreden na een hartinfarct berusten doorgaans op cirkelgeleiding van de elektrische impuls. Hierbij wordt de impuls als het ware gevangen in een cirkelpad. Dit cirkelpad blijkt te worden gevormd door overlevende hartspiervezels in het infarctgebied en bezit doorgaans een zone waarin de elektrische impuls abnormaal traag wordt voortgeleid. Ondanks vele studies is het nog niet geheel duidelijk welke vormen van cirkelgeleiding in de chronische fase van een hartinfarct kunnen optreden en wat de oorzaak van trage geleiding in het infarct is. Zo is bijvoorbeeld pas uit recent onderzoek gebleken dat met name ook de curvatuur van een elektrisch golffront een belangrijke determinant van de geleidingssnelheid is. Ook is nog onvoldoende begrepen waarom de behandeling van kamertachycardieën met behulp van geneesmiddelen, pacemakers en ablatietechnieken bij de ene patient wel en bij de andere juist weer niet effectief is. De studies in dit proefschrift werden uitgevoerd om 1) de geleidingseigenschappen van scherp draaiende golffronten met hoge curvatuur te onderzoeken, 2 ) te bestuderen welke vormen van cirkelgeleiding kunnen optreden in de chronische fase van een hartinfarct, 3) de effecten van elektrische stimulatie en anti-aritmische geneesmiddelen op de verschillende vormen van cirkelgeleiding te analyseren, en 4) trage geleiding door het hartinfarct te karakteriseren.

De studies werden uitgevoerd in geïsoleerde, Langendorff geperfundeerde konijnenharten. Door middel van een vriestechniek werd de hele rechter hartkamer en de binnenzijde van de linker kamer gedood, zodat er slechts een dunne buitenste (of epicardiale) laag spierweefsel van de linker kamer overbleef. In deze epicardiale laag zijn de spiervezels in lange evenwijdige banen gerangschikt. Om de geleidingseigenschappen van scherp draaiende golffronten te bestuderen werd in de dunne epicardiale laag een lineaire laesie parallel aan de vezelrichting gemaakt d.m.v. radio-frequency (RF) ablatie (hoofdstuk 2). Aan het uiteinde van de RF-laesie werd een dunne snede gezet. Door vlak naast de RF-laesie te prikkelen werden golffronten opgewekt, die een scherpe U-bocht rond de laesie maakten. Met een high density mapping electrode ( 240 elektrodes, onderlinge afstand $350-700 \mu \mathrm{m}$ ) werd de elektrische activatie van de U-bocht geanalyseerd. De geleidingssnelheid van de elektrische impuls varieerde sterk tijdens het draaien. Tijdens voortgeleiding langs de laesie was de geleidingssnelheid $70 \mathrm{~cm} / \mathrm{s}$. Op het draaipunt nam de snelheid af tot $15 \mathrm{~cm} / \mathrm{s}$. Een algehele reductie van de depolarizerende stroom door infusie van kalium of het anti-aritmische geneesmiddel flecainide vertraagde de geleiding van ronddraaiende golffronten met hoge curvatuur gemiddeld 1.6x meer dan normale recht doorgaande geleiding. Dit preferentiële effect op ronddraaiende golven werd veroorzaakt door zeer trage geleiding en geleidingsblok op het draaipunt. Met name tijdens snel prikkelen of na toediening van kort gekoppelde elektrische prikkels werden lijnen van geleidingsblok aan het uiteinde van de anatomische laesie geïnduceerd. Omdat het ronddraaiende golffront nu een wijdere bocht 
rond deze lijn van blok moest maken, veroorzaakte dit extra geleidingsvertraging. De preferentiële geleidingsvertraging op het draaipunt resulteerde in een verlenging van het korst mogelijke tijdsinterval tussen 2 opeenvolgende ronddraaiende golffronten distaal van het draaipunt (distale V1-V2 interval) (hoofdstuk 3). Omdat het distale V1-V2 interval nu langer was dan de tijd die de spiercellen nodig hadden om zich te herstellen van de voorgaande activatie (refractaire periode) ontstond een exciteerbare periode in het afgaande been van de U-bocht. De exciteerbare periode distaal van het draaipunt verdubbelde tijdens infusie met flecainide.

Om de mechanismen van hartritmestoornissen bij konijnen met een chronisch hartinfarct te bestuderen, werd een infaret van de linker hartkamer geproduceerd door zijtakken van de linker coronair arterie af te sluiten (hoofdstuk 4). Ongeveer 3 maanden na de operatie werden de harten verbonden aan een Langendorff perfusie systeem. In de harten met een infarct werden vaker en makkelijker kamerritmestoornissen opgewekt vergeleken met harten zonder infarct. Nadat d.m.v. de vriesprocedure een dunne epicardiale laag was gecreëerd konden 68 verschillende ventriculaire tachycardieën (VT) worden geïnduceerd in 41 harten met een chronisch myocardinfarct. Het activatiepatroon van de VTs werd bestudeerd door simultane registratie van de elektrische activatie van de linker kamerwand middels 248 elektroden met een onderlinge afstand van $2.25 \mathrm{~mm}$. Er werden 4 verschillende soorten cirkelgeleiding (reentry) onderscheiden: 1 ) anatomische reentry rond het infarct $(16 \%) ; 2)$ anatomische reentry met een segment van trage geleiding door het infarct $(61 \%)$; 3 ) reentry geheel in het infarct $(13 \%)$; 4 ) functionele reentry naast het infarct $(10 \%)$. In sommige harten werden verschillende VTs opgewekt. Het verschil tussen de VTs kon soms verklaard worden door de aanwezigheid van meerdere paden van overlevende spierbundeltjes in het infarctgebied. Dit leidde dan ofwel tot een andere uittrede plaats van de elektrische impuls uit het infarct ofwel tot een andere geleidingstijd door het infarct. In andere gevallen was het cirkelpad precies hetzelfde maar was de draairichting van de impuls tegenovergesteld. In een aantal harten werd met een hoge resolutie mapping elektrode (interelektrode afstand $500 \mu \mathrm{m}$ ) de geleiding door het infarct bestudeerd. Het verschil in activatietijd tussen naburige electrodes was soms wel $40 \mathrm{~ms}$, hetgeen overeenkomt met een wel zeer trage lokale geleidingssnelheid van ongeveer $1 \mathrm{~cm} / \mathrm{s}$. Trage geleiding kwam vooral voor op kruispunten van overlevende spierbundeltjes in het infarct en aan de in- en uitgang van het segment van abnormale geleiding door het infarct.

Door toediening van elektrische prikkels tijdens de VT bleek het mogelijk het type van cirkelgeleiding te differentiëren (hoofdstuk 5 en 6). Tijdens reentry rond het infarct leidde toediening van een vroeg gekoppelde (of premature) elektrische prikkel nauwelijks tot enige geleidingsvertraging in het reentry circuit. Deze VTs rond het infarct waren doorgaans ook niet te stoppen met zo'n premature elektrische prikkel en tijdens toediening van een reeks van 10 premature prikkels trad zelfs meestal een versnelling van de VT op. Tijdens reentry met een segment van abnormale geleiding door het infarct gaven premature elektrische prikkels doorgaans juist een aanzienlijke geleidingsvertraging in het reentry 
circuit. Meer dan 50\% van de VTs door het infarct kon gestopt worden met een enkele premature prikkel en alle VTs termineerden tijdens toediening van een reeks van 10 prikkels. Terminatie van de tachycardie was altijd het gevolg van geleidingsblok in het segment van abnormale geleiding door het infarct. Tevens bleek dat door elektrische stimulatie 'verborgen' paden in het infarctgebied ontmaskerd konden worden.

De verschillende typen VT reageerden ook verschillend op infusie van anti-aritmische geneesmiddelen (hoofdstuk 7). Zo was voor het stoppen van een VT rond het infaret een $2 \mathrm{x}$ hogere concentratie van flecainide nodig als voor het stoppen van een VT door het infarct. Dit werd verklaard door het feit dat flecainide de geleiding door het infarct preferentieel vertraagde. Tijdens infusie van flecainide veranderde in een aantal gevallen het reentry circuit, waardoor potentiële cirkelpaden zichtbaar werden.

\section{Beschouwing}

Om patiënten die lijden aan hartritmestoornissen zo goed mogelijk te behandelen is kennis omtrent het onderliggende mechanisme van hun ritmestoornis onmisbaar. Het doel van de studies zoals beschreven in dit proefschrift was om verder inzicht te krijgen in de mechanismen van levensbedreigende kamerritmestoornissen die kunnen voorkomen na een hart-infarct. De experimenten in de geïsoleerde konijnenhartjes toonden dat, net als bij patiënten, kamertachycardieën kunnen berusten op verschillende typen van cirkelgeleiding in het infarctgebied. Door gebruik te maken van elektrische stimulatie en anti-aritmische geneesmiddelen bleek het mogelijk de verschillende typen cirkelgeleiding van elkaar te onderscheiden en informatie te verkrijgen over de geleiding van de elektrische impuls in het infarctgebied. Aangetoond werd dat abnormaal trage geleiding met name kan voorkomen op plaatsen waar de curvatuur van het elektrisch golffront plotseling toeneemt, zoals op scherpe draaipunten en op kruispunten van overlevende spierbundels in het infarctgebied. Verder bleek dat de werking van bepaalde anti-aritmische geneesmiddelen wel eens zou kunnen berusten op preferentiële geleidingsvertraging en geleidingsblok op deze specifieke plaatsen. Als het mogelijk zou zijn om bij individuele patiënten het onderliggende substraat voor de kamerritmestoornis te typeren en de precieze oorzaken van trage geleiding in het infarctgebied te karakteriseren, zal de effectiviteit van de behandeling van deze patienten aanmerkelijk kunnen toenemen. 


\section{NAWOORD}

Toen ik na mijn arts-examen in het Medisch Centrum Alkmaar ging werken met de intentie internist te worden was het Dr. J. Ruiter die mij enthousiasmeerde voor de cardiologie en hartritmestoornissen in het bijzonder. Om iets meer over hartritmestoornissen te leren moest er verhuisd worden van Amsterdam naar Maastricht. De jaren in Maastricht zijn zeer waardevol geworden dankzij de samenwerking met vele mensen en de vriendschappen die zijn ontstaan. Prof. Maurits Allessie was een kritisch en inspirerend promotor en ik ben er trots op een pupil van hem te zijn. Zonder de 'schrijfles' bij hem thuis was dit proefschrift nooit tot stand gekomen. Vanaf de eerste maanden van mijn onderzoek, waarin ik mij voornamelijk bezig hield met temperatuur- en weerstandsmetingen in een bakje water, heb ik veel praktische steun gekregen van de technici Jan Hollen en Frits Schmitz. Maurits Wijffels hielp mij bij het schrijven van mijn eerste abstract en voor ik het wist deelden wij als arme AIO's het bed in een ranzig hotel tijdens mijn eerste congresbezoek te New Orleans. Met Frans Mast en Clifford Garratt deelde ik de interesse in de 'U-turn', met Peter Kelderman de arbeidsvitaminen tijdens langdurige operaties, met Jannie Ausma het eureka van het histologisch bewijs voor het 'verborgen pad' en met Sabine Eijsbouts het 'kanon' en tamsons vol met schimmel en algen. Mattias Duytschaever is als vriend en collega zeer belangrijk geweest, met name ook wanneer het onderzoek moeizaam verliep. Belgen hebben zeker en vast meer kwaliteiten dan alleen de dapperheid die Caesar ze toedichtte. De gastvrijheid van mijn goede vriend Frank Wolters en zijn vrouw Dorine heeft mij in staat gesteld mijn onderzoek af te ronden toen wij weer naar 'Holland' verhuisd waren. Bovenal is de totstandkoming van dit proefschrift te danken aan de steun van Marijke. Met haar herinner ik Maastricht als de geboortestad van onze dochter Laura. 


\section{PUBLICATIONS}

\section{Papers:}

P.W. Danse, C. Jacobs, A. Rotig, A.J.P. Veerman. Het syndroom van Pearson: een multisystem disorder gebaseerd op een mt-DNA deletie. Tijdschrift voor Kindergeneeskunde 1991: 59:196-204

P.W. Danse, C.J. Garratt, F. .Mast, M.A. Allessie. Preferential depression of conduction around a pivot point in rabbit ventricular myocardium by potassium and flecainide. J Cardiovasc Electrophysiol 2000: 11: 262-273

P.W. Danse, C.J. Garratt, M.A. Allessie. Flecainide widens the excitable gap at the pivot points of sharply turning wavelets in rabbit ventricular myocardium. J Cardiovasc Electrophysiol 2001;12:1010-1017

Duytschaever MF, Danse PW, Allessie MA. The supervulnerable phase immediately after termination of AF. J Cardiovasc Electrophysiol 2002:13:267-275.

Duytschaever MF, Danse PW, Eijsbouts S, et al. Is there an optimal pacing site to prevent atrial fibrillation? An experimental study in the chronically instrumented goat. J Cardiovasc Electrophysiol, 2002 (accepted).

P.W. Danse, M.Duytschaever, P. Kelderman, J. Ausma, M.A. Allessie. Reentrant ventricular tachycardia in rabbit hearts with a chronic myocardial infarction. Submitted.

\section{Abstracts:}

P.W. Danse, C.J. Garratt, F.Mast, M.A. Allessie. Mapping of preferential conduction delay at pivot points caused by flecainide and potassium. Circulation 1996; 94(8): I-161.

P.W. Danse, F.Mast, M.A. Allessie. Effects of potassium and flecainide on depolarization wave propagation with high curvature in the rabbit myocardium. Pflügers Arch - Eur J Physiol 1996; 432: R3.

P.W. Danse, C.J. Garratt, F.Mast, M.A. Allessie. Flecainide prolongs the functional refractory period at pivot points of turning depolarization waves. European Heart Journal 1997; 18: P-1155.

P.W. Danse, C.J. Garratt, F.Mast, M.A. Allessie. Flecainide preferentially depresses conduction at pivot points of sharp turning wavefronts. Pacing Clin Electrophysiol 1998; 21: 824.

P.W. Danse, P. Kelderman, M.A. Allessie. A new model of reentrant ventricular tachycardia in isolated rabbit hearts with a healed myocardial infarction. Pacing Clin Electrophysiol 1998; 21: 982 
P.W. Danse, M.Duytschaever, P. Kelderman, M.A. Allessie. Mapping and reset characteristics of anatomical reentry in healed myocardial infarction (MI) in the rabbit. Pacing Clin Electrophysiol 1999; 22:538

Duytschaever MF, Danse P, Eysbouts S, Allessie MA. The presence of a supervulnerable period immediately after conversion of atrial fibrillation. Pacing Clin Electrophysiol, $1999 ; 22: 707$

Duytschaever MF, Danse P, Allessie MA. Is there an optimal atrial pacing site to prevent atrial fibrillation? Pacing Clin Electrophysiol,1999; 22:777

Duytschaever MF, Danse P, Eysbouts S, et al. The window of inducibility of atrial fibrillation is determined by critical conduction block within Bachmann's bundle. Pacing Clin Electrophysiol, 1999;22: 880

Danse P, Duytschaever MF, Allessie M. Pleiomorphism of reentrant ventricular tachycardia in rabbit hearts with a healed myocardial infarction. Pacing Clin Electrophysiol, 2000;23: 728

P.W. Danse, M.Duytschaever, M.A. Allessie. Mechanisms of pleiomorphism of reentrant VT in rabbit hearts with a chronic myocardial infarction. Europace 2000: Supllement B10III.5

P.W. Danse, M.Duytschaever, M.A. Allessie. Effect of single premature stimuli during reentrant ventricular tachycardia (VT) in rabbit hearts with a healed myocardial infarction. Europace 2000: Supllement B10-III.6

P.W. Danse, M.Duytschaever, M.A. Allessie. Anti- and proarrhythmic effects of entrainment on reentrant VT in rabbit hearts with a healed myocardial infarction. Europace 2000: Supllement B10-III.7

Duytschaever MF, Danse P, Allessie MA. Is there an optimal atrial pacing site to prevent atrial fibrillation by ectopic beats originating in the left atrium. Pacing Clin Electrophysiol, 2000;23: 708

Duytschaever MF, Danse P, Eijsbouts S, Allessie MA. Widening of the window of inducibility of atrial fibrillation by electrical remodeling. Pacing Clin Electrophysiol, 2000;23: 730 .

P.W. Danse, M.Duytschaever, M.A. Allessie. Termination of reentrant ventricular tachycardia by single premature stimuli in rabbit hearts with a healed myocardial infarction. European Heart Journal 2000; 21: 3228. 


\section{CURRICULUM VITAE}

Danse, Peter Willem

1967:

7 januari, geboren te Den Haag

$1978-1984:$

Gymnasium-B, Chr. Lyceum, Gouda

$1984-1990$ :

Doctoraal Examen Geneeskunde, Vrije Universiteit, Amsterdam

$1990-1993:$

Artsexamen,

Vrije Universiteit, Amsterdam

$1993-1995$ :

AGNIO Cardiologie / Longziekten, Medisch Centrum Alkmaar

$1995-2000$ :

AIO Vakgroep Fysiologie,

Universiteit Maastricht

2000 - heden:

AGIO Cardiologie,

Rijnland Ziekenhuis, Leiderdorp

Leids Universitair Medisch Centrum

\section{Waarderingen}

1996:

Jonge Fysiologen Prijs 



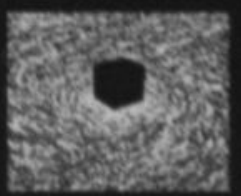

